\title{
The lipolytic pathway in the obese insulin resistant state
}

Citation for published version (APA):

Jocken, J. W. E. (2008). The lipolytic pathway in the obese insulin resistant state. [Doctoral Thesis, Maastricht University]. Datawyse / Universitaire Pers Maastricht. https://doi.org/10.26481/dis.20080229jj

Document status and date:

Published: 01/01/2008

DOI:

10.26481/dis.20080229jj

Document Version:

Publisher's PDF, also known as Version of record

\section{Please check the document version of this publication:}

- A submitted manuscript is the version of the article upon submission and before peer-review. There can be important differences between the submitted version and the official published version of record.

People interested in the research are advised to contact the author for the final version of the publication, or visit the DOI to the publisher's website.

- The final author version and the galley proof are versions of the publication after peer review.

- The final published version features the final layout of the paper including the volume, issue and page numbers.

Link to publication

\footnotetext{
General rights rights.

- You may freely distribute the URL identifying the publication in the public portal. please follow below link for the End User Agreement:

www.umlib.nl/taverne-license

Take down policy

If you believe that this document breaches copyright please contact us at:

repository@maastrichtuniversity.nl

providing details and we will investigate your claim.
}

Copyright and moral rights for the publications made accessible in the public portal are retained by the authors and/or other copyright owners and it is a condition of accessing publications that users recognise and abide by the legal requirements associated with these

- Users may download and print one copy of any publication from the public portal for the purpose of private study or research.

- You may not further distribute the material or use it for any profit-making activity or commercial gain

If the publication is distributed under the terms of Article $25 \mathrm{fa}$ of the Dutch Copyright Act, indicated by the "Taverne" license above, 


\section{The Lipolytic Pathway in the Obese Insulin Resistant State}




\section{otifim}

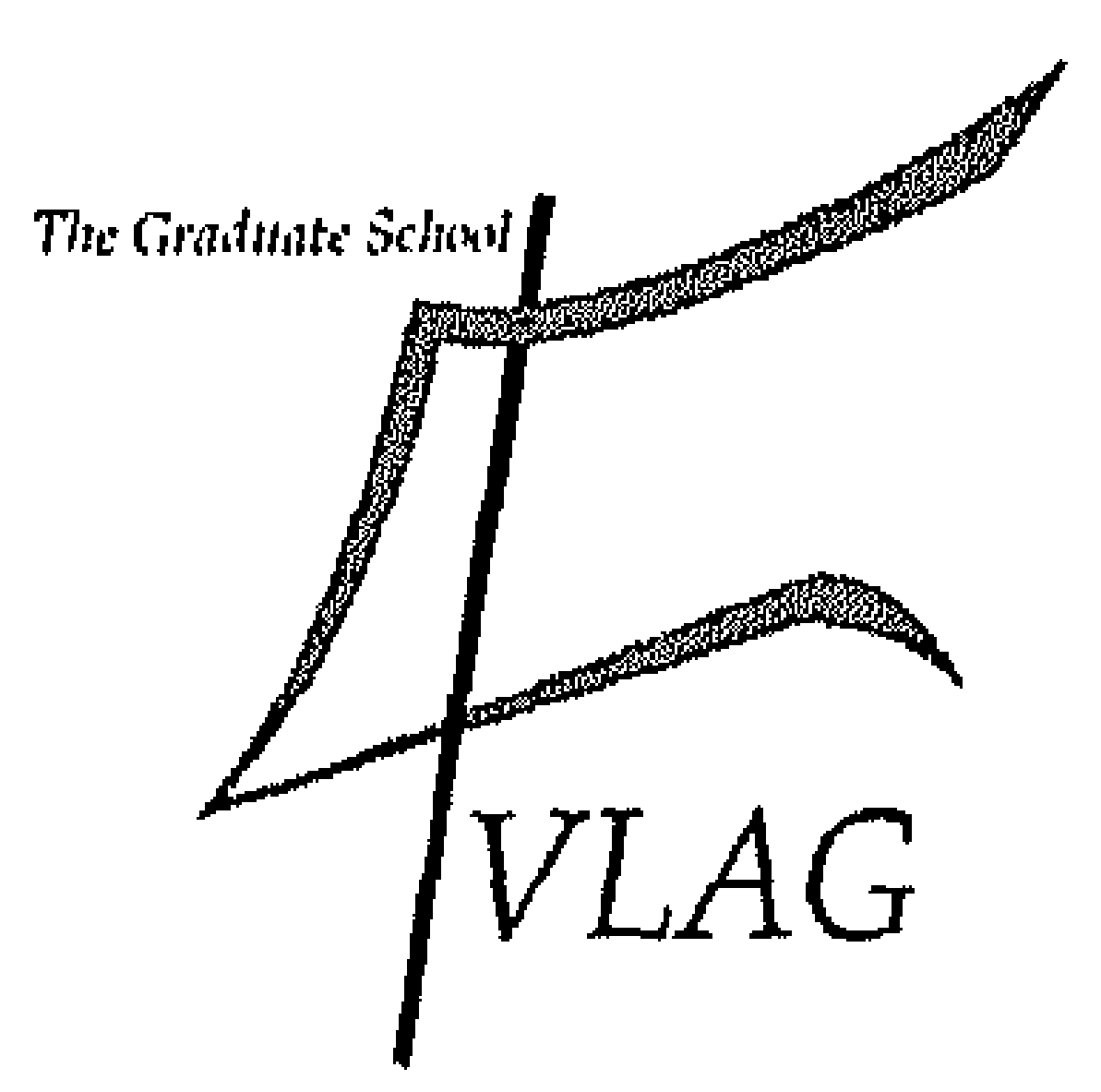

The studies described in this thesis were performed within the Nutrition and Toxicology Research Institute Maastricht (NUTRIM), which participates in the Graduate School VLAG (Food Technology, Agrobiotechnology, Nutrition and Health Sciences), accredited by the Royal Netherlands Academy of Arts and Sciences.

Cover design: Jean Scheijen (www.vierdrie.nl)

Layout: Johan Jocken

Printed by: Datawyse, Universitaire Pers Maastricht

(C) Copyright JWE Jocken, Maastricht 2008

ISBN 978-90-5278-691-9 


\title{
The Lipolytic Pathway in the Obese
}

\section{Insulin Resistant State}

\author{
DISSERTATION \\ to obtain the degree of doctor at \\ the Maastricht University, \\ on the authority of Rector Magnificus, \\ Prof. dr. G.P.M.F. Mols \\ in accordance with the decision of the Board of Deans \\ to be defended in public on \\ friday $29^{\text {th }}$ February 2008 at 14:00 hour \\ by

\section{Johan Wim Eddy Jocken} \\ born $1^{\text {th }}$ June 1981, Hasselt, Belgium
}

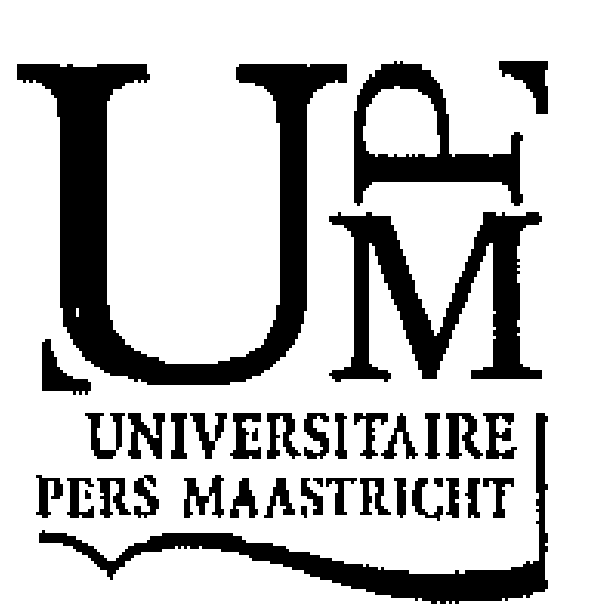




\section{Promotores}

Prof. dr. Ellen E Blaak

Prof. dr. Wim HM Saris

\section{Assessment Committee}

Prof. dr. J F.C. Glatz (Chairman)

Prof. dr. E.C. Mariman

Prof. dr. J.A. Romijn (Leids Universitair Medisch Centrum, Leiden)

Prof. dr. C.D.A. Stehouwer

Prof. dr. R Zechner (University of Graz, Austria)

The studies described in this thesis were supported by a grant from the Netherlands Organization for Scientific Research (NWO) (grant number 015.01.095).

Financial support by the Dutch Diabetes Research Foundation (DFN) and the Netherlands Association for the Study of Obesity (NASO) for the publication of this thesis is gratefully acknowledged.

AstraZeneca BV, Merck Sharp \& Dohme BV, Novo Nordisk BV, Pfizer BV and Sigma-Tau BV financially supported printing of this thesis. 
Aan mijn ouders 


\section{Content}

\section{Chapter 1}

General introduction

\section{Chapter 2}

Effect of beta-adrenergic stimulation on whole-body and abdominal

subcutaneous adipose tissue lipolysis in lean and obese men

Chapter 3

Comparative studies of the role of hormone sensitive lipase and adipose

triglyceride lipase in human fat cell lipolysis

\section{Chapter 4}

Adipose triglyceride lipase (ATGL) and hormone sensitive lipase (HSL) protein expression is decreased in the obese insulin resistant state

\section{Chapter 5}

HSL serine phosphorylation and glycerol exchange across skeletal muscle in lean and obese subjects: effect of beta-adrenergic stimulation

\section{Chapter 6}

Adipose triglyceride lipase (ATGL) expression in human skeletal muscle is type 1 (oxidative) fiber specific

\section{Chapter 7}

Association of a beta-2 adrenoceptor (ADRB2) gene variant with a blunted in vivo lipolysis and fat oxidation

\section{Chapter 8}

Blunted beta-adrenoceptor mediated fat oxidation in overweight subjects: a role for the hormone sensitive lipase gene

\section{Chapter 9}

General discussion

Summary - Samenvatting

Acknowledgements - Dankwoord

Curriculum vitae

List of publications

Abbreviations 


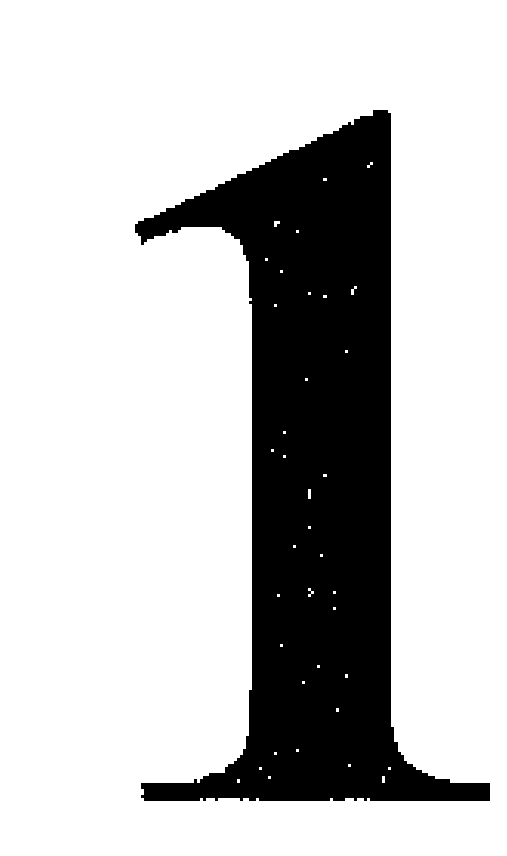

\section{General introduction}

Jocken JWE, Blaak EE. Adipose tissue and skeletal muscle lipolysis in obesity and insulin resistance: a critical review. Physiology \& Behavior (submitted) 
[Chapter 1

1. The lipolytic pathway

I.I The lipolytic pathway in adipose tissue 12

1.2 The lipolytic pathway in skeletal muscle 14

1.3 The lipolytic picture revisited: a new lipase enters the picture $\quad 17$

1.3.I Regulation of HSL activity 18

1.3.2 Regulation of ATGL activity $\quad 19$

2 Adipose tissue lipolysis in obesity $\quad 20$

2.1 Fasting lipolysis 20

2.2 Insulin sensitivity of adipose tissue lipolysis $\quad 21$

2.3 Catecholamine-induced lipolysis 21

2.4 Body fat distribution $\quad 22$

3. Skeletal muscle lipolysis in obesity 23

3.1 Fasting and catecholamine-induced lipolysis 23

4. Impaired catecholamine-induced lipolysis in the obese insulin 24 resistant state: cause or consequence?

4.1 A blunted lipolysis as cause for obesity $\quad 24$

4.2 A blunted lipolysis as biological adaptation to hyperinsulinemia 25

5. Outline of the thesis $\quad 26$

10] 
Obesity is one of the major public health problems reaching epidemic proportions in several countries. According to the World Health Organisation (WHO) obesity is defined as a body mass index (BMI) of $30 \mathrm{~kg} / \mathrm{m}^{2}$ or greater, and overweight is defined as a BMI between $25-30 \mathrm{~kg} / \mathrm{m}^{2}$ (WHO, Geneva, Switzerland). The prevalence of obesity is progressively increasing worldwide and reaches up to almost $10 \%$ in both men and women in the Netherlands (199). Today, worldwide more then 1.1 billion adults are overweight, and 312 million of them are obese (82).

The obese state is characterized by increased fat storage in the form of triacylglycerol (TAG), mainly in adipose tissue. Catecholamine resistance of adipose tissue lipolysis might contribute to the development or maintenance of increased fat stores and obesity (4). Moreover, an increased adipose tissue mass and a reduced insulinmediated suppression of lipolysis may lead to lipid overflow in the circulation. Inappropriately elevated fatty acid (FA) levels have many adverse metabolic effects and are associated with an increased risk for the development of insulin resistance, type 2 diabetes and cardiovascular diseases (47).

Furthermore, lipid overflow may lead to increased storage of fat in non-adipose tissues like muscle, liver and pancreas, also known as ectopic fat deposition. Increased storage of lipids (TAG) and in particular lipid intermediates (e.g. diacylglycerol (DAG), ceramides) in skeletal muscle may inhibit insulin signal transduction, leading to insulin resistance (142). Beside an increased lipid overflow also intrinsic disturbances in FA handling, oxidative capacity and lipolysis may contribute to increase muscle fat storage. So far, little information is available on the regulation of muscle lipolysis and to what extent disturbances in this regulation may contribute to the accumulation of TAG and lipid metabolites in muscle. Furthermore, increased delivery of FA to the liver increases hepatic glucose output (115) and VLDL-TAG output (48), may reduce insulin binding to hepatocytes (186) and thereby inducing hyperinsulinemia (72). Chronically elevated FA concentrations may also reduce insulin secretion in type 2 diabetes mellitus (147). Finally, elevated FA levels impair endothelial function and could therefore predispose to hypertension and cardiovascular diseases $(117,182)$.

The research described in this thesis focuses on the regulation of lipolysis in adipose tissue and skeletal muscle of obese subjects. In addition, possible molecular and genetic disturbances in the lipolytic pathway will be evaluated. The introduction of this thesis is composed of three main sections. At first, the regulation of endogenous lipolysis by hormones, lipases and proteins that associate with the lipid droplet is discussed (paragraph 1). The second section highlights disturbances in adipose tissue (paragraph 2) and skeletal muscle (paragraph 3) lipolysis of obese subjects. Third, it is questioned whether a blunted lipolysis is a cause or more a consequence of the obese state (paragraph 4). Finally, an overview is given of different topics and chapters covering the present thesis (paragraph 5).

\section{The lipolytic pathway}

Almost $95 \%$ of the body's fat is found in adipose tissue. Beside adipose tissue a small amount of fat is stored in muscle, liver and pancreas (i.e. ectopic fat deposition). An increased fat accumulation in skeletal muscle may have profound meta- 


\section{[Chapter 1}

bolic effects, since skeletal muscle makes up $30-65 \%$ of total body mass (180). In adipose and non-adipose tissues fat is stored as TAG in intracellular lipid droplets that can be mobilized in a regulated way. This catabolic process is called endogenous lipolysis and results in the release of FA and glycerol to meet tissue's energy need during high-energy demands (e.g. fasting and exercise). The aim of this section is to provide a detailed overview and comparison of the lipolytic pathway in adipose tissue (paragraph 1.1) and skeletal muscle (paragraph 1.2).

\subsection{The lipolytic pathway in adipose tissue}

The complexity of the lipolytic pathway in adipose tissue is illustrated in Figure 1. In human adipose tissue the regulation of lipolysis depends on the balance between lipolytic and anti-lipolytic hormones. Catecholamines (e.g. adrenaline and noradrenaline) are the major lipolytic hormones that regulate lipolysis through lipolytic $\beta$-adrenoceptors $\left(\beta_{1}, \beta_{2}\right.$ and $\left.\beta_{3}\right)$ and the antilipolytic $\alpha_{2}$-adrenoceptor. The balance between $\beta$ - and $\alpha_{2}$-adrenoceptor mediated signal transduction determines the net effect of catecholamines on lipolysis (102). In human subcutaneous adipose tissue the lipolytic effect of catecholamines seems to be mediated by both $\beta_{1}$ - and $\beta_{2}$-adrenoceptors (7). In contrast to rodents, the contribution of the $\beta_{3}$-adrenoceptor to human adipose tissue lipolysis is limited, although it may play a role in lipolysis in visceral adipose tissue $(7,120,167)$. Furthermore, the lipolytic effect of catecholamines is more pronounced in intra-abdominal (visceral) compared with subcutaneous adipocytes. This can be explained by differences at the receptor and postreceptor level $(6,44,45,70,126,154)$. These differences are of a primary nature because they are already present in pre-adipocytes from the two depots (195).

$\beta$-adrenoceptors are linked to stimulatory G-proteins (Gs) that activate adenylate cyclase (AC) resulting in an increased production of cyclic adenosine monophosphate (cAMP). This in turn activates protein kinase A (PKA) leading to the reversible phosphorylation of hormone-sensitive lipase (HSL) and the lipid droplet associated protein perilipin. In adipocytes two perilipin isoforms are identified: perilipin A (MW $\sim 62 \mathrm{kDa}$; dephosphorylated) is the predominant isoform, whereas perilipin B (MW $\sim 46 \mathrm{kDa}$ ) is a minor isoform ( $10 \%$ of total). Perilipin C and D are almost exclusively expressed in steroidogenic cells $(33,57,171)$. Phosphorylation of perilipin increases lipase access to the lipid substrate allowing translocation of phosphorylated HSL to the lipid droplet and subsequent TAG hydrolysis. In contrast to $\beta$-adrenoceptors, $\alpha_{2}$-adrenoceptors are coupled to inhibitory G-proteins (Gi) that inactivate $\mathrm{AC}$ resulting in a decreased cAMP content and a subsequent reduced PKA activation. Recently, the lipolytic picture has been revisited by the identification of a new lipase: 'Addipose TriGlyceride Lipase' (ATGL) (214). In paragraph $\mathbf{1 . 3}$ the revised lipolytic pathway and the regulation of HSL and ATGL activity will be discussed in more detail.

Beside catecholamines, also natriuretic peptides (NP) and tumor necrosis factor alpha (TNF- $\alpha$ ) have lipolytic effects in adipocytes, as extensively reviewed elsewere $(107,129)$. Briefly, atrial natriuretic peptide (ANP), the most potent lipolytic NP, acts through a lipolytic pathway distinct from catecholamines. In contrast to catecholamines and ANP, the lipolytic response of TNF- $\alpha$, produced by macrophages and adipocytes, increases only after hours of incubation of 3T3-L1 and hu- 
man adipocytes $(40,161,162)$. This suggests that stimulation of lipolysis by TNF- $\alpha$ is indirect and serves as a chronic regulator of lipolytic tone. Several distinct mechanisms have been proposed for the lipolytic effect of TNF- $\alpha$ (107).

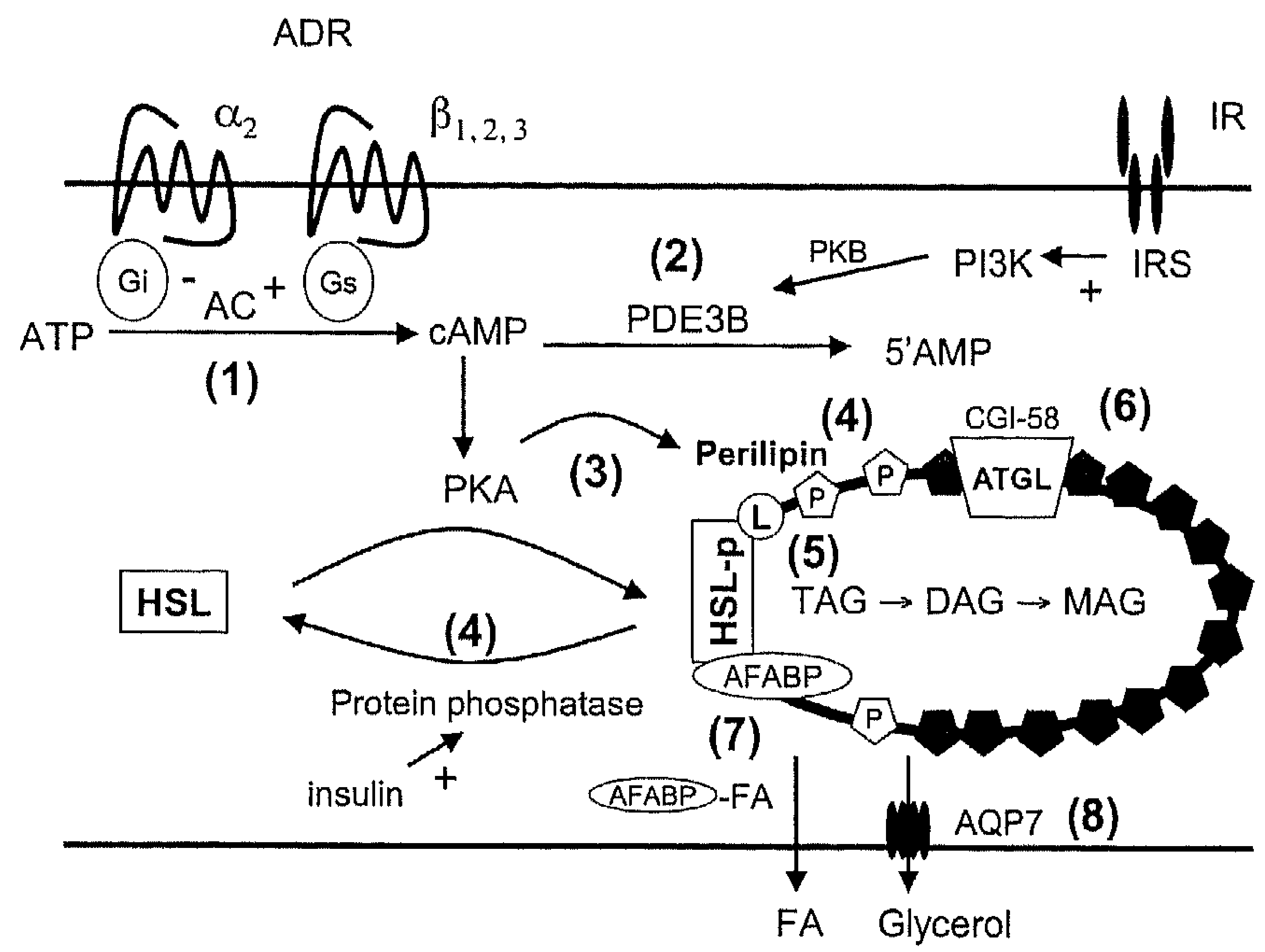

Figure 1. The PKA-dependent lipolytic pathway in adipocytes. This figure represents a schematic diagram of several control points in the lipolytic pathway in adipocytes. (1) Catecholamines act at adrenoceptores (ADR) that either stimulate or inhibit adenylate cyclase (AC), a reaction that is mediated by stimulatory (Gs) or inhibitory (Gi) G proteins. (2) Insulin binding to specific insulin receptors (IR) leads to the activation of insulin-like receptor substrates (IRS), activating phosphatidyl inositol 3 kinase (PI3K) and subsequent phosphorylaytion of phosphodiesterase 3B (PD3B) by protein kinase $B$ (PKB). PDE3B inactivates the cAMP produced by AC upon conversion to 5'AMP. (3) cAMP produced by $\mathrm{AC}$ activates protein kinase $\mathrm{A}(\mathrm{PKA})$. $\mathrm{PKA}$ phosphorylates and activates at least two substrates: hormone-sensitive lipase (HSL) and perilipin (P). HSL and perilipin phosphorylation leads to the translocation of HSL from the cytosol to the surface of the lipid dropley. (4) Insulin can activate protein phosphatases resulting in the subsequent dephosphorylation of HSL. (5) An interaction between phosphorylated HSL (HSL-p) and lipotransin (L) occurs at the surface of the lipid droplet. (6) Instead of phosphorylation and translocation, an activator protein (i.e. CGI-58), activates adipose triglyceride lipase (ATGL). The role of ATGL in adipose tissue lipolysis is under debate. (7) Interaction of HSL with adipocyte fatty acid binding protein (AFABP) favours a rapid evacuation of fatty acids (FA) resulting from the hydrolysis of TAG. (8) Glycerol is released from the adipocyte by aquaporin 7 (AQP7).

Insulin, the most potent antilipolytic hormone in human adipose tissue, exerts its antilipolytic effect through binding to specific cell-surface insulin receptors causing 


\section{[Chapter 1}

tyrosine phsophorylation and activation of the receptor. This leads to interaction with insulin-like receptor substrates (IRS-1 and IRS-2) (206) activating phosphatidyl inositol 3-kinase (PI3K) $(135,151,152)$. Subsequently protein kinase B (PKB) (208) phosphorylates phosphodiesterase 3B (PDE3B) $(31,122)$. PDE3B inactivates cAMP by converting it into 5'AMP resulting in a decrease of intracellular cAMP content (Figure 1). cAMP degradation is the main mechanism whereby insulin antagonizes catecholamine-induced lipolysis. Beside cAMP degradation, additional mechanisms exist via which insulin can antagonize catecholamine-induced lipolysis. For instance, insulin can inhibit $\mathrm{AC}(84)$ and may internalise $\beta$-adrenoceptors in human adipocytes (35). In addition, insulin can activate a protein phosphatase resulting in subsequent dephosphorylation of HSL (Figure 1) (184). There are major differences in insulin action between adipose tissue depots. The antilipolytic effect of insulin is blunted in visceral compared with subcutaneous adipocytes. Several functional differences between both depots have been identified at the level of the insulin receptor and post-receptor signalling $(17,209,212)$.

Beside insulin, some other molecules pocess antilipolytic activity via Gi protein coupled receptors; e.g. prostaglandines, nicotinic acid and adenosine $(3,157)$. However, their role in lipolysis regulation is probably minor. Furthermore, adrenomedullin, produced by endothelial and vascular smooth muscle cells, shows an inhibitory effect on lipolysis induced by the non-selective $\beta$-agonist isoprenaline in human adipocytes (67). A nitric oxide (NO)-dependent inactivation of the $\beta$ adrenergic agonists has been suggested for this effect (67).

The final step in the lipolytic pathway is the efflux of FA and glycerol into the circulation. FA are transported across the membrane by passive diffusion (66). In addition, several FA transporters facilitate the transport of FA through the plasma membrane (19). Nevertheless, their role in efflux of FA is poorly documented. On the other hand, aquaporin-7 (AQP7) appears to be one of the main channels for glycerol release from adipocytes (73).

\subsection{The lipolytic pathway in skeletal muscle}

As illustrated in Figure 2, skeletal muscle lipolysis is differently regulated than adipose tissue lipolysis. In skeletal muscle, only the $\beta_{2}$-adrenoceptor subtype is of importance for regulation of catecholamine-induced lipolysis $(64,116)$. In addition, no effect of ANP on in vivo skeletal muscle glycerol release has been observed, suggesting catecholamines are the major lipolytic hormones in skeletal muscle (10). Furthermore, HSL protein expression has been demonstrated in human skeletal muscle. This represents HSL in myocytes and not HSL originating from interlaced adipocytes $(77,104,106)$. HSL expression is higher in muscles containing predominantly type 1 and 2a fibers, and HSL expression correlates with the muscle TAG concentration and oxidative capacity (106). The effect of catecholamines on skeletal muscle HSL phosphorylation and activity will be discussed in paragraph 1.3.1. Beside HSL, ATGL may play a pivotal role in skeletal muscle lipolysis, since ATGL deficient animals show significant TAG accumulation in skeletal muscle (Table 1) (63). Accordingly, ATGL mRNA expression has been demonstrated in skeletal muscle of rodents (214). However, up to now, ATGL protein expression in human skeletal muscle has not been shown. 


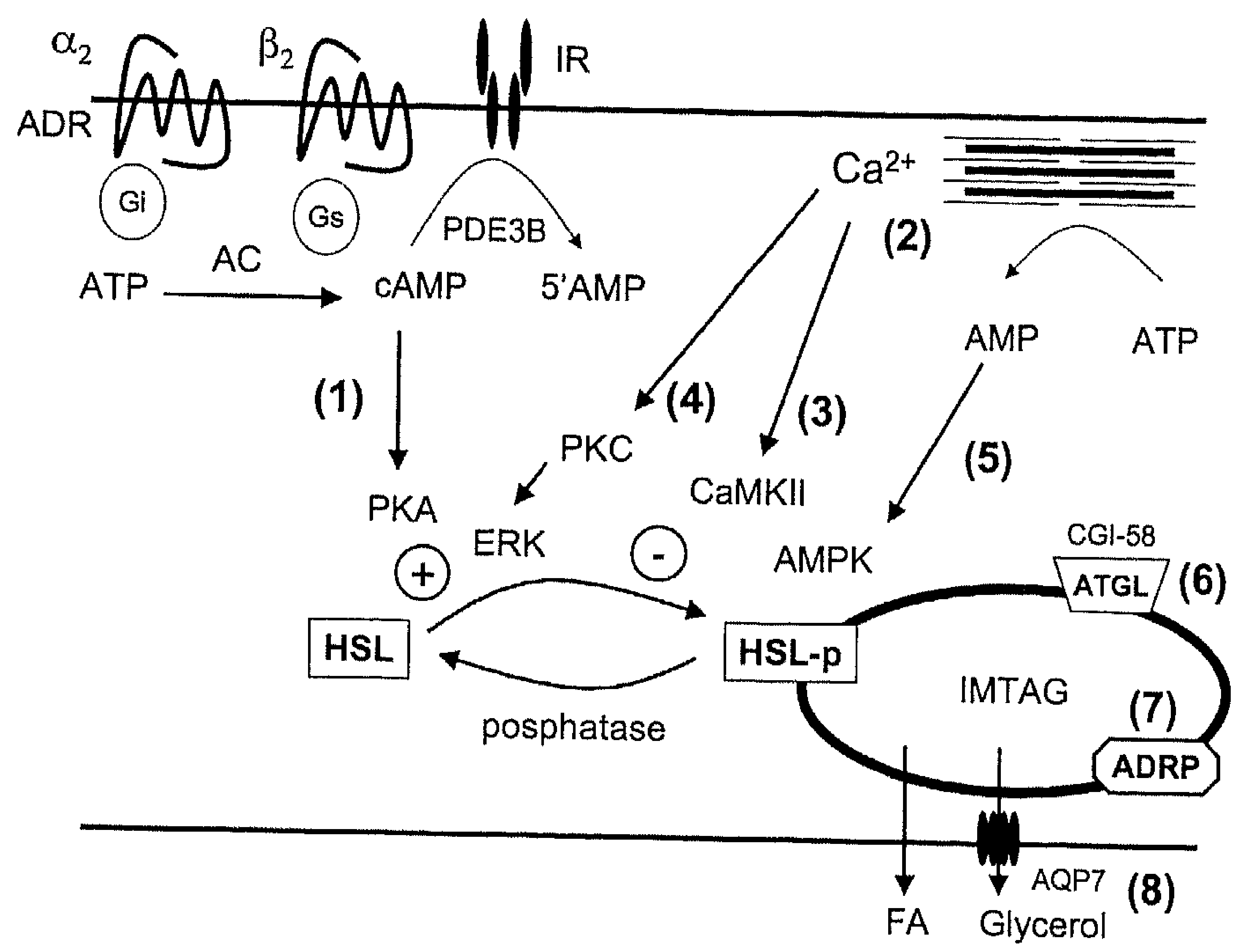

Figure 2. The lipolytic pathway in myocytes. Catecholamines and contraction can phosphorylate and activate hormone-sensitive lipase (HSL). (1) The effect of catecholamine on HSL phosphorylation and activation is mediated by adrenoceptors (ADR) and PKA. At the present it is unclear which of the PKA phosphorylation sites are important in mediating the effect of catecholamine on muscle HSL activity. (2) During muscle contraction intracellular calcium $\left(\mathrm{Ca}^{2+}\right)$ concentration increases. Calcium can phosphorylate HSL through activation of two kinases. (3) Calcium/calmoduline-dependent kinase II (CaMKII) rather inhibits than promotes HSL activity. (4) In contrast, protein kinase C (PKC) phosphorylates and activates HSL through the ERK pathway. (5) Furthermore, muscle contraction increases AMPK activity resulting in an increased HSL phosphorylation but no increased HSL activity. (6) In addition to HSL, the recently discoverd adipose triglyceride lipase (ATGL) and its co-factor CGI58 might play a role in skeletal muscle lipolysis. (7) In contrast to adipose tissue, perilipin is not expressed in muscle. It is suggested that the predominant lipid droplet associated protein in skeletal muscle is adipocyte differentiation-related protein (ADRP/adipophilin/ADPH). (8) AQP7 is expressed in skeletal muscle and might mediate glycerol efflux from skeletal muscle.

Muscle lipolysis is to lesser extent under hormonal control of insulin but may be more regulated by substrate supply (207). This seems to be supported by recent studies showing no apparent suppression of in vivo skeletal muscle lipolysis by either insulin or glucose in lean and obese subjects $(18,128)$. However, in type 1 diabetic subjects combined hyperinsulinemia and hyperglycemia but not hyperinsulinemia alone, suppresses human skeletal muscle lipolytic activity in vivo (150). The molecular basis for this tissue-specific variation in lipolysis regulation by insul- 


\section{[Chapter 1}

lin is not known. Different phosphodiesterase subtypes in adipose tissue and skeletal muscle could be involved (36).

Beside lipases also lipid droplet associated proteins are expressed in skeletal muscle. Perilipin protein expression has been demonstrated in human skeletal muscle, although levels were substantially lower than those observed in adipose tissue (65). It may be argued that this perilipin expression is originating from interlaced adipocytes. The predominant lipid droplet associated protein in human skeletal muscle has been suggested to be $\underline{\text { Adipose }}$ Differentiation-Related Protein (ADRP) (human orthologue called Adipophilin (ADPH)) (144). In contrast to its function in adipocytes, skeletal muscle ADRP might play a role in hormone-stimulated lipolysis (145). Finally, AQP7 expression has been demonstrated on the surface of human type 1 and 2 muscle fibers (202). However, more research is needed to elucidate the physiological role of muscle AQP7 expression in glycerol efflux from skeletal muscle.

Table 1. Phenotypic characteristics of lipase and lipid droplet associated protein deficient animals

\begin{tabular}{|c|c|c|c|c|}
\hline & HSL $-/-$ & ATGL-/- (63) & Perilipin - $/-$ & ADRP $/-(26)$ \\
\hline Body weight & $\begin{array}{c}=(132,138,140, \\
143,159,213)\end{array}$ & $\uparrow$ & $=(125,193)$ & $=$ \\
\hline Fat mass & $\begin{aligned} \downarrow /= & \text { WAT }(138,213) \\
& \uparrow \text { BAT }(138)\end{aligned}$ & $\begin{array}{l}\uparrow W A T \\
\uparrow B A T\end{array}$ & $\downarrow(125,193)$ & $=$ \\
\hline Lean body mass & $=$ & $=$ & $\uparrow(125,193)$ & $=$ \\
\hline Whole-body insulin sensitivity & $\begin{aligned} \downarrow & (132,159) \\
= & (140,200) \\
& \uparrow(143)\end{aligned}$ & $\uparrow$ & $\begin{array}{l}\downarrow(164,193) \\
\quad=(125)\end{array}$ & $=$ \\
\hline AT insulin sensitivity & $\begin{array}{l}\downarrow(132) \\
=(140)\end{array}$ & & & \\
\hline SM insulin sensitivity & $\begin{array}{l}\downarrow(132) \\
=(140)\end{array}$ & & & \\
\hline Basal lipolysis & $\downarrow(138)$ & $=$ & $\uparrow(125,193)$ & $=$ \\
\hline $\begin{array}{l}\text { Catecholamine-induced } \\
\text { lipolysis }\end{array}$ & $\downarrow(132,138)$ & $\downarrow$ & $\downarrow(125,193)$ & $=$ \\
\hline TAG hydrolyse activity & $\begin{array}{l}\downarrow(\text { WAT })(138) \\
\quad=(\mathrm{BAT})\end{array}$ & $\begin{array}{c}\downarrow \text { (WAT) } \\
\downarrow \text { (BAT) } \\
\downarrow \text { (SM, liver) }\end{array}$ & & \\
\hline DAG hydrolyse activity & $\begin{array}{l}\downarrow \text { (WAT) (132) } \\
\quad=(\text { SM }) \\
\quad=(\text { liver })\end{array}$ & & $\downarrow(\mathrm{WAT})(125)$ & \\
\hline
\end{tabular}

AT, adipose tissue; SM, skeletal muscle; TAG, triacylglycerol; DAG, diacylglycerol; WAT, white adipose tissue; BAT, brown adipose tissue. 
General introduction]

\section{TAG}

$\underset{(H S L)}{A T G L} \backslash$ FA

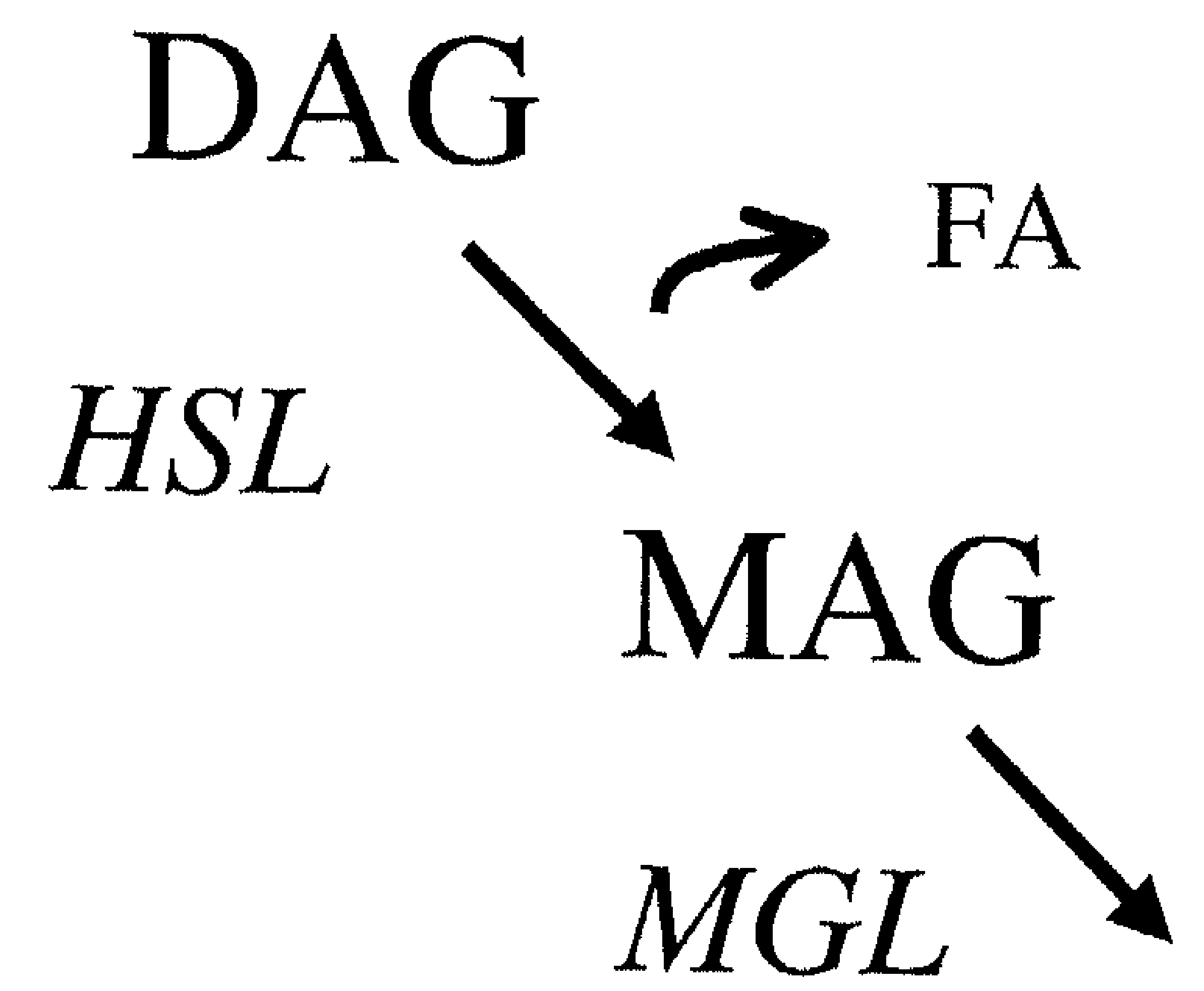

$\mathrm{FA}+\mathrm{G}$

Figure 3. The classic lipolytic picture revisited. The first ester bound in a TAG molecule is predominantly hydrolyzed by the recently discovered adipose triglyceride lipase (ATGL), providing DAG substrate for the subsequent action of hormone-sensitive lipase (HSL) resulting in the conversion of DAG into MAG. HSL has also TAG hydrolyse activity, although lower than its DAG hydrolase activity. Finally, monoacylglycerol lipase (MGL) is necessary for the complete hydrolysis of MAG into one fatty acid (FA) and glycerol (G).

\subsection{The lipolytic picture revisited: a new lipase enters the picture}

For more than 30 years, HSL has been seen as the rate-limiting lipase for TAG hydrolysis. So far three isoforms of HSL have been identified, ranging in size from 84 to $130 \mathrm{kDa}(78,79,118,131)$ hydrolyzing all acylglycerols: $(50,137,197)$. However, the activity against diacylglycerol (DAG) is higher than the activity against TAG and monoacylglycerol (MAG), by 10-12 fold and 5-10 fold, respectively (49, 137). The rate-limiting role for HSL in TAG hydrolysis has been further challenged by data from HSL deficient animals (Table 1). In these animals TAG lipase activity in white adipose tissue (WAT) was reduced by only $50 \%$ and an increased DAG accumulation was found in adipose and non-adipose tissues (e.g. skeletal muscle and liver) $(132,138)$. These data indicated that HSL is not rate-limiting for TAG breakdown, but for DAG breakdown, which suggested the existence of one or more lipases primarily involved in TAG breakdown. Recently, three independent groups identified a patatin domain containing lipase and called it respectively ATGL 
[Chapter 1

(MW 56 kDa) (214); desnutrin (198); calcium-independent phospholipase $A_{2}$ [zeta] (iPLA $\mathrm{A}_{2} \mathrm{~S}$ ) (87). In contrast to HSL, this lipase exhibits high substrate specificity for the hydrolysis of TAG. Together ATGL and HSL are responsible for more than $95 \%$ of the TAG hydrolase activity present in murine WAT (170). Additional known or unknown lipases appear to play only a quantitatively minor role in fat cell lipolysis. Finally, monoacylglycerol lipase (MGL; $M W \sim 33 \mathrm{kDa}$ ) is necessary for the complete hydrolysis of MAG into one FA and glycerol molecule (51). In contrast to HSL and ATGL, MGL is not under hormonal control. Taken together, in the revised lipolytic picture every step requires its own distinct lipase, as illustrated in Figure 3. Next the regulation of HSL (paragraph 1.3.1) and ATGL (paragraph 1.3.2) activity and their respective role in human lipolysis will be discussed in more detail.

\subsubsection{Regulation of HSL activity}

In adipose tissue catecholamines increase HSL activity by reversible phosphorylation and translocation from the cytosol to the lipid droplet. $(23,34,83)$. PKA phosphorylates HSL on at least three serine residues: $\operatorname{Ser}^{563}, \operatorname{Ser}^{659}$ and $\operatorname{Ser}^{660}$. Mutational exclusion of $\mathrm{Ser}^{659}$ and $\mathrm{Ser}^{660}$ completely abolishes activation and translocation of HSL, suggesting these sites to be the major PKA phosphorylation sites, at least in adipocytes (2). Furthermore, $\mathrm{Ser}^{565}$ appears to be phosphorylated at a high degree in unstimulated adipocytes and in vitro phosphorylation of this site does not affect HSL activity, suggesting this site is involved in basal unstimulated lipolysis (183). Moreover, phosphorylation of $\operatorname{Ser}^{565}$ prevents subsequent phoshorylation of $\mathrm{Ser}^{563}$; suggesting that phosphorylated $\mathrm{Ser}^{565}$ has an antilipolytic effect (55).

Beside PKA also protein kinase C (PKC) is involved in the lipolytic action of catecholamines. PKC increases HSL activity through phosphorylation of $\mathrm{Ser}^{600}$, at least in 3T3-L1 adipocytes (58). Phosphorylation of $\mathrm{Ser}^{600}$ in primary adipocytes remains to be demonstrated. Activation of both the PKA and PKC pathway in 3T3L1 adipocytes leads to HSL phophorylation at a similar degree. In contrast, perilipin is phosphorylated to a lower extent by PKC, explaining that the net effect of PKC in 3T3-L1 adipocytes is moderate (52). Interestingly, both the PKA and PKC pathway do not influence one another and act synergistically in terms of lipolysis (52). It remains to be determined which mechanisms are involved in this synergy

Like in adipose tissue the effect of catecholamines on HSL in skeletal muscle is mediated by $\beta$-adrenoceptors and PKA (106). At the present, however, it is unclear which of the PKA phosphorylation sites on HSL are important in mediating the effect of catecholamines on in vivo muscle HSL activity. Beside catecholamines, contraction can activate skeletal muscle HSL. Both stimuli have partially additive effects on HSL activity in muscle, indicating that catecholamines and contraction activate HSL by at least partly different signalling mechanisms (103). During muscle contraction HSL activation is triggered by an increased intramuscular calcium concentration and phosphorylation (105). From studies in adipocytes it is known that calcium/calmoduline-dependent kinase II (CaMKII) phosphorylates HSL Ser ${ }^{565}$. This rather inhibits than promotes HSL activity (54). Nevertheless, calcium might also promote HSL activity via PKC mediated phosphorylation of HSL Ser ${ }^{600}$ (58). Furthermore, HSL activity does not increase during exercise in adrenaline-deficient 
and adrenalectomised patients 1981 . Howerer. when adrenaline is inlused to mimic normal exercise lavels. HSL activity increased. This suggests that beside contraction-related mechanisms, also adrenaline is important for HSI. activation during exercise $(98)$. Finally, it has been shown that the exercise induced rise in HSL activity is complately aholished after glueose ingestion. suggesting that also hyperglycemia can play an important role in mediating muscle HSL activity (204).

Beside phosphorylation, proper action of HSL relies upon proteins that are not directly involved in the catalytic proceses. It has been shown that the N-terminal domain of HSL interacts with Adipocyte Fatty Acid Binding Protein (AFABP/FABP4/aP2), the major fatty acid binding protein (FABP) in adipocytes (Figure 1$)(88,174,178)$. AFABP/aP2 plays two roles in lipolysis. Firstly. $A F A B P / a_{2} 2$ favours a rapid evacuation of the $F A$ to the circulation, which is independent of physical association with HSL (178). Secondly, AFABP/aP2 with a bound FA serves a regulatory role in lipolysis by associating with the activated phosphorylated HSL on the surface of the lipid droplet (i.e. feedback inhibition) (178). Consistent with a regulatory role of $\mathrm{AFABP} / \mathrm{aP2}$ in lipolysis is the observation that primary adipocytes isolated from $\mathrm{AFABP} / \mathrm{aP} 2$ deficient mice exhibit decreased basal and catecholamine stimulated lipolysis in most studies $(27,165,194)$ but not all (172). FABP4/aP2 expression has also been shown in human skeletal muscle (42). However, its role in skeletal muscle lipolysis and FA efflux is unclear. Finally, it has been shown in 3T3-L1 adipocytes that upon phosphorylation HSL can interact with the protein lipotransin, which serves to dock the lipase at the outer surface of the lipid droplet (187). Once lipotransin is bound, it can undergo a cycle of ATP hydrolysis, permitting the dissociation of HSL and its direct association with the lipid droplet. It is not known which of the HSL phosphorylation sites control the binding of HSL to lipotransin. Interestingly, lipotransin is highly expressed in human skeletal muscle (187). It remains to be elucidated whether skeletal muscle lipotransin is also a HSL-interacting protein.

\subsubsection{Regulation of ATGL activity}

Insufficient time has passed since the discovery of ATGL to fully understand the nature of its regulation. However, from the limited data available, it appears that ATGL is regulated differently than HSL. ATGL is tightly associated with the intracellular lipid droplet of the adipocyte $(87,198,214)$ and the amount of lipid droplet associated ATGL is unaffected by $\beta$-adrenergic stimulation. In addition, ATGL can be phosphorylated but in contrast to HSL this is not mediated by PKA (214). These observations suggest that ATGL is not directly activated by phosphorylation and translocation to the lipid droplet as demonstrated for HSL. Instead, an activator protein regulates ATGL activity: CGI-58 (comparative gene identification 58: MW $-39 \mathrm{kDa})(111)$. (GI-58 is expressed in a wide variety of tissues (e.g. testis $>$ adipose tissue $\rightarrow$ liver $>$ muscle) (111) and ATGL seems to be the sole target for (CI58 mediated activation of lipolysis in adipose tissue $(111,170)$. Interestingly, in adipose tissue ('Gl-58 binds to the intracellular lipid droplet by interaction with perilipin A $(185,210)$. In response to PKA stimulation, perilipin is phosphorylated and C Cil-58 is released from the lipid droplet, thereby becoming available for bind- 
[Chapter 1

ing to ATGL and resulting in an increased TAG hydrolysis (185). The reversible binding of CGI-58 to perilipin could potentially represent an indirect PKAdependent mechanism controlling ATGL activity. Interestingly, CGI-58 also interacts with ADRP in cell lines lacking perilipin like CHO cells (210). Since ADRP is the predominant lipid-droplet associated protein in skeletal muscle, the interaction between CGI-58 and ADRP might play an important role in the regulation of ATGL activity in skeletal muscle.

Furthermore, the role of ATGL in basal and catecholamine-stimulated lipolysis is under debate. In murine adipose tissue it was shown that ATGL markedly augments basal and isoprenaline-stimulated lipolysis (214). Moreover, adipose tissue of ATGL and HSL deficient mice showed residual basal lipolysis and dramatically reduced isoprenaline-mediated lipolysis (Table 1) $(63,132,138)$, suggesting that in adipose tissue of rodents both HSL and ATGL are involved in catecholaminestimulated lipolysis. In contrast to murine adipose tissue, the role of ATGL in human adipose tissue lipolysis remains to be elucidated.

\section{Adipose tissue lipolysis in obesity}

The obese state is characterized by increased fat storage in adipose tissue. Catecholamine resistance of lipolysis might be responsible for the development and maintenance of increased adipose tissue stores and obesity, as will be discussed in paragraph 2.3. Furthermore, increased adipose tissue mass increases circulating FA levels in obesity. This might be due to mass action or a diminished inhibition of adipose tissue lipolysis by insulin (see paragraph 2.1 and 2.2). As mentioned before, elevated FA levels have many adverse metabolic effects and are associated with an increased risk for the development of insulin resistance, type 2 diabetes and cardiovascular diseases. Finally, regional differences in the regulation of lipolysis have implications for differences in body fat distribution between genders and obesity-related metabolic abnormalities (see paragraph 2.4).

\subsection{Fasting lipolysis}

The obese state is often associated with elevated circulating fasting FA concentrations (136). However, if all excess fat liberates FA at the same rate as in lean subjects, circulating FA concentrations in obesity would be much higher than observed (46). This indicates that the increased FA concentration in obesity is not proportional to the increased fat mass. One possible explanation is that adipose tissue lipolysis is considerably down-regulated in obesity. Indeed, in vivo after an overnight fast, the systemic FA and glycerol flux expressed per unit fat mass has been reported to be decreased in obesity in most $(11,24,80,81,89)$ but not all studies (12). However, data are not entirely consistent. Using in situ microdialysis, no difference in subcutaneous adipose tissue lipolysis was observed between obese and lean subjects after an overnight fast $(18,86,166)$. In contrast to in vivo and in situ studies, in vitro studies showed that obesity is accompanied by increased basal (non-stimulated) lipolysis in abdominal subcutaneous adipocytes when expressed per number of cells, but nearly normal values are found when related to weight of 
the fat cell (108). One possible explanation for this apparent discrepancy is the strong influence of adipocyte size on basal lipolytic rate, which increases with adipocyte size (108).

It has been argued that a down-regulation of adipose tissue lipolysis is attributable to the fasting hyperinsulinemia in obesity, which may be advantageous by preventing massive increases in circulating FA levels. Likewise, fasting insulin concentrations are inversely related to FA output from adipose tissue (94). Furthermore, lipase expression seems to be associated with hyperinsulinemia and insulin resistance. ATGL and HSL mRNA expression is down-regulated by insulin in 3T3-L1 adipocytes $(96,97,100)$. Secondly, HSL and ATGL mRNA expression is decreased in animal models for insulin resistance $(96,188)$. Moreover, improvement of insulin sensitivity, using the PPAR- $\gamma$ agonist rosiglitazone, results in significantly increased ATGL (173) and HSL mRNA expression in adipose tissue of these mice (41). In contrast to the effect of hyperinsulinemia and insulin resistance, there are indications that a decreased lipase expression and down-regulation of adipose tissue lipolysis might be an early or even primary defect in obesity, as will be discussed in more detail in paragraph 4.1 .

\subsection{Insulin sensitivity of adipose tissue lipolysis}

An impaired sensitivity to the antilipolytic effect of insulin might have profound metabolic effects during fasting and postprandial conditions. A characteristic of the obese insulin resistant state is hypersecretion of insulin, even under normal physiological circumstances. Moreover, a stronger insulin resistance of adipose tissue lipolysis in obesity has been shown in a number of in vivo studies. A diminished suppressive effect of insulin on whole-body FA and glycerol turnover during a stepwise euglycemic hyperinsulinemic clamp was shown in obese and non-obese insulin resistant subjects $(1,24,91)$, type 2 diabetic subjects $(59,61)$, and even glucose tolerant first-degree relatives of patient with type 2 diabetes (62). In addition, in vivo adipose tissue HSL and lipoprotein lipase (LPL) are not suppressed normally by insulin postprandially in obese subjects (29). This insulin resistance of adipose tissue lipolysis might be regarded as a biological adaptation prevailing hyperinsulinemia in obesity (46).

In contrast to insulin resistance of adipose tissue lipolysis, some in vivo studies show that plasma FA and glycerol turnover expressed per kilogram fat mass is normally suppressed by insulin in obese subjects $(60,158)$. Moreover, in vitro experiments with isolated subcutaneous adipocytes display similar dose-response curves of insulin with respect to antilipolysis in non-obese first-degree relatives of type 2 diabetic subjects $(38)$, obese and lean control subjects $(5,121)$, suggesting lipolysis is normally sensitive for insulin. Therefore, more in vivo research is needed on the effect of insulin on adipose tissue lipolysis under different insulin resistant conditions to resolve this apparent controversy.

\subsection{Catecholamine-induced lipolysis}

In vivo a blunted whole-body catecholamine-induced lipolysis has been observed in obese subjects $(14,15,28,81,89,205)$. In vitro studies suggest that the site of this catecholamine resistance is abdominal subcutaneous adipose tissue (155). Some 


\section{[Chapter 1}

(81) but not all $(20,166)$ in situ microdialysis studies support this. However, real in vivo evidence for the presence of catecholamine resistance in subcutaneous adipose tissues of obese subjects is lacking. Several receptor and post-receptor defects in the lipolytic signal transduction pathway are likely to be involved in the observed catecholamine resistance. First, in vitro (155) and in vivo (168) studies suggest that catecholamine resistance of abdominal subcutaneous adipose tissue lipolysis is re-

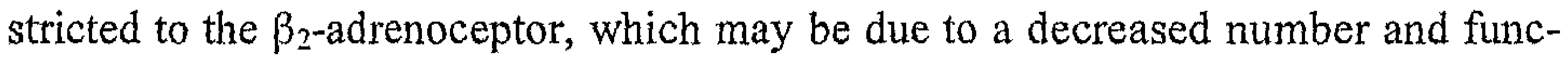
tion of $\beta_{2}$-adrenoceptors (155). Secondly, a decreased HSL expression and activity in subcutaneous adipose tissue of obese subjects $(110,119)$, or the presence of a catalytic inactive form of HSL might partly explain the blunted lipolysis in this adipose tissue depot of obese subjects $(112,153)$. Likewise, HSL deficient mice show a blunted isoprenaline-induced lipolysis in adipocytes (Table 1) $(132,138)$. These animals are lean despite the fact that they show increased lipid storage (i.e. DAG) and signs of impaired insulin sensitivity in adipose tissue $(132,138)$. However, as illustrated in Table 1, data of HSL deficient mice with respect to adipose tissue and whole-body insulin sensitivity are conflicting $(140,143,159,200)$. Differences in genetic background of HSL deficient mice and study design (in vitro vs. in vivo) might contribute to this apparent discrepancy. In contrast to HSL, the expression of ATGL protein in adipose tissue of obese subjects has not yet been investigated. However, ATGL deficient mice show mild obesity and have a reduced isoprenaline-induced lipolysis, suggesting ATGL might contribute to the catecholamine resistance and increased TAG storage in obesity, at least in mice (63). In contrast to murine adipose tissue, the exact role of ATGL in human adipose tissue lipolysis is unknown. So, more research is needed to find out whether ATGL is involved in basal and/or catecholamine-induced lipolysis in human adipose tissue and whether ATGL expression is impaired in obesity.

\subsection{Body fat distribution}

Regional differences in adipose tissue lipolysis could contribute to differences in body fat distribution between genders. Gluteal adipocytes from women tend to be larger than those from men, and when they are, higher basal lipolytic rates are found $(126,156,201)$. However, basal lipolytic rates in adipocytes from equal size have been repoted to be comparable between sites and gender (114). Furthermore, in vivo fasting $\mathrm{FA}$ release (expressed per $\mathrm{kg}$ fat mass) from upper-body adipose tissue (i.e. abdominal subcutaneous) is significantly higher than lower-body (e.g. gluteal) FA release in both men and women $(92,192)$. These data indicate that regional differences in fasting lipolytic rate are not a mechanism for differences in body fat distribution between men and women. Instead, differences in catecholamine-induced lipolysis might be involved, since in vitro and in vivo studies demonstrated a less pronounced lipolytic effect of catecholamines in the lower-body depots in women compared with men (90), most probably due to an increased number of $\alpha_{2}$-adrenoceptors (156). Furthermore, upper-body adipocytes are more sensitive to catecholamine stimulation than lower-body adipocytes in both men and women (201).

In contrast to upper-body obesity, lower-body obesity has been associated with a more favourable metabolic profile $(25,69,179,196)$. Indeed, upper-body fat is the 
major contributor to circulating FA and the major source of excess FA release in obesity $(99,124,133)$. Moreover, abdominal subcutaneous adipocytes have greater basal lipolytic rate than visceral adipocytes of equal size (70). Therefore, the upperbody subcutaneous fat region is more likely to be implicated in the increased systemic FA concentrations than upper-body visceral fat. Accordingly, FA released by the visceral depot contributes only a small percentage to circulating FA (133). However, increasing amounts of visceral fat probably result in a greater hepatic FA delivery, contributing to hepatic insulin resistance (133).

\section{Skeletal muscle lipolysis in obesity}

Beside an increased TAG storage in adipose tissue, the obese state is characterized by increased intramuscular TAG (IMTAG) storage (177). A strong link between increased IMTAG stores and skeletal muscle insulin resistance has been shown in lean and obese subjects $(85,101,139,141)$. Recent studies, however, have indicated that the accumulation of lipid intermediates (e.g. DAG and ceramides), and not TAG per se, might be the direct link with skeletal muscle insulin resistance, through interference with insulin signaling (142). Increased lipid storage in skeletal muscle of obese subjects may be due to an imbalance between FA uptake and oxidation. Weight reduction does not seem to improve skeletal muscle FA oxidation, suggesting this disturbance to be a primary factor leading to the development of increased IMTAG stores in obese and type 2 diabetic subjects $(16,175,176)$. A1though conflicting data are around in literature, mitochondrial dysfunction might be responsible for this diminished oxidative capacity $(8,22)$. Beside lipid overflow and a reduced FA oxidation, disturbances in the regulation of skeletal muscle lipolysis may play an important role in the increased accumulation of lipids and lipid intermediates in skeletal muscle of obese subjects, as will be discussed next.

\subsection{Fasting and catecholamine-induced lipolysis}

In situ microdialysis has shown that fasting glycerol release is comparable from gastrocnemius muscle of lean and obese subjects (18). However, marked differences in lipolytic activity among skeletal muscle group are found during fasting conditions (65). The highest lipolytic activity is found in muscles with a high portion of slow-twitch oxidative type 1 fibers, these muscle may need an endogenous source of fatty acids to a greater extent (e.g. endurance performance) than muscles with a relatively high content of fast-twitch, glycolytic type 2 fibers.

Although in vivo evidence is rare, a blunted increase in interstitial glycerol and local blood flow has been shown in gastrocnemius muscle of obese compared with lean subjects during local infusion of the $\beta_{2}$-agonist salbutamol (13). These data suggest a blunted catecholamine-induced lipolysis in skeletal muscle of obese subjects. Differences in muscle fiber type composition and $\beta_{2}$-adrenoceptor sensitivity between lean and obese subjects might partly explain the blunted catecholamine-induced lipolysis in skeletal muscle of obese subjects $(74,134)$. At the present, however, it is not known whether downstream disturbances in the lipolytic pathway are responsible for this blunted catecholamine-induced lipolysis in skeletal muscle of obese 


\section{[Chapter 1}

subjects. A reduced HSL expression, phosphorylation and activity are likely to be involved. Beside HSL, ATGL might be involved in skeletal muscle lipolysis: At the present ATGL protein expression in human skeletal muscle has not been shown and its role in lipolysis is under debate. However, it is tempting to speculate that an imbalance between ATGL and HSL expression might result in incomplete lipolysis and enhanced accumulation of lipid intermediates in skeletal muscle of obese insulin resistant subjects. In accordance, HSL deficient mice show an increased DAG storage and signs of impaired skeletal muscle insulin sensitivity (Table 1) (132, 138), while ATGL deficient mice that have increased TAG accumulation in skeletal muscle show improved insulin sensitivity (Table 1) (63). This highlights the importance of lipid intermediates in the development of insulin resistance.

\section{Impaired catecholamine-induced lipolysis in the obese insulin re- sistant state: cause or consequence?}

An impaired catecholamine-induced lipolysis might be a primary causative factor in the development of increased fat storage in adipose and non-adipose tissues of obese subjects (see paragraph 4.1). Alternatively, it might be more a secondary consequence of the obese state, a protective mechanism preventing excessive FA outflow in the circulation (see paragraph 4.2).

\subsection{A blunted lipolysis as cause for obesity}

It has been shown that an impaired catecholamine-induced lipolysis did not improve after weight reduction (15), is a feature of childhood onset obesity $(21,37)$ and is already present in adipocytes from first-degree relatives of obese subjects (71). These data indicate that catecholamine resistance of lipolysis may be an important early, even primary factor, for the development of increased fat stores in obesity. More evidence that a blunted lipolysis may be an early primary factor in obesity comes from polymorphisms in genes encoding key proteins of the lipolytic pathway. As will be discussed next, these polymorphisms are associated with a blunted catecholamine-induced lipolysis in adipocytes from obese subjects.

Several $\beta_{2}$-adrenoceptor gene (ADRB2) polymorphisms affect receptor function in vitro $(56,127)$. One is located at codon 16 substituting arginine for glycine (Arg16Gly). Two others are located at respectively codon 27 and 164 substituting glutamic acid for glutamine (Gln27Glu) and isoleucine for threonine (Thr164lle). In vitro studies showed that genetic variation in codon 16, 27 and 164 of the $A D R B 2$ gene is associated with a blunted catecholamine-induced lipolysis and obesity, although this has not been confirmed in all subsequent studies $(76,109,160)$. More recently, specific $A D R B 2$ gene haplotypes have been associated with receptor expression, in vitro sensitivity to catecholamine-induced lipolysis and obesity $(32,39$, 93).

$\beta$-adrenoceptors signal via G-proteins. In vitro studies indicated that allele $825 \mathrm{~T}$ in exon 10 of the gene that encodes the G-Protein $\beta_{3}$-subunit (GNB3) is associated with a decreased amount of $\mathrm{G} \beta_{3}$ in adipocytes, thereby inhibiting signaling through $\beta_{1^{-}}, \beta_{2^{-}}$, and $\alpha_{2}$-adrenoceptors. This resulted in decreased catecholamine action in 
isolated subcutaneous adipocytes of male and female obese subjects (163). Furthermore, this allele is associated with obesity in several, but not all, studied populations $(9,68,181)$.

TAG and DAG hydrolysis is mediated by HSL and the recently discovered ATGL. A decreased HSL expression and activity has been found in adipose tissue of nonobese first-degree relatives of obese subjects, suggesting a decreased HSL expression to be an early even primary defect in obesity $(71,110,119)$. A HSL promoter variant, $-60 \mathrm{C}>\mathrm{G}$, has been associated with a $40 \%$ reduced promoter activity in vitro (190). This polymorphism has opposite effects on adiposity in different populations $(53,191)$. Furthermore, a dinucleotide $(C A)_{n}$ repeat polymorphism in intron 6 of the HSL gene is associated with obesity, type 2 diabetes and a decreased in vitro catecholamine-induced lipolytic response in abdominal subcutaneous fat cells, being more pronounced in men than in women $(75,113,123)$. Nevertheless, this polymorphism is unlikely to result in functional conformational changes or to act alone.

Furthermore, genetic variation in the PNPLA2 gene, encoding ATGL, is associated with fasting FA and glucose levels, and type 2 diabetes, suggesting a role for the PNPLA2 gene in the pathway of the metabolic syndrome. (169). However, individuals with mutations in the PNPLA2 (ATGL) and ABHD5 (CGI-58) gene have neutral lipid storage disorders but are not obese, $(43,111)$. At the present the role of ATGL in human lipolysis is unclear and it is not known whether polymorphisms in the PNPLA2 and ABHD5 gene are associated with a blunted in vitro and in vivo lipolysis in obesity.

Finally, perilipin protects the lipid droplet from being hydrolyzed by lipases. A polymorphism in intron 6 of the Perilipin (PLIN) gene (11482G $>A$ ) is associated with decreased perilipin protein content and an increased in vitro basal and catecholamine-induced lipolysis in adipocytes from obese compared with lean female subjects (130). However, data on perilipin A and B expression in human subcutaneous adipose tissue of obese subjects are conflicting $(95,203)$. In contrast to human data (130), perilipin deficient mice showed a blunted catecholamine-induced lipolytic response in isolated adipocytes, due to a diminished HSL translocation (Table 1) $(125,189,193)$. The reason for this apparent discrepancy between mice and human is not clear at this time. Furthermore, additional intronic polymorphisms in the PLIN gene have been reported to be associated with the obese phenotype and resistance to weight loss following a low-energy diet $(30,148,149)$.

Taken together, there are indications that early genetic defects in the lipolytic pathway contribute to catecholamine resistance of lipolysis and excessive fat accumulation in obesity. However, evidence for the association of genetic variation with a blunted in vivo catecholamine-induced lipolysis is lacking.

\subsection{A blunted lipolysis as biological adaptation to hyperinsulinemia}

Alternatively, a blunted catecholamine mediated lipolysis can be more a consequence of obesity, decreasing FA outflow from adipose tissue so the body is not swamped with excess FA that can worsen the insulin resistant state. An increased adipose tissue mass in obesity may deliver more FA into the circulation, resulting in increased circulating FA concentrations when compared with lean subjects. How- 


\section{[Chapter 1}

ever, this is not found in all studies and observed circulating FA concentrations were lower than expected if all excess fat had been liberating FA $(99,146)$. As mentioned before in paragraph $\mathbf{2 . 1}$ and 2.2, tracer studies have shown that fasting FA release per unit fat mass is almost halved in obese compared to lean subjects, and this decrease was associated with fasting hyperinsulinemia (24). Likewise, fasting insulin concentrations are inversely related to FA output from adipose tissue (94). Furthermore, chronically high insulin levels, like observed in obese insulin resistant subjects, inhibit $\beta$-adrenoceptors from activating PKA (211). Nevertheless, it seems unlikely that the blunted catecholamine-induced lipolysis observed in obesity is just due the confounding influence of hyperinsulinemia. Indeed, a blunted in situ lipolytic response to catecholamine stimulation in abdominal subcutaneous adipose tissue of obese women was still observed when the confounding influence of hyperinsulinemia was excluded using a pancreatic hormonal clamp (81). However, it should be mentioned that both primary disturbances and secondary adaptational responses might coexist in obesity.

\section{Outline of the thesis}

This thesis describes a variety of human in vitro and in vivo studies designed to investigate lipolytic regulation in adipose tissue and skeletal muscle of obese subjects. The first step in this thesis was to elucidate whether in vivo beta-adrenoceptor mediated lipolysis is blunted in abdominal subctaneous adipose tissue (chapter 2) and forearm skeletal muscle (chapter 5) of obese compared with lean men. Local adipose tissue and forearm skeletal muscle lipolyis was investigated using the measurment of arterio-venous concentration differences in combination with $\left[^{2} \mathrm{H}_{5}\right]$ glycerol tracer methodology before and during $\beta$-adrenergic stimulation with the non-selective $\beta$-agonist isoprenaline. A pilot study was performed initially to determine the time period necessary for obtaining a steady-state in glycerol enrichment in both arterialized and venous blood draining from adipose tissue and skeletal muscle, since a lack of isotopic equilibration may explain previous discrepant findings on glycerol uptake (chapter 2 and 5). Recently, the lipolytic picture has been revisited by the identification of a new lipase called ATGL (214). However, the role of ATGL and HSL in basal and catecholamine-induced lipolysis in human is under debate. For this reason, we looked in chapter 3 at the respective role of HSL and ATGL on in vitro basal and catecholamine-induced lipolysis in human adipocytes of lean and obese subjects, using RNA interference methodology. To explain our in vivo findings on the molecular level, and to look at the respective role of fat mass and insulin resistance on adipose tissue ATGL and HSL mRNA and protein expression we studied a group of subjects with a broad range of insulin sensitivity and fat mass (chapter 4). Skeletal muscle HSL protein expression and phosphorylation at different serine residues was investigated in obese compared with lean subjects (chapter 5). Beside HSL, ATGL might play a pivotal role in skeletal muscle lipolysis, since ATGL deficient animals show significant TAG accumulation in skeletal muscle (63). For this reason we investigated whether ATGL protein is expressed in human skeletal muscle (chapter 6). To elucidate its potential physiological role we looked whether ATGL expression in human skeletal muscle is fiber type specific 
(chapter 6). Finally, we investigated whether the observed differences in the lipolytic pathway between obese and lean subjects might be genetically determined. Therefore we examined the effect of genetic variation in the $\beta_{2}$-adrenoceptor gene (ADRB2), the G-Protein $\beta_{3}$-subunit gene (GNB3) (chapter 7) and the HSL gene (chapter 8) on in vivo lipolysis and fat oxidation in overweight and obese subjects. In chapter 9, the results are discussed in a broader perspective and implications for future research are given.

\section{References}

1. Abbasi F, McLaughlin T, Lamendola C, and Reaven GM. Insulin regulation of plasma free fatty acid concentrations is abnormal in healthy subjects with muscle insulin resistance. Metabolism 49: $151-154,2000$.

2. Anthonsen MW, Ronnstrand L, Wernstedt C, Degerman E, and Holm C. Identification of novel phosphorylation sites in hormone-sensitive lipase that are phosphorylated in response to isoproterenol and govern activation properties in vitro. J Biol Chem 273:215-221, 1998.

3. Arner P. Adenosine, prostaglandins and phosphodiesterase as targets for obesity pharmacotherapy. Int J Obes Relat Metab Disord 17 Suppl 1: S57-59, 1993.

4. Arner P. Catecholamine-induced lipolysis in obesity. Int J Obes Relat Metab Disord 23 Suppl 1: 10-13, 1999.

5. Arner P, Bolinder J, Engfeldt P, Hellmer J, and Ostman J. Influence of obesity on the antilipolytic effect of insulin in isolated human fat cells obtained before and after glucose ingestion. $J$ Clin Invest 73: 673-680, 1984.

6. Arner P, Hellstrom L, Wahrenberg $\mathrm{H}$, and Bronnegard M. Beta-adrenoceptor expression in human fat cells from different regions. $J$ Clin Invest 86: 1595-1600, 1990.

7. Barbe P, Millet L, Galitzky J, Lafontan M, and Berlan M. In situ assessment of the role of the beta 1-, beta 2- and beta 3-adrenoceptors in the control of lipolysis and nutritive blood flow in human subcutaneous adipose tissue. Br J Pharmacol 117: 907-913, 1996.

8. Befroy DE, Falk Petersen K, Dufour S, Mason GF, de Graaf RA, Rothman DL, and Shulman GI. Impaired Mitochondrial Substrate Oxidation in Muscle of Insulin-Resistant Offspring of Type 2 Diabetic Patients. Diabetes 56: 1376-81, 2007.

9. Benjafield AV, Lin RC, Dalziel B, Gosby AK, Caterson ID, and Morris BJ. G-protein beta3 subunit gene splice variant in obesity and overweight. Int J Obes Relat Metab Disord 25: 777-780, 2001.

10. Birkenfeld AL, Boschmann M, Moro C, Adams F, Heusser K, Franke G, Berlan M, Luft FC, Lafontan $\mathrm{M}$, and Jordan J. Lipid mobilization with physiological atrial natriuretic peptide concentrations in humans. J Clin Endocrinol Metab 90: 3622-3628, 2005.

11. Birkenhager JC and Tjabbes T. Turnover rate of plasma FFA and rate of esterification of plasma FFA to plasma triglycerides in obese humans before and after weight reduction. Metabolism 18: 18-32, 1969.

12. Bjorntorp P, Bergman $\mathrm{H}$, and Varnauskas E. Plasma free fatty acid turnover rate in obesity. Acta Med Scand 185: 351-356, 1969.

13. Blaak EE, Schiffelers SL, Saris WH, Mensink M, and Kooi ME. Impaired beta-adrenergically mediated lipolysis in skeletal muscle of obese subjects. Diabetologia 47: 1462-8, 2004.

14. Blaak EE, Van Baak MA, Kemerink GJ, Pakbiers MT, Heidendal GA, and Saris WH. Betaadrenergic stimulation of energy expenditure and forearm skeletal muscle metabolism in lean and obese men. Am J Physiol 267: E306-315, 1994. 


\section{[Chapter 1}

15. Blaak EE, Van Baak MA, Kemerink GJ, Pakbiers MT, Heidendal GA, and Saris WH. betaAdrenergic stimulation of skeletal muscle metabolism in relation to weight reduction in obese men. Am J Physiol 267: E316-322, 1994.

16. Blaak EE, Wolffenbuttel BH, Saris WH, Pelsers MM, and Wagenmakers AJ. Weight reduction and the impaired plasma-derived free fatty acid oxidation in type 2 diabetic subjects. $J$ Clin Endocrinol Metab 86: 1638-1644, 2001.

17. Bolinder J, Kager L, Ostman J, and Arner P. Differences at the receptor and postreceptor levels between human omental and subcutaneous adipose tissue in the action of insulin on lipolysis. Diabetes 32: 117-123, 1983.

18. Bolinder J, Kerckhoffs DA, Moberg E, Hagstrom-Toft E, and Arner P. Rates of skeletal muscle and adipose tissue glycerol release in nonobese and obese subjects. Diabetes 49: 797-802, 2000.

19. Bonen A, Luiken JJ, and Glatz JF. Regulation of fatty acid transport and membrane transporters in health and disease. Mol Cell Biochem 239: 181-192, 2002.

20. Borsheim E, Lonnroth $P$, Knardahl S, and Jansson PA. No difference in the lipolytic response to beta-adrenoceptor stimulation in situ but a delayed increase in adipose tissue blood flow in moderately obese compared with lean men in the postexercise period. Metabolism 49:579-587, 2000.

21. Bougneres $P$, Stunff $C L$, Pecqueur C, Pinglier E, Adnot P, and Ricquier D. In vivo resistance of lipolysis to epinephrine. A new feature of childhood onset obesity. J Clin Invest 99: 2568-2573, 1997.

22. Boushel R, Gnaiger E, Schjerling P, Skovbro M, Kraunsoe R, and Dela F. Patients with type 2 diabetes have normal mitochondrial function in skeletal muscle. Diabetologia 50: 790-796, 2007.

23. Brasaemle DL, Levin DM, Adler-Wailes DC, and Londos C. The lipolytic stimulation of 3T3-L1 adipocytes promotes the translocation of hormone-sensitive lipase to the surfaces of lipid storage droplets. Biochim Biophys Acta 1483: 251-262, 2000.

24. Campbell PJ, Carlson MG, and Nurjhan N. Fat metabolism in human obesity. Am J Physiol 266: E600-605, 1994.

25. Canoy D, Luben R, Welch A, Bingham S, Wareham N, Day N, and Khaw KT. Fat distribution, body mass index and blood pressure in 22,090 men and women in the Norfolk cohort of the European Prospective Investigation into Cancer and Nutrition (EPIC-Norfolk) study. $J$ Hypertens 22: 2067-2074, 2004.

26. Chang BH, Li L, Paul A, Taniguchi S, Nannegari V, Heird WC, and Chan L. Protection against fatty liver but normal adipogenesis in mice lacking adipose differentiation-related protein. $\mathrm{Mol}$ Cell Biol 26: 1063-1076, 2006.

27. Coe NR, Simpson MA, and Bernlohr DA. Targeted disruption of the adipocyte lipid-binding protein (aP2 protein) gene impairs fat cell lipolysis and increases cellular fatty acid levels. J Lipid Res 40: 967-972, 1999.

28. Connacher AA, Bennet WM, Jung RT, Bier DM, Smith CC, Scrimgeour CM, and Rennie MJ. Effect of adrenaline infusion on fatty acid and glucose turnover in lean and obese human subjects in the post-absorptive and fed states. Clin Sci (Lond) 81: 635-644, 1991.

29. Coppack SW, Evans RD, Fisher RM, Frayn KN, Gibbons GF, Humphreys SM, Kirk ML, Potts JL, and Hockaday TD. Adipose tissue metabolism in obesity: lipase action in vivo before and after a mixed meal. Metabolism 41:264-272, 1992.

30. Corella D, Qi L, Sorli JV, Godoy D, Portoles O, Coltell O, Greenberg AS, and Ordovas JM. Obese subjects carrying the $11482 \mathrm{G}>\mathrm{A}$ polymorphism at the perilipin locus are resistant to weight loss after dietary energy restriction. $J$ Clin Endocrinol Metab 90:5121-5126, 2005.

31. Degerman E, Belfrage $P$, and Manganiello VC. Structure, localization, and regulation of cGMPinhibited phosphodiesterase (PDE3). J Biol Chem 272: 6823-6826, 1997.

32. Drysdale CM, McGraw DW, Stack CB, Stephens JC, Judson RS, Nandabalan K, Amold K, Ruano $\mathrm{G}$, and Liggett SB. Complex promoter and coding region beta 2-adrenergic receptor haplotypes alter receptor expression and predict in vivo responsiveness. Proc Natl Acad Sci U S A 97: 1048310488,2000 


\section{General introduction]}

33. Egan JJ, Greenberg AS, Chang MK, and Londos C. Control of endogenous phosphorylation of the major cAMP-dependent protein kinase substrate in adipocytes by insulin and beta-adrenergic stimulation. J Biol Chem 265: 18769-18775, 1990.

34. Egan JJ, Greenberg AS, Chang MK, Wek SA, Moos MC, Jr., and Londos C. Mechanism of hormone-stimulated lipolysis in adipocytes: translocation of hormone-sensitive lipase to the lipid storage droplet. Proc Natl Acad Sci U S A 89: 8537-8541, 1992.

35. Engfeldt $P$, Hellmer J, Wahrenberg $H$, and Arner P. Effects of insulin on adrenoceptor binding and the rate of catecholamine-induced lipolysis in isolated human fat cells. J Biol Chem 263: 15553 $15560,1988$.

36. Enoksson S, Degerman E, Hagstrom-Toft E, Large V, and Arner P. Various phosphodiesterase subtypes mediate the in vivo antilipolytic effect of insulin on adipose tissue and skeletal muscle in man. Diabetologia 41: 560-568, 1998.

37. Enoksson S, Talbot M, Rife F, Tamborlane WV, Sherwin RS, and Caprio S. Impaired in vivo stimulation of lipolysis in adipose tissue by selective beta2-adrenergic agonist in obese adolescent girls. Diabetes 49: 2149-2153, 2000.

38. Eriksson JW, Smith U, Waagstein F, Wysocki M, and Jansson PA. Glucose turnover and adipose tissue lipolysis are insulin-resistant in healthy relatives of type 2 diabetes patients: is cellular insulin resistance a secondary phenomenon? Diabetes 48: 1572-1578, 1999.

39. Eriksson P, Dahlman I, Ryden M, Hoffstedt J, and Arner P. Relationship between beta-2 adrenoceptor gene haplotypes and adipocyte lipolysis in women. Int J Obes Relat Metab Disord 28: 185190, 2004.

40. Feingold KR, Doerrler W, Dinarello CA, Fiers W, and Grunfeld C. Stimulation of lipolysis in cultured fat cells by tumor necrosis factor, interleukin-1, and the interferons is blocked by inhibition of prostaglandin synthesis. Endocrinology 130: 10-16, 1992.

41. Festuccia WT, Laplante M, Berthiaume M, Gelinas Y, and Deshaies Y. PPARgamma agonism increases rat adipose tissue lipolysis, expression of glyceride lipases, and the response of lipolysis to hormonal control. Diabetologia 49: 2427-2436, 2006.

42. Fischer H, Gustafsson T, Sundberg CJ, Norrbom J, Ekman M, Johansson O, and Jansson E. Fatty acid binding protein 4 in human skeletal muscle. Biochem Biophys Res Commun 346: 125-130, 2006.

43. Fischer J, Lefevre C, Morava E, Mussini JM, Laforet P, Negre-Salvayre A, Lathrop M, and Salvayre $\mathrm{R}$. The gene encoding adipose triglyceride lipase (PNPLA2) is mutated in neutral lipid storage disease with myopathy. Nat Genet 39: 28-30, 2007.

44. Fisher RM, Eriksson P, Hoffstedt J, Hotamisligil GS, Thorne A, Ryden M, Hamsten A, and Arner $P$. Fatty acid binding protein expression in different adipose tissue depots from lean and obese individuals. Diabetologia 44: 1268-1273, 2001.

45. Fisher RM, Thorne A, Hamsten A, and Arner P. Fatty acid binding protein expression in different human adipose tissue depots in relation to rates of lipolysis and insulin concentration in obese individuals. Mol Cell Biochem 239: 95-100, 2002.

46. Frayn KN. Obesity and metabolic disease: is adipose tissue the culprit? Proc Nutr Soc 64: 7-13, 2005.

47. Frayn $\mathrm{KN}$, Fielding BA, and Karpe F. Adipose tissue fatty acid metabolism and cardiovascular disease. Curr Opin Lipidol 16: 409-415, 2005.

48. Frayn $\mathrm{KN}$, Williams $\mathrm{CM}$, and Arner P. Are increased plasma non-esterified fatty acid concentrations a risk marker for coronary heart disease and other chronic diseases? Clin Sci (Lond) 90: 243$253,1996$.

49. Fredrikson $G$ and Belfrage P. Positional specificity of hormone-sensitive lipase from rat adipose tissue. J Biol Chem 258: 14253-14256, 1983.

50. Fredrikson G, Stralfors $P$, Nilsson NO, and Belfrage P. Hormone-sensitive lipase of rat adipose tissue. Purification and some properties. J Biol Chem 256: 6311-6320, 1981. 


\section{[Chapter 1}

51. Fredrikson $G$, Tornqvist $H$, and Belfrage $P$. Hormone-sensitive lipase and monoacylglycerol lipase are both required for complete degradation of adipocyte triacylglycerol. Biochim Biophys Acta 876: 288-293, 1986.

52. Fricke $\mathrm{K}$, Heitland $\mathrm{A}$, and Maronde E. Cooperative activation of lipolysis by protein kinase $\mathrm{A}$ and protein kinase C pathways in 3T3-L1 adipocytes. Endocrinology 145: 4940-4947, 2004.

53. Garenc C, Perusse L, Chagnon YC, Rankinen T, Gagnon J, Borecki IB, Leon AS, Skinner JS, Wilmore JH, Rao DC, and Bouchard C. The hormone-sensitive lipase gene and body composition: the HERITAGE Family Study. Int J Obes Relat Metab Disord 26: 220-227, 2002.

54. Garton AJ, Campbell DG, Carling D, Hardie DG, Colbran RJ, and Yeaman SJ. Phosphorylation of bovine hormone-sensitive lipase by the AMP-activated protein kinase. A possible antilipolytic mechanism. Eur J Biochem 179: 249-254, 1989.

55. Garton AJ and Yeaman SJ. Identification and role of the basal phosphorylation site on hormonesensitive lipase. Eur J Biochem 191: 245-250, 1990.

56. Green SA, Turki J, Bejarano P, Hall IP, and Liggett SB. Influence of beta 2-adrenergic receptor genotypes on signal transduction in human airway smooth muscle cells. Am J Respir Cell Mol Biol 13:25-33, 1995.

57. Greenberg AS, Egan JJ, Wek SA, Garty NB, Blanchette-Mackie EJ, and Londos C. Perilipin, a major hormonally regulated adipocyte-specific phosphoprotein associated with the periphery of lipid storage droplets. J Biol Chem 266: 11341-11346, 1991.

58. Greenberg AS, Shen WJ, Muliro K, Patel S, Souza SC, Roth RA, and Kraemer FB. Stimulation of lipolysis and hormone-sensitive lipase via the extracellular signal-regulated kinase pathway. $J$ Biol Chem 276: 45456-45461, 2001.

59. Groop LC, Bonadonna RC, DelPrato S, Ratheiser K, Zyck K, Ferrannini E, and DeFronzo RA. Glucose and free fatty acid metabolism in non-insulin-dependent diabetes mellitus. Evidence for multiple sites of insulin resistance. J Clin Invest 84: 205-213, 1989.

60. Groop LC, Bonadomna RC, Simonson DC, Petrides AS, Shank M, and DeFronzo RA. Effect of insulin on oxidative and nonoxidative pathways of free fatty acid metabolism in human obesity. Am J Physiol 263: E79-84, 1992.

61. Groop LC, Saloranta C, Shank M, Bonadonna RC, Ferrannini E, and DeFronzo RA. The role of free fatty acid metabolism in the pathogenesis of insulin resistance in obesity and noninsulindependent diabetes mellitus. J Clin Endocrinol Metab 72: 96-107, 1991.

62. Gulli G, Ferrannini E, Stern M, Haffner S, and DeFronzo RA. The metabolic profile of NIDDM is fully established in glucose-tolerant offspring of two Mexican-American NIDDM parents. Diabetes 41: 1575-1586, 1992.

63. Haemmerle G, Lass A, Zimmermann R, Gorkiewicz G, Meyer C, Rozman J, Heldmaier G, Maier R, Theussl C, Eder S, Kratky D, Wagner EF, Klingenspor M, Hoefler G, and Zechner R. Defective lipolysis and altered energy metabolism in mice lacking adipose triglyceride lipase. Science 312: 734-737, 2006

64. Hagstrom-Toft E, Enoksson S, Moberg E, Bolinder J, and Arner P. beta-Adrenergic regulation of lipolysis and blood flow in human skeletal muscle in vivo. Am J Physiol 275: E909-916, 1998.

65. Hagstrom-Toft E, Qvisth V, Nennesmo I, Ryden M, Bolinder H, Enoksson S, Bolinder J, and Arner P. Marked heterogeneity of human skeletal muscle lipolysis at rest. Diabetes 51: 3376-3383, 2002.

66. Hamilton JA and Kamp F. How are free fatty acids transported in membranes? Is it by proteins or by free diffusion through the lipids? Diabetes 48: 2255-2269, 1999.

67. Harmancey R, Senard JM, Pathak A, Desmoulin F, Claparols C, Rouet P, and Smih F. The vasoactive peptide adrenomedullin is secreted by adipocytes and inhibits lipolysis through NO-mediated beta-adrenergic agonist oxidation. Faseb J 19: 1045-1047, 2005.

68. Hegele RA, Anderson C, Young TK, and Connelly PW. G-protein beta3 subunit gene splice variant and body fat distribution in Nunavut Inuit. Genome Res 9: 972-977, 1999. 
69. Heitmann BL, Frederiksen P, and Lissner L. Hip circumference and cardiovascular morbidity and mortality in men and women. Obes Res 12: 482-487, 2004.

70. Hellmer J, Marcus C, Sonnenfeld T, and Arner P. Mechanisms for differences in lipolysis between human subcutaneous and omental fat cells. J Clin Endocrinol Metab 75: 15-20, 1992.

71. Hellstrom L, Langin D, Reynisdottir S, Dauzats M, and Arner P. Adipocyte lipolysis in normal weight subjects with obesity among first-degree relatives. Diabetologia 39: 921-928, 1996.

72. Hennes MM, Dua A, and Kissebah AH. Effects of free fatty acids and glucose on splanchnic insulin dynamics. Diabetes 46: 57-62, 1997.

73. Hibuse T, Maeda N, Funahashi T, Yamamoto K, Nagasawa A, Mizunoya W, Kishida K, Inoue K, Kuriyama H, Nakamura T, Fushiki T, Kihara S, and Shimomura I. Aquaporin 7 deficiency is associated with development of obesity through activation of adipose glycerol kinase. Proc Natl Acad Sci US A 102: 10993-10998, 2005.

74. Hickey MS, Carey JO, Azevedo JL, Houmard JA, Pories WJ, Israel RG, and Dohm GL. Skeletal muscle fiber composition is related to adiposity and in vitro glucose transport rate in humans. $A m J$ Physiol 268: E453-457, 1995.

75. Hoffstedt J, Arner P, Schalling M, Pedersen NL, Sengul S, Ahlberg S, Iliadou A, and Lavebratt C. A common hormone-sensitive lipase $i 6$ gene polymorphism is associated with decreased human adipocyte lipolytic function. Diabetes 50: 2410-2413, 2001.

76. Hoffstedt I, Iliadou A, Pedersen NL, Schalling M, and Arner P. The effect of the beta(2) adrenoceptor gene Thr164lle polymorphism on human adipose tissue lipolytic function. $B r J$ Pharmacol 133: 708-712, 2001 ,

77. Holm C, Belfrage P, and Fredrikson G. Immunological evidence for the presence of hormonesensitive lipase in rat tissues other than adipose tissue. Biochem Biophys Res Commun 148: 99$105,1987$.

78. Holm C, Kirchgessner TG, Svenson KL, Fredrikson G, Nilsson S, Miller CG, Shively JE, Heinzmann C, Sparkes RS, Mohandas T, and et al. Hormone-sensitive lipase: sequence, expression, and chromosomal localization to 19 cent-q13.3. Science 241: 1503-1506, 1988.

79. Holst LS, Langin D, Mulder H, Laurell H, Grober J, Bergh A, Mohrenweiser HW, Edgren G, and Holm C. Molecular cloning, genomic organization, and expression of a testicular isoform of hormone-sensitive lipase. Genomics 35: 441-447, 1996.

80. Horowitz JF, Coppack SW, Paramore D, Cryer PE, Zhao G, and Klein S. Effect of short-term fasting on lipid kinetics in lean and obese women. Am J Physiol 276: E278-284, 1999.

81. Horowitz JF and Klein S. Whole body and abdominal lipolytic sensitivity to epinephrine is suppressed in upper body obese women. Am J Physiol Endocrinol Metab 278: E1144-1152, 2000.

82. Hossain P, Kawar B, and El Nahas M. Obesity and diabetes in the developing world--a growing challenge. N Engl J Med 356:213-215, 2007.

83. Huttunen JK and Steinberg D. Activation and phosphorylation of purified adipose tissue hormonesensitive lipase by cyclic AMP-dependent protein kinase. Biochim Biophys Acta 239; 411-427, 1971.

84. Illiano $G$ and Cuatrecasas P. Modulation of adenylate cyclase activity in liver and fat cell membranes by insulin. Science 175: 906-908, 1972.

85. Jacob S, Machann J, Rett K, Brechtel K, Volk A, Renn W, Maerker E, Matthaei S, Schick F, Claussen $\mathrm{CD}$, and Haring HU. Association of increased intramyocellular lipid content with insulin resistance in lean nondiabetic offspring of type 2 diabetic subjects. Diabetes 48: 1113-1119, 1999.

86. Jansson PA, Larsson A, Smith $U$, and Lonnroth P. Glycerol production in subcutaneous adipose tissue in lean and obese humans. J Clin Invest 89: 1610-1617, 1992.

87. Jenkins CM, Mancuso DJ, Yan W, Sims HF, Gibson B, and Gross RW. Identification, cloning, expression, and purification of three novel human calcium-independent phospholipase A2 family members possessing triacylglycerol lipase and acylglycerol transacylase activities. $J$ Biol Chem 279: 48968-48975, 2004. 
[Chapter 1

88. Jenkins-Kruchten AE, Bennaars-Eiden A, Ross JR, Shen WJ, Kraemer FB, and Bernlohr DA. Fatty acid-binding protein-hormone-sensitive lipase interaction. Fatty acid dependence on binding. J Biol Chem 278: 47636-47643, 2003.

89. Jensen MD. Lipolysis: contribution from regional fat. Annu Rev Nutr 17: 127-139, 1997.

90. Jensen MD, Cryer PE, Johnson CM, and Murray MJ. Effects of epinephrine on regional free fatty acid and energy metabolism in men and women. Am J Physiol 270: E259-264, 1996.

91. Jensen MD, Haymond MW, Rizza RA, Cryer PE, and Miles JM. Influence of body fat distribution on free fatty acid metabolism in obesity. J Clin Invest 83: 1 168-1173, 1989.

92. Jensen MD and Johnson CM. Contribution of leg and splanchnic free fatty acid (FFA) kinetics to postabsorptive FFA flux in men and women. Metabolism 45: 662-666, 1996.

93. Jiao H, Dahlman I, Eriksson P, Kere J, and Arner P. A common beta2-adrenoceptor gene haplotype protects against obesity in Swedish women. Obes Res 13: 1645-1650, 2005.

94. Karpe F and Tan GD. Adipose tissue function in the insulin-resistance syndrome. Biochem Soc Trans 33: 1045-1048, 2005.

95. Kern PA, Di Gregorio G, Lu T, Rassouli N, and Ranganathan G. Perilipin expression in human adipose tissue is elevated with obesity. J Clin Endocrinol Metab 89: 1352-1358, 2004.

96. Kershaw EE, Hamm JK, Verhagen LA, Peroni O, Katic M, and Flier JS. Adipose triglyceride lipase: function, regulation by insulin, and comparison with adiponutrin. Diabetes 55: 148-157, 2006.

97. Kim JY, Tillison K, Lee JH, Rearick DA, and Smas CM. The adipose tissue triglyceride lipase ATGL/PNPLA2 is downregulated by insulin and TNF-\{alpha $\}$ in 3 T3-L1 adipocytes and is a target for transactivation by PPAR \{gamma\}. Am J Physiol Endocrinol Metab 291: E115-127, 2006.

98. Kjaer M, Howlett K, Langfort J, Zimmerman-Belsing T, Lorentsen J, Bulow J, Ihlemann J, FeldtRasmussen $U$, and Galbo $H$. Adrenaline and glycogenolysis in skeletal muscle during exercise: a study in adrenalectomised humans. J Physiol 528 Pt 2: 371-378, 2000.

99. Koutsari $\mathrm{C}$ and Jensen MD. Thematic review series: patient-oriented research. Free fatty acid metabolism in human obesity. J Lipid Res 47: 1643-1650, 2006.

100. Kralisch S, Klein J, Lossner U, Bluher M, Paschke R, Stumvoll M, and Fasshauer M. Isoproterenol, TNFalpha, and insulin downregulate adipose triglyceride lipase in 3T3-L1 adipocytes. Mol Cell Endocrinol 240: 43-49, 2005.

101. Krssak M, Falk Petersen K, Dresner A, DiPietro L, Vogel SM, Rothman DL, Roden M, and Shulman Gl. Intramyocellular lipid concentrations are correlated with insulin sensitivity in humans: a 1H NMR spectroscopy study. Diabetologia 42: 113-116, 1999.

102. Lafontan $\mathrm{M}$ and Berlan $\mathrm{M}$. Fat cell adrenergic receptors and the control of white and brown fat cell function. J Lipid Res 34: 1057-1091, 1993.

103. Langfort J, Ploug T, Ihlemann J, Baranczuk E, Donsmark M, Gorski J, and Galbo H. Additivity of adrenaline and contractions on hormone-sensitive lipase, but not on glycogen phosphorylase, in rat muscle. Acta Physiol Scand 178: 51-60, 2003.

104. Langfort J, Ploug T, Ihlemann J; Enevoldsen LH, Stallknecht B, Saldo M, Kjaer M, Holm C, and Galbo H. Hormone-sensitive lipase (HSL) expression and regulation in skeletal muscle. Adv Exp Med Biol 44I: 219-228, 1998.

105. Langfort J, Ploug T, Thlemann J, Holm C, and Galbo H. Stimulation of hormone-sensitive lipase activity by contractions in rat skeletal muscle. Biochem J 351:207-214, 2000.

106. Langfort J, Ploug T, Ihlemann J, Saldo M, Holm C, and Galbo H. Expression of hormone-sensitive lipase and its regulation by adrenaline in skeletal muscle. Biochem J 340 (Pt 2): 459-465, 1999.

107. Langin $D$ and Arner $P$. Importance of TNFalpha and neutral lipases in human adipose tissue lipolysis. Trends Endocrinol Metab 17: 314-320, 2006.

108. Large V and Arner P. Regulation of lipolysis in humans. Pathophysiological modulation in obesity, diabetes, and hyperlipidaemia. Diabetes Metab 24: 409-418, 1998. 
General introduction]

109. Large V, Hellstrom L, Reynisdottir S, Lonnqvist F, Eriksson P, Lannfelt L, and Arner P. Human beta-2 adrenoceptor gene polymorphisms are highly frequent in obesity and associate with altered adipocyte beta-2 adrenoceptor function. $J$ Clin Invest 100: 3005-3013, 1997.

110. Large V, Reynisdottir S, Langin D, Fredby K, Klannemark M, Holm C, and Arner P. Decreased expression and function of adipocyte hormone-sensitive lipase in subcutaneous fat cells of obese subjects. J Lipid Res 40: 2059-2066, 1999.

111. Lass A, Zimmermann R, Haemmerle G, Riederer M, Schoiswohl G, Schweiger M, Kienesberger P, Strauss JG, Gorkiewicz G, and Zechner R. Adipose triglyceride lipase-mediated lipolysis of cellular fat stores is activated by CGI-58 and defective in Chanarin-Dorfman Syndrome. Cell Metab 3: 309-319, 2006

112. Laurell H, Grober J, Vindis C, Lacombe T, Dauzats M, Holm C, and Langin D. Species-specific alternative splicing generates a catalytically inactive form of human hormone-sensitive lipase. Biochem J 328 (Pt 1): 137-143, 1997.

113. Lavebratt C, Ryden M, Schalling M, Sengul S, Ahlberg S, and Hoffstedt J. The hormone-sensitive lipase 16 gene polymorphism and body fat accumulation. Eur J Clin Invest 32: 938-942, 2002.

114. Leibel RL and Hirsch J. Site- and sex-related differences in adrenoreceptor status of human adipose tissue. J Clin Endocrinol Metab 64: 1205-1210, 1987.

115. Lewis GF, Carpentier A, Vranic M, and Giacca A. Resistance to insulin's acute direct hepatic effect in suppressing steady-state glucose production in individuals with type 2 diabetes. Diabetes 48: 570-576, 1999.

116. Liggett SB, Shah SD, and Cryer PE. Characterization of beta-adrenergic receptors of human skeletal muscle obtained by needle biopsy. Am J Physiol 254: E795-798, 1988.

117. Lind L, Fugmann A, Branth S, Vessby B, Millgard J, Berne C, and Lithell H. The impairment in endothelial function induced by non-esterified fatty acids can be reversed by insulin. Clin Sci (Lond) 99: 169-174, 2000.

118. Lindvall H, Nevsten P, Strom K, Wallenberg R, Sundler F, Langin D, Winzell MS, and Holm C. A novel hormone-sensitive lipase isoform expressed in pancreatic beta-cells. J Biol Chem 279: 38283836, 2004.

119. Lofgren P, Hoffstedt J, Ryden M, Thorne A, Holm C, Wahrenberg H, and Arner P. Major gender differences in the lipolytic capacity of abdominal subcutaneous fat cells in obesity observed before and after long-term weight reduction. J Clin Endocrinol Metab 87: 764-771, 2002.

120. Lonnqvist F, Thome A, Nilsell K, Hoffstedt J, and Arner P. A pathogenic role of visceral fat beta 3-adrenoceptors in obesity. J Clin Invest 95: 1109-1116, 1995.

121. Lonnroth $P$, Digirolamo $M$, Krotkiewski $M$, and Smith $U$. Insulin binding and responsiveness in fat cells from patients with reduced glucose tolerance and type II diabetes. Diabetes 32: 748-754, 1983.

122. Lonnroth $P$ and Smith $U$. The antilipolytic effect of insulin in human adipocytes requires activation of the phosphodiesterase. Biochem Biophys Res Commun 141: 1157-1161, 1986.

123. Magre J, Laurell H, Fizames C, Antoine PJ, Dib C, Vigouroux C, Bourut C, Capeau J, Weissenbach $\mathrm{J}$, and Langin $\mathrm{D}$. Human hormone-sensitive lipase: genetic mapping, identification of a new dinucleotide repeat, and association with obesity and NIDDM. Diabetes 47: 284-286, 1998.

124. Martin ML and Jensen MD. Effects of body fat distribution on regional lipolysis in obesity. $J$ Clin Invest 88: 609-613, 1991.

125. Martinez-Botas J, Anderson JB, Tessier D, Lapillonne A, Chang BH, Quast MJ, Gorenstein D, Chen $\mathrm{KH}$, and Chan $\mathrm{L}$. Absence of perilipin results in leanness and reverses obesity in Lepr $(\mathrm{db} / \mathrm{db})$ mice. Nat Genet 26: 474-479, 2000.

126. Mauriege $P$, Galitzky J, Berlan M, and Lafontan M. Heterogeneous distribution of beta and alpha2 adrenoceptor binding sites in human fat cells from various fat deposits: functional consequences. Eur J Clin Invest 17: 156-165, 1987. 


\section{[Chapter 1}

127. McGraw DW, Forbes SL, Kramer LA, and Liggett SB. Polymorphisms of the 5' leader cistron of the human beta2-adrenergic receptor regulate receptor expression. J Clin Invest 102: 1927-1932, 1998.

128. Moberg E, Sjoberg S, Hagstrom-Toft E, and Bolinder J. No apparent suppression by insulin of in vivo skeletal muscle lipolysis in nonobese women. Am J Physiol Endocrinol Metab 283: E295$301,2002$.

129. Moro C, Berlan M, and Lafontan M. [Physiological and pathophysiological features of the control of lipolysis and lipid mobilization by natriuretic peptides]. J Soc Biol 200: 67-76, 2006.

130. Mottagui-Tabar S, Ryden M, Lofgren P, Faulds G, Hoffstedt J, Brookes AJ, Andersson I, and Arner P. Evidence for an important role of perilipin in the regulation of human adipocyte lipolysis. Diabetologia 46: 789-797, 2003.

131. Mulder H, Holst LS, Svensson H, Degerman E, Sundler F, Ahren B, Rorsman P, and Holm C. Hormone-sensitive lipase, the rate-limiting enzyme in triglyceride hydrolysis, is expressed and active in beta-cells. Diabetes 48: 228-232, 1999.

132. Mulder H, Sorhede-Winzell M, Contreras JA, Fex M, Strom K, Ploug T, Galbo H, Anner P, Lundberg $C$, Sundler $F$, Ahren $B$, and Holm $C$. Hormone-sensitive lipase null mice exhibit signs of impaired insulin sensitivity whereas insulin secretion is intact. $J$ Biol Chem 278: 36380-36388, 2003.

133. Nielsen S, Guo Z, Johnson CM, Hensrud DD, and Jensen MD. Splanchnic lipolysis in human obesity. J Clin Invest 113: 1582-1588, 2004.

134. Nyholm B, Qu Z, Kaal A, Pedersen SB, Gravholt CH, Andersen JL, Saltin B, and Schmitz O. Evidence of an increased number of type $\mathrm{Ilb}$ muscle fibers in insulin-resistant first-degree relatives of patients with NIDDM. Diabetes 46: 1822-1828, 1997.

135. Okada T, Kawano Y, Sakakibara T, Hazeki O, and Ui M. Essential role of phosphatidylinositol 3kinase in insulin-induced glucose transport and antilipolysis in rat adipocytes. Studies with a selective inhibitor wortmannin. $J$ Biol Chem 269: 3568-3573, 1994.

136. Opie LH and Walfish PG. Plasma free fatty acid concentrations in obesity. $N$ Engl J Med 268: 757-760, 1963

137. Osterlund T, Danielsson B, Degerman E, Contreras JA, Edgren G, Davis RC, Schotz MC, and Holm C. Domain-structure analysis of recombinant rat hormone-sensitive lipase. Biochem J 319 (Pt 2): 411-420, 1996.

138. Osuga J, Ishibashi S, Oka T, Yagyu H, Tozawa R, Fujimoto A, Shionoiri F, Yahagi N, Kraemer FB, Tsutsumi $O$, and Yamada N. Targeted disruption of hormone-sensitive lipase results in male sterility and adipocyte hypertrophy, but not in obesity. Proc Natl Acad Sci U S A 97: 787-792, 2000.

139. Pan DA, Lillioja S, Kriketos AD, Milner MR, Baur LA, Bogardus C, Jenkins AB, and Storlien LH. Skeletal muscle triglyceride levels are inversely related to insulin action. Diabetes $46: 983-$ 988, 1997.

140. Park SY, Kim HJ, Wang S, Higashimori T, Dong J, Kim YJ, Cline G, Li H, Prentki M, Shulman Gl, Mitchell GA, and Kim JK. Hormone-sensitive lipase knockout mice have increased hepatic insulin sensitivity and are protected from short-term diet-induced insulin resistance in skeletal muscle and heart. Am J Physiol Endocrinol Metab 289: E30-39, 2005.

141. Perseghin G, Scifo P, De Cobelli F, Pagliato E, Battezzati A, Arcelloni C, Vanzulli A, Testolin G, Pozza G, Del Maschio A, and Luzi L. Intramyocellular triglyceride content is a determinant of in vivo insulin resistance in humans: a $1 \mathrm{H}-13 \mathrm{C}$ nuclear magnetic resonance spectroscopy assessment in offspring of type 2 diabetic parents. Diabetes 48: 1600-1606, 1999.

142. Petersen KF and Shulman GI. Etiology of insulin resistance. Am J Med 119: S10-16, 2006.

143. Peyot ML, Nolan CJ, Soni K, Joly E, Lussier R, Corkey BE, Wang SP, Mitchell GA, and Prentki M. Hormone-sensitive lipase has a role in lipid signaling for insulin secretion but is nonessential for the incretin action of glucagon-like peptide 1. Diabetes 53: 1733-1742, 2004. 
144. Phillips SA, Choe CC, Ciaraldi TP, Greenberg AS, Kong AP, Baxi SC, Christiansen L, Mudaliar SR, and Henry RR. Adipocyte differentiation-related protein in human skeletal muscle: relationship to insulin sensitivity. Obes Res 13: 1321-1329, 2005.

145. Prats C, Donsmark M, Qvortrup K, Londos C, Sztalryd C, Holm C, Galbo H, and Ploug T. Decrease in intramuscular lipid droplets and translocation of HSL in response to muscle contraction and epinephrine. JLipid Res 47: 2392-2399, 2006.

146. Prentice AM, Black AE, Coward WA, Davies HL, Goldberg GR, Murgatroyd PR, Ashford J, Sawyer M, and Whitehead RG. High levels of energy expenditure in obese women. Br Med J (Clin Res Ed) 292: 983-987, 1986.

147. Prentki $\mathrm{M}$ and Corkey BE. Are the beta-cell signaling molecules malonyl-CoA and cystolic longchain acyl-CoA implicated in multiple tissue defects of obesity and NIDDM? Diabetes 45: 273283, 1996.

148. Qi L, Corella D, Sorli JV, Portoles O, Shen H, Coltell O, Godoy D, Greenberg AS, and Ordovas JM. Genetic variation at the perilipin (PLIN) locus is associated with obesity-related phenotypes in White women. Clin Genet 66:299-310, 2004.

149. Qi L, Shen H, Larson I, Schaefer EJ, Greenberg AS, Tregouet DA, Corella D, and Ordovas JM. Gender-specific association of a perilipin gene haplotype with obesity risk in a white population. Obes Res 12: 1758-1765, 2004.

150. Qvisth V, Hagstrom-Toft E, Enoksson S, Sherwin RS, Sjoberg S, and Bolinder J. Combined hyperinsulinemia and hyperglycemia, but not hyperinsulinemia alone, suppress human skeletal mus* cle lipolytic activity in vivo. $J$ Clin Endocrinol Metab 89: 4693-4700, 2004.

151. Rahn T, Ridderstrale M, Tornqvist H, Manganiello V, Fredrikson G, Belfrage P, and Degerman E. Essential role of phosphatidylinositol 3-kinase in insulin-induced activation and phosphorylation of the cGMP-inhibited cAMP phosphodiesterase in rat adipocytes. Studies using the selective inhibitor wortmannin. FEBS Lett 350: 314-318, 1994.

152. Rahn T, Ronnstrand L, Leroy MJ, Wernstedt C, Tornqvist $H$, Manganiello VC, Belfrage $P$, and Degerman E. Identification of the site in the cGMP-inhibited phosphodiesterase phosphorylated in adipocytes in response to insulin and isoproterenol. J Biol Chem 271: 11575-11580, 1996.

153. Ray H, Beylot M, Arner P, Larrouy D, Langin D, Holm C, and Large V. The presence of a catalytically inactive form of hormone-sensitive lipase is associated with decreased lipolysis in abdominal subcutaneous adipose tissue of obese subjects. Diabetes 52: 1417-1422, 2003.

154. Reynisdottir S, Dauzats M, Thorne A, and Langin D. Comparison of hormone-sensitive lipase activity in visceral and subcutaneous human adipose tissue. $J$ Clin Endocrinol Metab 82: 41624166, 1997.

155. Reynisdottir S, Wahrenberg H, Carlstrom K, Rossner S, and Arner P. Catecholamine resistance in fat cells of women with upper-body obesity due to decreased expression of beta 2-adrenoceptors. Diabetologia 37: 428-435, 1994.

156. Richelsen B. Increased alpha 2- but similar beta-adrenergic receptor activities in subcutaneous gluteal adipocytes from females compared with males. Eur J Clin Invest 16: 302-309, 1986.

157. Richclsen B. Release and effects of prostaglandins in adipose tissue. Prostaglandins Leukot Essent Fatty Acids 47: 171-182, 1992.

158. Robinson C, Tamborlane WV, Maggs DG, Enoksson S, Sherwin RS, Silver D, Shulman GI, and Caprio S. Effect of insulin on glycerol production in obese adolescents. Am J Physiol 274: E737. 743, 1998.

159. Roduit R, Masiello P, Wang SP, Li H, Mitchell GA, and Prentki M. A role for hormone-sensitive lipase in glucose-stimulated insulin secretion: a study in hormone-sensitive lipase-deficient mice. Diabetes 50: 1970-1975, 2001.

160. Rosmond R. Association studies of genetic polymorphisms in central obesity: a critical review. Int J Obes Relat Metab Disord 27: 1141-1151, 2003.

161. Ryden M, Arvidsson E, Blomqvist L, Perbeck L, Dicker A, and Arner P. Targets for TNF-alphainduced lipolysis in human adipocytes. Biochem Biophys Res Commun 318: 168-175, 2004. 


\section{[Chapter 1}

162. Ryden M, Dicker A, van Harmelen V, Hauner H, Brunnberg M, Perbeck L, Lonnqvist F, and Arner P. Mapping of early signaling events in tumor necrosis factor-alpha -mediated lipolysis in human fat cells. J Biol Chem 277: 1085-1091, 2002.

163. Ryden M, Faulds G, Hoffstedt J, Wennlund A, and Arner P. Effect of the (C825T) Gbeta(3) polymorphism on adrenoceptor-mediated lipolysis in human fat cells. Diabetes 51: 1601-1608, 2002.

164. Saha PK, Kojima H, Martinez-Botas J, Sunehag AL, and Chan L. Metabolic adaptations in the absence of perilipin: increased beta-oxidation and decreased hepatic glucose production associated with peripheral insulin resistance but normal glucose tolerance in perilipin-null mice. J Biol Chem 279: 35150-35158, 2004.

165. Scheja L, Makowski L, Uysal KT, Wiesbrock SM, Shimshek DR, Meyers DS, Morgan M, Parker RA, and Hotamisligil GS. Altered insulin secretion associated with reduced lipolytic efficiency in aP2-/- mice. Diabetes 48: 1987-1994, 1999.

166. Schiffelers SL, Akkermans JA, Saris WH, and Blaak EE. Lipolytic and nutritive blood flow response to beta-adrenoceptor stimulation in situ in subcutaneous abdominal adipose tissue in obese men. Int J Obes Relat Metab Disord 27: 227-231, 2003.

167. Schiffelers SL, Blaak EE, Saris WH, and van Baak MA. In vivo beta3-adrenergic stimulation of human thermogenesis and lipid use. Clin Pharmacol Ther 67: 558-566, 2000.

168. Schiffelers SL, Saris WH, Boomsma F, and van Baak MA. beta(1)- and beta(2)-Adrenoceptormediated thermogenesis and lipid utilization in obese and lean men. J Clin Endocrinol Metab 86: 2191-2199, 2001.

169. Schoenborn V, Heid IM, Vollmert C, Lingenhel A, Adams TD, Hopkins PN, Illig T, Zimmermann $\mathrm{R}$, Zechner R, Hunt SC, and Kronenberg F. The ATGL gene is associated with free fatty acids, triglycerides, and type 2 diabetes. Diabetes 55: 1270-1275, 2006.

170. Schweiger M, Schreiber R, Haemmerle G, Lass A, Fledelius C, Jacobsen P, Tornqvist H, Zechner $\mathrm{R}$, and Zimmermann R. Adipose triglyceride lipase and hormone-sensitive lipase are the major enzymes in adipose tissue triacylglycerol catabolism. J Biol Chem 281: 40236-41, 2006.

171. Servetnick DA, Brasaemle DL, Gruia-Gray J, Kimmel AR, Wolff J, and Londos C. Perilipins are associated with cholesteryl ester droplets in steroidogenic adrenal cortical and Leydig cells. J Biol Chem 270: 16970-16973, 1995.

172. Shaughnessy S, Smith ER, Kodukula S, Storch J, and Fried SK. Adipocyte metabolism in adipocyte fatty acid binding protein knockout mice (aP2-/-) after short-term high-fat feeding: functional compensation by the keratinocyte [correction of keritinocyte] fatty acid binding protein. Diabetes 49: 904-911, 2000.

173. Shen WJ, Patel S, Yu Z, Jue D, and Kraemer FB. Effects of rosiglitazone and high fat diet on lipase/esterase expression in adipose tissue. Biochim Biophys Acta 1771: 177-184, 2007.

174. Shen WJ, Sridhar K, Bernlohr DA, and Kraemer FB. Interaction of rat hormone-sensitive lipase with adipocyte lipid-binding protein. Proc Natl Acad Sci US A 96: 5528-5532, 1999.

175. Shulman GI. Cellular mechanisms of insulin resistance. $J$ Clin Invest 106: 171-176, 2000.

176. Simoneau JA, Veerkamp JH, Turcotte LP, and Kelley DE. Markers of capacity to utilize fatty acids in human skeletal muscle: relation to insulin resistance and obesity and effects of weight loss. Faseb J 13: 2051-2060, 1999.

177. Sinha R, Dufour S, Petersen KF, LeBon V, Enoksson S, Ma YZ, Savoye M, Rothman DL, Shulman GI, and Caprio S. Assessment of skeletal muscle triglyceride content by (1)H nuclear magnetic resonance spectroscopy in lean and obese adolescents: relationships to insulin sensitivity, total body fat, and central adiposity. Diabetes 51: 1022-1027, 2002.

178. Smith AJ, Thompson BR, Sanders MA, and Bernlohr DA. Interaction of the adipocyte fatty acid binding protein with the hormone sensitive lipase: Regulation by fatty acids and phosphorylation. J Biol Chem, 2007.

179. Snijder MB, Dekker JM, Visser M, Bouter LM, Stehouwer CD, Yudkin JS, Heine RJ, Nijpels G, and Seidell JC. Trunk fat and leg fat have independent and opposite associations with fasting and postload glucose levels: the Hoorn study. Diabetes Care 27: 372-377, 2004. 
180. Spenst LF, Martin AD, and Drinkwater DT. Muscle mass of competitive male athletes. $J$ Sports Sci 11: 3-8, 1993.

181. Stefan N, Stumvoll M, Machicao F, Koch M, Haring HU, and Fritsche A. C825T polymorphism of the $G$ protein beta3 subunit is associated with obesity but not with insulin sensitivity. Obes Res 12: 679-683, 2004

182. Steinberg HO, Paradisi G, Hook G, Crowder K, Cronin J, and Baron AD. Free fatty acid elevation impairs insulin-mediated vasodilation and nitric oxide production. Diabetes 49: 1231-1238, 2000.

183. Stralfors $P$, Bjorgell $P$, and Belfrage $P$. Hormonal regulation of hormone-sensitive lipase in intact adipocytes: identification of phosphorylated sites and effects on the phosphorylation by lipolytic hormones and insulin. Proc Natl Acad Sci U S A 81: 3317-3321, 1984.

184. Stralfors $P$ and Honnor RC. Insulin-induced dephosphorylation of hormone-sensitive lipase. Correlation with lipolysis and cAMP-dependent protein kinase activity. Eur J Biochem 182: 379-385, 1989.

185. Subramanian V, Rothenberg A, Gomez C, Cohen AW, Garcia A, Bhattacharyya S, Shapiro L, Dolios G, Wang R, Lisanti MP, and Brasaemle DL. Perilipin A mediates the reversible binding of CGI-58 to lipid droplets in 3T3-L1 adipocytes. J Biol Chem 279: 42062-42071, 2004.

186. Svedberg J, Bjorntorp P, Smith U, and Lonnroth P. Effect of free fatty acids on insulin receptor binding and tyrosine kinase activity in hepatocytes isolated from lean and obese rats. Diabetes 41 : 294-298, 1992.

187. Syu LJ and Saltiel AR. Lipotransin: a novel docking protein for hormone-sensitive lipase. Mol Cell 4: 109-115, 1999.

188. Sztalryd C and Kraemer FB. Regulation of hormone-sensitive lipase in streptozotocin-induced diabetic rats. Metabolism 44: 1391-1396, 1995.

189. Sztalryd C, Xu G, Dorward H, Tansey JT, Contreras JA, Kimmel AR, and Londos C. Perilipin A is essential for the translocation of hormone-sensitive lipase during lipolytic activation. $J$ Cell Biol 161: 1093-1103, 2003.

190. Talmud PJ, Palmen J, and Walker M. Identification of genetic variation in the human hormonesensitive lipase gene and 5' sequences: homology of 5' sequences with mouse promoter and identification of potential regulatory elements. Biochem Biophys Res Commun 252: 661-668, 1998.

191. Talmud PJ, Palmen J, Wolf AM, and Beisiegel U. Investigation into the role of the hormone sensitive lipase $-60 \mathrm{C}>\mathrm{G}$ promoter variant in morbid obesity. Nutr Metab Cardiovasc Dis 15: 31-35, 2005.

192. Tan GD, Goossens GH, Humphreys SM, Vidal H, and Karpe F. Upper and lower body adipose tissue function: a direct comparison of fat mobilization in humans. Obes Res 12: 114-118, 2004.

193. Tansey JT, Sztalryd C, Gruia-Gray J, Roush DL, Zee JV, Gavrilova O, Reitman ML, Deng CX, Li $\mathrm{C}, \mathrm{Kimmel} \mathrm{AR}$, and Londos C. Perilipin ablation results in a lean mouse with aberrant adipocyte lipolysis, enhanced leptin production, and resistance to diet-induced obesity. Proc Natl Acad Sci U $S A$ 98: 6494-6499, 2001.

194. Uysal KT, Scheja L, Wiesbrock SM, Bonner-Weir S, and Hotamisligil GS. Improved glucose and lipid metabolism in genetically obese mice lacking aP2. Endocrinology 141:3388-3396, 2000.

195. van Harmelen V, Dicker A, Ryden M, Hauner H, Lonnqvist F, Naslund E, and Arner P. Increased lipolysis and decreased leptin production by human omental as compared with subcutaneous preadipocytes. Diabetes 51:2029-2036, 2002.

196. Van Pelt RE, Jankowski CM, Gozansky WS, Schwartz RS, and Kohrt WM. Lower-body adiposity and metabolic protection in postmenopausal women. J Clin Endocrinol Metab 90: 4573-4578, 2005.

197. Vaughan M, Berger JE, and Steinberg D. Hormone-Sensitive Lipase and Monoglyceride Lipase Activities in Adipose Tissue. J Biol Chem 239: 401-409, 1964.

198. Villena JA, Roy S, Sarkadi-Nagy E, Kim KH, and Sul HS. Desnutrin, an adipocyte gene encoding a novel patatin domain-containing protein, is induced by fasting and glucocorticoids: ectopic expression of desnutrin increases triglyceride hydrolysis. J Biol Chem 279: 47066-47075, 2004. 


\section{[Chapter 1}

199. Visscher TL, Kromhout D, and Seidell JC. Long-term and recent time trends in the prevalence of obesity among Dutch men and women. Int J Obes Relat Metab Disord 26: 1218-1224, 2002.

200. Voshol PJ, Haemmerle G, Ouwens DM, Zimmermann R, Zechner R, Teusink B, Maassen JA, Havekes LM, and Romijn JA. Increased hepatic insulin sensitivity together with decreased hepatic triglyceride stores in hormone-sensitive lipase-deficient mice. Endocrinology 144: 3456-3462, 2003.

201. Wahrenberg $H$, Lonnqvist $F$, and Arner $P$. Mechanisms underlying regional differences in lipolysis in human adipose tissue. $J$ Clin Invest 84: 458-467, 1989.

202. Wakayama Y, Inoue M, Kojima H, Jimi T, Shibuya S, Hara H, and Oniki H. Expression and localization of aquaporin 7 in normal skeletal myofiber. Cell Tissue Res 316: 123-129, 2004.

203. Wang Y, Sullivan S, Trujillo M, Lee MJ, Schneider SH, Brolin RE, Kang YH, Werber Y, Greenberg AS, and Fried SK. Perilipin expression in human adipose tissues: effects of severe obesity, gender, and depot. Obes Res 11: 930-936, 2003.

204. Watt MJ, Krustrup P, Secher NH, Saltin B, Pedersen BK, and Febbraio MA. Glucose ingestion blunts hormone-sensitive lipase activity in contracting human skeletal muscle. Am J Physiol Endocrinol Metab 286: E144-150, 2004.

205. Webber J, Taylor J, Greathead H, Dawson J, Buttery PJ, and Macdonald IA. A comparison of the thermogenic, metabolic and hacmodynamic responses to infused adrenaline in lean and obese subjects. Int J Obes Relat Metab Disord 18: 717-724, 1994.

206. White MF. The IRS-signalling system: a network of docking proteins that mediate insulin action. Mol Cell Biochem 182: 3-11, 1998.

207. Wicklmayr M, Dietze G, Rett K, and Mehnert H. Evidence for a substrate regulation of triglyceride lipolysis in human skeletal muscle. Horm Metab Res 17: 471-475, 1985.

208. Wijkander J, Landstrom TR, Manganiello V, Belfrage P, and Degerman E. Insulin-induced phosphorylation and activation of phosphodiesterase $3 \mathrm{~B}$ in rat adipocytes: possible role for protein kinase B but not mitogen-activated protein kinase or p70 S6 kinase. Endocrinology 139: 219-227, 1998.

209. Wu X, Hoffstedt J, Deeb W, Singh R, Sedkova N, Zilbering A, Zhu L, Park PK, Arner P, and Goldstein BJ. Depot-specific variation in protein-tyrosine phosphatase activities in human omental and subcutaneous adipose tissue: a potential contribution to differential insulin sensitivity. $J$ Clin Endocrinol Metab 86: 5973-5980, 2001.

210. Yamaguchi T, Omatsu N, Matsushita S, and Osumi T. CGI-58 interacts with perilipin and is localized to lipid droplets. Possible involvement of CGI-58 mislocalization in Chanarin-Dorfman syndrome. J Biol Chem 279: 30490-30497, 2004.

211. Zhang J, Hupfeld CJ, Taylor SS, Olefsky JM, and Tsien RY. Insulin disrupts beta-adrenergic signalling to protein kinase A in adipocytes. Nature 437: 569-573, 2005.

212. Zierath JR, Livingston JN, Thorne A, Bolinder J, Reynisdottir S, Lonnqvist F, and Arner P. Regional difference in insulin inhibition of non-esterified fatty acid release from human adipocytes: relation to insulin receptor phosphorylation and intracellular signalling through the insulin receptor substrate-1 pathway, Diabetologia 41: 1343-1354, 1998.

213. Zimmermann R, Haemmerle G, Wagner EM, Strauss JG, Kratky D, and Zechner R. Decreased fatty acid esterification compensates for the reduced lipolytic activity in hormone-sensitive lipasedeficient white adipose tissue. J Lipid Res 44: 2089-2099, 2003.

214. Zimmermann R, Strauss JG, Haemmerle G, Schoiswohl G, Birner-Gruenberger R, Riederer M, Lass A, Neuberger G, Eisenhaber F, Hermetter A, and Zechner R. Fat mobilization in adipose tissue is promoted by adipose triglyceride lipase. Science 306: 1383-1386, 2004. 


\section{2}

\section{Effect of beta-adrenergic stimulation on whole- body and abdominal subcutaneous adipose tissue lipolysis in lean and obese men}

Jocken JWE ${ }^{1}$, Goossens $\mathrm{GH}^{1}$, van Hees $\mathrm{AMJ}^{1}$, Frayn $\mathrm{KN}^{2}$, van Baak

$\mathrm{MA}^{1}$, Stegen $\mathrm{J}^{1}$, Pakbiers $\mathrm{MTW}^{3}$, Saris $\mathrm{WHM}^{1}$ and Blaak EE ${ }^{1}$

'Department of Human Biology, Nutrition and Toxicology Research Institute Maastricht (NUTRIM), Maastricht University, Maastricht, The Netherlands; ${ }^{2}$ Oxford Centre for Diabetes, Endocrinology and Metabolism, University of Oxford, Oxford, UK;

${ }^{3}$ Department of. Nuclear Medicine, University Hospital Maastricht, Maastricht, The Netherlands

Diabetologia (accepted-in press) 
[Chapter 2

\begin{abstract}
Background: Obesity is characterized by increased triacylglycerol (TAG) storage in adipose tissue. There is in vitro evidence for a blunted beta-adrenergically mediated lipolytic response in abdominal subcutaneous adipose tissue (SAT) of obese subjects, and evidence for this at the whole-body level in vivo. We hypothesized that the beta-adrenergically mediated effect on lipolysis in abdominal SAT is also impaired in vivo in obese humans.
\end{abstract}

Methods: We investigated for the first time in vivo whole-body and abdominal SAT glycerol metabolism during $3 \mathrm{~h}$ and $6 \mathrm{~h}$ $\left[{ }^{2} \mathrm{H}_{5}\right]$-glycerol infusion. Arterio-venous concentration differences were measured in 13 lean and 10 obese male subjects after an overnight fast and during intravenous infusion of the non-selective beta-adrenergic agonist isoprenaline (20ng. $\mathrm{kg}$ $\left.\mathrm{FFM}^{-1} \cdot \min ^{-1}\right)$.

Results: Lean and obese subjects showed comparable fasting glycerol uptake by SAT $(9.7 \pm 3.4$ vs. $9.3 \pm 2.5 \%$ of total release, $\mathrm{P}=0.92$ ). Furthermore, obese subjects showed an increased whole-body beta-adrenergically mediated lipolytic response. In contrast, obese subjects showed a blunted fasting lipolysis (glycerol Ra: $7.3 \pm 0.6$ vs. $13.1 \pm 0.9 \mu$ mol. $\mathrm{kg} \mathrm{FM}^{-1} \cdot \mathrm{min}^{-1}$, $\mathrm{P}<0.01)$ and beta-adrenergically mediated lipolytic response per unit SAT ( $\Delta$ total glycerol release: $140 \pm 71$ vs. $394 \pm 112 \mathrm{nmol}$. $100 \mathrm{~g}$ tissue $\left.\mathrm{e}^{-1} . \mathrm{min}^{-1}, \mathrm{P}<0.05\right)$ compared with lean subjects. Finally, net TAG flux tended to increase in the obese during betaadrenergic stimulation $(\Delta$ net TAG flux: $75 \pm 32$ vs. $16 \pm 11 \mathrm{nmol}$. $100 \mathrm{~g}$ tissue $\left.{ }^{-1} \cdot \mathrm{min}^{-1}, \mathrm{P}=0.06\right)$.

Conclusions: The present study demonstrates that betaadrenergically mediated lipolytic response in abdominal SAT is decreased in obesity. This may be an important factor in the development or maintenance of increased TAG stores in obesity. 
Adipose tissue lipolysis in obesity]

\section{Introduction}

Obesity is characterized by excess fat storage in adipose tissue, in the form of triacylglycerol (TAG). A blunted fat mobilization, due to decreased adipose tissue lipolysis, might be an important factor contributing to the development or maintenance of the expanded adipose tissue mass in obesity. Fasting lipolysis per unit lean body mass has been reported to be increased in obesity, whereas a decrease is reported when expressed per unit fat mass (8). The hormonal regulation of lipolysis is still under debate. There is strong evidence, from both in vitro and in vivo studies, for the existence of lipolytic resistance to catecholamines in obese subjects. $A$ blunted whole-body catecholamine-induced lipolysis has been shown in vivo in obese subjects $(2,16)$. This impaired lipolysis did not improve after weight reduction (3). Furthermore, a decreased lipolytic response to catecholamines is a feature of childhood onset obesity $(6,10)$ and is also present in adipocytes from first-degree relatives of obese subjects (15). These observations suggest that catecholamine resistance of lipolysis may be an important early, and perhaps primary factor, in the development of obesity. In vitro catecholamine resistance of lipolysis was reported in subcutaneous adipocytes of men and women with upper-body obesity, in relation with a decreased cell surface density of $\beta_{2}$-adrenoceptors (26). We hypothesized that in vivo beta-adrenergically mediated lipolytic response in abdominal subcutaneous adipose tissue (SAT) is blunted in obese subjects. If so, this might contribute to the increased fat storage in this adipose tissue depot.

To obtain an accurate estimation of lipolyis, state-of-the-art $\left[{ }^{2} \mathrm{H}_{5}\right]$-glycerol tracer methodology in combination with the measurement of arterio-venous concentration differences across abdominal SAT was used. Obese and lean male control subjects were investigated after an overnight fast and during catecholamine stimulation using the non-selective beta-adrenergic agonist isoprenaline (ISO). The primary outcome measures of the present study were glycerol rate of appearance (Ra) and glycerol exchange across abdominal SAT. A methodological issue that arises when determining local adipose tissue glycerol release is that it has been suggested that adipose tissue may also take up small amounts of glycerol $(19,27)$. A pilot study was performed initially to determine the time period necessary for obtaining a steadystate in glycerol enrichment in both arterialized and venous blood draining from adipose tissue, since a lack of isotopic equilibration may explain previous discrepant findings on glycerol uptake $(9,18)$.

\section{Subjects, materials and methods}

\section{Subjects}

Three lean $\left(2 \mathrm{~F} / 1 \mathrm{M} ; \mathrm{BMI}<25 \mathrm{~kg} / \mathrm{m}^{2}\right)$ subjects participated in a pilot experiment during which $\left[{ }^{2} \mathrm{H}_{5}\right]$-glycerol enrichment was measured during $6 \mathrm{~h}$ infusion in order to determine the time required for obtaining an isotopic steady-state. Thirteen lean $\left(\mathrm{BMI}<25 \mathrm{~kg} / \mathrm{m}^{2}\right)$ and ten obese (BMI $\left.\geq 30 \mathrm{~kg} / \mathrm{m}^{2}\right)$ non-smoking normotensive male subjects participated in the actual SAT lipolysis study during which $\left[{ }^{2} \mathrm{H}_{5}\right]$-glycerol was infused for a $3 \mathrm{~h}$ period. Clinical characteristics of the subjects are summarized 


\section{[Chapter 2}

in Table 1. Body weight and body density were determined after an overnight fast, as previously described (12). All subjects were in good health as assessed by their medical history, free of any medication and spent no more than $3 \mathrm{~h}$ a week in organized sports activities. The Medical Ethical Committee of Maastricht University approved the study protocol, and all subjects gave their written informed consent before participating in the study.

Table 1. Clinical characteristics of the subjects

\begin{tabular}{lcc}
\hline & Lean $(\mathrm{n}=13)$ & Obese $(\mathrm{n}=10)$ \\
\hline Age $(\mathrm{yr})$ & $43 \pm 3$ & $54 \pm 3$ \\
BMI $\left(\mathrm{kg} / \mathrm{m}^{2}\right)$ & $23.0 \pm 0.5$ & $31.9 \pm 0.6^{*}$ \\
FM $(\mathrm{kg})$ & $15.2 \pm 0.8$ & $32.4 \pm 1.2^{*}$ \\
WHR & $0.91 \pm 0.01$ & $1.01 \pm 0.01^{*}$ \\
SBP $(\mathrm{mmHg})$ & $126 \pm 3$ & $137 \pm 4$ \\
DBP $(\mathrm{mmHg})$ & $77 \pm 2$ & $85 \pm 3$ \\
HOMA & $1.8 \pm 0.2$ & $3.4 \pm 0.3^{*}$ \\
\hline
\end{tabular}

BMI, body mass index $\left(\mathrm{kg} / \mathrm{m}^{2}\right)$; FM, fat mass $(\mathrm{kg})$; WHR, waist to hip ratio; SBP, systolic blood pressure $(\mathrm{mmHg})$; DBP, diastolic blood pressure $\left(\mathrm{mmHg}^{2}\right.$; HOMA $\mathrm{IR}_{\mathrm{R}}$, homeostasis model assessment for insulin resistance; $\left({ }^{*}\right) \mathrm{P}<0.05$ obese vs. lean; Values are mean \pm SEM.

\section{Experimental protocol}

Pilot study The time course in $\left[{ }^{2} \mathrm{H}_{5}\right]$-glycerol enrichment was determined to investigate when steady-state levels were achieved $(n=3)$. Glycerol enrichment was measured in arterialized blood and blood draining the abdominal subcutaneous adipose tissue (adipose vein) during primed $\left(3 \mu \mathrm{mol} . \mathrm{kg}^{-1}\right)$ constant infusion for $6 \mathrm{~h}$ of $\left[{ }^{2} \mathrm{H}_{5}\right]-$ glycerol $\left(0.20 \mu \mathrm{mol} . \mathrm{kg}^{-1} \cdot \mathrm{min}^{-1}\right)$. Blood samples were taken simultaneously from the two sites, at baseline before the start of the tracer infusion (t0) and ten time points during glycerol infusion ( $\mathrm{t} 60, \mathrm{t} 90, \mathrm{t} 120, \mathrm{t} 150, \mathrm{t} 180, \mathrm{t} 210, \mathrm{t} 240, \mathrm{t} 330, \mathrm{t} 345$, t360).

Whole-body and SAT lipolysis study Glycerol enrichment and exchange across abdominal SAT were investigated during primed $\left(3 \mu \mathrm{mol} . \mathrm{kg}^{-1}\right)$ constant infusion of $\left.{ }^{2} \mathrm{H}_{5}\right]$-glycerol for $3 \mathrm{~h}\left(0.20 \mu \mathrm{mol} . \mathrm{kg}^{-1}\right.$. $\left.\mathrm{min}^{-1}\right)$. Following a $120 \mathrm{~min}$ baseline period, ISO was infused at a rate of $20 \mathrm{ng}$. $\mathrm{kg} \mathrm{FFM}^{-1}$. $\mathrm{min}^{-1}$ for 60 minutes. During the experiment, heart rate was recorded continuously by means of a three-lead electrocardiogram (ECG). When heart rate increased more than 40 beats $/ \mathrm{min}$ or in case of ECG irregularities, ISO infusion was stopped ( $\mathrm{n}=2$, one lean and one obese subject). Before the start of the tracer infusion an arterialized blood sample was taken for background enrichment. Furthermore, blood samples were taken simultaneously from the arterialized and adipose vein at three baseline time points (t90, t105 and t120) and at three time points during the last $30 \mathrm{~min}$ of ISO infusion (t150, t165 and t180). Adipose tissue blood flow (ATBF) was monitored continuously using the ${ }^{133}$ xenon $\left({ }^{133} \mathrm{Xe}\right)$ wash-out technique (21). ATBF results have been published previously in another context (13). 
Adipose tissue lipolysis in obesity]

\section{Clinical methods}

All subjects were asked to refrain from drinking alcohol and to perform no strenuous exercise for a period of $24 \mathrm{~h}$ before the study. Subjects came to the laboratory by car or bus at 8 a.m. after an overnight fast. Three cannulas were inserted before the start of the experiment. Arterialized venous blood was obtained through a 20-gauge cannula inserted retrogradely into a superficial dorsal hand vein. The hand was warmed in a hotbox, which was maintained at $60^{\circ} \mathrm{C}$ to achieve adequate arterialization (1). In the same arm, a second cannula was inserted in a forearm antecubital vein for the infusion of $\left[{ }^{2} \mathrm{H}_{5}\right]$-glycerol tracer and the non-selective beta-adrenergic agonist isoprenaline (ISO) at a rate of $20 \mathrm{ng}$. $\mathrm{kg} \mathrm{FFM}^{-1} \cdot \mathrm{min}^{-1}$. At this infusion rate plasma ISO concentrations are comparable in lean and obese subjects (2). Finally, after identification of the veins on the anterior abdominal wall with a fiber-optic light source, a 10-cm 22-gauge catheter (Central venous catheter kit Seldinger technique, Becton Dickinson BV, Alphen aan den Rijn, The Netherlands) was introduced anterogradely over a guide wire into one of the superficial veins and threaded towards the groin, so that its tip lay just superior to the inguinal ligament, to obtain adipose tissue venous blood (11). This provides the drainage from the adipose tissue of the abdomen, uncontaminated by muscle drainage and with only a minor contribution from skin (11). The adipose vein was kept patent by continuous saline $(9 \mathrm{~g} / \mathrm{L}$ $\mathrm{NaCl}$ ) infusion at a rate of $80 \mathrm{~mL} / \mathrm{h}$. The subjects rested in a supine position for the duration of the study.

\section{Analytical methods}

A small portion of blood was used for the measurement of oxygen saturation $\left(\% \mathrm{HbO}_{2}\right)$ to ensure adequate arterialization (ABL510, Radiometer, Copenhagen, Denmark). Blood was collected in tubes containing EDTA and immediately centrifuged for $10 \mathrm{~min}$ at $3000 \mathrm{rpm}, 4^{\circ} \mathrm{C}$. The plasma was removed for the enzymatic colorimetric quantification of free fatty acids (NEFA C kit, Wako, Neuss, Germany), glycerol (Boehringer Mannheim, Germany) and triacylglycerol (Sigma, St Louis, USA) on a COBAS FARA centrifugal spectrophotometer (Roche Diagnostica, Basal, Switzerland). Plasma glucose concentration (ABX Diagnostics, Montpellier, France) was measured on a COBAS MIRA automated spectrophotometer (Roche Diagnostica). Plasma insulin was measured with a double antibody radioimmunoassay (Linco Research Inc., St. Charles, Missouri, USA). Insulin sensitivity was assessed by the homeostasis model assessment index for insulin resistance $\left(\mathrm{HOMA}_{\mathrm{IR}}\right)$, calculated from fasting glucose and insulin (23). Hematocrit was measured using a microcapillary system (Hirschmann Laborgeräte $\mathrm{GmbH} \& \mathrm{CoKG}$, Eberstadt, Germany).

\section{Isotope enrichment}

To determine isotopic enrichment of glycerol, samples first were derivatized. $1 \mathrm{~mL}$ acetone was added to $150 \mu \mathrm{L}$ plasma and each tube was vortexed for $2 \mathrm{~min}$ and centrifuged for $20 \mathrm{~min}$ at $3500 \mathrm{rpm}, 4^{\circ} \mathrm{C}$. The supernatant was transferred to a clean tube and dried under nitrogen at $37^{\circ} \mathrm{C}$ and derivatized by adding $80 \mu \mathrm{L}$ ethyl acetate (cat. no. 45765, Sigma-Aldrich GmbH, Seelze, Germany) and $80 \mu \mathrm{L}$ heptafluorobu- 


\section{[Chapter 2}

tyric acid anhydride (HFAA; cat. no. 63164, Pierce Biotechnology, Rockford, IL, USA). The tubes were vortexed for $2 \mathrm{~min}$ and incubated for $1 \mathrm{~h}$ at $70^{\circ} \mathrm{C}$. Samples were than rotated for $5 \mathrm{~min}$ at $3000 \mathrm{rpm}, 25^{\circ} \mathrm{C}$ and evaporated under nitrogen at room temperature. $70 \mu \mathrm{L}$ of ethyl acetate was added before injection into the GCMS (Finnigan MAT 252, Bremen, Germany) for measurement of glycerol enrichment. Stable isotope enrichment was analyzed by selectively monitoring the massto-charge ratio $(\mathrm{m} / \mathrm{z})$ of molecular ions 253 and 257 for glycerol (4).

\section{Calculations}

The net exchange (flux) of metabolites across abdominal SAT was calculated by multiplying the arterio-venous concentration difference of metabolites by adipose tissue plasma flow. Plasma flow was calculated as ATBF $\times$ (1-hematocrit), with hematocrit expressed as a fraction. A positive net flux indicates net uptake from plasma, whereas a negative net flux indicates net tissue release.

The expected adipose vein enrichment was calculated as arterialized enrichment multiplied by arterialized glycerol concentration divided by the measured adipose vein enrichment.

The rate of appearance $(\mathrm{Ra})$ of glycerol was calculated according to the following steady-state equation:

$$
R a\left(\mu m o l . \mathrm{kg}^{-1} \cdot \mathrm{min}^{-1}\right)=T T R^{-1} \times F
$$

TTR is tracer/tracee ratio and $\mathrm{F}$ is the isotope infusion rate $\left(\mu \mathrm{mol} \cdot \mathrm{kg}^{-1} \cdot \mathrm{min}^{-1}\right)$.

The fractional extraction (fract) of glycerol across abdominal SAT was calculated by dividing the arterio-venous concentration difference of $\left[{ }^{2} \mathrm{H}_{5}\right]$-glycerol by the arterialized $\left[{ }^{2} \mathrm{H}_{5}\right]$-glycerol concentration. Abdominal SAT total glycerol uptake was calculated as follows:

$$
\text { Abdominal SAT total glycerol uptake }=\text { fract } \times\left[\text { glycerol }_{\text {ar }}\right] \times A T B F
$$

were the units are nmol. $100 \mathrm{~g}$ tissue ${ }^{-1} \cdot \mathrm{min}^{-1}$; [glycerol $\mathrm{arr}_{\text {r }}$ is arterialized glycerol concentration $(\mu \mathrm{mol} / \mathrm{L})$; and ATBF is adipose tissue blood flow (mL.100g tissue $\left.{ }^{-1} \cdot \mathrm{min}^{-1}\right)$. Abdominal SAT total glycerol release was calculated from the formula:

$$
\begin{gathered}
\text { Abdominal SAT total glycerol release }=\text { abdominal SAT net glycerol flux }-a b- \\
\text { dominal SAT total glycerol uptake }
\end{gathered}
$$

\section{Statistical analysis}

Baseline fasting values and changes (delta beta-adrenergic stimulation to baseline) were compared between groups (obese vs. lean) using Student's unpaired t-test. Statistical calculations were performed with SPSS for Macintosh (version11.0; SPSS inc., Chicago, IL, USA). Data are presented as mean \pm standard error of the mean (SEM). $\mathrm{P}<0.05$ was considered statistically significant. 
Adipose tissue lipolysis in obesity]

\section{Results}

Obese subjects had significantly higher BMI, fat mass, waist-to-hip ratio and fasting circulating TAG and insulin levels compared with lean subjects (Tables 1 and 2).

Table 2. Circulating (arterialized) metabolite levels during baseline (fasting) and isoprenaline infusion in lean and obese subjects

\begin{tabular}{lcccc}
\hline & \multicolumn{2}{c}{ Lean } & \multicolumn{2}{c}{ Obese } \\
& Baseline $(\mathrm{n}=13)$ & ISO $(\mathrm{n}=10)$ & Baseline $(\mathrm{n}=10)$ & ISO $(\mathrm{n}=7)$ \\
\hline TAG $(\mu \mathrm{mol} / \mathrm{L})$ & $701 \pm 66$ & $648 \pm 64$ & $1464 \pm 190 \dagger$ & $1667 \pm 217^{*}$ \\
FFA $(\mu \mathrm{mol} / \mathrm{L})$ & $661 \pm 41$ & $942 \pm 53$ & $638 \pm 42$ & $1124 \pm 82^{*}$ \\
Glycerol $(\mu \mathrm{mol} / \mathrm{L})$ & $102 \pm 5$ & $118 \pm 7$ & $106 \pm 4$ & $147 \pm 10^{*}$ \\
Glycerol Ra & $199 \pm 12$ & $311 \pm 28$ & $220 \pm 15$ & $391 \pm 30$ \\
Glycerol Ra/FM & $13.1 \pm 0.9$ & $20.9 \pm 1.6$ & $7.3 \pm 0.6 \dagger$ & $12.9 \pm 1.1^{*}$ \\
Glucose $(\mathrm{mmol} / \mathrm{L})$ & $5.3 \pm 0.1$ & $5.4 \pm 0.1$ & $5.5 \pm 0.2$ & $5.4 \pm 0.1$ \\
Insulin $(\mathrm{mU} / \mathrm{L})$ & $7.2 \pm 0.6$ & $10.7 \pm 0.9$ & $13.6 \pm 1.0 \dagger$ & $24.0 \pm 2.3^{*}$ \\
\hline
\end{tabular}

ISO, Isoprenaline; FFA, Free Fatty Acids; TAG, Triacylglycerol; Ra, rate of appearance ( $\left.\mu \mathrm{mol} . \mathrm{min}^{-1}\right)$; $\mathrm{Ra} / \mathrm{FM}$, rate of appearance per $\mathrm{kg}$ fat mass $\left(\mu \mathrm{mol} . \mathrm{kg} \mathrm{FM}^{-1} . \mathrm{min}^{-1}\right) ;(\dagger) \mathrm{P}<0.05$ basline obese vs. lean, $\left({ }^{*}\right) \mathrm{P}<0.05$ change (delta) from baseline obese vs. lean using Student's unpaired t-test; Values are Mean \pm SEM.

\section{Tracer/tracee ratio}

In the pilot experiment, the tracer/tracee ratios (TTR) obtained during a $6 \mathrm{~h}\left[{ }^{2} \mathrm{H}_{5}\right]-$ glycerol infusion after an overnight fast were examined $(n=3)$. Arterialized and adipose vein TTR reached a steady-state after $1 \mathrm{~h}$ of infusion (Figure 1). Mean values are presented since all subjects $(n=3)$ showed the same pattern. The measured adipose vein enrichment was consistently lower than the expected enrichment, implying uptake of glycerol by adipose tissue. In the actual SAT lipolysis experiment (3h $\left[{ }^{2} \mathrm{H}_{5}\right]$-glycerol infusion) TTR also reached a steady-state after $\mathrm{th}$ and remained stable during ISO infusion. Data in lean and obese men were comparable (data not shown).

\section{Circulating metabolites}

Beta-adrenergic stimulation with ISO increased arterialized TAG concentrations in obese subjects, whilst in lean subjects TAG concentrations decreased during ISO infusion (Table 2). Thus, the change in arterialized TAG concentrations from baseline to ISO was different between obese and lean subjects ( $\triangle \mathrm{TAG}$ obese vs. lean: $100 \pm 37$ vs. $-45 \pm 22, \mathrm{P}<0.05$, Table 2).

Furthermore, beta-adrenergic stimulation increased arterialized fatty acid and glycerol concentrations in lean and obese subjects. The beta-adrenergic mediated increase in arterialized fatty acid $(\triangle \mathrm{FFA} 454 \pm 68$ vs. $271 \pm 46, \mathrm{P}<0.05)$ and glycerol 


\section{[Chapter 2}

concentration ( $\Delta$ glycerol $40 \pm 8$ vs. $15 \pm 5, \mathrm{P}<0.05$ ) was more pronounced in obese than in lean subjects (Table 2), suggesting a higher whole-body lipolytic response in the obese. Indeed, beta-adrenergic stimulation increased whole-body glycerol $\mathrm{Ra}$ in lean and obese subjects (Table 2), and this increase tended to be higher in the obese ( $\Delta$ glycerol Ra obese vs. lean: $172 \pm 19$ vs. $109 \pm 13 \mu$ mol. $\mathrm{min}^{-1}, \mathrm{P}=0.07$; Table 2 ). Expressed per unit fat mass fasting glycerol Ra was significantly reduced in obese compared with lean subjects $(\mathrm{P}<0.05$, Table 2$)$, as has previously been shown in upper body obese women (16). Interestingly, the beta-adrenergically mediated increase in glycerol $\mathrm{Ra}$ per unit fat mass was significantly blunted in the obese (Aglycerol Ra per unit FM: $5.4 \pm 0.9$ vs. $7.7 \pm 1.5 \mu$ mol.kg $\mathrm{FM}^{-1} . \mathrm{min}^{-1}, \mathrm{P}<0.05$, Table 2 ), suggesting a blunted lipolytic response per unit fat mass in obese subjects.

Finally, beta-adrenergic stimulation increased arterialized insulin concentrations in lean and obese (Table 2), and this increase in circulating insulin levels was significantly higher in obese than in lean subjects ( $\Delta$ insulin $8.9 \pm 1.9$ vs. $3.6 \pm 0.6 \mathrm{mU} / \mathrm{L}$, $\mathrm{P}<0.05$, Table 2).

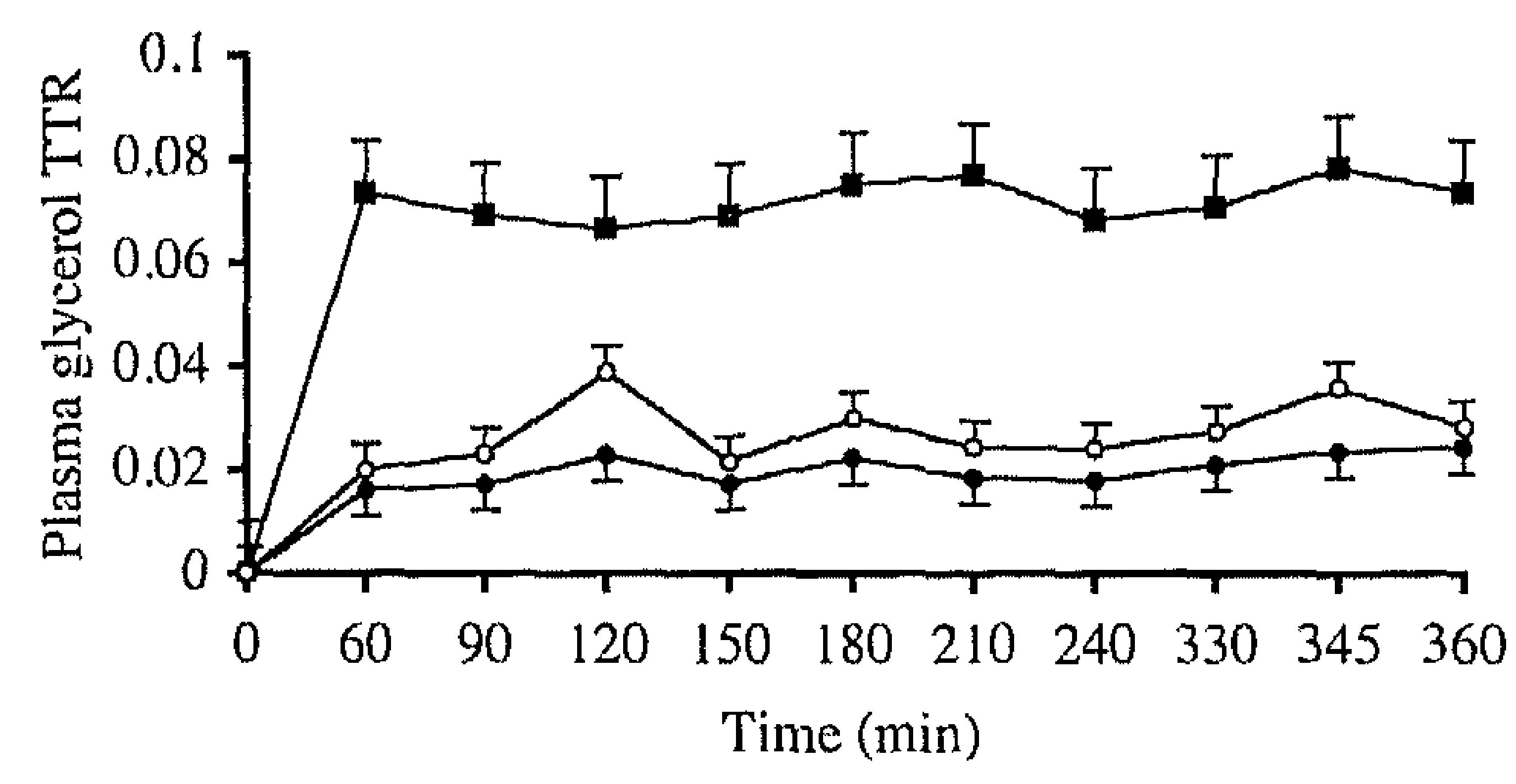

Figure 1. Plasma glycerol tracer/tracee ratio (TTR) during $6 \mathrm{~h}$ primed constant infusion of $\left[{ }^{2} \mathrm{H}_{5}\right]$-glycerol $(n=3)$ in arterialized blood (घ), blood draining from abdominal subcutaneous adipose tissue (adipose vein, -) and expected adipose vein enrichment $(O)$. The measured adipose vein enrichment was consistently lower than the expected enrichment.

\section{Abdominal SAT lipolysis}

Glycerol uptake by abdominal SAT was observed in lean and obese subjects after an overnight fast (Figure 2a). Fractional extraction of $\left[{ }^{2} \mathrm{H}_{5}\right]$-glycerol from the circulation (lean vs. obese: $16.6 \pm 4.5$ vs. $13.9 \pm 6.7 \%$ ) and total glycerol uptake expressed relative to total glycerol release were very small (lean vs. obese: $9.7 \pm 3.4$ vs. $9.3 \pm 2.5 \%$ of total release) with no significant difference between lean and obese subjects $(\mathrm{P}=0.74$ and $\mathrm{P}=0.92$, respectively). Adipose tissue total glycerol uptake increased during beta-adrenergic stimulation in lean and obese subjects, but this increase was not significantly different between groups ( $\Delta$ total glycerol uptake obese vs. lean: $4 \pm 9$ vs. $21 \pm 5, P=0.15$, Figure $2 a$ ). The increased total glycerol uptake during beta-adrenergic stimulation appeared to be partly explained by the increase in ATBF $(r=0.633, P<0.05)$. 
a

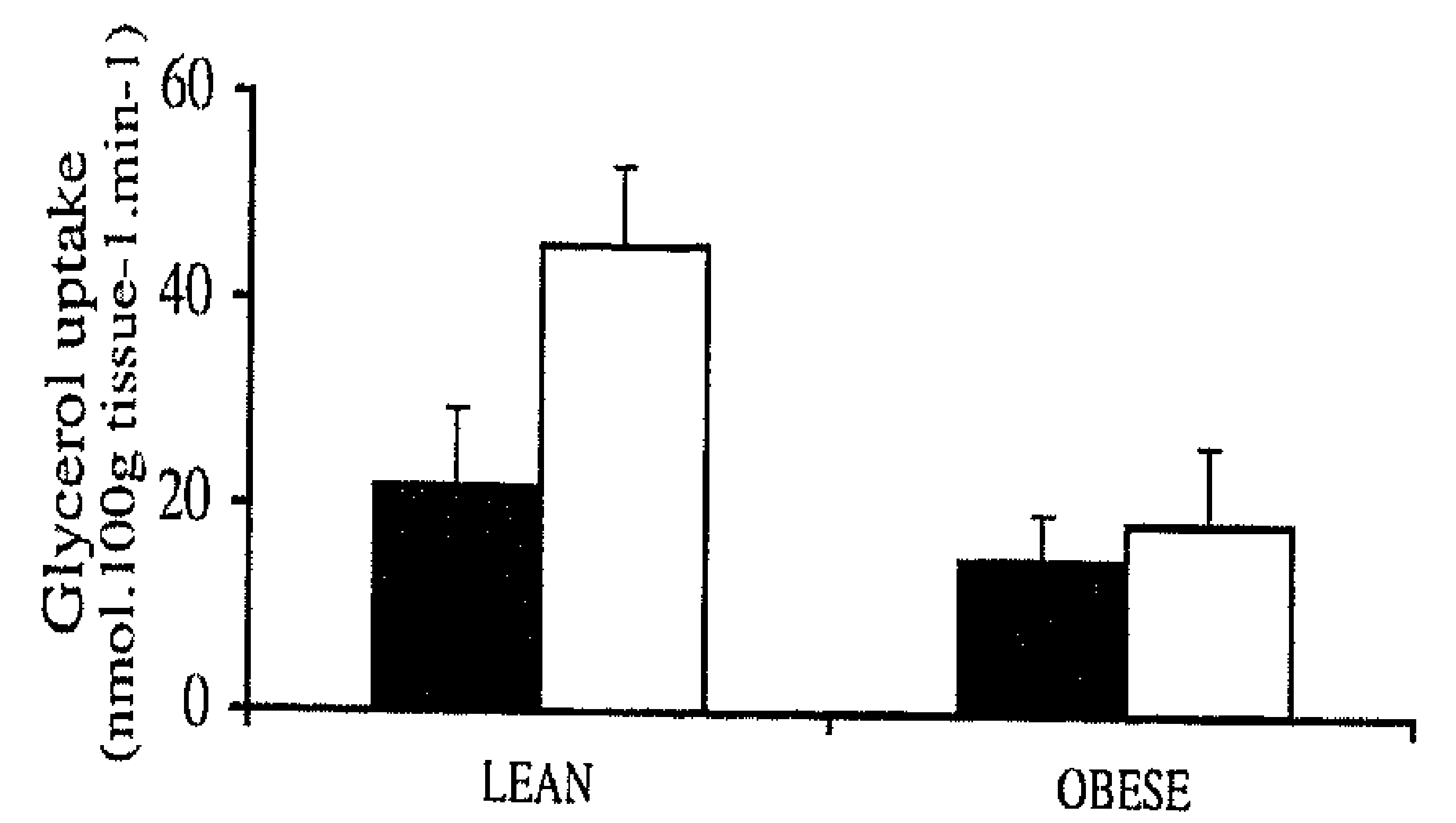

b

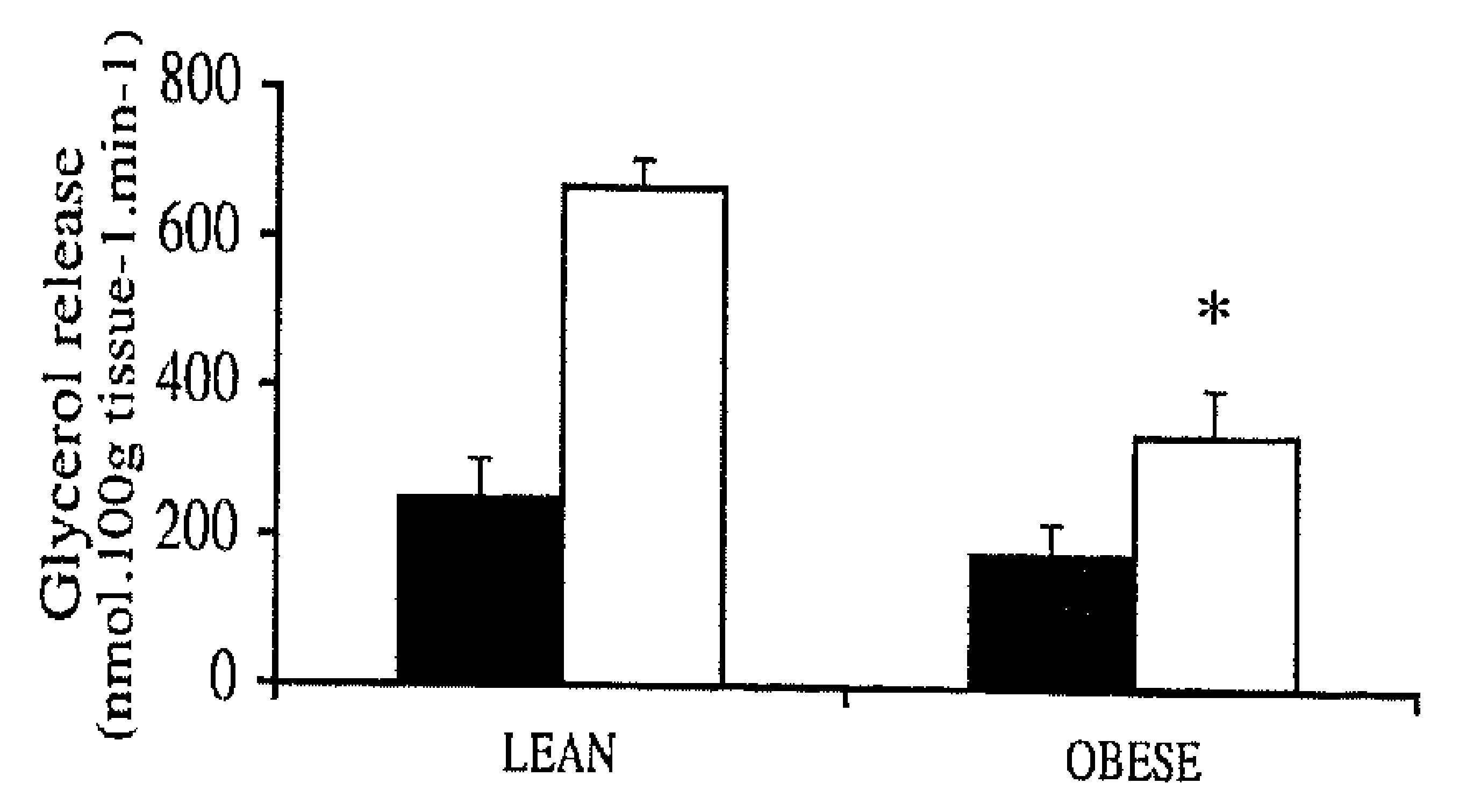

Figure 2. Total glycerol uptake (a) and release (b) across abdominal SAT after an overnight fast (black bars, and during beta-adrenergic stimulation (white bars, $\square$ ) in obese vs. lean subjects during $3 \mathrm{~h}\left[{ }^{2} \mathrm{H}_{5}\right]$-glycerol infusion; $\left({ }^{*}\right)$ $\mathrm{P}<0.05$ change (delta) from baseline obese vs. lean; Values are mean \pm SEM.

Fasting net glycerol and fatty acid release across abdominal SAT were comparable between lean and obese subjects (Table 3). Beta-adrenergic stimulation increased net fatty acid and glycerol release across abdominal SAT to a greater extent in lean as compared with obese subjects, although changes were not significantly different between groups (Table 3 ). In line with these findings, the beta-adrenergically mediated increase in total glycerol release across abdominal SAT was blunted in the obese ( $\Delta$ total glycerol release obese vs. lean: $140 \pm 71$ vs. $394 \pm 112 \mathrm{nmol} .100 \mathrm{~g}$ tissue ${ }^{1}$ min $^{-1}, \mathrm{P}<0.05$, Figure $2 \mathrm{~b}$ ), suggesting a blunted lipolytic response per unit abdominal SAT in obese subjects. Finally, obese men tended to show an increased net TAG flux across abdominal SAT during beta-adrenergic stimulation ( $\triangle$ net TAG flux obese vs. lean: $75 \pm 32$ vs. $16 \pm 11 \mathrm{nmol} .100 \mathrm{~g}$ tissue ${ }^{-1} \cdot \mathrm{min}^{-1}, \mathrm{P}=0.06$, Table 3 ).

\section{Discussion}

The present study was designed to investigate in vivo whole-body and abdominal SAT lipolysis in obese and lean men. To our knowledge, this is the first study to show in vivo that obese subjects have a blunted beta-adrenergically mediated lipolytic response per unit adipose tissue. 
[Chapter 2

Table 3. Blood flow and net SAT fluxes during baseline (fasting) and isoprenaline infusion in lean and obese subjects

\begin{tabular}{lcccc}
\hline & \multicolumn{2}{c}{ Lean } & \multicolumn{2}{c}{ Obese } \\
& Baseline $(\mathrm{n}=13)$ & ISO $(\mathrm{n}=10)$ & Baseline $(\mathrm{n}=10)$ & ISO $(\mathrm{n}=7)$ \\
\hline ATBF & $2.2 \pm 0.2$ & $6.3 \pm 1.2$ & $1.4 \pm 0.2 \dagger$ & $3.6 \pm 0.6$ \\
net SAT Fluxes (nmol.100g tissue $\left.{ }^{-1} \cdot \mathrm{min}^{-1}\right)$ & & & \\
TAG & $25 \pm 8$ & $43 \pm 17$ & $34 \pm 29$ & $113 \pm 62$ \\
FFA & $-780 \pm 160$ & $-2101 \pm 371$ & $-486 \pm 101$ & $-1824 \pm 667$ \\
Glycerol & $-229 \pm 49$ & $-640 \pm 148$ & $-211 \pm 51$ & $-486 \pm 128$ \\
Glucose & $53 \pm 49$ & $-69 \pm 151$ & $-143 \pm 96$ & $-677 \pm 632$ \\
\hline
\end{tabular}

SAT, subcutaneous adipose tissue; ISO, Isoprenaline; ATBF, adipose tissue blood flow (mL.100g tissue $\left.^{-1}, \min ^{-1}\right)$; FFA, Free Fatty Acids; TAG, Triacylglycerol. A positive net flux indicates net uptake from plasma, whereas a negative net flux indicates net tissue release; $(\dagger) \mathrm{P}<0.05$ baseline obese vs. lean using Student's unpaired t-test; Values are mean \pm SEM.

\section{Methodological considerations}

A point of discussion with studies on glycerol uptake and release using tracer methodology is the infusion time of the labeled glycerol. In previous studies the infusion time was relatively short $(1-3 \mathrm{~h})$, opening the possibility that equilibration between labeled glycerol and the adipose tissue glycerol pool is not complete $(9,19)$. We investigated glycerol enrichment during a $3 \mathrm{~h}$ and $6 \mathrm{~h}$ period of $\left[{ }^{2} \mathrm{H}_{5}\right]$-glycerol infusion. Steady-state levels in labeled $\left[{ }^{2} \mathrm{H}_{5}\right]$-glycerol were achieved in arterialized and adipose vein enrichment after $1 \mathrm{~h}$ and remained constant for the subsequent $5 \mathrm{~h}$. Thus, our data support the use of a relatively short infusion time (1h) to study glycerol metabolism.

\section{Glycerol uptake}

The present data show a slight glycerol uptake by abdominal SAT of lean and obese subjects. Glycerol uptake was not significantly different between lean and obese subjects. Uptake and dilution of $\left[{ }^{2} \mathrm{H}_{5}\right]$-glycerol across abdominal SAT has been shown previously during $1 \mathrm{~h}(19)$ and $7 \mathrm{~h}(27)$ tracer infusion. In these studies the dilution of the labeled glycerol was consistently greater than expected from the measured net release of glycerol, indicating significant uptake of glycerol by adipose tissue. In line with these studies, we observed a 2-5 fold higher glycerol enrichment in arterialized compared to venous blood draining adipose tissue. The observed enrichment in venous blood was universally lower than that predicted from the net addition of glycerol to venous blood. This indicates that there must be exchange between enriched glycerol in the blood and the unenriched free glycerol pool in adipose tissue. In contrast, some studies were unable to detect significant uptake of glycerol by adipose tissue after $1 \mathrm{~h}$ tracer infusion $(9,18)$. The reason for this apparent discrepancy remains to be elucidated. It should be mentioned that glycerol uptake is low in human adipose tissue as is the activity of the enzyme glyc- 
Adipose tissue lipolysis in obesity]

erol kinase (32). This enzyme is responsible for the phosphorylation of glycerol into glycerol-3-phosphate, making it available for re-esterification.

\section{Abdominal SAT lipolytic response to beta-adrenergic stimulation}

A blunted ISO-induced increase in total glycerol release per unit abdominal SAT was observed in obese men, indicating a blunted in vivo beta-adrenergic mediated lipolytic response in abdominal SAT of obese subjects. Our data are consistent with evidence of catecholamine resistance in vitro and in situ in obese subjects $(2,3,16)$, in children with obesity $(6,10)$ as well as in relatives of obese subjects $(15)$. Defects in catecholamine signal transduction have been observed at the $\beta_{2}$-adrenoceptor level, further downstream or directly involve hormone-sensitive lipase (HSL) (20, $22,25,26,30)$. However, it is not possible from our experiments to determine at what level the observed defect is located. Interestingly, catecholamine resistance is observed in adipose tissue of first-degree relatives of obese subjects (15) and persists after weight reduction (3), suggesting that catecholamine resistance may be a primary defect in obesity. Furthermore, plasma insulin concentrations may play an important role in regulating lipolysis (17). Therefore, we cannot fully exclude that the observed blunted lipolytic response per unit adipose tissue mass is a secondary phenomenon, due to the higher degree of hyperinsulinemia during beta-adrenergic stimulation in obese compared with lean subjects. However, this explanation seems unlikely, since a blunted in situ lipolytic response in abdominal subcutaneous adipose tissue of obese women was still observed when the confounding influence of hyperinsulinemia was excluded using a pancreatic hormonal clamp (16).

In contrast to the present study, two in situ microdialysis studies performed in men found no difference in the increase in interstitial glycerol with ISO administration between lean and obese subjects $(5,29)$. A possible explanation for this may be that in microdialysis studies interstitial glycerol is used as a measure of lipolysis. Since glycerol is taken up by adipose tissue, interstitial glycerol concentration may not reflect the overall rate of lipolysis. Rather, it may be the net result of TAG and glycerol metabolism and thus reflects net glycerol tumover (31).

\section{Whole-body beta-adrenergically mediated lipolytic response}

Whole-body lipolytic response during ISO infusion was significantly higher in obese subjects. This was reflected by a higher increase in circulating fatty acid and glycerol concentrations during beta-adrenergic stimulation compared with lean subjects. The difference between lean and obese subjects with respect to whole-body beta-adrenergically mediated lipolytic response disappeared after correction for fat mass. This suggests that the increased whole-body beta-adrenergically mediated lipolytic response in obese individuals is directly linked to the increased adipose tissue mass, as has been shown before (16). Increased release of fatty acids into the circulation increases fatty acid delivery to the liver, resulting in an increased hepatic VLDL-TAG output and hence increased circulating TAG levels during betaadrenergic stimulation, as was observed in the obese subjects. The control of wholebody lipid metabolism is, to a large extent, dependent on the efficient regulation of lipid metabolism in adipose tissue and the liver. Moreover, hepatic VLDL-TAG is a precursor of TAG stored in adipose tissue $(7,14)$. As a consequence, a greater 


\section{[Chapter 2}

VLDL-TAG delivery to adipose tissue and greater lipoprotein lipase (LPL) mediated hydrolysis might explain the tendency towards increased positive TAG flux across abdominal SAT of obese subjects during beta-adrenergic stimulation. Our observation is in agreement with a study by Samra et al. (28) showing an increased rate of action of LPL during epinephrine infusion. These in vivo findings are in contrast with in vitro studies showing that LPL expression and activity are suppressed by epinephrine $(24,33)$. Future studies are needed to elucidate whether an increased TAG flux across SAT might contribute to the increased TAG storage in adipose tissue of obese subjects.

In conclusion, the present study demonstrates that obese subjects have a blunted in vivo beta-adrenergically mediated lipolytic response in abdominal subcutaneous adipose tissue. Therefore, a blunted lipolysis during beta-adrenergic stimulation may be an important factor in the development or maintenance of increased TAG stores in obesity.

\section{Acknowledgments}

The authors greatly appreciate the technical support of Paula van der Baan and the willingness of the volunteers to participate in this study. This research was supported by a grant from the Netherlands Organization for Scientific Research (NWO/ZonMw contract no. 015.01.095) to Prof. dr. EE Blaak.

\section{References}

1. Abumrad NN, Rabin D, Diamond MP, and Lacy WW. Use of a heated superficial hand vein as an alternative site for the measurement of amino acid concentrations and for the study of glucose and alanine kinetics in man. Metabolism 30: 936-940, 1981.

2. Blaak EE, Van Baak MA, Kemerink GJ, Pakbiers MT, Heidendal GA, and Saris WH. Betaadrenergic stimulation of energy expenditure and forearm skeletal muscle metabolism in lean and obese men. Am J Physiol 267: E306-315, 1994.

3. Blaak EE, Van Baak MA, Kemerink GJ, Pakbiers MT, Heidendal GA, and Saris WH. betaAdrenergic stimulation of skeletal muscle metabolism in relation to weight reduction in obese men. Am J Physiol 267: E316-322, 1994.

4. Blaak EE, Wagenmakers AJ, Glatz JF, Wolffenbuttel BH, Kemerink GJ, Langenberg CJ, Heidendal GA, and Saris WH. Plasma FFA utilization and fatty acid-binding protein content are diminished in type 2 diabetic muscle. Am J Physiol Endocrinol Metab 279: E146-154, 2000.

5. Borsheim E, Lonnroth P, Knardahl S, and Jansson PA. No difference in the lipolytic response to beta-adrenoceptor stimulation in situ but a delayed increase in adipose tissue blood flow in moderately obese compared with lean men in the postexercise period. Metabolism 49:579-587, 2000.

6. Bougneres $P$, Stunff CL, Pecqueur C, Pinglier E, Adnot P, and Ricquier D. In vivo resistance of lipolysis to epinephrine. A new feature of childhood onset obesity. J Clin Invest 99: 2568-2573, 1997.

7. Bulow J, Simonsen L, Wiggins D, Humphreys SM, Frayn KN, Powell D, and Gibbons GF. Coordination of hepatic and adipose tissue lipid metabolism after oral glucose. J Lipid Res 40: 2034 $2043,1999$. 
8. Campbell PJ, Carlson MG, and Nurjhan N. Fat metabolism in human obesity. Am J Physiol 266: E600-605, 1994.

9. Coppack SW, Persson M, Judd RL, and Miles JM. Glycerol and nonesterified fatty acid metabolism in human muscle and adipose tissue in vivo. Am J Physiol 276: E233-240, 1999.

10. Enoksson S, Talbot M, Rife F, Tamborlane WV, Sherwin RS, and Caprio S. Impaired in vivo stimulation of lipolysis in adipose tissue by selective beta2-adrenergic agonist in obese adolescent girls. Diabetes 49: 2149-2153, 2000.

11. Frayn KN, Coppack SW, Humphreys SM, and Whyte PL. Metabolic characteristics of human adipose tissue in vivo. Clin Sci (Lond) 76: 509-516, 1989.

12. Goossens GH, Blaak EE, Saris WH, and van Baak MA. Angiotensin II-induced effects on adipose and skeletal muscle tissue blood flow and lipolysis in normal-weight and obese subjects. $J$ Clin Endocrinol Metab 89: 2690-2696, 2004.

13. Goossens GH, Jocken JW, Blaak EE, Schiffers PM, Saris WH, and van Baak MA. Endocrine role of the renin-angiotensin system in human adipose tissue and muscle: effect of beta-adrenergic stimulation. Hypertension 49: 542-547, 2007.

14. Havel RJ, Kane JP, Balasse EO, Segel N, and Basso LV. Splanchnic metabolism of free fatty acids and production of triglycerides of very low density lipoproteins in normotriglyceridemic and hypertriglyceridemic humans. J Clin Invest 49: 2017-2035, 1970.

15. Hellstrom L, Langin D, Reynisdottir S, Dauzats M, and Arner P. Adipocyte lipolysis in normal weight subjects with obesity among first-degree relatives. Diabetologia 39: 921-928, 1996.

16. Horowitz JF and Klein S. Whole body and abdominal lipolytic sensitivity to epinephrine is suppressed in upper body obese women. Am J Physiol Endocrinol Metab 278: E1144-1152, 2000.

17. Karpe F and Tan GD. Adipose tissue function in the insulin-resistance syndrome. Biochem Soc Trans 33: 1045-1048, 2005 .

18. Klein S, Coppack S, Chinkes D, and Villanueva-Meyer J. Regional transendothelial glycerol kinetics in humans. FASEB journal 10: A520, 1996.

19. Kurpad A, Khan K, Calder AG, Coppack S, Frayn K, Macdonald I, and Elia M. Effect of noradrenaline on glycerol turnover and lipolysis in the whole body and subcutaneous adipose tissue in humans in vivo. Clin Sci (Lond) 86: 177-184, 1994.

20. Large V, Reynisdottir S, Langin D, Fredby K, Klannemark M, Holm C, and Arner P. Decreased expression and function of adipocyte hormone-sensitive lipase in subcutaneous fat cells of obese subjects. J Lipid Res 40: 2059-2066, 1999.

21. Larsen OA, Lassen NA, and Quaade F. Blood flow through human adipose tissue determined with radioactive xenon. Acta Physiol Scand 66: 337-345, 1966.

22. Lofgren P, Hoffstedt J, Ryden M, Thorne A, Holm C, Wahrenberg H, and Arner P. Major gender differences in the lipolytic capacity of abdominal subcutaneous fat cells in obesity observed before and after long-term weight reduction. J Clin Endocrinol Metab 87: 764-771, 2002.

23. Matthews DR, Hosker JP, Rudenski AS, Naylor BA, Treacher DF, and Turner RC. Homeostasis model assessment: insulin resistance and beta-cell function from fasting plasma glucose and insulin concentrations in man. Diabetologia 28: 412-419, 1985.

24. Ong JM, Saffari B, Simsolo RB, and Kern PA. Epinephrine inhibits lipoprotein lipase gene expression in rat adipocytes through multiple steps in posttranscriptional processing. Mol Endocrinol 6: 61-69, 1992.

25. Reynisdottir S, Ellerfeldt K, Wahrenberg H, Lithell H, and Arner P. Multiple lipolysis defects in the insulin resistance (metabolic) syndrome. J Clin Invest 93: 2590-2599, 1994.

26. Reynisdottir $\mathrm{S}$, Wahrenberg $\mathrm{H}$, Carlstrom $\mathrm{K}$, Rossner $\mathrm{S}$, and Arner $\mathrm{P}$. Catecholamine resistance in fat cells of women with upper-body obesity due to decreased expression of beta 2-adrenoceptors. Diabetologia 37: 428-435, 1994.

27. Samra JS CM, Humpreys SM, Bannister PA, Summers LKM, Macdonald IA, Frayn KN. Evidence for glycerol uptake by adipose tissue. Proc Nutr Soc 58: A164, 1999. 


\section{[Chapter 2}

28. Samra JS, Simpson EJ, Clark ML, Forster CD, Humphreys SM, Macdonald IA, and Frayn KN. Effects of epinephrine infusion on adipose tissue: interactions between blood flow and lipid metabolism. Am J Physiol 271: E834-839, 1996.

29. Schiffelers SL, Akkermans JA, Saris WH, and Blaak EE. Lipolytic and nutritive blood flow response to beta-adrenoceptor stimulation in situ in subcutaneous abdominal adipose tissue in obese men. Int J Obes Relat Metab Disord 27: 227-231, 2003.

30. Schiffelers SL, Saris WH, Boomsma F, and van Baak MA. beta(1)- and beta(2)-Adrenoceptormediated thermogenesis and lipid utilization in obese and lean men. J Clin Endocrinol Metab 86: 2191-2199, 2001

31. Sjostrand M, Gudbjornsdottir S, Holmang A, Strindberg L, Ekberg K, and Lonnroth P. Measurements of interstitjal muscle glycerol in normal and insulin-resistant subjects. $J$ Clin Endocrinol Metab 87: 2206-2211, 2002.

32. Tan GD, Debard C, Tiraby C, Humphreys SM, Frayn KN, Langin D, Vidal H, and Karpe F. A "futile cycle" induced by thiazolidinediones in human adipose tissue? Nat Med 9:811-812; author reply $812,2003$.

33. Yukht A, Davis RC, Ong JM, Ranganathan G, and Kern PA. Regulation of lipoprotein lipase translation by epinephrine in 3T3-L1 cells. Importance of the 3' untranslated region. $J$ Clin Invest 96: 2438-2444, 1995. 


\title{
Comparative Studies of the Role of Hormone Sensitive Lipase and Adipose Triglyceride Lipase in Human Fat Cell Lipolysis
}

\author{
Rydén $\mathrm{M}^{1}$, Jocken $\mathbf{J}^{2}$, van Harmelen $\mathrm{V}^{1}$, Dicker $\mathrm{A}^{1}$, Hoffstedt $\mathrm{J}^{1}$, Wirén \\ $\mathrm{M}^{6}$, Blomqvist $\mathrm{L}^{1}$, Mairal $\mathrm{A}^{3,4}$, Langin $\mathrm{D}^{3,4,5}$, Blaak $\mathrm{E}^{2}$ and Arner $\mathrm{P}^{1}$ \\ ${ }^{\prime}$ Department of Medicine, Karolinska Institutet, Karolinska University Hospital, 14186 \\ Stockholm, Sweden \\ ${ }^{2}$ Department of Human Biology, Nutrition and Toxicology Research Institute Maastricht \\ (NUTRIM), University of Maastricht, Maastricht, The Netherlands \\ ${ }^{3}$ Inserm, U586, Unité de Recherches sur les Obésités, Toulouse, F-31432 France \\ ${ }^{4}$ Université Paul Sabatier, Institut Louis Bugnard IFR31, Toulouse, F-31432 France \\ ${ }^{5}$ Centre Hospitalier Universitaire de Toulouse, Biochimie, Institut Fédératif de Biologie \\ de Purpan, Toulouse, F-31059 France \\ ${ }^{6}$ Department of Surgery, Karolinska Institutet, Karolinska University Hospital, 14186 \\ Stockholm, Sweden
}

Am J Physiol Endocrinol Metab 2007;292(6):E1847-55 
[Chapter 3

\begin{abstract}
Background: Hormone sensitive lipase (HSL) and adipose triglyceride lipase (ATGL) regulate adipocyte lipolysis in rodents. Objective: To compare the roles of these lipases for lipolysis in human adipocytes.
\end{abstract}

Methods: Subcutaneous adipose tissue was investigated. HSL and ATGL protein expression were related to lipolysis in isolated mature fat cells. ATGL or HSL were knocked down by RNA interference or selectively inhibited and effects on lipolysis studied in differentiated preadipocytes or adipocytes derived from human mesenchymal stem cells (hMSC). Setting and subjects: Outpatient investigation. Subjects were all women, 12 lean controls, 8 lean with polycystic ovary syndrome and 27 otherwise healthy obese.

Results: Noradrenaline-induced lipolysis was positively correlated with HSL protein levels $(P<0.0001)$ but not with ATGL protein. Women with PCOS or obesity had significantly decreased noradrenaline-induced lipolysis and HSL protein expression but no change in ATGL protein expression. HSL knock-down by RNAi reduced basal and catecholamineinduced lipolysis. Knock-down of ATGL decreased basal lipolysis but did not change catecholamine-stimulated lipolysis. Treatment of hMSC with a selective HSL inhibitor during and/or after differentiation into adipocytes reduced basal lipolysis by $50 \%$ while stimulated lipolysis was inhibited completely.

Conclusions: In contrast to findings in rodents, ATGL is of less importance than HSL in regulating catecholamine-induced lipolysis and cannot replace HSL when this enzyme is continuously inhibited. However both lipases regulate basal lipolysis in human adipocytes. ATGL expression, unlike HSL, is not influenced by obesity or PCOS. 
ATGL and HSL in human lipolysis]

\section{Introduction}

Mobilization of lipids through lipolysis in fat cells is a key event in energy homeostasis. Lipolysis is disturbed in many insulin resistant disorders such as obesity and polycystic ovary syndrome (PCOS), which in turn are important risk factors for type 2 diabetes mellitus (1). Lipolysis in fat cells is under intense hormonal control. Hormone sensitive lipase (HSL) has for decades been regarded as the main regulatory step in mammal lipolysis (14). It is stimulated by catecholamines and other prolipolytic hormones and inhibited by insulin.

Lipids are mainly stored in fat cells as triacylglycerols (TAG). When lipolysis is stimulated, TAG are usually completely hydrolyzed into glycerol and free fatty acids (FFA). In rodents and humans there is also some partial lipolysis leading to the formation of diacylglycerols (DAG) and FFA but not glycerol $(2,29)$. HSL hydrolyzes both TAG and DAG, although the affinity for the latter is ten-fold higher (9). Therefore, incomplete hydrolysis of TAG to DAG during lipolysis may be due to the lower substrate affinity of HSL to TAG, rather than the existence of a specific TAG lipase with a different regulation than HSL. The pivotal role of HSL in adipocyte lipolysis was first questioned when data from HSL -/- mice were reported. The animals showed normal weight, had markedly blunted stimulated fat cell lipolysis but retained residual basal lipolysis $(26,32)$. Subsequent analysis demonstrated that knockout animals displayed an accumulation of DAG in several tissues (12), suggesting that although HSL may catalyze the rate-limiting step in TAG hydrolysis, the major physiological substrates are DAG and not TAG. Recently, a novel triacylglycerol-specific lipase has been isolated and termed adipose triglyceride lipase (ATGL-the term used in this work) (34), desnutrin (33) and $\mathrm{iPLA}_{2} \xi$ (15). The murine $A T G L$ gene codes for a 486 amino acid long protein while the human homologue, displaying $86 \%$ identity, codes for a 506 amino acid protein. Studies in rodents have shown that ATGL is predominantly expressed in white and brown adipose tissue although significant levels are also expressed in cardiac and skeletal muscle. The enzyme displays substrate specificity for TAG but unlike HSL, activation of ATGL is not dependent on phosphorylation events. Further studies have shown that ATGL expression is increased by fasting (33) and decreased by insulin (16). Recently, the phenotype of mice homozygous for a null mutation in the $A T G L$ gene was described (11). In these animals both basal and catecholamine-stimulated lipolysis were markedly decreased and this was true for both glycerol and FFA release (11). ATGL $-/$ mice display a slightly larger white adipose tissue (WAT) mass but more importantly, a massive TAG accumulation in non-adipose tissue, in particular heart muscle. This results in a rapidly developing heart failure and reduced life span. Furthermore, the animals display a defective cold adaptation indicating that ATGL is essential to provide FFAs to fuel thermogenesis. A reduction in FFA availability results in an increase in glucose utilization, which could explain the increase in glucose tolerance and insulin sensitivity observed in these animals. Finally, it was recently demonstrated in immortalized non-human cell lines that the lipid droplet associated protein CGI-58 was essential for ATGL activity although the molecular mechanisms remain to be elucidated (20). In summary, data from animal studies suggest that ATGL is essential for basal and 


\section{[Chapter 3}

stimulated lipolysis and of major importance for energy homeostasis. Accordingly, in a mouse fat cell line, overexpression of ATGL resulted in increased basal and stimulated lipolysis, while inhibition by RNA interference (RNAi) had the opposite effect (16). Gene knock-down of HSL only decreased catecholamine-stimulated lipolysis. Similar results were obtained with FFA and glycerol measurements. These results suggest a critical role for ATGL as a regulator of both basal (i.e. spontaneous) and stimulated lipolysis while HSL only determines stimulated lipolysis.

In contrast to these findings primarily obtained in rodents, the role of ATGL in humans is much less clear. An association between single nucleotide polymorphisms in the $A T G L$ gene and circulating levels of FFA, TAG and risk for type 2 diabetes mellitus was recently demonstrated (27). Moreover, mutations in the CGI-58 gene are associated with Chanarin-Dorfman Syndrome, a rare genetic disease characterized by excessive TAG accumulation in non-adipose tissues. Recently, the importance of ATGL in human lipolysis was indirectly determined using a selective inhibitor of HSL in adipocytes from healthy donors (17). It was found that catecholamine or natriuretic peptide-stimulated lipolysis was completely inhibited whereas basal lipolysis was only partially abrogated. This suggests that HSL is the major rate limiting lipase in human lipolysis and that ATGL may above all play a role in the regulation of basal lipolysis. Other human studies demonstrated that ATGL mRNA, as opposed to HSL mRNA expression, is not regulated by obesity and that the in vitro TAG hydrolase activity of ATGL, in the absence of CGI-58, is substantially lower than that of HSL (22). Thus, the enzymatic contributions of HSL and ATGL to TAG hydrolysis and thereby lipolysis may differ between humans and rodents. However, the comparison between HSL and ATGL is incomplete so far in man since there is no information on ATGL protein levels or effects of genetic manipulation of lipase expression in relation to lipolysis in human fat cells.

In the present study, we have compared the physiological roles of HSL and ATGL in human fat cell lipolysis. This was done through parallel determinations of protein level, adipocyte lipolytic activity, and modulation of HSL and ATGL levels using RNAi technology. We also compared their expression in conditions with altered lipolysis namely obesity and polycystic ovary syndrome, which are two conditions with decreased expression and function of HSL (1).

\section{Material and Methods}

\section{Subjects}

One cohort consisted of obese women who underwent bariatric surgery or gall stone operations $(n=19)$ or were investigated as healthy volunteers $(n=8)$. Obesity was defined as a body mass index (BMI) $>30 \mathrm{~kg} / \mathrm{m}^{2}$. The second cohort consisted of 12 healthy lean women with $\mathrm{BMI}<25 \mathrm{~kg} / \mathrm{m}^{2}$. The third cohort was composed of 8 young lean women diagnosed with polycystic ovary syndrome (PCOS). The latter diagnosis was defined as infertility in combination with ovarian cysts detected by ultrasound investigation. The PCOS women were otherwise healthy. We chose to 
study young and lean PCOS women because we have previously shown that they have blunted catecholamine-induced lipolysis without being insulin resistant (8). These cohorts were investigated for lipolysis regulation and comparison of HSL and ATGL protein expression. Except for the 19 operated women, abdominal subcutaneous adipose tissue was obtained by biopsy under local anesthesia. For the operated women, abdominal subcutaneous adipose tissue was obtained from the surgical incision at the beginning of surgery, which was performed under general anesthesia. We have previously shown that lipolysis regulation in isolated adipocytes is identical whether the tissue is obtained during general surgery or by local biopsy (19). Clinical data for the subjects in cohort 1-3 are summarized in Table 1. All subjects were examined at $8 \mathrm{a}$ a.m. after an overnight fast. Their height and weight were measured. Venous plasma samples were drawn for the analysis of insulin, glucose, S-testosterone and sex hormone binding globuline (SHBG) by the hospital's accredited clinical chemistry laboratory. From these measures, the testosterone/SHBG ratio and HOMA index [plasma glucose (mmol/l) times plasma insulin (mU/l)] divided by 22.5 (7) were calculated. HOMA is an indirect measure of in vivo insulin sensitivity. A fourth cohort consisted of six otherwise healthy women (age $43 \pm 2.8$ years and BMI $25 \pm 2.8 \mathrm{~kg} / \mathrm{m}^{2}$ ) who underwent cosmetic abdominal subcutaneous liposuction. These subjects did not have clinical signs of diabetes or other diseases, which may influence adipocyte function. The adipose tissue from these individuals was used to isolate preadipocytes and human mesenchymal stem cells (hMSC) for subsequent RNA interference studies and investigations of HSL inhibition. Subjects from all four cohorts included in this study were healthy and free of medication. The studies were approved by the ethical committee at Karolinska Institutet and explained in detail to each of the subjects, from whom informed consent was obtained.

Table 1. Antropometric data and relevant values on subjects from cohorts 1,2 and 3

\begin{tabular}{lccccccc}
\hline & $\begin{array}{c}\text { Obese } \\
(\mathrm{n}=27)\end{array}$ & $\begin{array}{c}\text { Lean } \\
(\mathrm{n}=12)\end{array}$ & $\begin{array}{c}\text { PCOS } \\
(\mathrm{n}=8)\end{array}$ & $\begin{array}{c}P \\
\text { ANOVA }\end{array}$ & $\begin{array}{c}\text { Lean } \\
\text { vs }\end{array}$ & $\begin{array}{c}\text { Lean } \\
\text { Os }\end{array}$ & $\begin{array}{c}\text { PCOS } \\
\text { vs }\end{array}$ \\
\hline Age (years) & $38 \pm 1.6$ & $31 \pm 1$ & $30 \pm 1.3$ & 0.01 & 0.02 & 0.69 & 0.01 \\
BMI $\left(\mathrm{kg} / \mathrm{m}^{2}\right)$ & $41.8 \pm 1.2$ & $22.6 \pm 0.5$ & $22.9 \pm 1.0$ & $<0.0001$ & $<0.0001$ & 0.89 & $<0.0001$ \\
Testosterone/SHBG & & & & & & & \\
(ratio) & $0.068 \pm 0.009$ & $0.019 \pm 0.004$ & $0.076 \pm 0.010$ & 0.01 & 0.008 & 0.008 & 0.64 \\
P-Insulin (mU/l) & $19.6 \pm 2.2$ & $5.0 \pm 0.58$ & $8.1 \pm 1.1$ & 0.0001 & $<0.0001$ & 0.50 & 0.006 \\
P-glucose (mmol/l) & $5.9 \pm 0.3$ & $4.7 \pm 0.11$ & $4.8 \pm 0.07$ & 0.004 & 0.003 & 0.85 & 0.022 \\
HOMA index & $5.7 \pm 1.0$ & $1.1 \pm 0.11$ & $1.8 \pm 0.3$ & 0.0006 & 0.0004 & 0.73 & 0.04 \\
\hline
\end{tabular}

Data is presented as mean \pm SE. Statistical significance between the three groups was calculated by ANOVA and by Student's t-test for comparisons between two groups.

\section{Lipolysis assessment in mature fat cells and predipocyte cultures}

Lipolysis experiments in mature fat cells were performed as described in detail previously (22). In brief, cells were incubated in an albumin-containing buffer ( $\mathrm{pH}$ 


\section{[Chapter 3}

7.4) for 2 hrs at $37^{\circ} \mathrm{C}$ with air as a gas phase without (basal) or with increasing concentrations of the natural catecholamine $10^{-4} \mathrm{M}$ noradrenaline or $10^{-5} \mathrm{M}$ isoprenaline (a non-selective $\beta$-adrenoceptor agonist). Following incubation, medium was removed and kept at $-20^{\circ} \mathrm{C}$ for subsequent measurement of glycerol concentration (an index of lipolysis) using a bioluminescence method (13). Lipolysis was then expressed as noradrenaline- or isoprenaline-induced glycerol release at maximum effective concentration divided by basal. When stated, lipolysis was also expressed as absolute values ( $\mu \mathrm{mol}$ of glycerol $/ 2 \mathrm{~h} / 10^{7}$ cells or $\mu \mathrm{mol}$ of glycerol $/ 2 \mathrm{~h} / \mathrm{g}$ lipids). We preferred to use the relative expression of lipolysis because it correlates strongly with the protein expression of HSL in human fat cells (18). Lipolysis in human preadipocyte cultures was performed as described previously (4) with or without $10^{-5} \mathrm{M}$ isoprenaline. Glycerol release was expressed per gram protein. Protein content was assayed spectrophotometrically using BCA Protein Assay Reagent Kit (PIERCE, Rockford, IL, USA) on 96-well microtiter plates with BSA as a standard. Glycerol was measured by bioluminescence (13) and fatty acid release by chemiluminescence (24).

\section{Studies of hMSCs}

Human MSCs were obtained from adult adipose tissue and differentiated into the adipogenic lineage as described in detail elsewhere (3). We have previously shown that these cells display lipolytic activity comparable with differentiated human preadipocytes. hMSC derived from two different donors were used. Functional assessment of adipocyte differentiation was performed by determining glycerol-3phosphate dehydrogenase (GPDH) activity as described previously (31). Cells from two wells were washed with phosphate buffered saline (PBS) (pH 7.4) and harvested in pre-chilled $25 \mathrm{mmol} / 1 \mathrm{Tris}-\mathrm{HCl}$ buffer containing $1 \mathrm{mmol} / \mathrm{l} \mathrm{EDTA}(\mathrm{pH}$ 7.4) and $1 \mathrm{mmol} / 12$-mercapto-ethanol. After sonication, aliquots of the cell extracts were added to an assay mixture containing $100 \mathrm{mmol} / 1$ triethanolamine- $\mathrm{HCl}$ buffer $(\mathrm{pH} 7.5), 2.5 \mathrm{mmol} / \mathrm{l}$ EDTA, $0.12 \mathrm{mmol} / 1 \mathrm{NADH}$ and $0.1 \mathrm{mmol} / 1 \quad \beta$-mercaptoethanol and GPDH activity was measured spectrophotometrically, at $340 \mathrm{~nm}$. The reactions were started by adding $0.2 \mathrm{mmol} / \mathrm{l}$ dihydroxyaceton phosphate. The GPDH activity was related to the total protein content in each well and expressed as $\mathrm{mU} / \mu \mathrm{g}$ of total protein. Total protein lysates were obtained from cells in two wells using a lysis buffer that contained $1 \%$ Triton $\mathrm{X}-100,50 \mathrm{mmol} / \mathrm{l}$ Tris- $\mathrm{HCl}(\mathrm{pH} 7.6)$, $150 \mathrm{mmol} / \mathrm{l} \mathrm{NaCl}$ and phenylmethylsulfonyl fluoride (PMSF, $1 \mathrm{mmol} / \mathrm{l}$ ), supplemented with protease inhibitors. Lipolysis experiments were performed on differentiated cells as described previously (31). In brief, cells were washed with DMEM/NUT.MIX.F-12 medium and then incubated in duplicates for $3 \mathrm{~h}$ at $37^{\circ} \mathrm{C}$ with DMEM/NUT.MIX.F-12 medium containing $20 \mathrm{~g} / 1$ BSA. The following concentrations were used for each agent; $10^{-8} \mathrm{M}$ isoprenaline, $10^{-5} \mathrm{M}$ noradrenaline, $10^{-}$ ${ }^{4} \mathrm{M}$ yohimbine, $10^{-3} \mathrm{M}$ dibutyryl cAMP (dcAMP) and $10^{-4} \mathrm{M}$ atrial natriuretic peptide (ANP). Incubation without drugs was made to determine basal lipolysis. The selective HSL inhibitor 4-isopropyl-3-methyl-2-[1-(3-(S)-methyl-piperidin-1-yl)methanoyl]-2H-isoxazol-5-1 BAY (21) has previously been described in detail (17) and was used at the concentration of $1 \mu \mathrm{M}$. Following incubation, medium was re- 
ATGL and HSL in human lipolysis]

moved and kept at $-20^{\circ} \mathrm{C}$ for subsequent measurement of glycerol concentration (an index of lipolysis) using a bioluminescence method (13).

\section{Protein expression of HSL and ATGL}

Approximately $300 \mathrm{mg}$ of WAT was crushed and lysed in protein lysis buffer ( $1 \%$ Triton-X 100, Tris-HCL pH 7.6 and $\left.150 \mathrm{mmol} / \mathrm{L} \mathrm{NaCl}, 4^{\circ} \mathrm{C}\right)$, supplemented with protease inhibitors $(1 \mathrm{mmol} / \mathrm{L}$ PMSF and Complete $B$ (Boehringer Mannheim, Mannheim, Germany), and homogenized using a microtome. The homogenate was centrifuged at $14,000 \mathrm{rpm}$ for $30 \mathrm{~min}$, and the infranatant was collected and saved. Protein content was assayed using BCA Protein Assay Reagent Kit (PIERCE, Rockford, IL, USA) as described above. In order to test if proteins remained in the fat cake following our protein extraction procedure we performed the following control procedure. The fat cake was removed and subjected to methanol- $\mathrm{CHCl}_{3}$ extraction (23), which effectively collects all proteins. These extracted proteins were dissolved in the same lysis buffer as above. Protein levels in fat cake extracts were below the detection limit of our assay. Thus, there are insignificant amounts of lipases left in the fat cake. One hundred micrograms of total cellular protein was loaded on polyacrylamide gels and separated by standard 12\% SDS-PAGE (sodium dodecyl sulphate-polyacrylamide gel electrophoresis). Gels were transferred to PVDF (polyvinylidine fluoride) membranes (Amersham Pharmacia Biotech, Little Chaffore, U.K.). For HSL and $\beta$-actin detection, blots were blocked for $1 \mathrm{~h}$ at room temperature in Tris-buffered saline with $0.1 \%$ Tween- 20 and $5 \%$ non-fat dried milk. This was followed by an overnight incubation at $4^{\circ} \mathrm{C}$ in the presence of antibodies directed against HSL or protein $\beta$-actin (SIGMA, St Louis, USA). The humanspecific HSL antibody was a generous gift from C Holm (Lund University, Sweden) and has been characterized elsewhere (8). For the detection of ATGL, an affinity purified polyclonal antibody was raised in rabbit against a 15 amino-acid peptide (amino-acids 386-400, GRHLPSRLPEQVERL) of human ATGL. To test antibody specificity we expressed ATGL protein in COS cells by transfection with cDNA coding for human ATGL. For detection of ATGL the following conditions were used. Blocking was performed in phosphate buffered saline (PBS) supplemented with $4 \%$ BSA. This solution was used for antibody incubation after addition of $0.1 \%$ Tween- 20 while PBS $+0.1 \%$ Tween- 20 was used as wash solution. All incubations with the ATGL antibody were performed at room temperature. Secondary $\alpha$ rabbit antibodies conjugated to horseradish peroxidase were from Sigma (St. Louis, $\mathrm{MO}$ ). Antigen-antibody complexes were detected by chemiluminescence using a kit of reagents form Pierce (Supersignal; Rockford, Rockford, IL) and specific bands were detected using a Chemidoc XRS system (BioRad, Germany). Images were analyzed using the Quantity One Software supplied by the manufacturer (BioRad). To control for differences in loading etc, $\beta$-actin was used as a control protein and values for HSL and ATGL were expressed as the quotient to $\beta$-actin in relative units $(\mathrm{RU})$. Furthermore, proteins from two subjects were ran on all gels in order to ensure similar exposure times etc to further improve interexperimental comparison. 
[Chapter 3

\section{RNA interference}

RNAi in human preadipocytes was essentially performed as described previously using short interfering RNA oligonucleotides (siRNA) (25). For each oligonucleotide, optimal transfection conditions were determined in separate titration experiments using different amounts of siRNA oligonucleotides (Qiagen GmbH, Hilden, Germany) and transfection reagent RNAiFect $囚$ (Qiagen GmbH, Hilden, Germany). Cells at day 12 of differentiation (a time-point where the cells are almost fully differentiated) were transfected with or without ATGL or HSL siRNAs (Qiagen GmbH, Hilden, Germany). The siRNA sequences were (sense strand): ATGL 5'CGG CGA GAA UGU CAU UAU, HSL 5'-GCC UGC UUC AAA CCA AAG A. To control for unspecific RNAi effects, control cells were transfected with nonsilencing siRNA oligos without known similarities to human sequences (Qiagen $\mathrm{GmbH}$, Hilden, Germany). Cells were incubated for $24 \mathrm{~h}$, a time-point where a significant gene silencing effect was observed. Conditioned cell media aliquots were then analyzed for glycerol content, while cells were lysed for RNA or protein isolation as indicated above to confirm gene silencing.

\section{$R N A$ analysis}

Total RNA from preadipoyte cultures was extracted using the RNeasy mini kit (Qiagen, Hilden, Germany). RNA concentration and purity was assessed spectrophotometrically. A bioanalyser (Agilent 2100, Agilent Technologies, Kista, Sweden) was used to confirm RNA integrity. One microgram of total RNA was reverse transcribed using a kit (Omniscript RT, Qiagen) and random hexamers (Invitrogen, Tåstrup, Denmark). To minimize methodological errors due to variation in cDNAsynthesis, cDNA-synthesis was performed simultaneously for all subjects included in the analysis. PCR conditions and primers for HSL, ATGL and $18 \mathrm{~S}$ have previously been described (22). The primer pairs were selected to yield a single amplicon based on dissociation curves and analysis by agarose gel electrophoresis. Quantitative real-time PCR was performed in an iCycler IQ ${ }^{\mathrm{TM}}$ (Bio-Rad Laboratories Inc., Hercules, CA, USA). In RNAi experiments, ATGL and HSL mRNA levels were significantly reduced to less than $20 \%$ of that in control cells and each condition was repeated at least three times with cells from different donors. Experiments where gene silencing was not efficient were discarded and not used for further analysis.

\section{Statistical Analysis}

Values are given as mean \pm standard error (SE). They were compared with Student's unpaired t-test, ANOVA, post-hoc tests and linear regression analysis using standard software packages. A $P$-value of 0.05 or less was considered to be statistically significant. It is difficult to find young, lean and otherwise healthy women with PCOS. Prior to recruitment, we made a power calculation for the comparison of lean, young women with or without PCOS based on previous findings with HSL protein expression and lipolysis (8). We can detect a $20 \%$ difference between groups in either result with $P<0.05$ and with a power of $80 \%$ by investigating, as performed in this study, 12 control and 8 PCOS subjects. 
ATGL and HSL in human lipolysis]

Drugs and chemicals

Bovine serum albumin (BSA) fraction V (lot no. A-9418), glucose, glycerol kinase, and noradrenaline, were obtained from Sigma Chemical (Sigma, St. Louis, MO, USA). All chemicals used were of the highest grade of purity that was commercially available.

\section{Results}

\section{Clinical data}

The clinical findings in cohort 1-3 are shown in Table 1 . The obese subjects were insulin resistant and somewhat older than the other groups. Healthy lean and PCOS women had almost identical BMI, age and insulin sensitivity but the PCOS subjects had a 4-fold higher testosterone/SHBG ratio.

\section{Methodological experiments}

Similar concentrations of protein $(3-6 \mu \mathrm{g} / \mu \mathrm{l})$ were obtained in the tissue extracts. However, no protein was detected in the extracts from the fat cake (detection limit is $0.01 \mu \mathrm{g} / \mu \mathrm{l})$. From these findings we calculated that $<0.2 \%$ of all protein in adipose tissue following extraction for Western blot remained in the fat cake. In Western blot analysis of tissue extracts a single band at $56 \mathrm{kD}$ was detected which disappeared after preincubation of the antibody with the immunizing peptide. This band corresponds to the predicted molecular mass of human ATGL protein. Specificity of the antibody was further confirmed by Western blot of protein lysates from COS cells transfected with cDNA coding for human ATGL. We used these cells to ensure the specificity of the antibody since COS cells lack ATGL. Here, a single 56 $\mathrm{kD}$ band was observed (Figure $1 \mathrm{~A}$ ).

Glycerol release following down regulation of HSL and ATGL by RNA interference We used RNA interference to determine the effects of selective lipase downregulation on basal and catecholamine (i.e. isoprenaline)-stimulated lipolysis in differentiated human preadipocytes. This system was chosen since we have recently developed efficient RNAi protocols in these cells (25) and since freshly isolated mature fat cells display a limited survival in vitro (hours). Lipolysis was determined as glycerol release. We also attempted to measure FFA release using a sensitive chemiluminescence method as well as gas chromatography, but the concentrations were below threshold sensitivity for the assays (data not shown). To control for non-specific effects of siRNA, scrambled non-silencing oligonucleotides were used to transfect control cells under otherwise identical conditions. Using either siRNA directed against HSL or ATGL we were able to down regulate HSL and ATGL mRNA in the same order of magnitude $(15 \pm 2.5$ and $12 \pm 4 \%$, respectively, $n=4$, Figure 1B). There was no effect of ATGL oligonucleotides on HSL mRNA expression or vice versa (Figure 1B) nor of control (scrambled) oligonucleotides (data not shown). Moreover, down regulation of mRNA resulted in a clearly observable reduction of the cognate protein down to about $30 \%$ (35 3.5 and $32 \pm 2.5 \%$, for HSL 


\section{[Chapter 3}

and ATGL vs control, respectively, $P<0.01, n=4$, Figure 1C). Following downregulation of HSL, a $35 \%$ decrease of both basal $(P=0.028$, Figure $1 D)$ and isoprenaline-stimulated lipolysis $(P=0.017$, Figure $1 \mathrm{E})$ was observed.

A

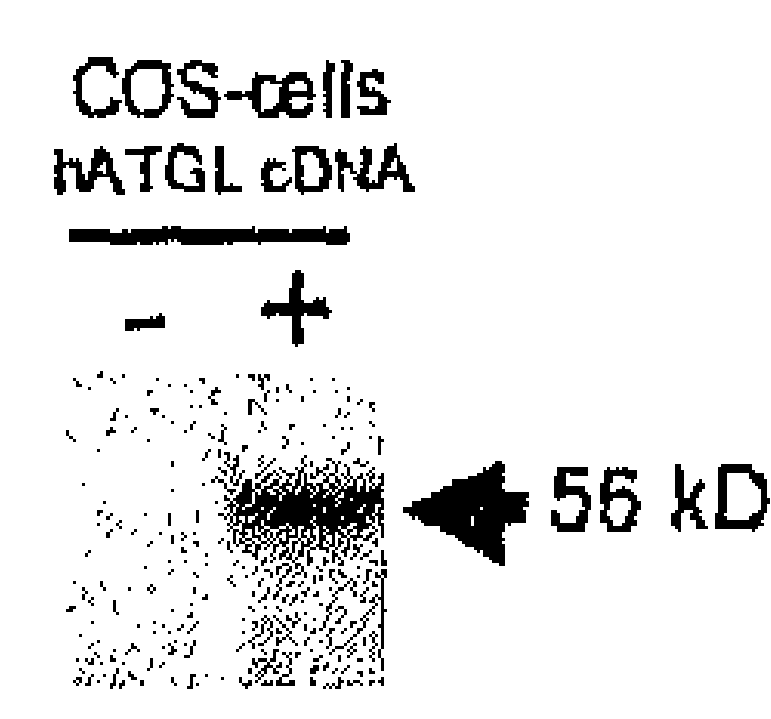

B

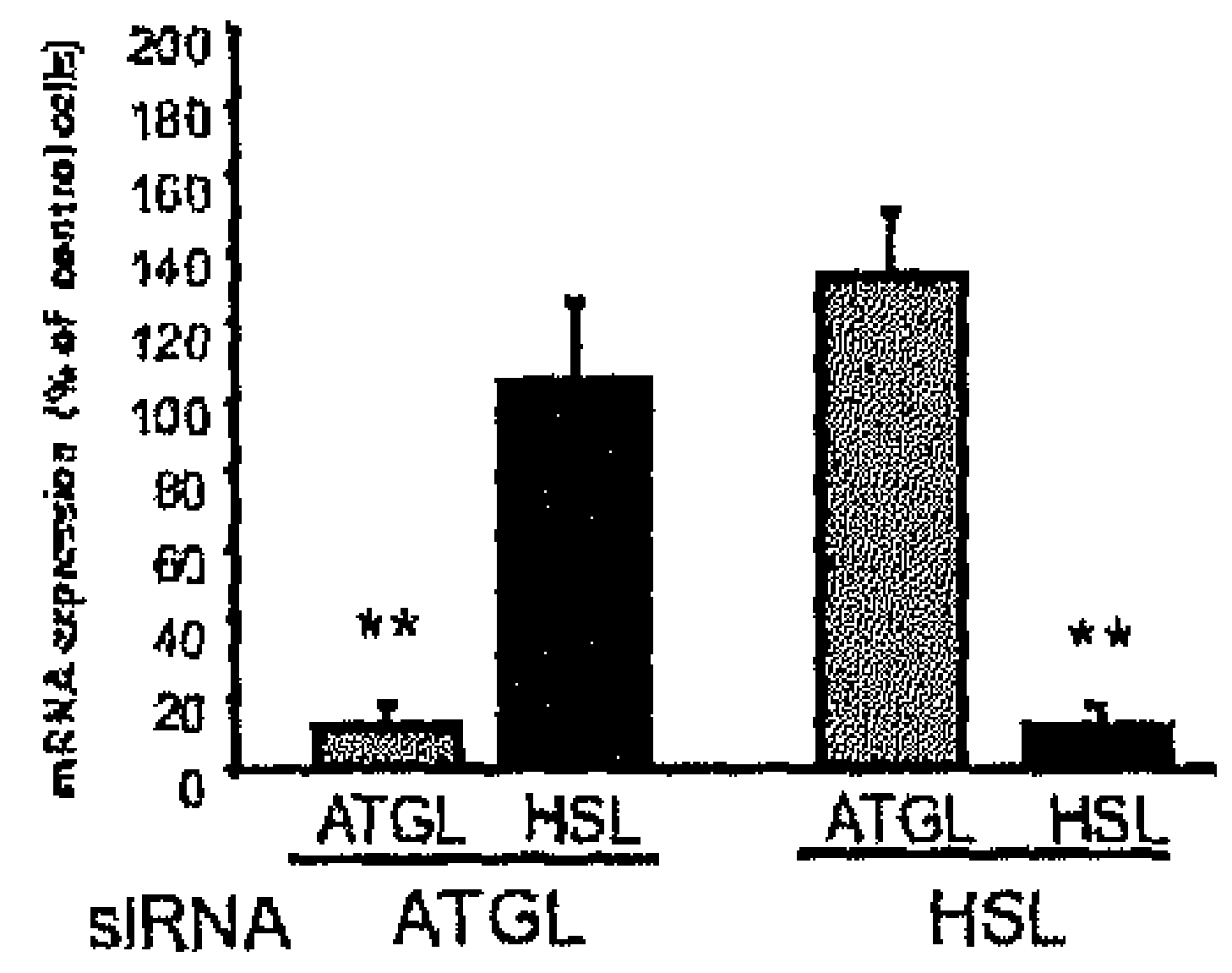

C

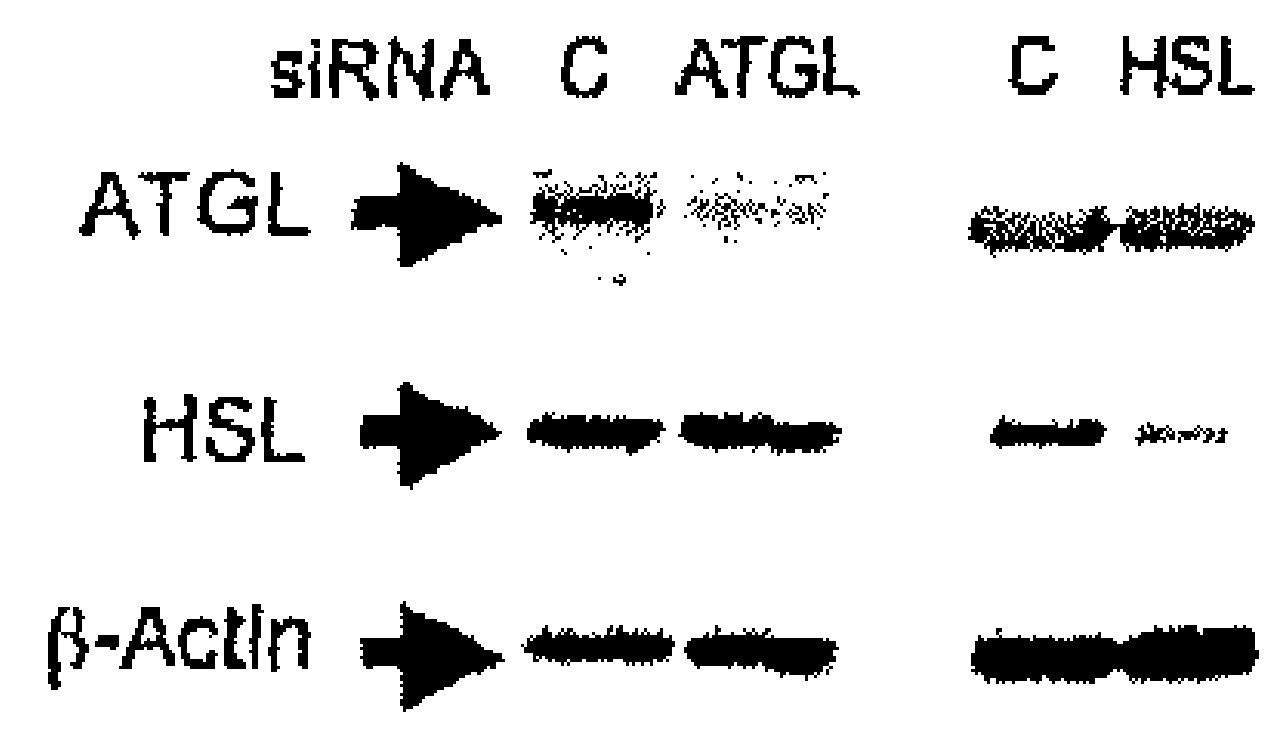

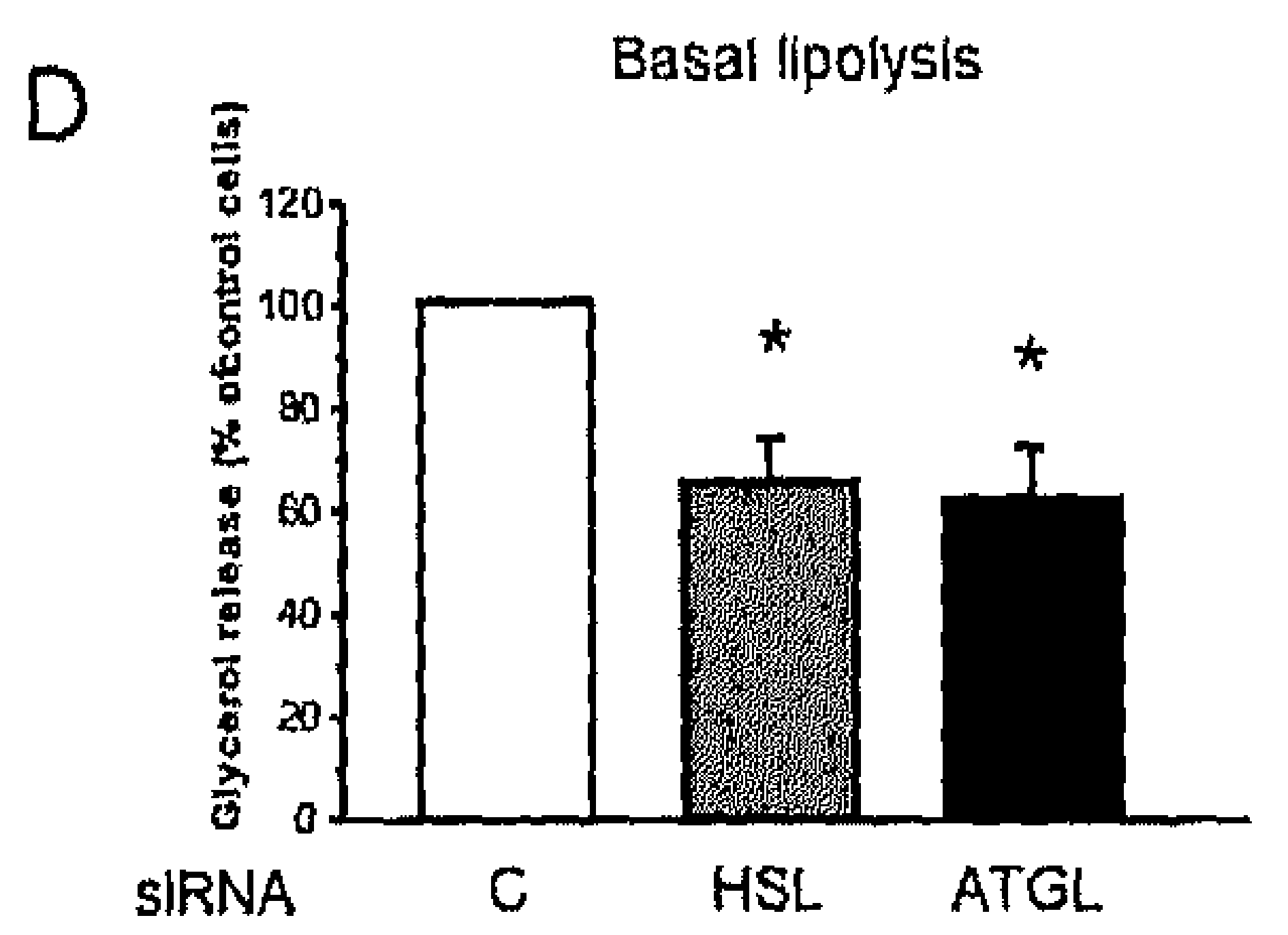

$E$

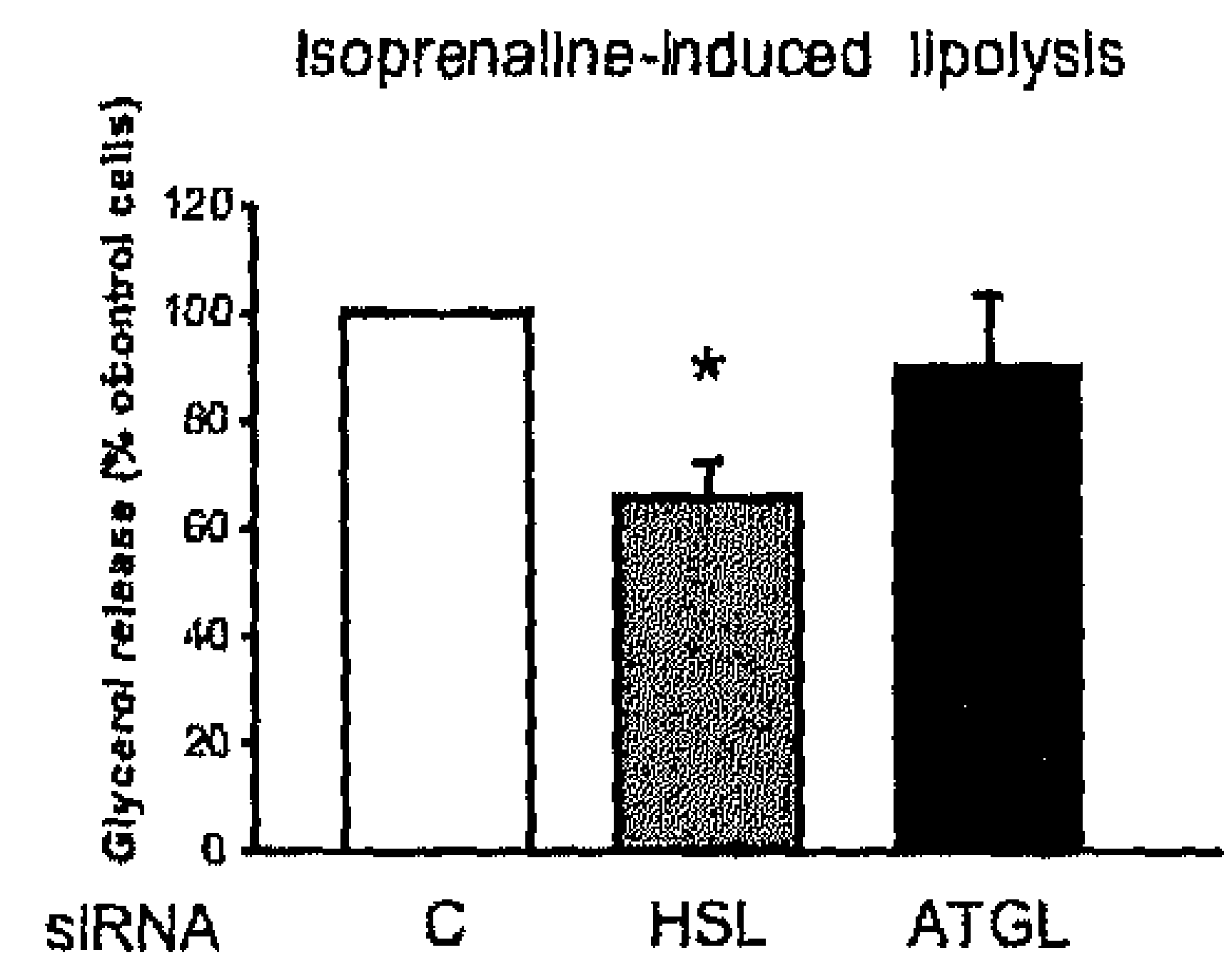

Figure 1. Effect of HSL and ATGL gene knock-down in human differentiated preadipocytes. A. Western blot analysis of protein extracts from $\operatorname{COS}$ cells transfected with an expression vector coding for human ATGL. Control cells were transfected with empty vector. Blots were probed with the ATGL antibody described in materials and methods. A single band of $56 \mathrm{kD}$ was detected. B-E. Differentiated human preadipocytes were transfected with scrambled control (C), ATGL or HSL siRNA oligonucleotides as indicated. B. Effects on mRNA expression by siRNA transfection. Cells were transfected with the indicated siRNAs and expression of HSL and ATGL mRNA was determined by quantitative real time PCR. Levels were related to those of cells transfected with control oligonucleotides. $P$ values were calculated with Student's t-test and asterisks denote $P<0.01, n=4$ C. Results at the mRNA level were confirmed at the protein level by Western blot analysis probing the blots with the indicated antibodies. A representative example from one out of four independent experiments is shown. D-E. Lipolysis was measured as glycerol release in the basal state and after incubation with isoprenaline. Glycerol release ( $\mathrm{mmol} / \mathrm{mg}$ protein) in cells transfected with scrambled siRNA oligonucleotides was (mean \pm SE) $4 \pm 1.5$ in the basal state and $16 \pm 4.5$ in the isoprenaline-stimulated state. Mean lipolysis in control cells was set at $100 \%$ and glycerol release in cells transfected with specific RNAi was expressed relative to control. D. Effect of siRNA treatment on basal lipolysis as indicated. E. Effect of siRNA on isoprenalineinduced lipolysis. Results in graphs are mean $\pm \mathrm{SE}$ of four independent experiments. Asterisks in D-E denote $P<0.05$ by post-hoc analysis of HSL or ATGL vs control. ANOVA for all three groups showed $P<0.01$. 
In contrast, RNAi knock-down with siRNA oligonucleotides specific for ATGL decreased basal lipolysis by $40 \%(P=0.018$, Figure $1 \mathrm{D})$ but had no effect on isoprenaline-induced lipolysis $(P=0.73$, Figure $1 \mathrm{E})$.

\section{Lipolysis in $h M S C$}

The role of HSL for lipolysis in adipocyte precursor cells was examined using the selective HSL inhibitor BAY at the maximum effective concentration (Figure 2).

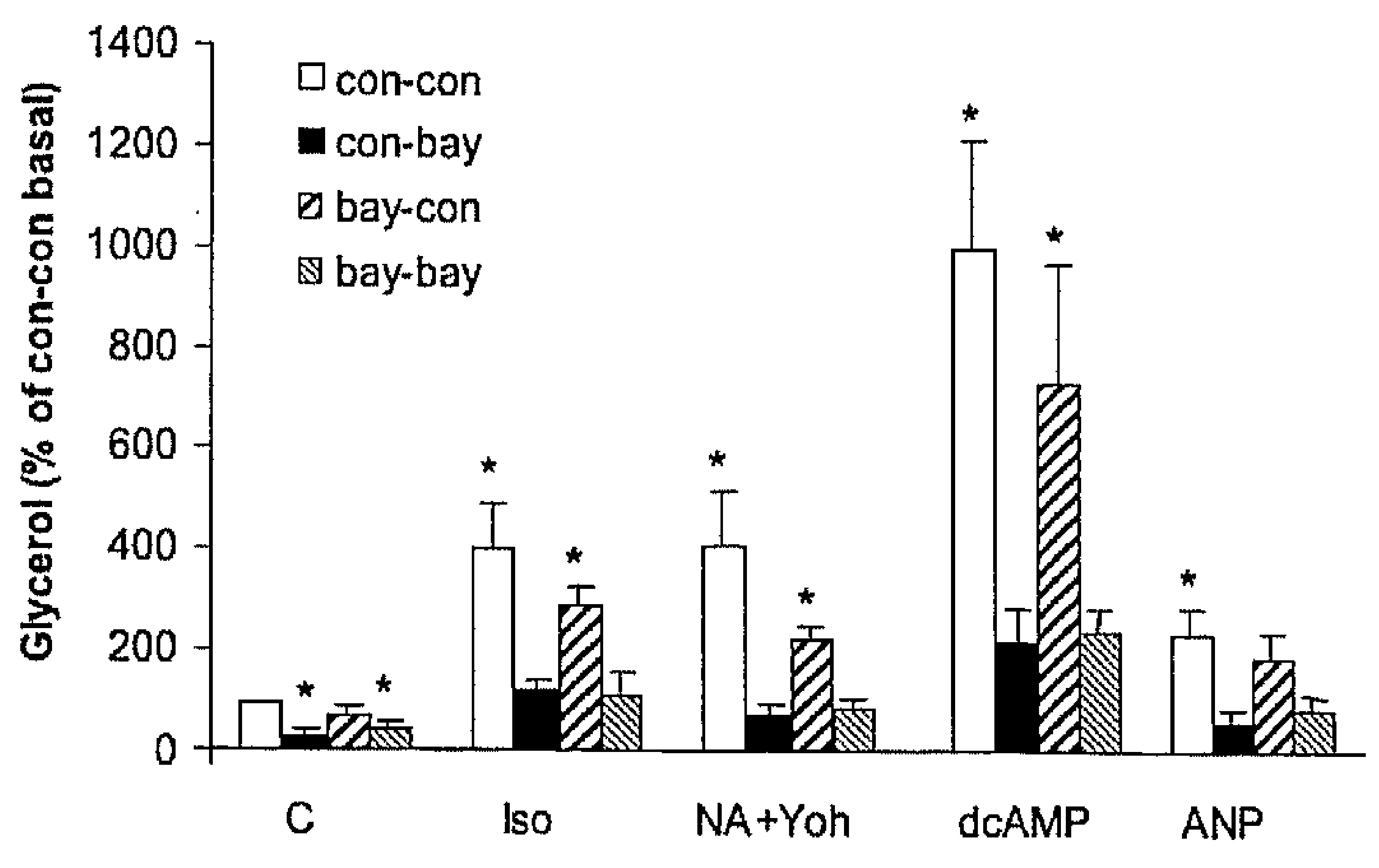

Figure 2. Effect of HSL inhibition on basal and stimulated lipolysis of adipocytes differentiated from hMSC. Human MSCs were proliferated and differentiated into the adipose lineage followed by a threehour incubation with or without the indicated prolipolytic agents. One micromolar BAY was added at different time points. Cells were incubated with BAY during the entire differentiation process and BAY was then either retained (bay-bay) or omitted (bay-con) during the lipolytic stimulation. In addition cells were acutely incubated with BAY only during the lipolytic assessment (con-bay). Cells not exposed to BAY at any step (con-con) served as control cells. Lipolysis was expressed as glycerol release and related to basal levels of glycerol release in con-con cells. $C$; basal conditions without exogenous lipolytic stimulus (basal glycerol release), Iso; Isoprenaline, NA+Y; noradrenaline and the $\alpha 2$-adrenergic receptor inhibitor yohimbine, dcAMP; dibutyryl cAMP, ANP; atrial natriuretic peptide. Results are based on five independent experiments using hMSC from two different donors. Error bars are SE. Asterisks denote $P<0.05$ by t-test analysis vs basal glycerol release in con-con. ANOVA in each of the five conditions showed $P<0.01$ for the overall difference.

This inhibitor does not influence any other lipase apart from HSL, including ATGL. We chose to use a recently established cell system based on hMSC isolated from human adipose tissue. These cells can be efficiently differentiated in vitro into adipocytes and display all the morphological and functional characteristics of human adipocytes (3). Furthermore, these are the only human cells that can be used to block HSL from the earliest stage of differentiation since preadipocytes are commit- 


\section{[Chapter 3}

ted to the adipogenic lineage. hMSC were allowed to proliferate and then differentiate into fat cells. Thereafter, a 3-hour lipolysis experiment was performed. Inhibiton of HSL with BAY after adipose differentiation (con-bay) reduced basal lipolysis by half and almost completely counteracted lipolysis stimulated by isoprenaline, noradrenaline and the $\alpha 2$ adrenergic receptor inhibitor yohimbine, a cyclic AMP analogue (dcAMP) and atrial natriuretic peptide (ANP, which stimulates lipolysis via the cyclic GMP pathway) compared with control cells not exposed to BAY (con-con, Figure 2, $P<0.05, \mathrm{n}=5$ ). Almost identical results as with con-bay treated cells were obtained with hMSC-derived adipocytes continuously exposed to BAY during the entire experiment, i.e. during the differentiation process as well as the lipolytic experiment (bay-bay). In contrast, cells exposed to BAY during differentiation but not during the lipolytic assessment (bay-con) displayed a lipolytic response that was very similar to control cells (con-con). BAY treatment did not influence adipocyte differentiation of hMSCs according to measurements of GPDH activity (not shown).

Lipolysis and lipase protein expression in lean controls, obese and lean PCOS subjects

In order to compare lipolysis and HSL or ATGL levels in subjects with different lipolytic capacity we investigated lean, obese and PCOS-subjects. Catecholamineinduced lipolysis (in mature adipocytes) and protein expression (in adipose tissue) of ATGL and HSL were determined. The maximal lipolytic capacity expressed as noradrenaline-stimulated lipolysis over basal, was significantly and markedly blunted in obese and PCOS compared with adipocytes from lean subjects $(9.2 \pm 1.7$; $2.7 \pm 0.2 ; 3.0 \pm 0.7$ for lean, obese and PCOS, respectively, mean $\pm \mathrm{SD}, P<0.0001$, Figure $3 \mathrm{~A}$ ). Basal rate of glycerol release was similar in lean controls and PCOS subjects but slightly increased in the obese $(\mathrm{P}=0.056$, graph not shown). HSL protein levels were $50-65 \%$ decreased in PCOS and obese subjects (Figure 3B, $P=0.0022)$. Post-hoc analysis of HSL data revealed a significant difference between lean versus obese $(P=0.0005)$ and PCOS versus lean $(P=0.046)$ but there was no significant difference between obese and PCOS. In contrast there was no difference in ATGL protein levels between the three groups $(P=0.96$, Figure $3 C)$. The mean value for obese and PCOS was identical $(1.75 \mathrm{RU})$. The value for lean controls was $10 \%$ lower than that for obese subjects. $\beta$-actin expression was similar in the three groups and used to correct values to enable comparison between blots.

Since obese women were somewhat older than lean and PCOS women, values for lipolysis and protein expression were also corrected for age in the ANOVA analysis (i.e ANCOVA). This did not alter the outcome of the results. We also excluded the obese undergoing general surgery. The results with the remaining 8 obese investigated as the lean and PCOS women were the same as for the whole group except that this obese subgroup had almost the same mean age as the two other groups (30.5 years).

The expression of HSL and ATGL protein from the obese, lean and PCOS subjects was plotted against maximal lipolytic capacity (expressed as noradrenaline/basal 
ATGL and HSL in human lipolysis]

lipolysis). There was a positive correlation between HSL levels and lipolysis (Figure $3 \mathrm{D}, P<0.0001, \mathrm{R}=0.72$ ). In contrast, we observed no significant correlation between ATGL protein expression and lipolysis although a slight negative trend was observed (graph not shown, $P=0.15, \mathrm{R}=-0.23$ ). We also expressed noradrenalineinduced glycerol release in absolute values corrected for either per $\mathrm{g}$ lipids or per $10^{7}$ cells, and correlated this with lipase expression. When expressing lipolysis per $\mathrm{g}$ lipids, results did not differ from those obtained using noradrenaline over basal lipolysis (graph not shown).

A

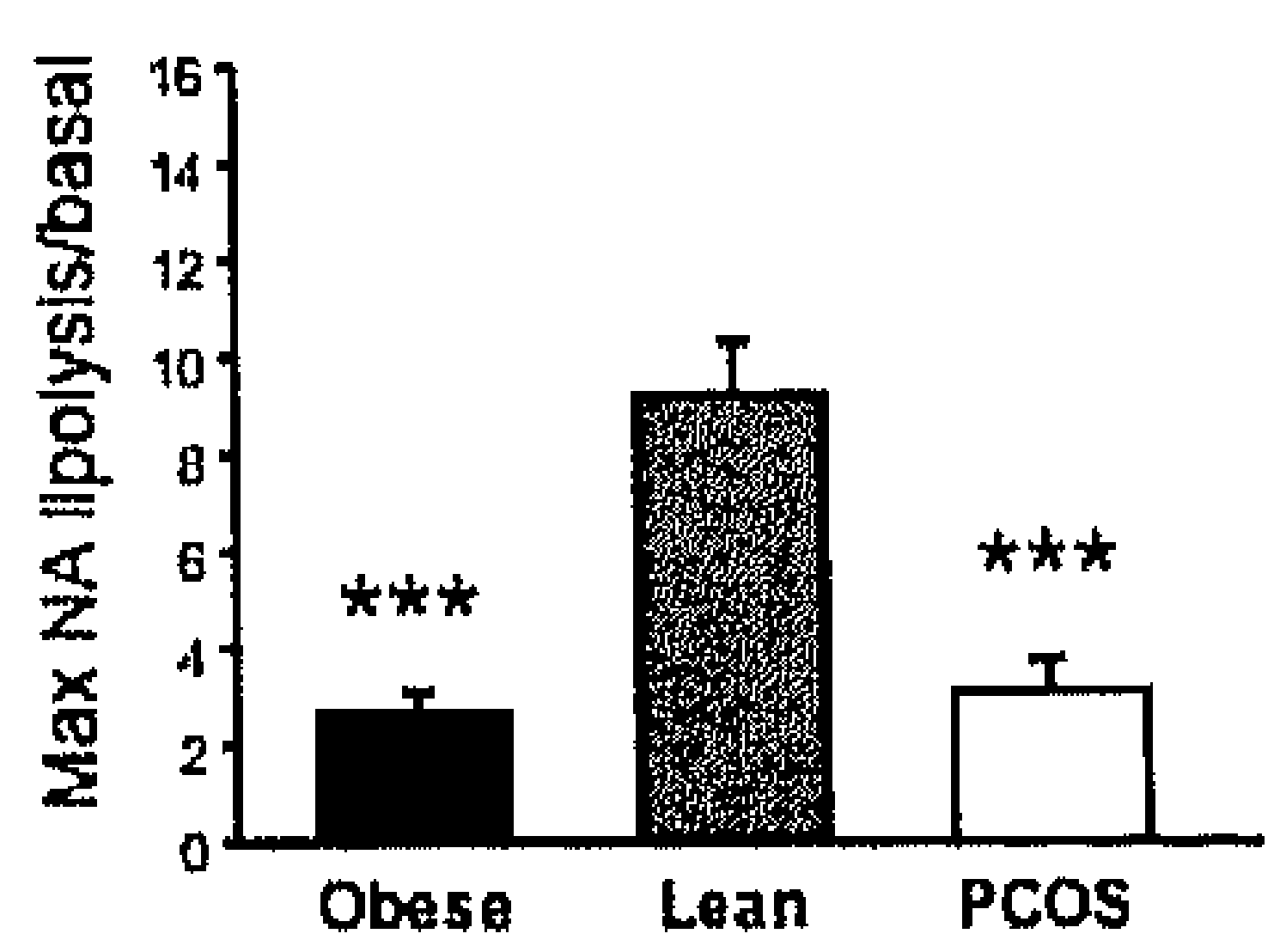

C

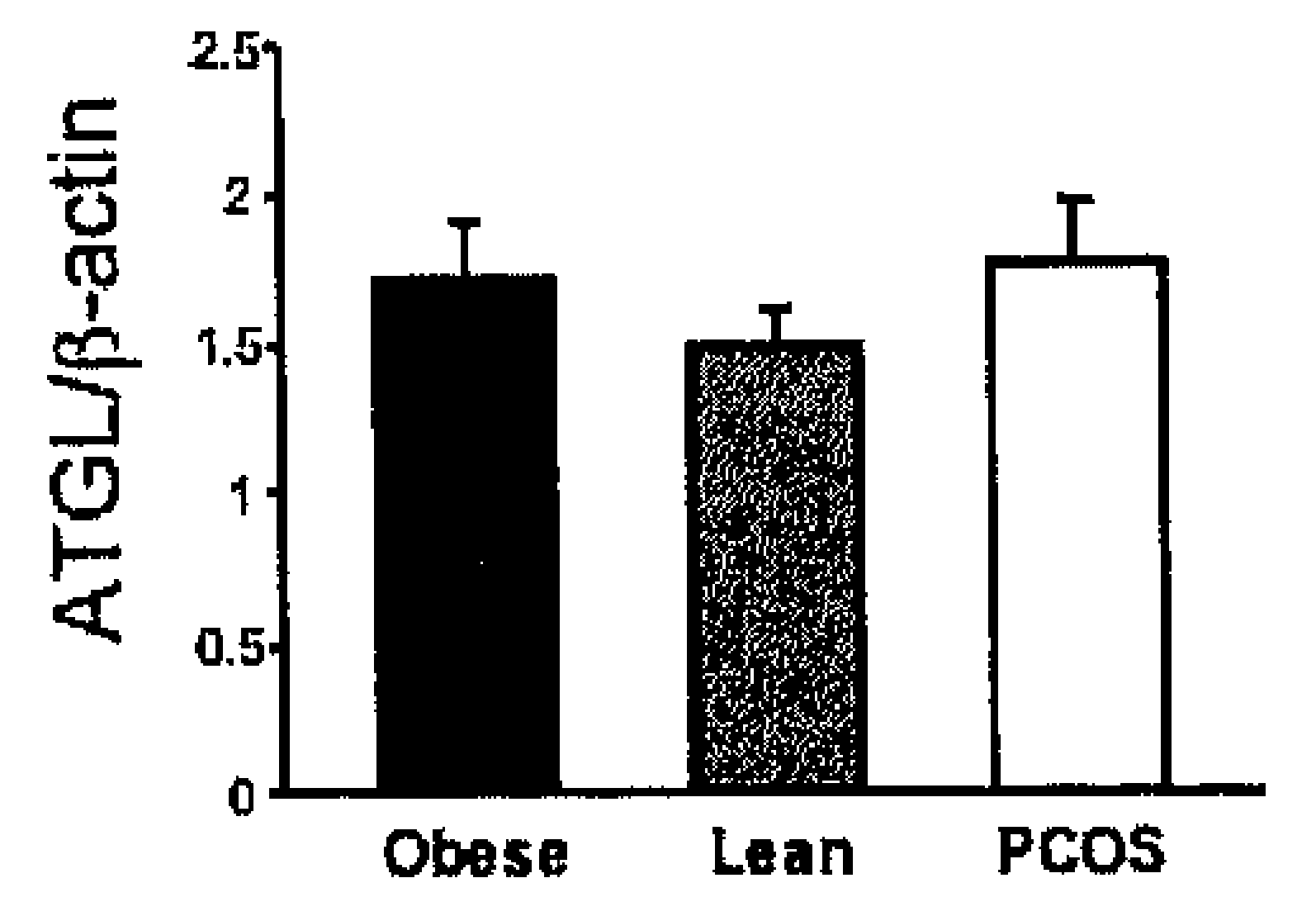

B

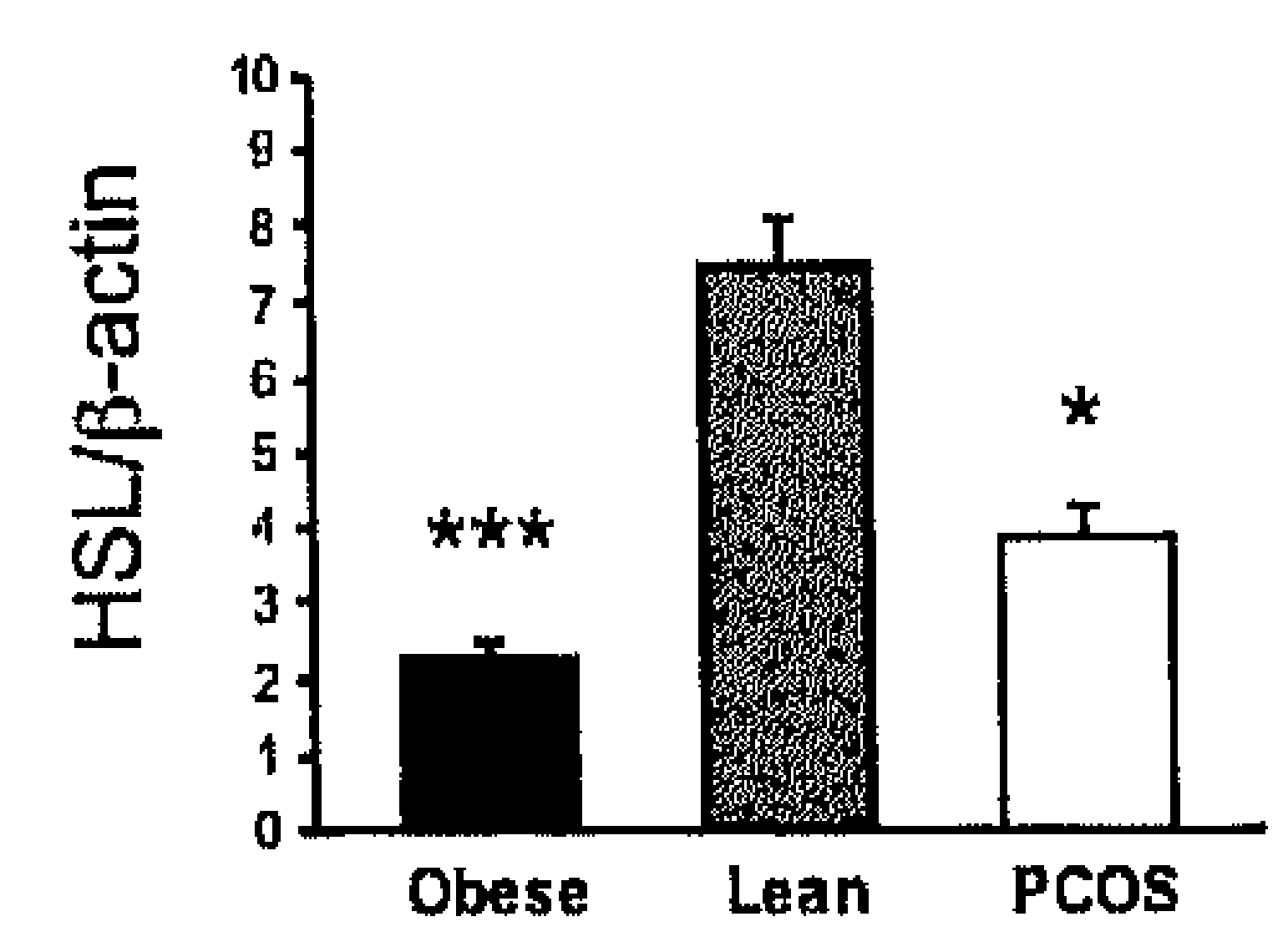

D

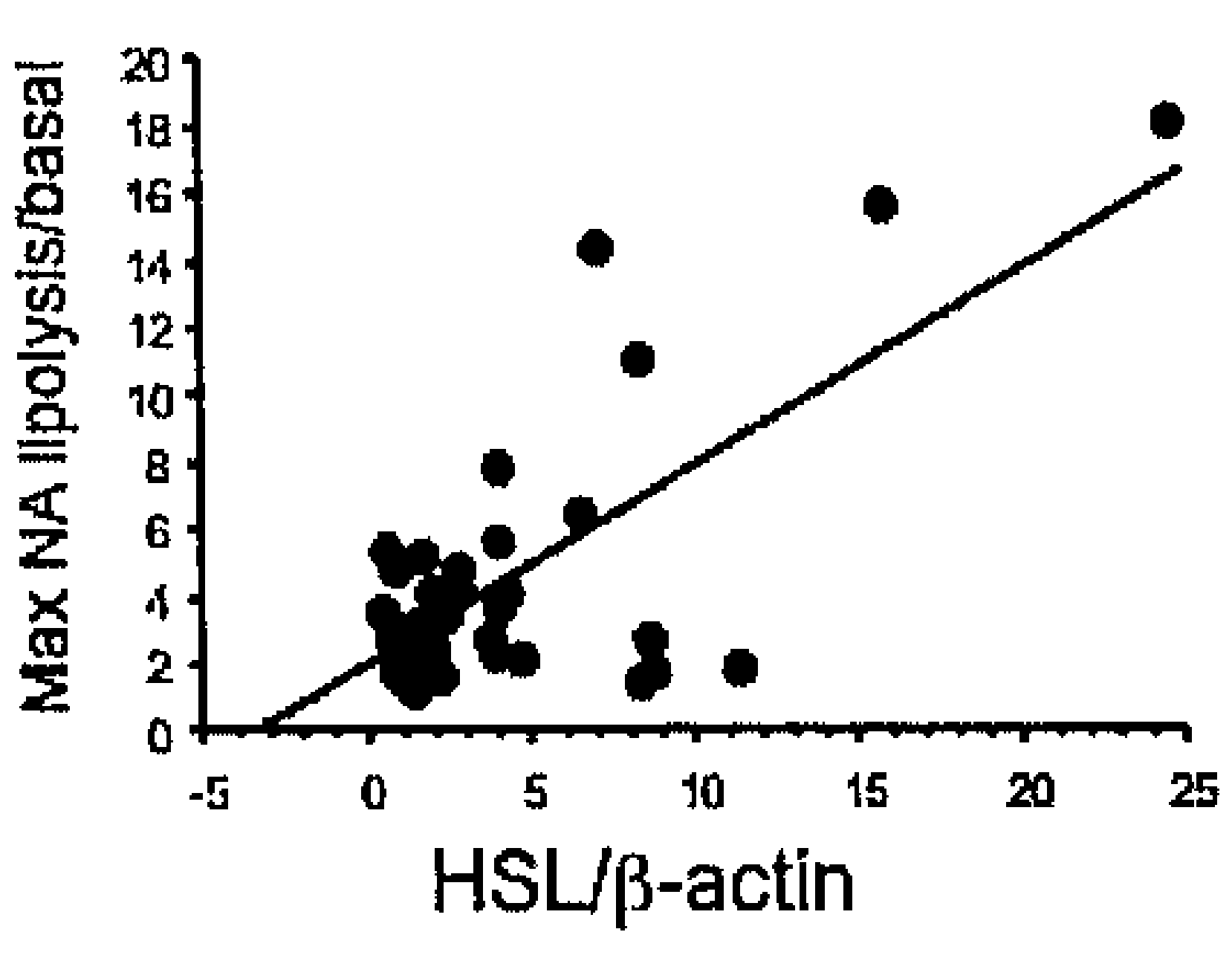

Figure 3. Lipolysis and protein expression in lean $(n=12)$, obese $(n=27)$ and lean PCOS $(n=8)$ subjects. A. In vitro lipolysis on freshly isolated mature fat cells was performed on lean, obese and PCOS subjects as indicated using noradrenaline. Lipolysis was measured as glycerol release and expressed as maximum noradrenaline lipolysis/basal glycerol release (Max NA/basal). Data are presented as mean \pm SE. B-C. Western blot analysis was performed on subcutaneous adipose tissue from the same subjects as in A. The blot was probed with antibodies directed against B. HSL or C. ATGL and corrected for $\beta$-actin in order to enable comparison between blots. Error bars are SE. Results in A$\mathrm{C}$ were first compared by ANOVA giving $P<0.01$ in $\mathrm{A}$ and $\mathrm{B}$. Asterisks denote statistically significant difference $\left(* * *=P<0.001\right.$ and $\left.{ }^{*}=P<0.05\right)$ for post-hoc analysis of obese or PCOS vs lean subjects. $\mathbf{D}$. HSL expression was plotted against lipolysis (Max NA/basal) for all subjects and examined by linear regression analysis. Results were analyzed by linear regression $(P<0.0001, \mathrm{R}=0.72)$.

However, no correlation between lipolysis and lipase expression was obtained using glycerol release per number of fat cells (graph not shown). Basal glycerol release 
[Chapter 3

did not correlate with ATGL or HSL expression. Furthermore, insulin or HOMA levels did not correlate with either ATGL or HSL expression.

These data were obtained by combining the results from two separate Western blots corrected for protein expression by $\beta$-actin to allow comparison between blots. However, the same results were obtained if the gels were analyzed separately (graphs not shown).

\section{Discussion}

The role of ATGL for human fat cell lipolysis is not clear. Previous comparisons of mRNA and enzyme activity for HSL and ATGL have demonstrated clear differences in their regulation and hydrolase activity. In this work we have assessed the relative importance of ATGL and HSL protein for human fat cell lipolysis. We compared the protein levels and lipolysis in two independent conditions with altered HSL function and lipolysis, i.e. subjects with obesity and PCOS. We also determined the effect of gene knock-down of the two enzymes and inhibition of HSL during and/or after adipogenesis. With regard to ATGL expression we developed a human-specific ATGL antibody which was very selective since it recognized only one protein band with the expected molecular size on extracts from adipose tissue or cells transfected with cDNA coding for human ATGL. The selectivity of the HSL antibody is well documented. Some protein extraction methods do not sufficiently remove lipid droplet associated proteins (including lipases) from the fat cake of adipose tissue protein extracts. Methodological experiments revealed that no or insignificant amounts of protein remained in the fat cake using our protein extraction protocol. In addition, the HSL inhibitor has no effect on other lipases at the concentration used in this study.

Due to the difficulties in recruiting lean PCOS subjects the number of these women and their matched controls was limited. However, our power calculation prior to recruitment showed that the number of subjects was large enough to significantly detect the observed differences. Although there was a small difference in age between obese and the other two study groups, age correction of results and a subgroup analysis showed that there was no significant effect of age on these results. We found a positive correlation between HSL, but not ATGL, protein levels and lipolytic capacity in response to catecholamines. This indicates that HSL is more important in promoting catecholamine-stimulated lipolysis at least when considering complete hydrolysis of TAG into glycerol and FFA. There may also be incomplete lipolysis resulting in the formation of DAG from TAG (2) and the DAG pool in human adipose tissue, although small ( $\sim 1 \%$ of all lipids), is subject to rapid turnover (5). We can therefore not exclude the possibility that ATGL, with its' high affinity to TAG, is more important than HSL for the regulation of incomplete lipolysis (TAG to DAG) resulting in release of FFA but not glycerol that occurs in human fat cells. In order to answer this question it is necessary to measure DAG and FFA. Unfortunately, although we have developed among the most sensitive assays for the measurements of glycerol (end product in DAG analysis) and FFAs in human fat cells, the amounts of FFAs released from our primary cultures and the 
intracellular levels of DAG were below the detection limit of our methods. Therefore, at present, such experiments cannot be performed. However, our results are valid for complete hydrolysis of TAG or DAG, which always results in the release of glycerol.

Little is known regarding the regulation of ATGL expression in man although adipose tissue mRNA expression was not altered by obesity. This was in contrast to HSL mRNA, which was significantly down-regulated in this condition (22). We presently compared activation of basal lipolysis with lipase protein expression in subcutaneous adipose tissue of lean, obese and lean PCOS women. Noradrenalineinduced lipolysis and HSL expression is decreased in the latter two states as reviewed (1). Obesity is associated with insulin resistance and some PCOS women are also insulin resistant. The PCOS subjects included in this study displayed no insulin resistance, presumably because they were young and lean. This confirms findings in a similar cohort of PCOS women investigated previously (8). We could also confirm previous findings from our laboratory, namely that lean, non-insulin resistant PCOS and obese insulin resistant women have a blunted catecholamineinduced lipolysis and reduced HSL expression $(6,8)$. More important is the concomitant observation that ATGL protein expression is not altered at all in obesity or PCOS. These results give further support to the notion that ATGL plays a less important role in regulating catecholamine-stimulated lipolysis in human fat cells. It is possible, though, that there is not a simple one-to-one relationship between HSL expression and lipolysis activation. Firstly, there was a considerable dispersion in the relationship between HSL and lipolysis in Figure 3D. Secondly, although lipolysis activation was almost identical in obese and PCOS (Figure 3A), HSL expression was slightly but not significantly lower in obese than in PCOS women (Figure 3B).

Although the data discussed so far favour HSL over ATGL in lipolytic regulation by catecholamines they only provide indirect evidence for this hypothesis. However, direct proof is obtained from the RNAi experiments. We have recently optimized conditions for RNAi in primary cultures of human adipocytes (25) and we are currently perfecting a similar approach in hMSC-derived adipocytes. These studies demonstrate that gene knock-down of HSL results in decreased basal as well as catecholamine-stimulated lipolysis whereas siRNAs directed against ATGL only inhibit basal glycerol release. It may appear strange why an $85 \%$ reduction in mRNA for either ATGL or HSL only reduces basal lipolysis by $35-40 \%$ and stimulated lipolysis by $35 \%$ (the latter for HSL). It should be noted though, that siRNA only inhibit protein expression transiently and have no effect on protein degradation. The endogenous half-lives of ATGL and HSL proteins are not known. Moreover, although protein expression for both lipases was clearly reduced using their cognate siRNA oligonucleotide, protein levels in these primary cultures were still easily detectable. As discussed above, there is probably a non-linear relationship between the amounts of lipase (HSL and ATGL) present in the adipocyte and the lipolytic activity. Thus, considerable lipolytic activity is present in cells where lipase expression has been reduced by approximately $70 \%$. It would of course be of interest to assess the effects of double knock-down by RNAi. At present, however, 


\section{[Chapter 3}

this is not feasible because of off-target effects that are yet be resolved in our cellular system. The ideal experiments would be to induce long-term stable reductions of these lipases. Unfortunately such experiments are presently impossible to perform due to the lack of established human fat cell lines. The use of plasmid vectors is also not an option because the transfection efficiency is too low in human adipocytes. Nevertheless, basal and isoprenaline-induced lipolysis were simultaneously measured. It is evident that for ATGL the obtained reduction of this lipase only affects basal lipolysis. Even if data with double knock-down could be generated, the outcome would in no way change the present interpretation of our single knockdown experiments.

The RNAi results obtained in these primary human cells contrast findings in a murine preadipocyte cell line (16). We used the same protocols (decreasing gene expression of ATGL or HSL with siRNA and measuring basal and isoprenalineinduced glycerol release). The earlier study (16) also reported data on fatty acids. As mentioned above, we were not able to measure these lipids although we used an ultra sensitive bioluminescence assay. Nevertheless, the murine study showed that ATGL is important for basal and stimulated lipolysis while HSL is mainly required for stimulated lipolysis in adipocytes. This is not the only regulatory aspect of lipolysis that is subject to major species differences when results of human and murine fat cells are compared (for reviews see (1)). For example, rodent adipocytes utilize the $\beta 3$-adrenoceptor for catecholamine-induced lipolysis whereas human fat cells respond mainly to the prolipolytic $\beta 1$-and $\beta 2$ - and the antilipolytic $\alpha 2 \mathrm{~A}$ adrenoceptors. Moreover, human fat cells display a unique prolipolytic response to natriuretic peptides (30). Overall, this warrants caution in interpreting data obtained from murine fat cell models and extrapolate them to the human level.

The strongest evidence for a superior role of HSL among lipases in regulating human fat cell lipolysis can be obtained from our studies in hMSCs. When these cells were subjected to complete HSL inhibition during proliferation, differentiation and lipolysis experiments, basal lipolysis was inhibited by $50 \%$ while stimulated lipolysis (using a range of different agonists) was almost completely blunted. Identical results were obtained if HSL was temporarily inhibited only during the lipolysis experiment. Conversely, hMSC-derived adipocytes exposed to the HSL inhibitor during the entire differentiation process but where the HSL inhibitor was withdrawn immediately before the lipolytic experiment displayed essentially the same lipolytic activity as control cells. These data suggest that ATGL cannot replace HSL during chronic inhibition of the latter lipase and that HSL can immediately re-establish its lipolytic role when it is disinhibited. This is independent of the route of stimulation by either catecholamines, by direct activation of protein kinase A or through activation of cGMP.

Detailed clinical characteristics were available for cohort 1-3 (partly summarized in Table 1) but not for cohort 4 . It could be argued that the results obtained in cells from cohort 4 could be influenced by specific clinical conditions of the donors. However, we find this less likely since all donors were requested to be otherwise healthy and free of medication. Moreover, these immature cells from the stroma- 
ATGL and HSL in human lipolysis]

vascular portion of adipose tissue were isolated and differentiated in vitro for 2-3 weeks thereby avoiding confounding environmental factors normally present when freshly isolated fat cells are used. In fact, we have previously shown that this system is efficient in establishing primary and secondary causes to alterations in fat cell function $(17,31)$.

On the basis of the present and previous $(17,22)$ comparisons of ATGL and HSL in man we propose the following model on their respective roles in lipolytic regulation in human fat cells. HSL is of greater importance than ATGL in regulating complete hydrolysis of TG (to glycerol) following catecholamine or natriuretic peptide stimulation in normal conditions and obesity or PCOS. However, both lipases are important for the regulation of basal complete hydrolysis of TAG to glycerol. We admit that we cannot preclude the possibility that ATGL may have roles in lipolysis, which are not revealed until more is known regarding the details of this lipase (e.g phosphorylation, intracellular localization and protein-protein interactions). In fact, recent data suggest that the regulation of enzyme activity of HSL and ATGL is more complex than previously recognized (10). However, such more advanced studies of lipase function/activity can, for the moment, only be performed in fat cell lines and not in primary cells used in the present work. Furthermore, specific ATGL inhibitors that are essential for a detailed enzymatic analysis are not yet available. In addition, we cannot excluded the possibility that our use of different human fat cell models, which was mandatory to answer all questions raised in the present work, could obscure some differences regarding ATGL versus HSL function. Finally, this study has only examined HSL and ATGL. It is possible that additional lipases are active in human fat cells that may have yet undefined roles in the regulation of lipolysis. However, the importance of such lipases is doubtful since HSL and ATGL are responsible for $>95 \%$ of triacylglycerol hydrolase activity in mouse fat cells (28).

In summary, this study suggests that in contrast to findings in rodents, HSL is more important than ATGL in regulating catecholamine-induced lipolysis in human fat cells under normal and insulin resistant conditions. However, both ATGL and HSL regulate basal lipolytic activity of human fat cells. The role of these lipases in partial hydrolysis of TG to DAG remains to be defined.

\section{Acknowledgments}

This study was supported with grants from the Swedish Research Council, the Swedish Medical Association, the Swedish Diabetes Association, the Swedish Heart and Lung Foundation, the Foundation of Gustav V and Queen Victoria, the Novo Nordisk Foundation, grants from the Netherlands Organisation for Scientific Research and the EU Sixth Framework Programme Hepadip, http://www.hepadip.org, contract LSHM-CT-2005-018734. We would like to thank Gaby Åström and Kerstin Wåhlen for excellent technical assistance. 


\section{[Chapter 3}

\section{References}

1. Arner P. Human fat cell lipolysis: biochemistry, regulation and clinical role. Best Pract Res Clin Endocrinol Metab 19: 471-482, 2005.

2. Arner P and Ostman J. Mono-acid diacylglycerols in human adipose tissue. Biochim Biophys Acta 369: 209-221, 1974.

3. Dicker A, Le Blanc K, Astrom G, van Harmelen V, Gotherstrom C, Blomqvist L, Arner P, and Ryden $M$. Functional studies of mesenchymal stem cells derived from adult human adipose tissue. Exp Cell Res 308: 283-290, 2005.

4. Dicker A, Ryden M, Naslund E, Muehlen IE, Wiren M, Lafontan M, and Arner P. Effect of testosterone on lipolysis in human pre-adipocytes from different fat depots. Diabetologia 47: 420-428, 2004.

5. Edens NK, Leibel RL, and Hirsch J. Lipolytic effects on diacylglycerol accumulation in human adipose tissue in vitro. J Lipid Res 31: 1351-1359, 1990.

6. Ek I, Arner P, Ryden M, Holm C, Thorne A, Hoffstedt J, and Wahrenberg H. A unique defect in the regulation of visceral fat cell lipolysis in the polycystic ovary syndrome as an early link to insulin resistance. Diabetes 51: 484-492, 2002.

7. Emoto M, Nishizawa Y, Maekawa K, Hiura Y, Kanda H, Kawagishi T, Shoji T, Okuno Y, and Morii H. Homeostasis model assessment as a clinical index of insulin resistance in type 2 diabetic patients treated with sulfonylureas. Diabetes Care 22: 818-822, 1999.

8. Faulds G, Ryden M, Ek I, Wahrenberg H, and Arner P. Mechanisms behind lipolytic catecholamine resistance of subcutaneous fat cells in the polycystic ovarian syndrome. J Clin Endocrinol Metab 88: 2269-2273, 2003.

9. Fredrikson G, Stralfors P, Nilsson NO, and Belfrage P. Hormone-sensitive lipase of rat adipose tissue. Purification and some properties. J Biol Chem 256: 6311-6320, 1981.

10. Granneman JG, Moore HP, Granneman RL, Greenberg AS, Obin MS, and Zhu Z. Analysis of lipolytic protein trafficking and interactions in adipocytes. J Biol Chem, 2006.

11. Haemmerle G, Lass A, Zimmermann R, Gorkiewicz G, Meyer C, Rozman J, Heldmaier G, Maier R, Theussl C, Eder S, Kratky D, Wagner EF, Klingenspor M, Hoefler G, and Zechner R. Defective lipolysis and altered energy metabolism in mice lacking adipose triglyceride lipase. Science 312: 734-737, 2006.

12. Haemmerle G, Zimmermann R, Hayn M, Theussl C, Waeg G, Wagner E, Sattler W, Magin TM, Wagner $\mathrm{EF}$, and Zechner R. Hormone-sensitive lipase deficiency in mice causes diglyceride accumulation in adipose tissue, muscle, and testis. J Biol Chem 277: 4806-4815, 2002.

13. Hellmer J, Marcus C, Sonnenfeld T, and Arner P. Mechanisms for differences in lipolysis between human subcutaneous and omental fat cells. J Clin Endocrinol Metab 75: 15-20, 1992.

14. Holm C. Molecular mechanisms regulating hormone-sensitive lipase and lipolysis. Biochem Soc Trans 31: 1120-1 124, 2003.

15. Jenkins CM, Mancuso DJ, Yan W, Sims HF, Gibson B, and Gross RW. Identification, cloning, expression, and purification of three novel human calcium-independent phospholipase A2 family members possessing triacylglycerol lipase and acylglycerol transacylase activities. $J$ Biol Chem 279: 48968-48975, 2004.

16. Kershaw EE, Hamm JK, Verhagen LA, Peroni O, Katic M, and Flier JS. Adipose triglyceride lipase: function, regulation by insulin, and comparison with adiponutrin. Diabetes 55: 148-157, 2006.

17. Langin D, Dicker A, Tavernier G, Hoffstedt J, Mairal A, Ryden M, Arner E, Sicard A, Jenkins CM, Viguerie N, van Harmelen V, Gross RW, Holm C, and Arner P. Adipocyte lipases and defect of lipolysis in human obesity. Diabetes 54:3190-3197, 2005.

18. Large V, Arner P, Reynisdottir S, Grober J, Van Harmelen V, Holm C, and Langin D. Hormonesensitive lipase expression and activity in relation to lipolysis in human fat cells. $J$ Lipid Res 39: 1688-1695, 1998. 
ATGL and HSL in human lipolysis]

19. Large V, Reynisdottir S, Eleborg L, van Harmelen V, Strommer L, and Arner P. Lipolysis in human fat cells obtained under local and general anesthesia. Int $J$ Obes Relat Metab Disord 21: 7882, 1997.

20. Lass A, Zimmermann R, Haemmerle G, Riederer M, Schoiswohl G, Schweiger M, Kienesberger P, Strauss JG, Gorkiewicz G, and Zechner R. Adipose triglyceride lipase-mediated lipolysis of cellular fat stores is activated by CGI-58 and defective in Chanarin-Dorfman Syndrome. Cell Metab 3: 309-319, 2006.

21. Lowe DB, Magnuson S, Qi N, Campbell AM, Cook J, Hong Z, Wang M, Rodriguez M, Achebe F, Kluender H, Wong WC, Bullock WH, Salhanick AI, Witman-Jones T, Bowling ME, Keiper C, and Clairmont $\mathrm{KB}$. In vitro SAR of $(5-(2 \mathrm{H})$-isoxazolonyl) ureas, potent inhibitors of hormonesensitive lipase. Bioorg Med Chem Lett 14: 3155-3159, 2004.

22. Mairal A, Langin D, Arner P, and Hoffstedt J. Human adipose triglyceride lipase (PNPLA2) is not regulated by obesity and exhibits low in vitro triglyceride hydrolase activity. Diabetologia 49 : 1629-1636, 2006.

23. Mottagui-Tabar S, Ryden M, Lofgren P, Faulds G, Hoffstedt J, Brookes AJ, Andersson I, and Arner P. Evidence for an important role of perilipin in the regulation of human adipocyte lipolysis. Diabetologia 46: 789-797, 2003.

24. Naslund BM, Bernstrom K, Lundin A, and Arner P. Free fatty acid determination by peroxidase catalysed luminol chemiluminescence. J Biolumin Chemilumin 3: 115-124, 1989.

25. Nordstrom EA, Ryden M, Backlund EC, Dahlman I, Kaaman M, Blomqvist L, Cannon B, Nedergaard $\mathrm{J}$, and Arner $\mathrm{P}$. A human-specific role of cell death-inducing DFFA (DNA fragmentation factor-alpha)-like effector A (CIDEA) in adipocyte lipolysis and obesity. Diabetes 54: 1726-1734, 2005.

26. Osuga J, Ishibashi S, Oka T, Yagyu H, Tozawa R, Fujimoto A, Shionoiri F, Yahagi N, Kraemer FB, Tsutsumi O, and Yamada N. Targeted disruption of hormone-sensitive lipase results in male sterility and adipocyte hypertrophy, but not in obesity. Proc Natl Acad Sci U S A 97: 787-792, 2000.

27. Schoenborn V, Heid IM, Vollmert C, Lingenhel A, Adams TD, Hopkins PN, Illig T, Zimmermann R, Zechner R, Hunt SC, and Kronenberg F. The ATGL gene is associated with free fatty acids, triglycerides, and type 2 diabetes. Diabetes 55; 1270-1275, 2006.

28. Schweiger M, Schreiber R, Haemmerle G, Lass A, Fledelius C, Jacobsen P, Tornqvist H, Zechner $\mathrm{R}$, and Zimmermann R. Adipose Triglyccride Lipase and Hormone-sensitive Lipase Are the Major Enzymes in Adipose Tissue Triacylglycerol Catabolism. J Biol Chem 281: 40236-40241, 2006.

29. Scow RO, Stricker FA, Pick TY, and Clary TR. Effect of ACTH on FFA release and diglyceride content in perfused rat adipose tissue. Ann N Y Acad Sci 131:288-301, 1965.

30. Sengenes C, Bouloumie A, Hauner H, Berlan M, Busse R, Lafontan M, and Galitzky J. Involvement of a cGMP-dependent pathway in the natriuretic peptide-mediated hormone-sensitive lipase phosphorylation in human adipocytes. J Biol Chem 278: 48617-48626, 2003.

31. van Harmelen V, Dicker A, Ryden M, Hauner H, Lonnqvist F, Naslund E, and Arner P. Increased lipolysis and decreased leptin production by human omental as compared with subcutaneous preadipocytes. Diabetes 51:2029-2036, 2002.

32. Wang SP, Laurin N, Himms-Hagen J, Rudnicki MA, Levy E, Robert MF, Pan L, Oligny L, and Mitchell GA. The adipose tissue phenotype of hormone-sensitive lipase deficiency in mice. Obes Res 9: 119-128, 2001.

33. Villena JA, Roy S, Sarkadi-Nagy E, Kim KH, and Sul HS. Desnutrin, an adipocyte gene encoding a novel patatin domain-containing protein, is induced by fasting and glucocorticoids: ectopic expression of desnutrin increases triglyceride hydrolysis. J Biol Chem 279: 47066-47075, 2004.

34. Zimmermann R, Strauss JG, Haemmerle G, Schoiswohl G, Birner-Gruenberger R, Riederer M, Lass A, Neuberger G, Eisenhaber F, Hermetter A, and Zechner R. Fat mobilization in adipose tissue is promoted by adipose triglyceride lipase. Science 306: 1383-1386, 2004. 


\section{4}

\section{Adipose TriGlyceride Lipase (ATGL) and Hormone-Sensitive Lipase (HSL) protein expression is decreased in the obese insulin resistant state}

Jocken $\mathbf{J W}^{1}$, Langin $\mathrm{D}^{2,3,4}$, Smit $\mathrm{E}^{1}$, Saris $\mathrm{WH}^{1}$, Valle $\mathrm{C}^{2,3}$, Hul GB ${ }^{1}$, Holm $\mathrm{C}^{5}$, Arner $\mathrm{P}^{6}$ and Blaak $\mathrm{E}^{1}$

\footnotetext{
'Department of Human Biology, Nutrition and Toxicology Research Institute Maastricht (NUTRIM), Maastricht University, Maastricht, The Netherlands ${ }^{2}$ Inserm, U586, Obesity Research Unit, Toulouse, F-31432 France

${ }^{3}$ Paul Sabatier University, Louis Bugnard Institute, IFR31, Toulouse, F-31432 France ${ }^{4} \mathrm{CHU}$ de Toulouse, Biochemistry Laboratory, Biology Institute of Purpan, Toulouse, F31059 France

${ }^{5}$ Department of Experimental Medical Science, Division of Diabetes, Metabolism and Endocrinology, Lund University, Lund, Sweden

${ }^{6}$ Department of Medicine, Karolinska Institutet, Karolinska University Hospital, Huddinge, Stockholm, Sweden
}

$J$ Clin Endocrinol Metab 2007;92(6):2292-9 


\title{
[Chapter 4
}

\begin{abstract}
Background: Obesity is associated with increased triacylglycerol (TAG) storage in adipose tissue and insulin resistance. The mobilization of stored TAG is mediated by HSL and the recently discovered ATGL. The aim of the present study was to examine whether ATGL and HSL mRNA and protein expression are altered in insulin resistant conditions. In addition, we investigated whether a possible impaired expression could be reversed by a period of weight reduction.
\end{abstract}

Methods: Adipose tissue biopsies were taken from obese subjects $(n=44)$ with a wide range of insulin resistance, before and just after a 10-week hypocaloric diet. ATGL and HSL protein, and mRNA expression was determined by Western blot and RT-qPCR, respectively.

Results: Fasting insulin levels and the degree of insulin resistance $\left(\mathrm{HOMA}_{\text {ir }}\right)$ were negatively correlated with ATGL and HSL protein expression; independent of age, gender, fat cell size and body composition. Both mRNA and protein levels of ATGL and HSL were reduced in insulin resistant compared to insulin sensitive subjects $(P<0.05)$. Weight reduction significantly decreased ATGL and HSL mRNA and protein expression. A positive correlation between the decrease in leptin and the decrease in ATGL protein level after weight reduction was observed. Finally, ATGL and HSL mRNA and protein levels seem to be highly correlated, indicating a tight coregulation and transcriptional control.

Conclusions: In obese subjects insulin resistance and hyperinsulinemia are strongly associated with ATGL and HSL mRNA and protein expression independent of fat mass. Data on weight reduction indicated that also other factors (e.g. leptin) relate to ATGL and HSL protein expression. 
ATGL and HSL in obesity]

\section{Introduction}

Obesity is characterized by increased triacylglycerol (TAG) storage in adipose tissue and insulin resistance. The mobilization of stored TAG (lipolysis) is mediated by hormone-sensitive lipase (HSL). For more than 30 years, the paradigm has been that HSL is the rate-limiting enzyme responsible for TAG breakdown. Studies in HSL knockout mice $(8-10,28,29,40)$ raised doubt on the rate-limiting role of HSL in TAG metabolism and suggested that at least one additional lipase in adipose tissue should be active that preferentially hydrolyzes the first ester bond of the TAG molecule. Recently, a new TAG lipase that belongs to a gene family characterized by the presence of a patatin-domain was identified $(12,39,41)$. Zimmermann et al. termed this new non-HSL lipase: adipose triglyceride lipase (ATGL), being predominantly expressed in adipose tissue (41).

An impaired catecholamine-induced lipolysis and a reduced HSL expression in preadipocytes and differentiated adipocytes is observed in obesity $(2,21,32)$. This blunted catecholamine-induced lipolysis has been proposed to be a cause of excessive accumulation of body fat. Indeed, studies in first-degree relatives of obese subjects demonstrate an impaired catecholamine-mediated lipolysis (11). Furthermore, the impaired catecholamine-induced lipolysis did not improve after weight loss, indicating that it may be an early factor in the development or maintenance of increased fat stores $(3,4,24,31)$. A plausible other interpretation is that this reduced lipolytic response is an appropriate downregulation of lipolysis per unit fat mass to prevent an excessive fatty acid outflow from the expanded fat mass and to prevent worsening of the insulin resistant state. In line, fasting insulin concentrations have been shown to be inversely related to fatty acid efflux from adipose tissue (13). Moreover, insulin downregulates ATGL and HSL mRNA expression in 3T3-L1 adipocytes and HSL mRNA expression is increased in adipocytes from insulindeficient animals $(15,16,18,35)$. In addition, ATGL is downregulated in animal models for insulin resistance (ob/ob and $\mathrm{db} / \mathrm{db}$ ) and HSL knockout animals show signs of impaired insulin sensitivity in adipose tissue and skeletal muscle $(28,39)$. Thus, there seems to be a negative relationship between insulin, ATGL and HSL expression.

The aim of the present study was to investigate whether the degree of insulin resistance and hyperinsulinemia are, independently of fat mass, related to an impaired ATGL and HSL protein expression in a group of overweight-obese subjects with a wide range of insulin resistance, selected from an existing cohort. In addition, we investigated the impact of weight loss by means of a hypocaloric diet (low-fat $v s$. medium-fat diet) on adipose tissue ATGL and HSL protein levels. To the best of our knowledge this is the first time that ATGL protein levels are measured in human adipose tissue. 
[Chapter 4

\section{Material and Methods}

\section{Subjects}

This study was part of the European multicentre study NUGENOB (NUtrientGENe Interactions in human OBesity), which is described in detail elsewhere (30, 36,38 ). Only the overweight-obese subjects from the Maastricht centre participated in this part of the study. The basic selection criteria for overweight-obese subjects were age $20-50 \mathrm{y}$ and $\mathrm{BMI} \geq 26 \mathrm{~kg} / \mathrm{m}^{2}$. Exclusion criteria were: weight change $>3 \mathrm{~kg}$ within the 3 months prior to the study start; drug treated hypertension, diabetes or hyperlipidemia; thyroid disease; surgically treated obesity; pregnancy, alcohol or drug abuse and participation in other simultaneous ongoing trials. All subjects were recruited by means of an advertisement in a local newspaper, informed in detail about the investigation and their consent was obtained before participating in the study. From the 116 participants at the Maastricht centre, a selection of 22 insulin sensitive (IS) and 22 insulin resistant (IR) subjects was made. Insulin sensitivity was assessed by the HOMA (homeostasis model assessment) index for insulin resistance $\left(\mathrm{HOMA}_{\mathrm{ir}}\right)$ calculated from fasting glucose and insulin according to the equation of Matthews (27). The median for HOMA ir in the total Maastricht cohort was 2.19 (range: $0.4-9.9$ ). Subjects above the $50^{\text {th }}$ percentile of $\mathrm{HOMA}_{\text {ir }}$ were assigned as IR and subjects below the $50^{\text {th }}$ percentile as IS. Before entering the study, all subjects were in good health as assessed by medical history and physical examination. The Medical Ethical Review Committee of Maastricht University approved the study protocol and the clinical investigations were performed according to the Declaration of Helsinki.

\section{Study design}

A clinical investigation day took place before and just after a 10-week dietary intervention with either low-fat or medium-fat diets. Subjects anrived at the clinical research centre at 8:00 a.m. after a 12 hours overnight fast and a 3-day run in period, in which they had to avoid excessive physical activity and alcohol consumption, described previously in detail (30). During this day the subjects underwent anthropometric measurements and an adipose tissue biopsy was taken. In addition, a venous basal blood sample was drawn for further biochemical analysis.

\section{Dietary intervention}

Subjects followed one of two energy-restricted diets: a medium-fat $(n=23)$ or a lowfat $(n=21)$ diet. Data on the different diets and how the diet was controlled are published elsewhere (30). The target macronutrient composition of the two diets was as follows: low-fat diet, $20-25 \%$ of total energy was provided by fat; the corresponding figure for the medium-fat diet was $40-45 \%$. Both diets derived $15 \%$ of total energy from protein and the remainder $(60-65 \%$ and $40-45 \%$ for the low-fat and medium-fat diets, respectively) from carbohydrates. Both diets were designed to provide $600 \mathrm{kcal} /$ day less than the individual estimated energy expenditure based on resting metabolic rate, measured using a ventilated hood system, expressed in $\mathrm{kcal} /$ day and multiplied by 1.3 . 
ATGL and HSL in obesity]

\section{Anthropometric measurements}

After subjects voided their bladder body weight was determined on a calibrated electronic scale, accurate to $0.1 \mathrm{~kg}$. Waist and hip circumference measurements to the nearest $1 \mathrm{~cm}$ were made midway between the lower rib and iliac crest with the participant standing upright. Height was measured using a wall-mounted stadiometer. BMI was calculated as body weight in kilograms divided by squared height in meters. Fat mass (FM) and fat-free mass (FFM) were assessed using multifrequency bioimpedance (QuadScan 4000; Bodystat, Douglas, Isle of Man, British Isles). The percentage body fat $(\% \mathrm{BF})$ was calculated from total fat mass $(\mathrm{kg})$ and body weight.

\section{Adipose tissue biopsy}

A subcutaneous adipose tissue biopsy was taken from the abdominal region early in the morning after an overnight fast. The second biopsy was taken in week 10 of the dietary intervention. Biopsies were performed under local anesthesia (Xylocaine (B) $0,5 \%$, Lidocaine $0,5 \%$; AstraZeneca BV, Zoetermeer, The Netherlands) on the left or right side of the abdomen about $5 \mathrm{~cm}$ lateral from the umbilicus using a Hepafix(B)-luerlock syringe (Braun Medical) and a 146x3 1/5" $(2,10 \times 80 \mathrm{~mm})$ Braun-Sterican ${ }^{\circledR}$ needle. The biopsy was washed in physiological saline and stored in a sterile polypropylene tube at $-80^{\circ} \mathrm{C}$ until further analysis.

\section{Biochemical analysis}

Plasma glucose concentrations (ABX Diagnostics, Montpellier, France) were measured on a COBAS MIRA automated spectrophotometer (Roche Diagnostica, Basal, Switzerland). Triacylglycerol (TAG) (Sigma, St Louis, USA), free fatty acids (FFA) (NEFA C kit, Wako Chemicals, Neuss, Germany) and glycerol (Boehringer Mannheim, Germany) were measured on a COBAS FARA centrifugal spectrophotometer (Roche Diagnostica, Basal, Switzerland). Standard samples with known concentrations were included in each run for quality control. Plasma insulin and serum leptin were measured with double antibody radioimmunoassays (Insulin RIA 100, Kabi-Pharmacia, Uppsala, Sweden; Human leptin RIA kit, Linco research, Inc, St.Charles, Missouri, USA).

\section{Fat cell volume (FCV) and fat cell weight (FCW)}

Fat cell characteristics were determined in a subset of the same cohort $(n=39$; $19 \mathrm{IS} / 20 \mathrm{IR} ; \mathrm{HOMA}_{\mathrm{ir}}: 1.4 \pm 0.1$ vs. $4.7 \pm 0.5, \mathrm{P}<0.01$ ). Weight loss after diet was the same among these subjects as in the whole cohort (data not shown). Also, with respect to other metabolic parameters this subgroup was comparable to the group in which ATGL and HSL protein and mRNA expression was determined (see under results). Adipose tissue was subjected to collagenase treatment, and the mean volume and weight of the isolated fat cells were determined as previously described (23). 
[Chapter 4

\section{Sample preparation}

About $200 \mathrm{mg}$ adipose tissue was ground to a fine powder under liquid nitrogen and homogenized in $200 \mu \mathrm{l}$ of ice-cold buffer: 8M urea, 2\% 3-[(3-cholamidopropyl)dimethylammonio]-1-propane sulfonate (CHAPS, Sigma C9426), $65 \mathrm{mM}$ dithiotreitol (DTT, Bio-Rad 161-0611), protease inhibitor (Sigma P8340) and phosphatase inhibitor cocktail (Sigma P5726). The homogenate was vortexed for 5 min and centrifuged at $20000 \times \mathrm{g}$ for 30 minutes at $4^{\circ} \mathrm{C}$. The supernatant was carefully collected and aliquots were stored at $-80^{\circ} \mathrm{C}$. The protein concentration was determined by Bradford based protein assay (Bio-Rad 500-0006).

\section{Western blot analysis}

Ten $\mu \mathrm{g}$ of protein were separated using 10\% SDS-PAGE and then transferred to a nitocellulose membrane. An affinity purified polyclonal antibody was raised in rabbit against a 15 amino-acid peptide (amino-acids 386-400, GRHLPSRLPEQVERL) of human ATGL (Eurogentec, Seraing, Belgium). In Western blot analysis a single band at $56 \mathrm{kDa}$ was detected which disappeared after preincubation of the antibody with the peptide. This band corresponds to the predicted molecular mass of the human ATGL protein (41). In addition, when COS cells were transfected with CDNA coding for human ATGL, a single band of $56 \mathrm{kDa}$ was observed following western blot of extracted cellular protein. HSL was detected using a rabbit polyclonal antibody, raised and purified against recombinant human HSL. The HSL antibody has been previously validated (20). The secondary antibody was a horseradish peroxidase-conjugated anti-rabbit immunoglobin (DAKO, Glostrup, Denmark). Antigenantibody complexes were visualized using enhanced chemiluminescence (ECL+, Amersham Biosciences, UK) and a Kodak Image Station (Kodak, Glostrup, Denmark). Quantification of antigen-antibody complexes was performed using Quantity One $\otimes 1-D$ analysis software (Bio-Rad). Optical density units are expressed as adjusted volume (Adj. Vol. OD, sum of pixels inside the volume boundary $\times$ area of a single pixel (in $\mathrm{mm}^{2}$ ) minus the background volume). Differences in loading were adjusted to $\beta$-actin protein levels and an isolated mature adipocyte lysate was included as positive control.

\section{Adipose tissue mRNA analysis}

ATGL and HSL mRNA expression was determined in a subset of adipose tissue samples of 26 subjects (13IS/13IR; 14F/12M) before and after the diet. Total RNA was extracted from adipose tissue using the RNeasy mini kit (Qiagen, Hilden, Germany). The RNA concentration and purity were assessed spectrophotometrically. An Agilent 2100 bioanalyser (Agilent Technologies, Massy, France) was used to confirm the integrity of the RNA. From each sample, $1 \mu \mathrm{g}$ of total RNA was reverse-transcribed to cDNA using Superscript II Revserse Transcriptase (InVitroGen, Cergy Pontoise, France) and random hexamer primers (Invitrogen). HSL and ATGL mRNAs were quantified using pre-made gene expression assays (Applied Biosystems). 18S ribosomal RNA was used as control to normalize gene expression. 
ATGL and HSL in obesity]

\section{Statistics}

All variables were checked for normal distribution and variables with a skewed distribution were $\ln$-transformed to satisfy conditions of normality.

First, univariate regression analysis was performed to identify variables that contribute to ATGL and HSL protein expression and to changes in protein expression induced by weight loss. Subsequently, a multivariate regression analyses was performed with ATGL or HSL protein levels as dependent variables and age, gender, FM, FFM, waist circumference, circulating insulin and leptin levels as independent variables (model 1). The same model was repeated with $\mathrm{HOMA}_{\text {ir }}$ as independent instead of insulin (model 2). To study the impact of weight reduction, changes in ATGL or HSL protein level were entered as dependent variable in the multivariate regression model with age, gender, change in fat mass, fat-free mass, circulating insulin and leptin as independents. ATGL and HSL mRNA and protein levels were compared between insulin sensitive (IS) and insulin resistant (IR) subjects using Student's unpaired t-test. Antropometric and metabolic parameters, HSL and ATGL mRNA and protein levels were compared before and after the diets using Student's paired $t$-test. The differential effect of the diets was assessed with analysis of covariance using diet as fixed factor. To avoid multicolinearity in the regression model independent variables with a correlation $>0.8$ were not simultaneously included in the model. The impact of the independent variables is described as unstandardized beta or regression coefficients. A P-value less then or equal to 0.05 was considered statistically significant. All analyses were performed using SPSS for Mac Os X version 11.0 (SPSS, Chicago, IL, USA).

\section{Results}

\section{Characteristics of the study subjects}

Anthropometric and metabolic characteristics of the study subjects before and after a 10-week hypocaloric diet are displayed in Table 1. Extensive data on the effects of the hypocaloric diet in the total NUGENOB cohort were reported previously (30). The diet resulted in significant loss of body weight (before $v$ s. after: $98.7 \pm 3.2$ vs. $90.0 \pm 3.3 \mathrm{~kg}, \mathrm{P}<0.001)$, fat mass $(37.4 \pm 1.6$ vs. $30.7 \pm 1.5 \mathrm{~kg}, \mathrm{P}<0.001)$ and a significantly decreased BMI $\left(34.1 \pm 0.7\right.$ vs. $\left.31.3 \pm 0.7 \mathrm{~kg} / \mathrm{m}^{2}, \mathrm{P}<0.001\right)$. In addition circulating fatty acids $\left(506 \pm 24 v s .418 \pm 22 \mu \mathrm{M} . \mathrm{L}^{-1}, \mathrm{P}=0.016\right)$, glycerol $(105 \pm 11$ vs. $83 \pm 8$ $\left.\mu \mathrm{M} . \mathrm{L}^{-1}, \mathrm{P}=0.003\right)$ and leptin $(24.7 \pm 2.3$ vs. $14.5 \pm 1.5 \mathrm{ng} / \mathrm{ml}, \mathrm{P}<0.001)$ decreased. There were no significant differences in fasting glucose, insulin and $\mathrm{HOMA}_{\text {ir }}$. As reported previously, the low-fat and medium-fat diet resulted in similar changes in anthropometric and metabolic parameters $(30,38)$.

Relationship between the degree of insulin resistance and adipose tissue ATGL and HSL protein levels

Univariate regression analysis, indicated a negative correlation between $\mathrm{HOMA}_{\mathrm{ir}}$, fasting insulin and ATGL or HSL protein levels (all $\mathrm{P}<0.05$ ), whilst age, gender, 
[Chapter 4

body composition (waist, FM, FFM) and levels of circulating leptin were not significantly related to ATGL or HSL protein levels (all $\mathrm{P}>0.10$ ).

Table 1. Anthropometric and metabolic parameters before and after a 10-week hypocaloric diet

\begin{tabular}{|c|c|c|c|c|}
\hline & \multicolumn{2}{|c|}{ Before } & \multicolumn{2}{|c|}{ After } \\
\hline & IS & $\mathrm{IR}$ & IS & $\mathrm{IR}$ \\
\hline$N(f / m)$ & $22(16 / 6)$ & $22(12 / 10)$ & $18(13 / 5)$ & $17(9 / 8)$ \\
\hline Age $(y r)$ & $39.7 \pm 1.5$ & $44.4 \pm 5.0 *$ & - & - \\
\hline Weight (kg) & $91.0 \pm 3.6$ & $106.4 \pm 4.8 *$ & $84.2 \pm 3.7 \dagger$ & $96.2 \pm 5.1 \dagger$ \\
\hline Height (m) & $1.68 \pm 0.02$ & $1.71 \pm 0.02$ & $\sim$ & - \\
\hline BMI & $32.1 \pm 0.7$ & $36.2 \pm 0.9^{*}$ & $29.7 \pm 0.8 \dagger$ & $32.9 \pm 1.0 \dagger$ \\
\hline Waist $(\mathrm{cm})$ & $105 \pm 3$ & $115 \pm 3 *$ & $99 \pm 3 \dagger$ & $105 \pm 3.8 \dagger$ \\
\hline Hip (cm) & $113 \pm 8$ & $117 \pm 2$ & $108 \pm 2 \dagger$ & $112 \pm 2.1 \dagger$ \\
\hline WHR & $0.93 \pm 0.02$ & $0.98 \pm 0.02$ & $0.91 \pm 0.02 \dagger$ & $0.94 \pm 0.03 \dagger$ \\
\hline$\% \mathrm{BF}$ & $38.2 \pm 1.6$ & $38.4 \pm 1.6$ & $33.6 \pm 1.7 \dagger$ & $34.6 \pm 1.8 \dagger$ \\
\hline $\mathrm{FFA}\left(\mu \mathrm{M}, \mathrm{L}^{-1}\right)$ & $504 \pm 30$ & $507 \pm 37$ & $418 \pm 29$ & $418 \pm 35$ \\
\hline Free Glycerol $\left(\mu \mathrm{M} . L^{-1}\right)$ & $114 \pm 21$ & $95 \pm 8$ & $89 \pm 13 \dagger$ & $76 \pm 8 \dagger$ \\
\hline $\operatorname{TAG}\left(\mu M \cdot L^{-1}\right)$ & $937 \pm 69$ & $1476 \pm 125 *$ & $932 \pm 80$ & $1230 \pm 136$ \\
\hline Glucose $\left(m M \cdot L^{-1}\right)$ & $5.2 \pm 0.1$ & $5.7 \pm 0.1 *$ & $5.1 \pm 0.1$ & $5.4 \pm 0.1$ \\
\hline Insulin $\left(\mu \mathrm{U} \cdot \mathrm{ml}^{-1}\right)$ & $7.2 \pm 0.4$ & $15.8 \pm 1.4 *$ & $7.4 \pm 0.6$ & $12.4 \pm 1.4$ \\
\hline HOMA $_{i r}$ & $1.7 \pm 0.1$ & $4.0 \pm 0.4 *$ & $1.7 \pm 0.2$ & $3.1 \pm 0.4$ \\
\hline Leptin (ng/ml) & $23 \pm 3$ & $26 \pm 4$ & $14 \pm 2 \dagger$ & $15 \pm 2 \dagger$ \\
\hline $\mathrm{FCV}(\mathrm{pl}) \#$ & $775 \pm 36$ & $869 \pm 33 *$ & $655 \pm 36 \dagger$ & $744 \pm 29 \dagger$ \\
\hline FCW (ng)\# & $709 \pm 33$ & $795 \pm 24 *$ & $600 \pm 33 \dagger$ & $681 \pm 27 \uparrow$ \\
\hline
\end{tabular}

Values are mean \pm SEM. IS insulin sensitive, IR Insulin resistant, BMI Body Mass Index, FFM fat-free mass, FM fat mass, \%BF percentage body fat, FFA free fatty acids, TAG triacylglycerol, HOMA homeostasis model assessment index for insulin resistance. \#FCV fat cell volume, FCW fat cell weight are measured in a subgroup of the same cohort $(n=39 ; 19 I S / 201 S)$ with similar characteristics. $* P<0.05$ IS $v$ s. IR unpaired t-test; $\uparrow P<0.05$ before $v$ s. after paired $t$-test.

Multivariate regression analysis, shown in Table 2, indicated the same negative correlation between HOMA $_{\text {ir }}$ (ATGL beta-coefficient: $-1.33, \mathrm{P}=0.045$; HSL betacoefficient: $-0.965, \mathrm{P}=0.039$; see Table 2 ) fasting insulin (ATGL beta-coefficient: 1.41, $\mathrm{P}=0.048$; HSL beta-coefficient: $-1.07, \mathrm{P}=0.032$; see Table 2) and ATGL or HSL protein levels. These data indicate that the insulin resistant state rather than fat mass per se causes the decrease in adipose tissue ATGL and HSL protein levels.

To illustrate the impact of insulin resistance on ATGL and HSL protein levels, subjects were assigned as insulin sensitive (IS) or insulin resistant (IR) based on HOMA $_{\text {ir }}$ (see Material \& Methods, Subjects). Anthropometric and metabolic characteristics of IS and IR subjects are displayed in Table 1. Adipose tissue ATGL and HSL protein levels were found to be dramatically reduced in IR compared to IS obese subjects. ATGL protein levels were decreased by $72 \%$ in IR compared to IS obese subjects (IR vs. IS: $2.6 \pm 1.3$ vs. $9.3 \pm 3.6$ Adj.Vol.OD, $\mathrm{P}=0.025$; see Figure 1B), whereas the corresponding figure for HSL was $57 \%(6.6 \pm 2.3$ vs. $15.4 \pm 3.0$ Adj.Vol.OD, $P=0.001$; see Figure 1B). ATGL and HSL protein levels were highly correlated (beta-coefficient: $1.05, r=0.568, \mathrm{P}=0.0001$; see Figure 2), indicating that 
ATGL and HSL in obesity]

ATGL and HSL protein levels might be tightly coregulated in adipose tissue of obese subjects.

As indicated in the methods section, FCV and FCW were determined in a subset of insulin sensitive $(n=19)$ and insulin resistant $(n=20)$ subjects from the same cohort with similar characteristics with respect to $\mathrm{HOMA}_{\text {ir }}(1.5 \pm 0.1$ vs. $4.7 \pm 0.5 ; \mathrm{P}<0.01)$, body fat $\%(42.5 \pm 1.1$ vs. $42.8 \pm 2.0 ; \mathrm{P}=0.742)$ and waist $(108 \pm 2$ vs. $114 \pm 2 ; \mathrm{P}=0.031)$ and similar diet-induced changes. Fat cell volume (FCV) and fat cell weight (FCW) were significantly higher $(12 \% ; \mathrm{P}=0.039)$ in IR compared with IS subjects and decreased significantly after weight loss $(\mathrm{P}<0.01)$, see Table 1 . When ATGL and HSL protein expression was corrected for mean FCV or FCW the difference between groups remained significant (for ATGL, IR vs. IS: $2.6 \pm 0.6$ vs. $3.9 \pm 0.5, \mathrm{P}<0.01$; for HSL, IR vs. IS: $9.2 \pm 1.5$ vs. $13.4 \pm 1.6$. $\mathrm{P}<0.01)$.

Table 2. Determinants of ATGL and HSL protein levels in multivariate regression analysis

\begin{tabular}{|c|c|c|c|c|c|c|}
\hline \multirow{2}{*}{$\begin{array}{l}\text { Dependent variable: } \\
(\mathrm{n}=44)\end{array}$} & \multicolumn{3}{|c|}{ ATGL expression } & \multicolumn{3}{|c|}{ HSL expression } \\
\hline & $B^{\#}$ & $95 \% \mathrm{CI}$ & P-value & $\mathbf{B}^{\#}$ & $95 \% \mathrm{CI}$ & P-value \\
\hline \multicolumn{7}{|l|}{ MODEL 1} \\
\hline Age (yr) & $5.98^{\mathrm{E}} \cdot 02$ & $-3.37^{\mathrm{i}}-02-0.15$ & 0.199 & $5.29^{\mathrm{E}}-02$ & $-1.24^{\mathrm{E}}-02-0.12$ & 0.107 \\
\hline \multicolumn{7}{|l|}{ Gender: } \\
\hline Male & 0 & 0 & & 0 & 0 & \\
\hline Female & -0.606 & $-4.27-3.06$ & 0.736 & -0.72 & $-3.27-1.85$ & 0.570 \\
\hline Waist (cm) & $-3.77^{\mathrm{E}}-02$ & $-0.13-5.15^{\mathrm{E}}-02$ & 0.392 & $-1.01^{\mathrm{E}}-02$ & $-7.23^{\mathrm{E}}-02-5.22^{\mathrm{E}}-02$ & 0.742 \\
\hline FFM (kg) & $-5.79^{\mathrm{l}}-03$ & $-0.13-0.12$ & 0.926 & $-2.14^{E}-02$ & $-0.11-6.72^{\mathrm{E}}-02$ & 0.622 \\
\hline $\mathrm{FM}(\mathrm{kg})$ & $2.78^{\mathrm{E}}-02$ & $-9.57^{\mathrm{E}}-02-0.15$ & 0.646 & $3.51^{\mathrm{E}}-02$ & $-5.13^{E}-02-0.12$ & 0.410 \\
\hline Insulin $\left(\mu \mathrm{U} \cdot \mathrm{ml}^{-1}\right)^{*}$ & -1.41 & $-2.81--1.57^{\mathrm{E}}-02$ & 0.048 & -1.07 & $-2.05--9.95^{\mathrm{E}}-02$ & 0.032 \\
\hline Leptin $(\mathrm{ng} / \mathrm{ml})^{*}$ & $7.79^{\mathrm{E}}-03$ & $-4.97^{\mathrm{E}}-02-6.53^{\mathrm{E}}-02$ & 0.782 & $9.43^{\mathrm{E}}-03$ & $-3.08^{\mathrm{E}}-02-4.96^{\mathrm{E}}-02$ & 0.633 \\
\hline \multicolumn{7}{|l|}{ MODEL 2} \\
\hline HOMA $_{\text {ir }}{ }^{*}$ & -1.33 & $-2.63--3.43^{\mathrm{E}}-02$ & 0.045 & -0.965 & $-1.88--5.14^{\mathrm{E}}-02$ & 0.039 \\
\hline
\end{tabular}

ATGL and HSL mRNA expression in insulin sensitive versus insulin resistant subjects

Additionally, ATGL and HSL mRNA expression was determined in a subset of adipose tissue samples of 26 subjects. In agreement with the protein expression data, ATGL and HSL mRNA expression were significantly lower in IR $(n=13)$ compared to IS $(n=13)$ obese subjects $(P=0.006$ and $P=0.057$, respectively; see Figure 1A). Also, a positive correlation was found for ATGL and HSL mRNA expression (beta-coefficient: $0.531, \mathrm{r}=0.253, \mathrm{P}=0.005$ ), suggesting that the two enzymes belong to a common regulatory network with tight transcriptional control. 
[Chapter 4

A

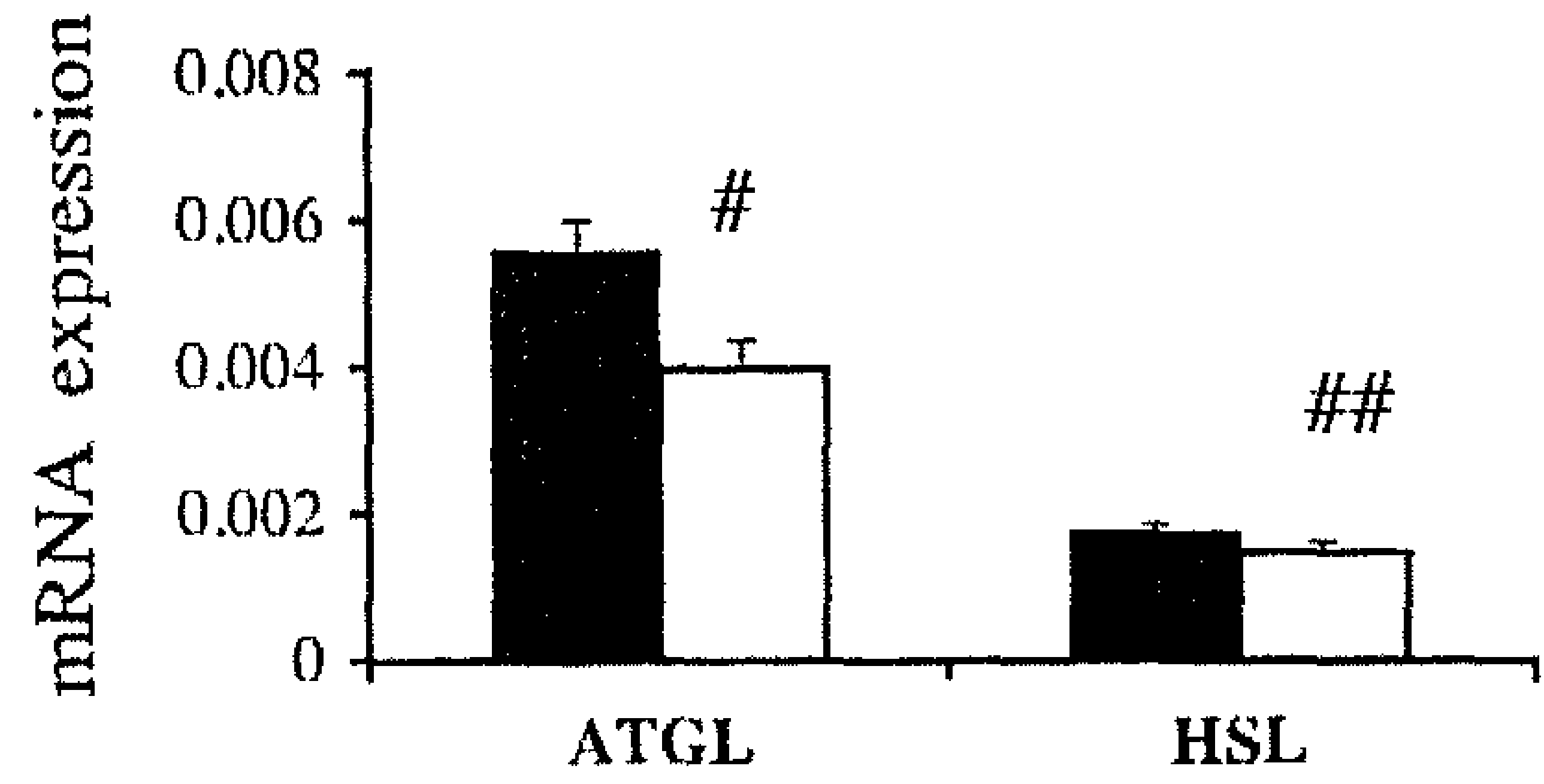

B

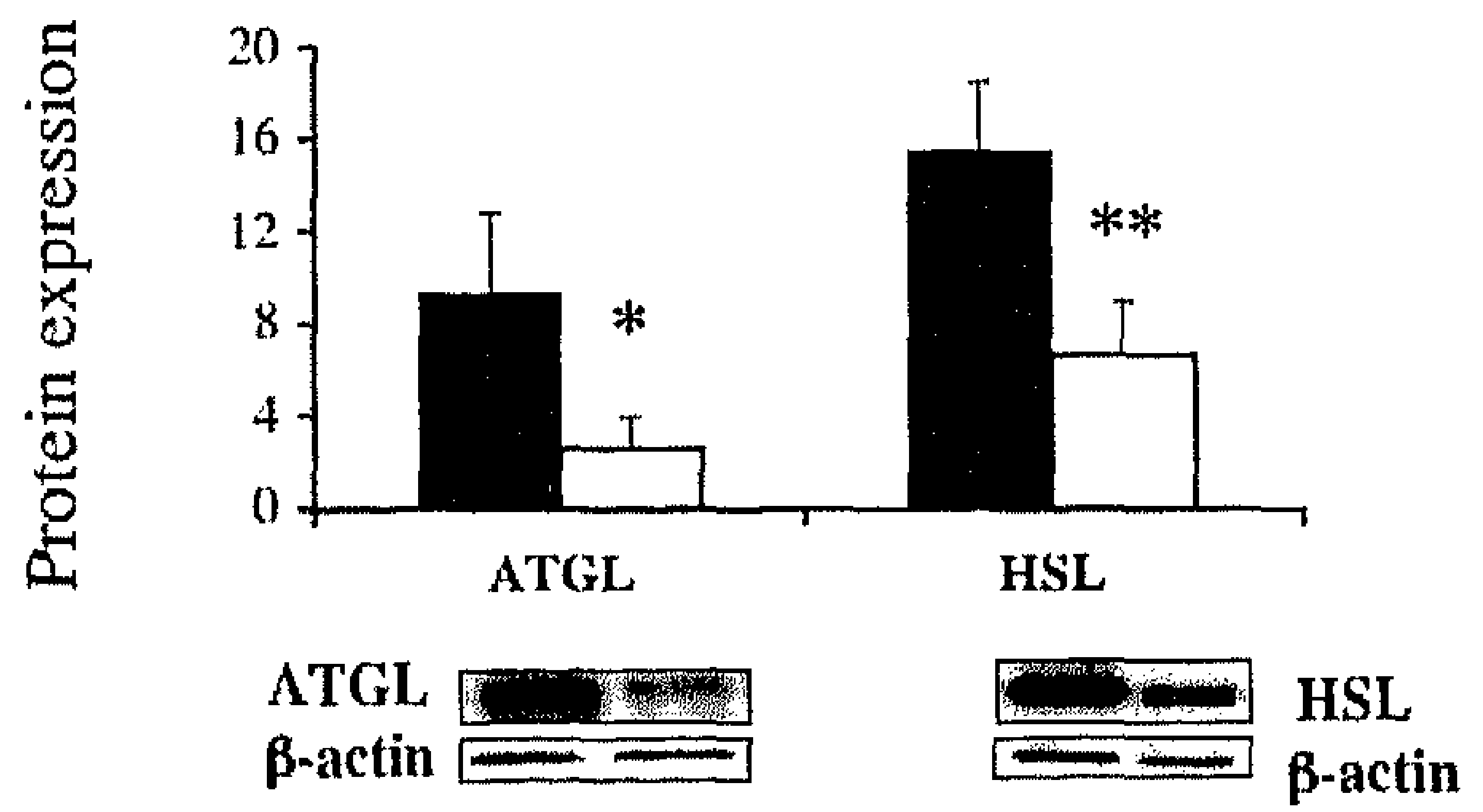

Figure 1. ATGL and HSL mRNA and protein expression in subcutaneous adipose tissue of insulin sensitive (black bars, $\square$ IS) versus insulin resistant (white bars, $\square$ IR) overweight-obese subjects. (A) ATGL and HSL mRNA expression was significantly lower in IR $(n=13)$ compared to IS $(n=13)$ subjects (\# $\mathrm{P}=0.006$ and \#\# $\mathrm{P}=0.057$, respectively). mRNA levels were quantified by $R T-q P C R$ and normalized with $18 \mathrm{~S}$ rRNA. (B) In line, ATGL and HSL protein expression was significantly lower in IR ( $n=22)$ compared to IS $(n=22)$ subjects $\left(* P=0.025\right.$ and ${ }^{* *} P=0.001$, respectively). ATGL and HSL protein expression was quantified using Western blot and expression was related to the structural protein beta-actin. IS versus IR using Student's unpaired t-test statistics. Values are mean \pm SEM.

\section{Effect of weight reduction on adipose tissue ATGL and HSL protein levels}

A 10-week hypocaloric diet resulted in a decreased adipose tissue ATGL (before vs. after $5.7 \pm 1.8$ vs. $1.4 \pm 0.4$ Adj.Vol.OD, $P=0.04$; see Figure $3 \mathrm{~B}$ ) and HSL (before vs. after: $10.8 \pm 1.9$ vs. $5.9 \pm 1.3$ Adj.Vol.OD, $P=0.023$; see Figure $3 \mathrm{~B}$ ) protein level. When ATGL and HSL protein expression was corrected for mean FCV or FCW the difference remained significant (for ATGL, before vs. after: $3.2 \pm 0.5$ vs. $2.1 \pm 0.4$, $\mathrm{P}=0.02$; for HSL: before $v s$. after: $11.1 \pm 1.8 v s .7 .5 \pm 1.4, \mathrm{P}<0.01$ ). Low-fat and medium-fat diets resulted in similar changes in ATGL and HSL protein levels. To find out the effect of changes in anthropometric and metabolic parameters on ATGL and HSL protein levels univariate and multivariate regression analysis was applied (see Table 3). 
ATGL and HSL in obesity]

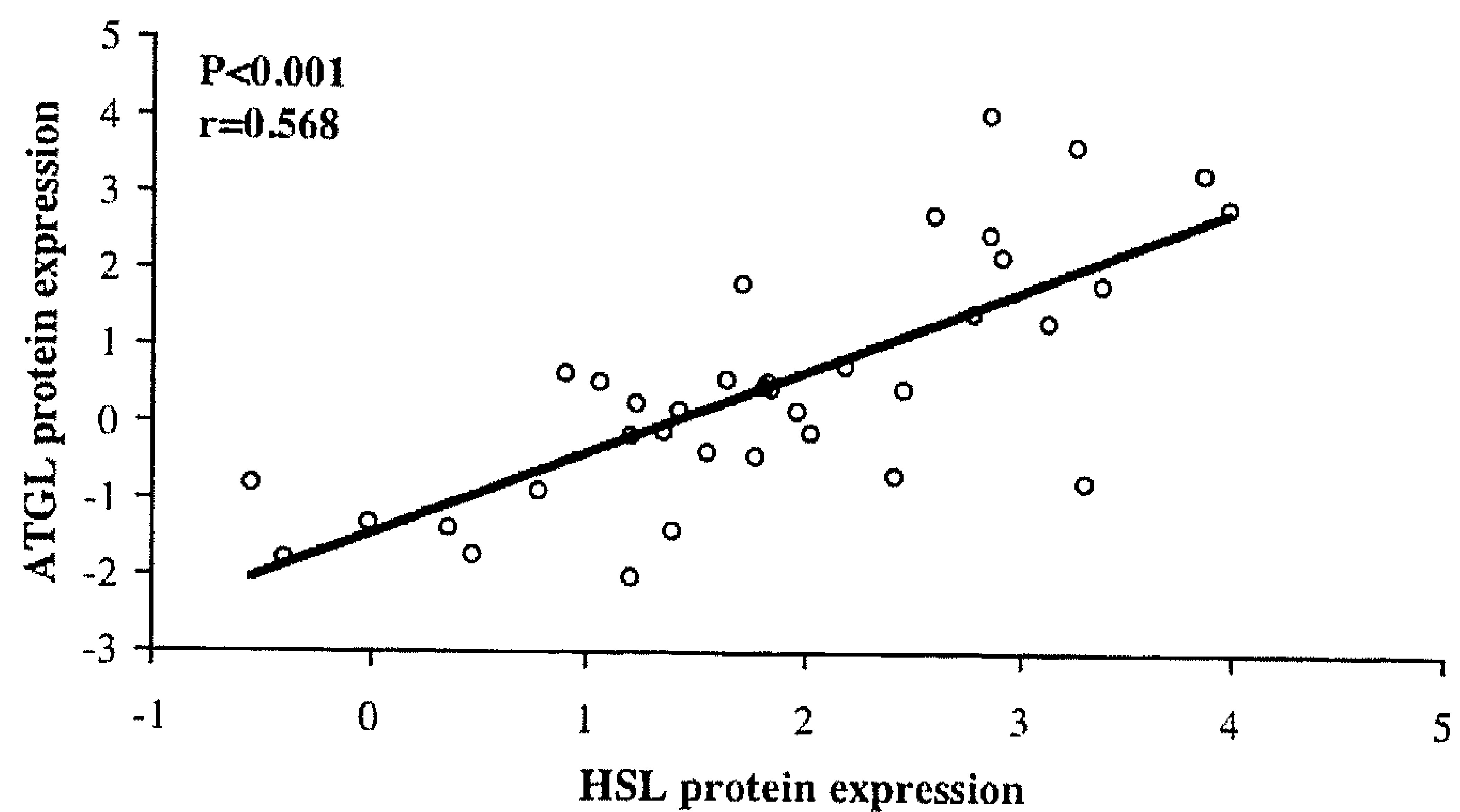

Figure 2. Correlation between ATGL and HSL protein levels in subcutaneous adipose tissue of overweight-obese subjects. ATGL and HSL protein levels were quantified by Western blot analysis (values are Adj.Vol.OD*mm2). ATGL and HSL protein levels are entered after being $\ln$-transformed.

Table 3. Determinants of change in ATGL and HSL protein level after a 10-week hypocaloric diet in multivariate regression analysis

\begin{tabular}{|c|c|c|c|c|c|c|}
\hline \multirow{2}{*}{$\begin{array}{l}\text { Dependent variable: } \\
(\mathrm{n}=35)\end{array}$} & \multicolumn{3}{|c|}{ Change in ATGL } & \multicolumn{3}{|c|}{ Change in HSL } \\
\hline & B $^{\#}$ & $95 \% \mathrm{CI}$ & P-value & B $^{\#}$ & $95 \% \mathrm{CI}$ & P-value \\
\hline \multicolumn{7}{|l|}{ MODEL } \\
\hline Age (yr) & $4.32^{\mathrm{F}}-03$ & $\begin{array}{l}-4.17^{\mathrm{f}}-02- \\
5.03^{\mathrm{E}}-02\end{array}$ & 0.841 & $-6.28^{E}-02$ & $-0.18-5.17^{\mathrm{E}}-02$ & 0.242 \\
\hline \multicolumn{7}{|l|}{ Gender: } \\
\hline Male & 0 & 0 & & 0 & 0 & \\
\hline Female & -0.14 & $-1.22-0.94$ & 0.781 & -0.76 & $-3.88-2.35$ & 0.587 \\
\hline Delta FFM (kg) & $4.95^{\mathrm{l}}-02$ & $-9.39^{2}-02-0.19$ & 0.464 & 0.67 & $0.14-1.21$ & 0.020 \\
\hline Delta FM $(\mathrm{kg})$ & $4.38^{\mathrm{E}}-02$ & $-0.18-0.27$ & 0.676 & 0.16 & $-0.16-0.49$ & 0.283 \\
\hline Delta Insulin $\left(\mu \mathrm{U} \cdot \mathrm{ml}^{-1}\right)^{*}$ & $-6.12^{\mathrm{E}}-02$ & $-0.14-1.47^{\mathrm{E}}-02$ & 0.105 & $3.24^{\mathrm{E}}-02$ & $-0.14-0.20$ & 0.676 \\
\hline Delta Leptin $(\mathrm{ng} / \mathrm{ml})^{*}$ & $6.05^{\mathrm{E}}-02$ & $9.70^{\mathrm{E}}-03-0.11$ & 0.023 & $1.04^{\mathrm{E}}-02$ & $-0.16-0.18$ & 0.889 \\
\hline
\end{tabular}

"Values are entered in the model after being In-transformed; " unstandardized beta-coefficient; FFM fat-free mass, FM fat mass, CI confidence interval.

Univariate regression analysis, indicated a positive correlation between the decrease in leptin and the decrease in ATGL protein level after weight reduction $(\mathrm{P}<0.05)$ whilst age, gender, changes in body composition (FM, FFM) and insulin were not significantly related to changes in ATGL protein level (all $\mathrm{P}>0.10$ ). Multivariate 
[Chapter 4

regression analysis (see Table 3 ) indicated the same positive correlation between the decrease in leptin and the decrease in ATGL protein level after weight reduction (beta-coefficient: $6.05^{\mathrm{E}}-02, \mathrm{P}=0.023$; see Table 3 ). In addition, univariate regression analysis indicated a positive correlation between the decrease in FFM and the decrease in HSL protein level after weight reduction $(\mathrm{P}<0.05)$ whilst age, gender, changes in fat mass, circulating levels of insulin and leptin were not significantly related to changes in HSL protein level (all $P>0.10$ ). Multivariate regression analysis (see Table 3) indicated the same positive correlation between the decrease in FFM and decrease in HSL protein level after weight reduction (beta-coefficient: $0.67, \mathrm{P}=0.020$; see Table 3).

A

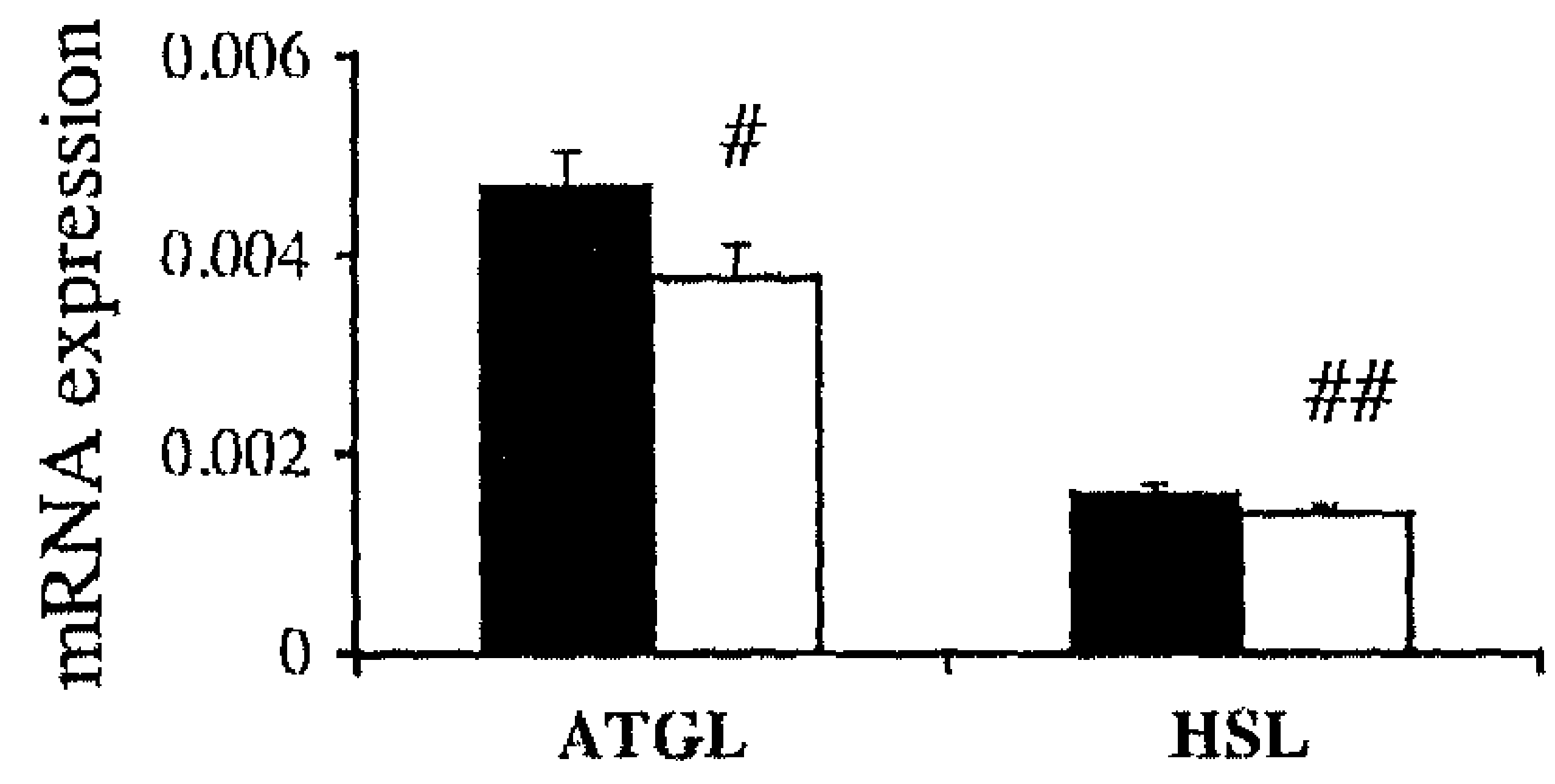

B

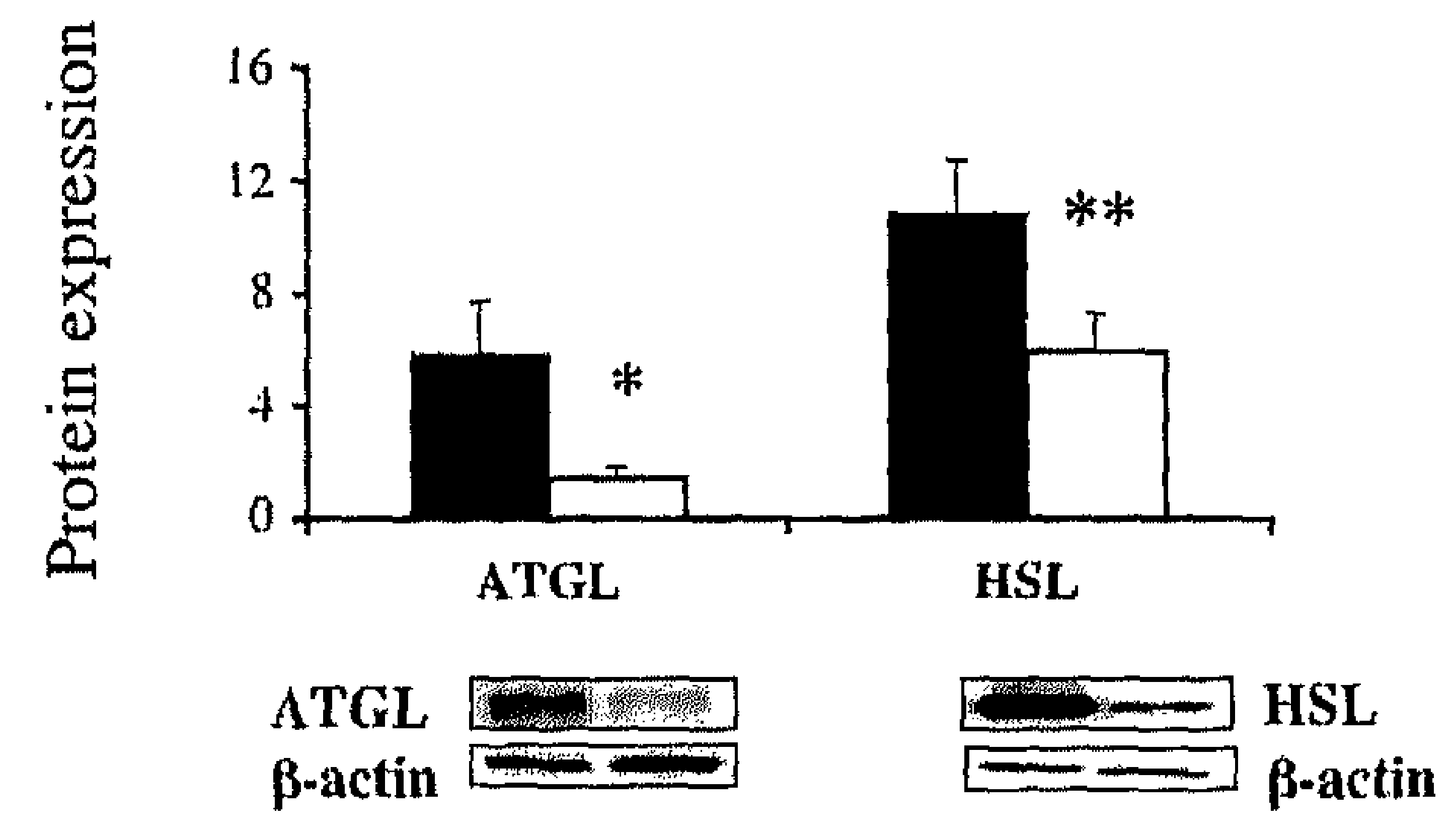

Figure 3. ATGL and HSL mRNA (panel A) and protein expression (panel B) before (black bars, and after (white bars, $\square$ ) a 10-week hypocaloric diet. (A) The hypocaloric diet resulted in a significantly decreased ATGL and HSL mRNA expression $(n=26 ; \# P=0.001$ and \#\# $P=0.007$, respectively). mRNA levels were quantified by $R T-q P C R$ and normalized with $18 S \mathrm{SRNA}$. (B) In line, a significantly decreased ATGL and HSL protein expression was observed after the diet $\left({ }^{*} \mathrm{P}=0.04\right.$ and ** $P=0.023$, respectively). ATGL and HSL protein expression was quantified using Western blot and expression was related to the structural protein beta-actin. Before versus after using Student's paired ttest statistics. Values are mean \pm SEM.

Finally, the correlation between ATGL and HSL protein levels found during habitual dietary conditions was also observed after a 10-week hypocaloric diet (betacoefficient: $0.99, \mathrm{r}=0.484, \mathrm{P}<0.0001$ ). Also, changes in ATGL and HSL induced by 
ATGL and HSL in obesity]

weight loss highly correlated to each other (beta-coefficient: 1.01, $\mathrm{r}=0.503$, $\mathrm{P}=0.004$; see Figure 4). This coordinated variation in ATGL and HSL expression during various dietary conditions suggests that the two enzymes share a common regulatory network.

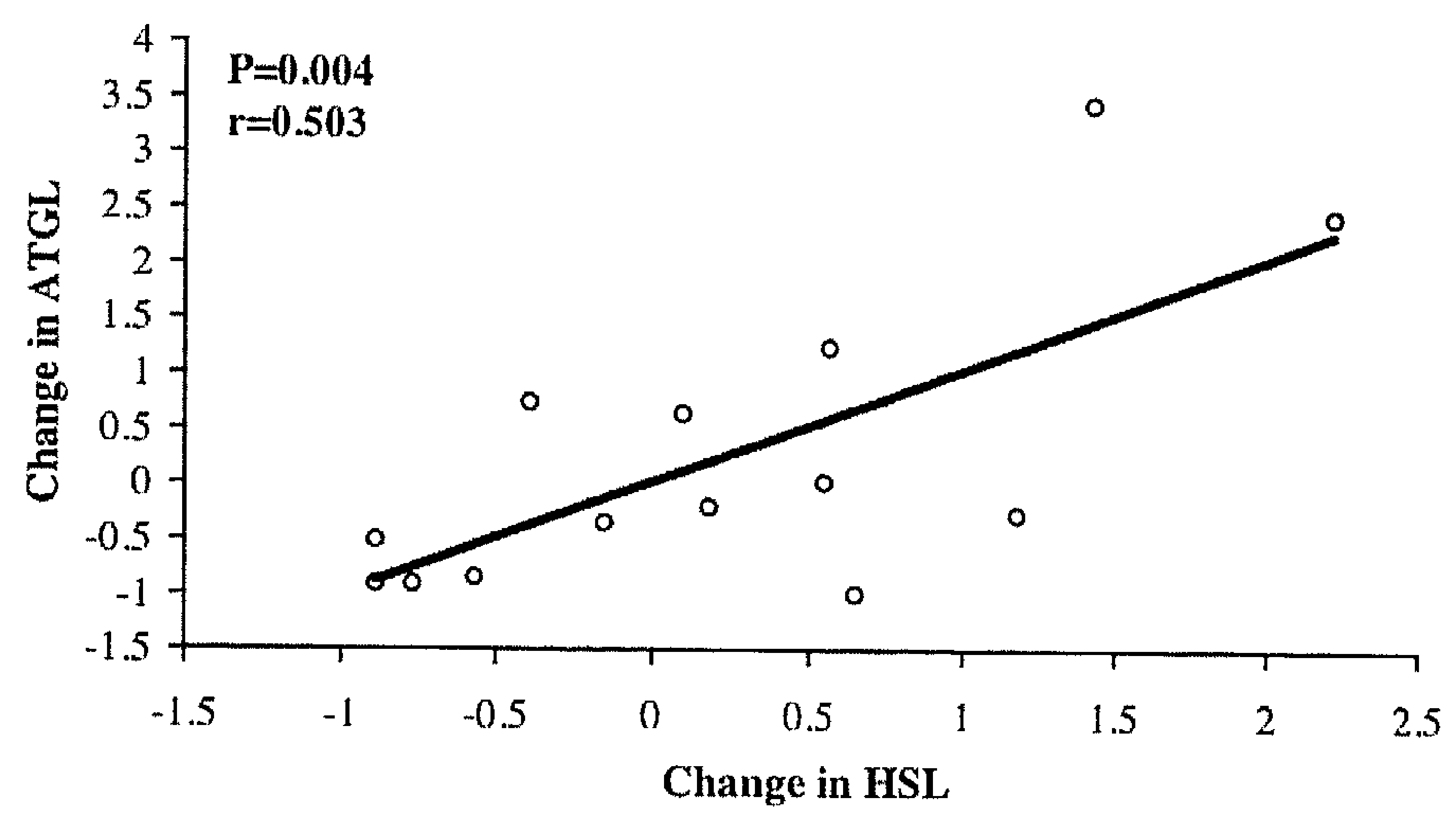

Figure 4. Correlation between change in ATGL and HSL protein levels after a hypocaloric diet. ATGL and HSL protein levels were measured before and after a 10-week hypocaloric diet using Western blot analysis (Values are Adj.Vol. OD* $\mathrm{mm} 2$ ). The changes are calculated as follows for each individual: (protein level after the diet - protein level before the diet)/protein level before the diet.

\section{ATGL and HSL MRNA expression after the diet}

In line with the protein expression data a 10 -week hypocaloric diet significantly lowered adipose tissue ATGL $(\mathrm{P}=0.001)$ and HSL $(\mathrm{P}=0.007)$ mRNA expression, see Figure 3A. Low-fat and medium-fat diets resulted in similar changes in ATGL and HSL mRNA expression. A strong positive correlation was found between ATGL and HSL mRNA expression after the diet (beta-coefficient: 0.761, $\mathrm{r}=0.578$, $\mathrm{P}<0.0001)$. The changes in ATGL and HSL mRNA expression induced by weight loss tended to correlate positively $(\mathrm{P}=0.135)$.

\section{Discussion}

Our study, for the first time, examined the relationship between adipose tissue ATGL and HSL mRNA and protein expression, and whole-body insulin sensitivity in a group of obese subjects. The major finding of the present study is that a reduced ATGL and HSL mRNA and protein expression is associated with insulin 


\section{[Chapter 4}

resistance independent of fat mass. Weight reduction decreased, rather than increased ATGL and HSL mRNA and protein expression. When ATGL and HSL protein expression was corrected for mean FCV or FCW the differences between groups remained significant. In addition, ATGL and HSL mRNA and protein expression seem to be tightly coregulated in adipose tissue, suggesting that they belong to a common regulatory network.

Our data indicate that the degree of insulin resistance and hyperinsulinemia in obesity rather than the increase in fat mass and body fat distribution per se is associated with a reduced ATGL and HSL protein and mRNA level. Since we only studied expression in abdominal subcutaneous fat we cannot rule out depot-specific differences in ATGL and HSL expression. For instance, it has been shown that HSL mRNA expression is significantly different in subcutaneous and visceral adipose tissue, a finding that could not be confirmed for ATGL mRNA expression (26). There is accumulating evidence from in vitro and animals studies that insulin reduces HSL and ATGL expression. It is documented that insulin downregulates ATGL and HSL mRNA levels in 3T3-L1 adipocytes in a dose dependent manner $(15,16,18)$. More interestingly, ATGL is downregulated in a mouse model for insulin resistance by $50 \%$ (39). In accordance, our data indicate a $72 \%$ reduction in adipose tissue ATGL protein levels of insulin resistant compared to insulin sensitive obese subjects. Moreover, HSL mRNA levels are increased in adipocytes from insulin-deficient streptozotocin-treated rats as compared to controls suggesting a negative effect of insulin on HSL expression (35).

Weight reduction decreased, rather than increased ATGL and HSL protein and mRNA expression levels with no effect of diet composition and independent of changes in fat mass. This seems consistent with Viguerie et al. reporting a similar decrease in HSL mRNA for the low-fat and medium-fat diet (38). This downregulation of key enzymes for triacylglycerol breakdown and the increase in lipoprotein lipase mRNA level after weight loss (14), potentially enhances lipid storage and making further weight loss more difficult. In contrast, Mairal et al. showed that adipose tissue ATGL mRNA expression was unchanged and HSL mRNA expression increased after long-term weight reduction in obese subjects (26). It should be mentioned that in this study the second biopsy was taken 2-4 years after surgery. A factor explaining the inconsistent findings may be that different conditions are compared. In the present study subjects were investigated while still on the energyrestricted diet (second biopsy taken just at the end of the diet). The negative energy balance produced by the energy-restricted diet is known to profoundly modify adipocyte metabolism, particular the lipolytic pathway, making it impossible to differentiate between the chronic effect of weight reduction per se and the acute effect of energy restriction. Interestingly, the decrease in leptin correlated positively with the decrease in ATGL expression after energy restriction, independent of changes in fat mass, fat-free mass and circulating insulin levels. Flier et al. advocate that this decrease in leptin concentration serves as an important signal from fat to the brain that the body is starving (6). In addition, it has been proposed that an important function of leptin is to confine storage of triacylglycerols to adipocytes (i.e. to affect adipose tissue lipolysis) and to prevent triacylglycerol storage in non-adipocytes (e.g. myocytes), protecting them from lipotoxicity (37). 
In obese subjects we observed no strict relationship between fat mass and ATGL or HSL expression, and fat cell size per se was not important for our findings. When the obese state has already developed insulin resistance and hyperinsulinemia seem to be the major determinants for ATGL and HSL protein expression. This seems in line with the observation of a negative correlation between fasting insulin and in vivo fatty acid outflow per unit of adipose tissue in insulin resistant conditions (13), suggesting that a reduced expression of ATGL and HSL may be a secondary phenomenon to insulin resistance. It can be speculated that hyperinsulinemia may downregulate adipose tissue lipolysis and thereby prevent worsening of the insulin resistant state $(1,25)$. In the present study weight loss had no significant effect on insulin sensitivity. To fully elucidate the effect of insulin resistance on ATGL and HSL expression an intervention should be performed which significantly improves insulin sensitivity (e.g. exercise training or treatment with a PPAR- \{gamma\} agonist). It has been shown that ATGL is subject to transcriptional control by PPAR\{gamma\} mediated signals (15). In addition, Festuccia et al. recently showed that treatment of mice with the PPAR-\{gamma\} agonist rosiglitazone significantly increased ATGL and HSL mRNA expression (5), indicating that an improved insulin sensitivity increases adipose tissue ATGL and HSL expression. Finally, we cannot rule out that a decreased ATGL and HSL expression is a primary defect in obesity. Interestingly, ATGL-deficient mice have an increased fat storage in adipose and non-adipose tissues (7). Further, studies in first-degree relatives of obese subjects have demonstrated an impaired lipolytic function of adipocytes, suggesting that also primary adipocyte lipolysis defects are present in obesity (11). Expression of HSL is markedly decreased in subcutaneous adipocytes and differentiated preadipocytes from obese subjects, suggesting a decreased HSL expression to be a primary defect in obesity $(21,24,32,38)$. Also several studies suggest that genetic variation in the HSL and ATGL gene are associated with obesity and type 2 diabetes mellitus (17, $33)$. Further research is needed to elucidate the exact order of events.

The coregulation between ATGL and HSL protein levels or mRNA expression (19) during different dietary conditions suggests that the two enzymes belong to a common regulatory network with tight transcriptional control. A recent study indicated that HSL is the major lipase catalyzing the rate-limiting step in stimulated lipolysis, whereas ATGL participates in basal lipolysis (19). Insufficient time has passed since the discovery of ATGL to understand the nature of its regulation. However from the limited data available, it appears that in comparison to HSL, ATGL is not a direct target for protein kinase A (PKA)-mediated phosphorylation and is localized on the lipid droplet in the basal and hormone-stimulated state of the cell (41). These observations suggest that ATGL is not activated by phosphorylation and translocation to the lipid droplet as demonstrated for HSL. Instead, an activator protein regulates ATGL activity: CGI-58 (comparative gene identification 58) (22) (34). It will be important to establish whether the decreased HSL and ATGL protein and mRNA expression observed in insulin resistant subjects is accompanied by a decreased activity of both enzymes.

In conclusion, ATGL and HSL expression are decreased in the obese insulin resistant state. When the obese state has already developed insulin resistance or hyperinsulinemia seem to be the major determinant of ATGL and HSL protein expression independent of fat mass. On the other hand, there are also indications that a reduced 


\section{[Chapter 4}

ATGL and HSL protein expression is a primary defect in obesity. Weight reduction decreased ATGL and HSL expression, independent of circulating insulin and FM, indicating that also other factors (e.g. leptin) relate to ATGL and HSL protein expression in obesity.

\section{Acknowledgments}

This study has received support from the NUGENOB project (NUtrient-GENe interaction in human OBesity - implications for dietary guidelines) supported by the European Commission (contract QLK1-CT-2000-00618), the HEPADIP project ("Hepatic and adipose tissue and functions in the metabolic syndrome") supported by the European Commission as an Integrated Project under the 6th Framework Programme (Contract LSHM-CT-2005-018734) and the Swedish Research Council (project no. 112 84).

\section{References}

1. Arner P, Bolinder J, Engfeldt P, Hellmer J, and Ostman J. Influence of obesity on the antilipolytic effect of insulin in isolated human fat cells obtained before and after glucose ingestion. J Clin Invest 73: 673-680, 1984.

2. Blaak EE, Van Baak MA, Kemerink GJ, Pakbiers MT, Heidendal GA, and Saris WH. Betaadrenergic stimulation of energy expenditure and forearm skeletal muscle metabolism in lean and obese men. Am J Physiol 267: E306-315, 1994.

3. Blaak EE, Van Baak MA, Kemerink GJ, Pakbiers MT, Heidendal GA, and Saris WH. betaAdrenergic stimulation of skeletal muscle metabolism in relation to weight reduction in obese men. Am J Physiol 267: E316-322, 1994.

4. Blaak EE, Wolffenbuttel BH, Saris WH, Pelsers MM, and Wagenmakers AJ. Weight reduction and the impaired plasma-derived free fatly acid oxidation in type 2 diabetic subjects. $J$ Clin Endocrinol Metab 86: 1638-1644, 2001.

5. Festuccia WT, Laplante M, Berthiaume M, Gelinas Y, and Deshaies Y. PPARgamma agonism increases rat adipose tissue lipolysis, expression of glyceride lipases, and the response of lipolysis to hormonal control. Diabetologia 49: 2427-2436, 2006.

6. Flier JS. Obesity wars: molecular progress confronts an expanding epidemic. Cell 116: 337-350, 2004.

7. Haemmerle G, Lass A, Zimmermann R, Gorkiewicz G, Meyer C, Rozman J, Heldmaier G, Maier R, Theussl C, Eder S, Kratky D, Wagner EF, Klingenspor M, Hoefler G, and Zechner R. Defective lipolysis and altered energy metabolism in mice lacking adipose triglyceride lipase. Science 312: 734-737, 2006.

8. Haemmerle G, Zimmermann R, Hayn M, Theussl C, Waeg G, Wagner E, Sattler W, Magin TM, Wagner EF, and Zechner R. Hormone-sensitive lipase deficiency in mice causes diglyceride accumulation in adipose tissue, muscle, and testis. $J$ Biol Chem 277: 4806-4815, 2002.

9. Haemmerle G, Zimmermann R, Strauss JG, Kratky D, Riederer M, Knipping G, and Zechner R. Hormone-sensitive lipase deficiency in mice changes the plasma lipid profile by affecting the tissue-specific expression pattern of lipoprotein lipase in adipose tissue and muscle. $J$ Biol Chem 277: 12946-12952, 2002. 
10. Harada K, Shen WJ, Patel S, Natu V, Wang J, Osuga J, Ishibashi S, and Kraemer FB. Resistance to high-fat diet-induced obesity and altered expression of adipose-specific genes in HSL-deficient mice. Am J Physiol Endocrinol Metab 285: E1 182-1 195, 2003.

11. Hellstrom L, Langin D, Reynisdottir S, Dauzats $M$, and Arner P. Adipocyte lipolysis in normal weight subjects with obesity among first-degree relatives. Diabetologia 39; 921-928, 1996.

12. Jenkins CM, Mancuso DJ, Yan W, Sims HF, Gibson B, and Gross RW. Identification, cloning, expression, and purification of three novel human calcium-independent phospholipase A2 family members possessing triacylglycerol lipase and acylglycerol transacylase activities. $J$ Biol Chem 279: 48968-48975, 2004

13. Karpe F and Tan GD. Adipose tissue function in the insulin-resistance syndrome. Biochem Soc Trans 33: 1045-1048, 2005.

14. Kern PA, Ong JM, Saffari B, and Carty J. The effects of weight loss on the activity and expression of adipose-tissue lipoprotein lipase in very obese humans. $N$ Engl J Med 322: 1053-1059, 1990.

15. Kershaw EE, Hamm JK, Verhagen LA, Peroni O, Katic M, and Flier JS. Adipose triglyceride lipase: function, regulation by insulin, and comparison with adiponutrin. Diabetes 55: 148-157, 2006.

16. Kim JY, Tillison $\mathrm{K}$, Lee JH, Rearick DA, and Smas CM. The adipose tissue triglyceride lipase ATGL/PNPLA2 is downregulated by insulin and TNF-\{alpha\} in 3T3-L1 adipocytes and is a target for transactivation by PPAR \{gamma\}. Am J Physiol Endocrinol Metab 291: E115-127, 2006.

17. Klannemark M, Orho M, Langin D, Laurell H, Holm C, Reynisdottir S, Arner P, and Groop L. The putative role of the hormone-sensitive lipase gene in the pathogenesis of Type II diabetes mellitus and abdominal obesity. Diabetologia 41: 1516-1522, 1998.

18. Kralisch S, Klein J, Lossner U, Bluher M, Paschke R, Stumvoll M, and Fasshauer M. Isoproterenol, TNFalpha, and insulin downregulate adipose triglyceride lipase in 3T3-L1 adipocytes. Mol Cell Endocrinol 240: 43-49, 2005.

19. Langin D, Dicker A, Tavernier G, Hoffstedt J, Mairal A, Ryden M, Arner E, Sicard A, Jenkins CM, Viguerie N, van Harmelen V, Gross RW, Holm C, and Arner P. Adipocyte lipases and defect of lipolysis in human obesity. Diabetes 54: 3190-3197, 2005.

20. Large V, Arner P, Reynisdottir S, Grober J, Van Harmelen V, Holm C, and Langin D. Hormonesensitive lipase expression and activity in relation to lipolysis in human fat cells. $J$ Lipid Res 39: 1688-1695, 1998.

21. Large V, Reynisdottir S, Langin D, Fredby K, Klannemark M, Holm C, and Arner P. Decreased expression and function of adipocyte hormone-sensitive lipase in subcutaneous fat cells of obese subjects. J Lipid Res 40: 2059-2066, 1999.

22. Lass A, Zimmermann R, Haemmerle G, Riederer M, Schoiswohl G, Schweiger M, Kienesberger $P$, Strauss JG, Gorkiewicz G, and Zechner R. Adipose triglyceride lipase-mediated lipolysis of cellular fat stores is activated by CGI-58 and defective in Chanarin-Dorfman Syndrome. Cell Metab 3: 309-319, 2006 .

23. Lofgren P, Andersson I, Adolfsson B, Leijonhufvud BM, Hertel K, Hoffstedt J, and Arner P. Long-term prospective and controlled studies demonstrate adipose tissue hypercellularity and relative leptin deficiency in the postobese state. J Clin Endocrinol Metab 90: 6207-6213, 2005.

24. Lofgren P, Hoffstedt J, Ryden M, Thorne A, Holm C, Wahrenberg H, and Arner P. Major gender differences in the lipolytic capacity of abdominal subcutaneous fat cells in obesity observed before and after long-term weight reduction. J Clin Endocrinol Metab 87: 764-771, 2002.

25. Lonnroth $P$, Digirolamo $M$, Krotkiewski $M$, and Smith U. Insulin binding and responsiveness in fat cells from patients with reduced glucose tolerance and type II diabetes. Diabetes 32: 748-754, 1983.

26. Mairal A, Langin D, Arner P, and Hoffstedt J. Human adipose triglyceride lipase (PNPLA2) is not regulated by obesity and exhibits low in vitro triglyceride hydrolase activity. Diabetologia 49: $1629-1636,2006$ 


\section{[Chapter 4}

27. Matthews DR, Hosker JP, Rudenski AS, Naylor BA, Treacher DF, and Turner RC. Homeostasis model assessment: insulin resistance and beta-cell function from fasting plasma glucose and insulin concentrations in man. Diabetologia 28: 412-419, 1985.

28. Mulder H, Sorhede-Winzell M, Contreras JA, Fex M, Strom K, Ploug T, Galbo H, Arner P, Lundberg $C$, Sundler F, Ahren B, and Holm C. Hormone-sensitive lipase null mice exhibit signs of impaired insulin sensitivity whereas insulin secretion is intact. J Biol Chem 278: 36380-36388, 2003.

29. Osuga J, Ishibashi S, Oka T, Yagyu H, Tozawa R, Fujimoto A, Shionoiri F, Yahagi N, Kraemer FB, Tsutsumi $O$, and Yamada $N$. Targeted disruption of hormone-sensitive lipase results in male sterility and adipocyte hypertrophy, but not in obesity. Proc Natl Acad Sci U S A 97: 787-792, 2000.

30. Petersen M, Taylor MA, Saris WH, Verdich C, Toubro S, Macdonald I, Rossner S, Stich V, GuyGrand B, Langin D, Martinez JA, Pedersen O, Holst C, Sorensen TI, and Astrup A. Randomized, multi-center trial of two hypo-energetic diets in obese subjects: high-versus low-fat content. Int $J$ Obes (Lond), 2005.

31. Reynisdottir S, Langin D, Carlstrom K, Holm C, Rossner S, and Anner P. Effects of weight reduction on the regulation of lipolysis in adipocytes of women with upper-body obesity. Clin Sci (Lond) 89: 421-429, 1995.

32. Reynisdottir S, Wahrenberg H, Carlstrom K, Rossner S, and Arner P. Catecholamine resistance in fat cells of women with upper-body obesity due to decreased expression of beta 2-adrenoceptors. Diabetologia 37: 428-435, 1994.

33. Schoenborn V, Heid IM, Vollmert C, Lingenhel A, Adams TD, Hopkins PN, Illig T, Zimmermann $\mathrm{R}$, Zechner R, Hunt SC, and Kronenberg F. The ATGL gene is associated with free fatty acids, triglycerides, and type 2 diabetes. Diabetes 55: 1270-1275, 2006.

34. Schweiger M, Schreiber R, Haemmerle G, Lass A, Fledelius C, Jacobsen P, Tornqvist H, Zechner $\mathrm{R}$, and Zimmermann $\mathrm{R}$. Adipose triglyceride lipase and hormone-sensitive lipase are the major enzymes in adipose tissue triacylglycerol catabolism. J Biol Chem, 2006.

35. Sztalryd $\mathrm{C}$ and Kraemer FB. Regulation of hormone-sensitive lipase in streptozotocin-induced diabetic rats. Metabolism 44: 1391-1396, 1995.

36. Tehard B, Saris WH, Astrup A, Martinez JA, Taylor MA, Barbe P, Richterova B, Guy-Grand B, Sorensen TI, and Oppert JM. Comparison of two physical activity questionnaires in obese subjects: the NUGENOB study. Med Sci Sports Exerc 37: 1535-1541, 2005.

37. Unger RH, Zhou YT, and Orci L. Regulation of fatty acid homeostasis in cells: novel role of leptin. Proc Natl Acad Sci US A 96: 2327-2332, 1999.

38. Viguerie N, Vidal H, Arner P, Holst C, Verdich C, Avizou S, Astrup A, Saris WH, Macdonald IA, Klimcakova E, Clement K, Martinez A, Hoffstedt J, Sorensen TI, and Langin D. Adipose tissue gene expression in obese subjects during low-fat and high-fat hypocaloric diets. Diabetologia 48: 123-131, 2005.

39. Villena JA, Roy S, Sarkadi-Nagy E, Kim KH, and Sul HS. Desnutrin, an adipocyte gene encoding a novel patatin domain-containing protein, is induced by fasting and glucocorticoids: ectopic expression of desnutrin increases triglyceride hydrolysis. J Biol Chem 279: 47066-47075, 2004.

40. Zimmermann R, Haemmerle G, Wagner EM, Strauss JG, Kratky D, and Zechner R. Decreased falty acid esterification compensates for the reduced lipolytic activity in hormone-sensitive lipasedeficient white adipose tissue. J Lipid Res 44: 2089-2099, 2003.

41. Zinmermann R, Strauss JG, Haemmerle G, Schoiswohl G, Birner-Gruenberger R, Riederer M, Lass A, Neuberger G, Eisenhaber F, Hermetter A, and Zechner R. Fat mobilization in adipose tissue is promoted by adipose triglyceride lipase. Science 306: 1383-1386, 2004. 


\section{HSL serine phosphorylation and glycerol exchange across skeletal muscle in lean and obese subjects: effect of beta-adrenergic stimulation}

Jocken JWE ${ }^{1}$, Roepstorff $C^{2}$, Goossens $\mathrm{GH}^{1}$, van der Baan $\mathrm{P}^{1}$, van Baak $\mathrm{MA}^{1}$, Saris WHM${ }^{1}$, Kiens $\mathrm{B}^{2}$ and Blaak $\mathrm{EE}^{1}$

'Department of Human Biology, Nutrition and Toxicology Research Institute Maastricht (NUTRIM), Maastricht University, Maastricht, The Netherlands

${ }^{2}$ The Copenhagen Muscle Research Centre, Department of Human Physiology, Institute of Exercise and Sport Sciences, University of Copenhagen, Copenhagen, Denmark

Diabetes (revised) 
[Chapter 5

\begin{abstract}
Background: Increased intramuscular triacylglycerol (IMTAG) storage is a characteristic of the obese insulin resistant state. We aimed to investigate whether a blunted fasting or betaadrenergically mediated lipolysis contributes to this increased IMTAG storage in obesity.
\end{abstract}

Methods: Forearm skeletal muscle (SM) lipolysis was investigated in thirteen lean and ten obese men using $\left[{ }^{2} \mathrm{H}_{5}\right]$-glycerol combined with the measurement of arterio-venous differences before and during beta-adrenergic stimulation using the nonselective beta-agonist isoprenaline. Muscle biopsies were taken from the vastus lateralis muscle before and during ISO to investigate HSL protein expression and serine phosphorylation.

Results: Baseline total glycerol release across the forearm was significantly blunted in obese compared with lean subjects $(\mathrm{P}<0.05)$. The reduced baseline SM lipolysis in obese subjects was accompanied by lower HSL protein expression $(\mathrm{P}<0.05)$, and HSL phosphorylation on PKA sites $\operatorname{Ser}^{563}(\mathrm{P}<0.05)$ and $\operatorname{Ser}^{659}(\mathrm{P}=0.09)$ and on the AMPK site $\operatorname{Ser}^{565}(\mathrm{P}<0.05)$. Total forearm glycerol uptake during baseline did not differ significantly between groups while higher net fatty acid uptake across the forearm was observed in the obese $(\mathrm{P}<0.05)$. ISO induced an increase in total glycerol release from SM $(\mathrm{P}<0.05)$, which was not significantly different between groups. Interestingly, this was accompanied by an increase in HSL Ser ${ }^{659}$ phosphorylation in obese subjects during ISO compared with baseline $(\mathrm{P}<0.01)$.

Conclusions: Obesity is accompanied by impaired baseline SM lipolysis and lower HSL protein expression and serine phosphorylation. It remains to be determined whether this is a primary factor or an adaptational response to the obese insulin resistant state. 


\section{Introduction}

The obese insulin resistant state is characterized by incrased triatylycerol t TACi storige in adipose and non-adipose tissues tectopie latt, sth as skeletal muscle (34). A strong link between increased intramuscular triacy lglycerol (IMTAG) stores and skeletal muscle insulin resintance has heen shown in lean and obese subjects 118. 28. Recent studies have, houever, indicated that intramuscular accumulation of lipid intermediates rather than IAG per se may he the direct cause of skeletal muscle insulin resistance. through interference with insulin signaling $29 \%$. Impaired uptake and a reduced oxidation of fatty acids has been reported in skeletal musele under post-absorptive conditions, during heta-adrenergic stimulation and in moderate-intensity exercise in obere subjects with type 2 diabetes $(3,4,17)$. Besides these disturbances, an impaired regulation of skeletal muscle lipolysis mat contribute to the increased IMTAG and lipid metaholites. So far, little is known on the in vivo regulation of skeletal muscle lipolysis in ohesity. Data from our laboratory indicate that the catecholamine-induced increase in interstitial glycerol concentration as well as local blood flow is blunted in obese subjects $(5)$. a factor that may contribute to an increase in content of tissue TAG and diacylglycerol (DAG).

Although the molecular mechanisms that underlie muscle lipolysis are not known into detail, it has been shown that hormone-sensitive lipase (HSL) is expressed in skeletal muscle in rats $(19,20)$ and humans $(32)$. HSL activity appears to be regulated by site-specific phosphorylation on several serine residues. It has been demonstrated that skeletal muscle HSL can be phosphorylated on at least five serine resi-

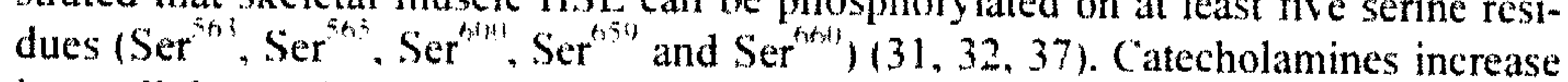
intracellular cyclic AMP concentration resulting in the activation of protein kinase

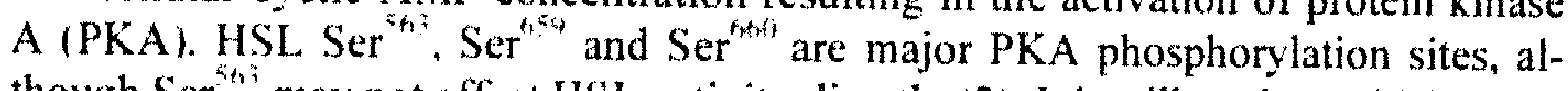
though Ser ${ }^{3 / 2}$ may not affect HSL activity directly (2). It is still unclear which of the PKA phosphorylation sites on HSL are important in mediating the effect of catecholamines on in vivo muscle HSL activity. Ser ${ }^{6: 4}$ appears to be a likely candidate, since HSL Ser ${ }^{\text {t. } 4}$ phosphorylation and HSL activity show a similar response to exercise with concomitant increase in circulating epinephrine (31). In vitro studies on purified bovine adipocyte HSL have shown that AMP-activated protein kinase (AMPK) phosphorylates HSL on Ser ${ }^{569}$ thereby abolishing PKA induced HSL activation (12). In human skeletal muscle, changes in AMPK activity during exercise were also associated with an increased HSL Ser ${ }^{565}$ phosphorylation but this was not accompanied by an increased HSL activity, suggesting that AMPK can phosphorylate HSL on Ser $^{567}$ but that AMPK is of minor importance as a regulator of HSL activity in human skeletal muscle during exercise (32).

So far, limited data are available on the differences in in vivo regulation of skeletal muscle lipolysis between lean and obese subjects. The aim of the present study was to investigate whether in vivo baseline and/or catecholamine-induced lipolysis is impaired in skeletal muscle of obese compared with lean subjects. For this reason $\left[{ }^{2} \mathrm{H}_{5}\right]$-glycerol tracer methodology was used to investigate in vivo whole-body and regional forearm skeletal muscle lipolysis in lean and obese subjects after an overnight fast and during beta-adrenergic stimulation. using the non-selective betaadrenergic agonist isoprenaline. To obtain more information on the underlying 
[Chapter 5

mechanism at the molecular level, we measured skeletal muscle HSL protein expression and serine phosphorylation on $\mathrm{Ser}^{563}, \mathrm{Ser}^{565}$ and $\mathrm{Ser}^{659}$.

\section{Material and methods}

\section{Subjects}

Three healthy lean $\left(2 \mathrm{~F} / 1 \mathrm{M}\right.$; Age $20 \pm 1 \mathrm{yr}$; BMI $\left.22.3 \pm 1.1 \mathrm{~kg} / \mathrm{m}^{2}\right)$ subjects participated in a pilot experiment during which $\left[{ }^{2} \mathrm{H}_{5}\right]$-glycerol enrichment was investigated during $6 \mathrm{~h}$ infusion in order to determine the time required to achieve an isotopic steady-state. Thirteen lean and ten obese non-smoking normotensive male subjects participated in the actual muscle lipolysis experiment during which $\left[{ }^{2} \mathrm{H}_{5}\right]$-glycerol was infused for $3 \mathrm{~h}$. Clinical characteristics of the subjects included in the experiment are summarized in Table 1. Body weight and body density (by hydrostatic weighing), used for calculations of percentage body fat (\%BF), fat mass (FM) and fat-free mass (FFM), were determined after an overnight fast, as previously described (13). All subjects were in good health as assessed by medical history, were free of any medication and spent no more than $3 \mathrm{~h}$ a week in organized sports activities. The Medical Ethical Committee of Maastricht University approved the study protocol, and all subjects gave their written informed consent before participating in the study.

Table 1. Subjects' characteristics

\begin{tabular}{lcc}
\hline & Lean $(\mathrm{n}=13)$ & Obese $(\mathrm{n}=10)$ \\
\hline Age $(\mathrm{yr})$ & $43 \pm 3$ & $54 \pm 3$ \\
BMI $\left(\mathrm{kg} / \mathrm{m}^{2}\right)$ & $23.0 \pm 0.5$ & $31.9 \pm 0.6^{\prime}$ \\
BF\% $(\mathrm{kg})$ & $20.2 \pm 1.0$ & $31.7 \pm 0.5^{\prime}$ \\
FFM $(\mathrm{kg})$ & $60.1 \pm 1.5$ & $69.7 \pm 2.1^{\prime}$ \\
WHR & $0.91 \pm 0.01$ & $1.01 \pm 0.01^{\prime}$ \\
SBP $(\mathrm{mmHg})$ & $126 \pm 3$ & $137 \pm 4$ \\
DBP $(\mathrm{mmHg})$ & $77 \pm 2$ & $85 \pm 3$ \\
HOMA & $1.8 \pm 0.2$ & $3.4 \pm 0.3^{\prime}$ \\
\hline
\end{tabular}

BMI, body mass index $\left(\mathrm{kg} / \mathrm{m}^{2}\right)$; BF\%, body fat percentage; FFM, fat-free mass; WHR, waist to hip ratio; SBP, systolic blood pressure $(\mathrm{mmHg})$; $\mathrm{DBP}$, diastolic blood pressure $(\mathrm{mmHg})$; HOMA $\mathrm{IR}$, homeostasis model assessment for insulin resistance; ${ }^{1} \mathrm{P}<0.05$ obese vs. lean using; Values are mean $\pm \mathrm{SEM}$.

\section{Experimental protocol}

In a pilot study in 3 subjects, the time course of $\left[{ }^{2} \mathrm{H}_{5}\right]$-glycerol enrichment was determined to investigate when steady-state levels were achieved. Glycerol enrichment was measured in arterialized blood and venous blood draining the forearm during primed $\left(3 \mu \mathrm{mol} . \mathrm{kg}^{-1}\right)$ constant infusion of $\left[{ }^{2} \mathrm{H}_{5}\right]$-glycerol $\left(0.20 \mu \mathrm{mol} . \mathrm{kg}^{-1}\right.$. $\mathrm{min}^{-1}$ ) for $6 \mathrm{~h}$. Blood samples were taken simultaneously from the two sites, at base- 
line for background enrichment $(\mathrm{t} 0)$ and at ten time points during $\left[{ }^{2} \mathrm{H}_{5}\right]$-glycerol infusion ( $\mathrm{t} 60, \mathrm{t} 90, \mathrm{t} 120, \mathrm{t} 150, \mathrm{t} 180, \mathrm{t} 210, \mathrm{t} 240, \mathrm{t} 330, \mathrm{t} 345, \mathrm{t} 360)$.

During the actual muscle lipolysis experiment, glycerol enrichment and exchange across the forearm were investigated during primed $\left(3 \mu \mathrm{mol} . \mathrm{kg}^{-1}\right)$ constant infusion of $\left.{ }^{2} \mathrm{H}_{5}\right]$-glycerol $\left(0.20 \mu \mathrm{mol} . \mathrm{kg}^{-1}\right.$. $\left.\mathrm{min}^{-1}\right)$ for $3 \mathrm{~h}$. Following a $120 \mathrm{~min}$ baseline period, isoprenaline (ISO) was infused at a rate of $20 \mathrm{ng}$. kg FFM ${ }^{-1} \cdot \min ^{-1}$ for $60 \mathrm{~min}$. At this infusion rate plasma ISO concentrations are comparable in lean and obese subjects (6). At the beginning of the experiment an arterialized blood sample was taken for measurement of background enrichment. Furthermore, arterialized and deep venous blood samples were taken simultaneously at three baseline time points (t90, t105 and t120) and at three time points during the last 30 min of ISO infusion $(\mathrm{t} 150, \mathrm{t} 165$ and t180). In both the pilot and muscle lipolysis experiment, forearm blood flow (FBF) was measured just before blood sampling to calculate substrate fluxes across the forearm (see forearm blood flow). Skeletal muscle biopsies were taken from the vastus lateralis muscle under local anesthesia of the skin and fascia (Xylocaine ${ }^{\circledR}$, AstraZeneca BV, Zoetermeer, The Netherlands) immediately before the baseline period $(\mathrm{t} 0)$ and just before the end of ISO infusion ( $\mathrm{t} 180)$. Muscle biopsies were immediately frozen in liquid nitrogen and stored at $-80^{\circ} \mathrm{C}$ until further analysis. During the experiment, heart rate was recorded continuously by means of a three-lead electrocardiogram (ECG). When heart rate increased more than 30 beats/min or in case of ECG irregularities, ISO infusion was stopped. This occurred in one lean and one obese subject.

\section{Clinical methods}

All subjects were asked to refrain from drinking alcohol and to perform no strenuous exercise for a period of $24 \mathrm{~h}$ before the experiment. Subjects came to the laboratory by car or bus at 8 a.m. after an overnight fast. Before initiating the experiment a catheter was inserted retrogradely into a superficial dorsal hand vein to obtain tained at $60^{\circ} \mathrm{C}$ to blood. The hand was warmed in a hotbox, which was maintained at $60^{\circ} \mathrm{C}$ to achieve adequate arterialization (1). In the same arm, a second catheter was inserted in a forearm antecubital vein for the infusion of $\left[{ }^{2} \mathrm{H}_{5}\right]$-glycerol tracer and ISO. In the contralateral arm, a third catheter was introduced retrogradely in an antecubital vein of the forearm for sampling of deep venous blood, draining forearm skeletal muscle. The subjects rested in a supine position for the entire duration of the study.

\section{Forearm blood flow (FBF)}

FBF was measured by venous occlusion plethysmography (EC5R plethysmograph, Hokanson, Bellevue, USA) using mercury-in-silastic strain gauges applied to the widest part of the forearm (38). During measurement periods, the hand circulation was occluded by rapid inflation of a sphygmomanometer cuff (E20 rapid cuff inflator, Hokanson, Bellevue, USA) placed around the wrist to a pressure of $200 \mathrm{mmHg}$. In this way, FBF can be assessed without interference of the hand circulation. A second cuff, placed just above the anticubital fossa, was inflated to $45 \mathrm{mmHg}$ (which was lower than the diastolic blood pressure, which was $>70 \mathrm{mmHg}$ in all subjects) to achieve venous occlusion and obtain plethysmographic recordings. 
[Chapter 5

During venous occlusion, the plethysmographic recordings reflect the rate of arterial inflow, indicating FBF.

\section{Muscle lysates}

Muscle tissue was freeze-dried, dissected free of all visible adipose tissue, connective tissue, and blood under a microscope, and was subsequently homogenized $(1: 80 \mathrm{w} / \mathrm{v})$ in a buffer containing $50 \mathrm{mM}$ HEPES (pH 7.5), $150 \mathrm{mM} \mathrm{NaCl}, 20 \mathrm{mM}$ sodium pyrophosphate, $20 \mathrm{mM}$ L-glycerophosphate, $10 \mathrm{mM} \mathrm{NaF}, 2 \mathrm{mM}$ sodium orthovanadate, $2 \mathrm{mM}$ EDTA, $1 \%$ Nonidet P-40, 10\% glycerol, $2 \mathrm{mM}$ PMSF, $1 \mathrm{mM}$ $\mathrm{MgCl}_{2}, 1 \mathrm{mM} \mathrm{CaCl}, 10 \mu \mathrm{g} / \mathrm{ml}$ leupeptin, $10 \mu \mathrm{g} / \mathrm{ml}$ aprotinin, and $3 \mathrm{mM}$ benzamidine. Homogenates were rotated end over end for $1 \mathrm{~h}$ at $4^{\circ} \mathrm{C}$ and then cleared by centrifugation for $1 \mathrm{~h}$ at $17500 \mathrm{~g}, 4^{\circ} \mathrm{C}$. Protein content in the supernatant was measured by the bicinchoninic acid (BCA) protein assay (Pierce, Illinois, USA).

\section{Western blotting}

Expression of HSL as well as phosphorylation of HSL Ser ${ }^{563}, \mathrm{Ser}^{565}$ and $\mathrm{Ser}^{659}$ were detected by Western blotting on the muscle lysates. The lysates were boiled in Laemmli buffer before being subjected to SDS-PAGE and immunoblotting. Primary antibodies were rabbit anti-HSL (kindly donated by Prof. dr. Cecilia Holm, Dept. of Cell and Molecular Biology, Lund University, Sweden) and sheep antiphospho HSL Ser ${ }^{563}$, sheep anti-phosho HSL $\operatorname{Ser}^{565}$ (32) and sheep anti-phosho HSL $\operatorname{Ser}^{659}(31)$. Secondary antibodies were horseradish peroxidase-conjugated anti-rabbit (cat. no. P0448 DAKO, Glostrup, Denmark), and anti-sheep (cat. no. 818620; Zymed, CA, USA). Antigen-antibody complexes were visualized using enhanced chemiluminescence (ECL+, Amersham Biosciences, UK) and quantified by a Kodak Image Station E440CF (Kodak, Glostrup, Denmark).

\section{Analytical methods}

A small portion of blood was used for the measurement of oxygen saturation $\left(\% \mathrm{HbO}_{2}\right)$ to ensure adequate arterialization (ABL510, Radiometer, Copenhagen, Denmark). Blood was collected in tubes containing EDTA and centrifuged for 10 min at $1000 \mathrm{~g}, 4^{\circ} \mathrm{C}$. The supernatant (plasma) was used for the enzymatic colorimetric quantification of fatty acids (NEFA C kit; Wako Chemicals, Neuss, Germany), free glycerol (Boehringer, Mannheim, Germany) and triacylglycerol (TAG, Sigma, St Louis, USA) on a COBAS FARA centrifugal spectrophotometer (Roche Diagnostica, Basel, Switzerland). Plasma glucose concentration (ABX Diagnostics, Montpellier, France) and lactate (ABX diagnostics) were measured enzymatically on a COBAS MIRA automated spectrophotometer (Roche Diagnostica). Plasma insulin was measured with a double antibody radioimmunoassay (Linco Research Inc., St. Charles, Missouri, USA). Insulin sensitivity was assessed by the homeostasis model assessment index for insulin resistance $\left(\mathrm{HOMA}_{\mathrm{IR}}\right)$, calculated from baseline glucose and insulin (25). Hematocrit was measured using a microcapillary system (Hirschmann Laborgeräte GmbH \& CoKG, Eberstadt, Germany). 


\section{Isotope enrichment}

To determine isotopic enrichment of glycerol, samples were first derivatized. $1 \mathrm{ml}$ acetone was added to $150 \mu \mathrm{L}$ plasma and each tube was vortexed for $2 \mathrm{~min}$ and centrifuged for $20 \mathrm{~min}$ at $17500 \mathrm{~g}, 4^{\circ} \mathrm{C}$. The supernatant was transferred to a clean tube, dried under nitrogen at $37^{\circ} \mathrm{C}$ and derivatized using $80 \mu \mathrm{L}$ ethyl acetate (cat. no. 45765, Sigma-Aldrich $\mathrm{GmbH}$, Seelze, Germany) and $80 \mu \mathrm{L}$ heptafluorobutyric acid anhydride (HFAA; cat. no. 63164, Pierce Biotechnology, Rockford, IL, USA). The tubes were vortexed for $2 \mathrm{~min}$ and incubated for $1 \mathrm{~h}$ at $70^{\circ} \mathrm{C}$. Samples were then rotated end over end for $5 \mathrm{~min}, 25^{\circ} \mathrm{C}$ and evaporated under nitrogen at room temperature. $70 \mu \mathrm{L}$ of ethyl acetate was added before injection into the GC-MS (Finnigan MAT 252, Bremen, Germany) for measurement of glycerol enrichment by selectively monitoring the mass-to-charge ratio $(\mathrm{m} / \mathrm{z})$ of molecular ions 253 and 257 for glycerol (8).

\section{Calculations}

The exchange of metabolites across the forearm was calculated by multiplying the arterio-venous plasma concentration difference of metabolites by forearm plasma flow. Plasma flow was calculated as FBF $\times$ (1-hematocrit), with hematocrit expressed as a fraction. A positive net exchange indicates net uptake, whereas a negative net exchange indicates net release.

The expected deep venous glycerol enrichment, in case of no glycerol uptake, was calculated as arterialized enrichment multiplied by arterialized glycerol concentration and subsequently divided by deep venous glycerol concentration.

The rate of appearance ( $\mathrm{Ra}$ ) of glycerol was calculated according to the following steady-state equation:

$$
R a\left(\mu \mathrm{mol} . \mathrm{kg}^{-1} \cdot \mathrm{min}^{-1}\right)=T T R^{-1} \times F
$$

TTR is tracer/tracee ratio and $\mathrm{F}$ is the isotope infusion rate $\left(\mu \mathrm{mol} . \mathrm{kg}^{-1} \cdot \mathrm{min}^{-1}\right)$.

The fractional extraction (fract) of glycerol across the forearm was calculated by dividing the arterio-venous concentration difference of $\left[{ }^{2} \mathrm{H}_{5}\right]$-glycerol by the arterialized $\left[{ }^{2} \mathrm{H}_{5}\right]$-glycerol concentration. Total glycerol uptake across the forearm was then calculated as follows:

$$
\text { Total glycerol uptake }=\text { fract } \times\left[\text { glycerol } l_{a r}\right] \times F B F
$$

where the unit is $\mathrm{nmol} .100 \mathrm{ml}$ tissue ${ }^{-1} \cdot \mathrm{min}^{-1}$; [glycerol $\mathrm{art}_{\text {art }}$ is arterialized glycerol concentration $(\mu \mathrm{mol} / 1)$; and FBF is forearm skeletal muscle blood flow $(\mathrm{ml} .100 \mathrm{ml}$ tis$\left.\mathrm{sue}^{-1} \cdot \mathrm{min}^{-1}\right)$. Forearm total glycerol release was calculated from the formula:

$$
\text { Total glycerol release }=\text { net glycerol balance }- \text { total glycerol uptake }
$$


[Chapter 5

\section{Statistical analysis}

Differences within groups (i.e. between baseline and ISO) were tested using Student's paired t-test. Comparisons between groups (at baseline and during ISO infusion, respectively) were made using Student's unpaired t-test. Differences between groups in the change from baseline to ISO were also tested using Student's unpaired t-test. Statistical calculations were performed using SPSS for Macintosh (version 11.0; SPSS inc., Chicago, IL, USA). Data are presented as mean \pm standard error of the mean (SEM). $\mathrm{P}<0.05$ was considered statistically significant.

\section{Results}

\section{Pilot experiment}

In a pilot experiment, we investigated the tracer/tracee ratios (TTR) obtained with a 6h $\left[{ }^{2} \mathrm{H}_{5}\right]$-glycerol infusion after an overnight fast $(\mathrm{n}=3)$. In Figure 1, we show that arterialized and deep venous TTR reach a steady-state after $1 \mathrm{~h}$ of infusion. Mean values of 3 subjects are presented and all subjects showed the same pattern. The measured deep venous enrichment was consistently lower than the expected enrichment, implying uptake of glycerol across the forearm (Figure 1). In the actual muscle lipolysis experiment ( $3 \mathrm{~h}\left[{ }^{2} \mathrm{H}_{5}\right]$-glycerol infusion) TTR also reached a steady-state after $1 \mathrm{~h}$ and remained stable during ISO infusion (data not shown).

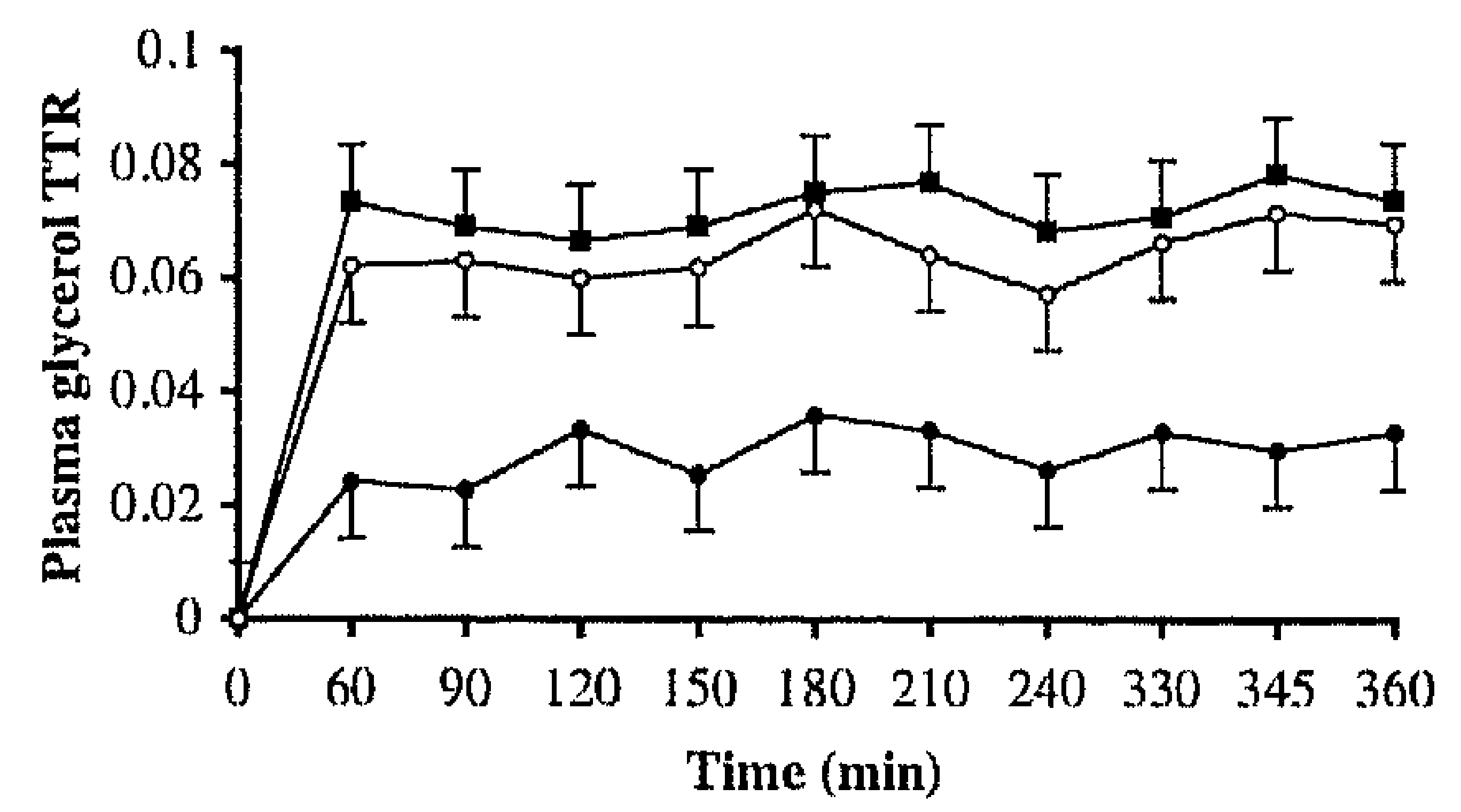

Figure 1. Plasma glycerol tracer/tracee ratio (TTR) during $6 \mathrm{~h}$ primed constant infusion of $\left[{ }^{2} \mathrm{H}_{5}\right]-$ glycerol $(n=3)$ in arterialized blood $(\mathbf{m})$, forearm venous blood $(\bullet)$ and expected forearm venous enrichment (O). The expected deep venous glycerol enrichment was calculated as arterialized enrichment multiplied by arterialized glycerol concentration divided by deep venous glycerol concentration. The measured venous enrichment was consistently lower than the expected deep venous enrichment $(\mathrm{P}<0.05)$, implying uptake of glycerol across the forearm. Values are mean \pm SEM.

\section{Circulating metabolites}

Obese subjects had significantly higher baseline plasma arterialized TAG concentrations than lean subjects $(\mathrm{P}<0.05$, Table 2$)$. Beta-adrenergic stimulation increased plasma arterialized TAG levels in obese subjects $(\mathrm{P}<0.05)$, whilst in lean subjects 
Skeletal muscle lipolysis]

TAG concentrations decreased during ISO $(\mathrm{P}<0.05$, Table 2). Thus, the change in plasma arterialized TAG levels from baseline to ISO was different between lean and obese subjects $(\mathrm{P}<0.05$, Table 2$)$.

Table 2. Circulating arterialized metabolite levels during baseline and isoprenaline infusion in lean and obese subjects

\begin{tabular}{lcccc}
\hline & \multicolumn{2}{c}{ Lean } & \multicolumn{2}{c}{ Obese } \\
& Baseline $(\mathrm{n}=13)$ & ISO $(\mathrm{n}=10)$ & Baseline $(\mathrm{n}=10)$ & ISO $(\mathrm{n}=7)$ \\
\hline TAG $(\mu \mathrm{mol} / \mathrm{l})$ & $701 \pm 66$ & $648 \pm 64^{3}$ & $1464 \pm 190^{2}$ & $1667 \pm 217^{1.2,3}$ \\
FFA $(\mu \mathrm{mol} / \mathrm{l})$ & $661 \pm 41$ & $942 \pm 53^{3}$ & $638 \pm 42$ & $1124 \pm 82^{1.3}$ \\
Glycerol $(\mu \mathrm{mol} / \mathrm{l})$ & $102 \pm 5$ & $118 \pm 7^{3}$ & $106 \pm 4$ & $147 \pm 10^{1,2,3}$ \\
Glycerol Ra & $199 \pm 12$ & $311 \pm 28^{3}$ & $220 \pm 15$ & $391 \pm 30^{3}$ \\
Glycerol Ra/FFM & $3.4 \pm 0.2$ & $5.5 \pm 0.5^{3}$ & $3.3 \pm 0.3$ & $5.8 \pm 0.6^{3}$ \\
Glucose $(\mathrm{mmol} / \mathrm{l})$ & $5.3 \pm 0.1$ & $5.4 \pm 0.1$ & $5.5 \pm 0.2$ & $5.4 \pm 0.1$ \\
Insulin $(\mathrm{mU} / \mathrm{l})$ & $7.2 \pm 0.6$ & $10.7 \pm 0.9^{3}$ & $13.6 \pm 1.0^{2}$ & $24.0 \pm 2.3^{1.2 .3}$ \\
Lactate $(\mathrm{mmol} / \mathrm{l})$ & $0.61 \pm 0.04$ & $0.72 \pm 0.03^{2}$ & $0.98 \pm 0.11^{2}$ & $0.99 \pm 0.06^{2}$ \\
\hline
\end{tabular}

ISO, Isoprenaline; TAG, Triacylglycerol; FFA, Free Fatty Acids; Ra, rate of appearance ( $\mu$ mol. min $^{-1}$ ); $\mathrm{Ra} / \mathrm{FFM}$, rate of appearance per $\mathrm{kg}$ fat-free mass $\left(\mu \mathrm{mol} . \mathrm{kg} \mathrm{FFM}^{-1} . \mathrm{min}^{-1}\right) .{ }^{1} \mathrm{P}<0.05$ change (delta) from baseline obese vs. lean, ${ }^{2} \mathrm{P}<0.05$ obese vs. lean, ${ }^{3} \mathrm{P}<0.05$ ISO vs. baseline. Values are mean $\pm \mathrm{SEM}$.

Baseline plasma arterialized FFA and glycerol levels did not differ significantly between lean and obese subjects. Beta-adrenergic stimulation increased FFA and glycerol in lean and obese subjects $(\mathrm{P}<0.05$, Table 2). Moreover, the betaadrenergic mediated increase in arterialized FFA and glycerol was more pronounced in obese subjects $(P<0.05$, Table 2$)$, suggesting a higher whole-body lipolytic response in the obese. Likewise, beta-adrenergic stimulation increased whole-body glycerol $\mathrm{Ra}$ in lean and obese subjects $(\mathrm{P}<0.05$, Table 2$)$, and this increase tended to be higher in the obese ( $\mathrm{P}=0.07$; Table 2). Expressed per unit fatfree mass, baseline glycerol $\mathrm{Ra}$ was not significantly different between groups. Beta-adrenergic stimulation increased the glycerol Ra per unit fat-free mass in lean and obese subjects $(P<0.05$, Table 2$)$, but this increase in glycerol Ra per unit fatfree mass was not significantly different between groups.

Plasma arterialized insulin and lactate levels were higher in obese than in lean subjects during baseline and ISO $(\mathrm{P}<0.05$, Table 2$)$, while glucose did not differ significantly between lean and obese subjects in both conditions. Beta-adrenergic stimulation increased circulating insulin levels in lean and obese $(\mathrm{P}<0.05$, Table 2), and this increase in circulating insulin levels was significantly higher in obese than in lean subjects $(P<0.05$, Table 2$)$. Circulating glucose and lactate levels were unchanged during beta-adrenergic stimulation.

\section{Regional forearm metabolism}

Baseline FBF was not different between lean and obese subjects $(\mathrm{P}=0.15$, Table 3$)$. FBF was significantly elevated during beta-adrenergic stimulation in both lean and 
[Chapter 5

obese subjects $(\mathrm{P}<0.05)$, but the increase in FBF during beta-adrenergic stimulation was not significantly different between groups.

Table 3. Regional forearm blood flow and net metabolite flux during baseline and isoprenaline infusion in lean and obese subjects

\begin{tabular}{|c|c|c|c|c|}
\hline & \multicolumn{2}{|c|}{ Lean } & \multicolumn{2}{|c|}{ Obese } \\
\hline & Baseline $(n=13)$ & $\operatorname{ISO}(n=10)$ & Baseline $(n=10)$ & ISO $(n=7)$ \\
\hline \multicolumn{5}{|c|}{ FBF $\left(\mathrm{ml} .100 \mathrm{ml}\right.$ tissue $\left.{ }^{-1} \cdot \mathrm{min}^{-1}\right)$} \\
\hline & $2.9 \pm 0.2$ & $4.6 \pm 0.4^{3}$ & $2.5 \pm 0.3$ & $3.5 \pm 0.3^{3}$ \\
\hline \multicolumn{5}{|c|}{ Forearm net flux (nmol.100ml tissue $\left.{ }^{-1} \cdot \min ^{-1}\right)$} \\
\hline TAG & $17 \pm 5$ & $24 \pm 19$ & $-2 \pm 9$ & $46 \pm 31$ \\
\hline FFA & $6 \pm 59$ & $-53 \pm 143$ & $156 \pm 42^{2}$ & $230 \pm 88$ \\
\hline Glycerol & $-21 \pm 11$ & $-39 \pm 33$ & $11 \pm 5^{2}$ & $6 \pm 21$ \\
\hline Glucose & $142 \pm 51$ & $213 \pm 117$ & $226 \pm 81$ & $289 \pm 223$ \\
\hline Lactate & $-90 \pm 27$ & $-171 \pm 73$ & $8 \pm 45$ & $-327 \pm 78^{3}$ \\
\hline
\end{tabular}

${ }^{1} \mathrm{P}<0.05$ change (delta) from baseline obese vs. lean; ${ }^{2} \mathrm{P}<0.05$ obese vs. lean; ${ }^{3} \mathrm{P}<0.05$ ISO vs. baseline. Values are mean \pm SEM.

Fractional extraction of $\left[{ }^{2} \mathrm{H}_{5}\right]$-glycerol from the circulation (lean vs. obese: $40.2 \pm 3.4$ vs. $40.5 \pm 6.1 \%$ ) was not significantly different between groups. Significant glycerol uptake across the forearm was observed in both obese and lean subjects $(\mathrm{P}<0.0001$ compared to zero, Figure $2 \mathrm{~A}$ ). The increase in total glycerol uptake during betaadrenergic stimulation was not significantly different between groups.

Baseline net glycerol efflux across the forearm was significantly lower in the obese than in the lean subjects $(\mathrm{P}<0.05$; Table 3$)$. Accordingly, obese subjects showed significantly less total glycerol release across the forearm at baseline compared with lean subjects $(\mathrm{P}<0.05$, Figure $2 \mathrm{~B})$. These data indicate a blunted glycerol release during baseline in obese subjects. Total glycerol uptake expressed relative to total glycerol release at baseline was not significantly different between lean and obese subjects (lean vs. obese: $92.7 \pm 13.5$ vs. $91.7 \pm 23.9 \%$ of total release). Furthermore, obese subjects had higher net fatty acid uptake across the forearm at baseline $(\mathrm{P}<0.05$, Table 3). Beta-adrenergic stimulation increased total glycerol release in lean and obese subjects (Figure 2B), but this increase was not significantly different between groups. Finally, net lactate efflux during beta-adrenergic stimulation was significantly higher in obese than in lean subjects $(\mathrm{P}<0.05$; Table 3$)$.

\section{Discussion}

The present study revealed a blunted fasting muscle lipolysis in obese compared to lean men (Fig. 2B). This blunted skeletal muscle lipolysis was accompanied by a lower total HSL protein expression and phosphorylation of HSL Ser ${ }^{563}, \mathrm{Ser}^{565}$ and $\mathrm{Ser}^{659}$ (Fig. 3). The beta-adrenergic mediated lipolytic response was not signifi- 
cantly different between lean and obese subjects. In contrast to lean subjects, an increased HSL Ser ${ }^{659}$ phosphorylation was observed in skeletal muscle of obese subjects during beta-adrenergic stimulation compared with baseline.

A

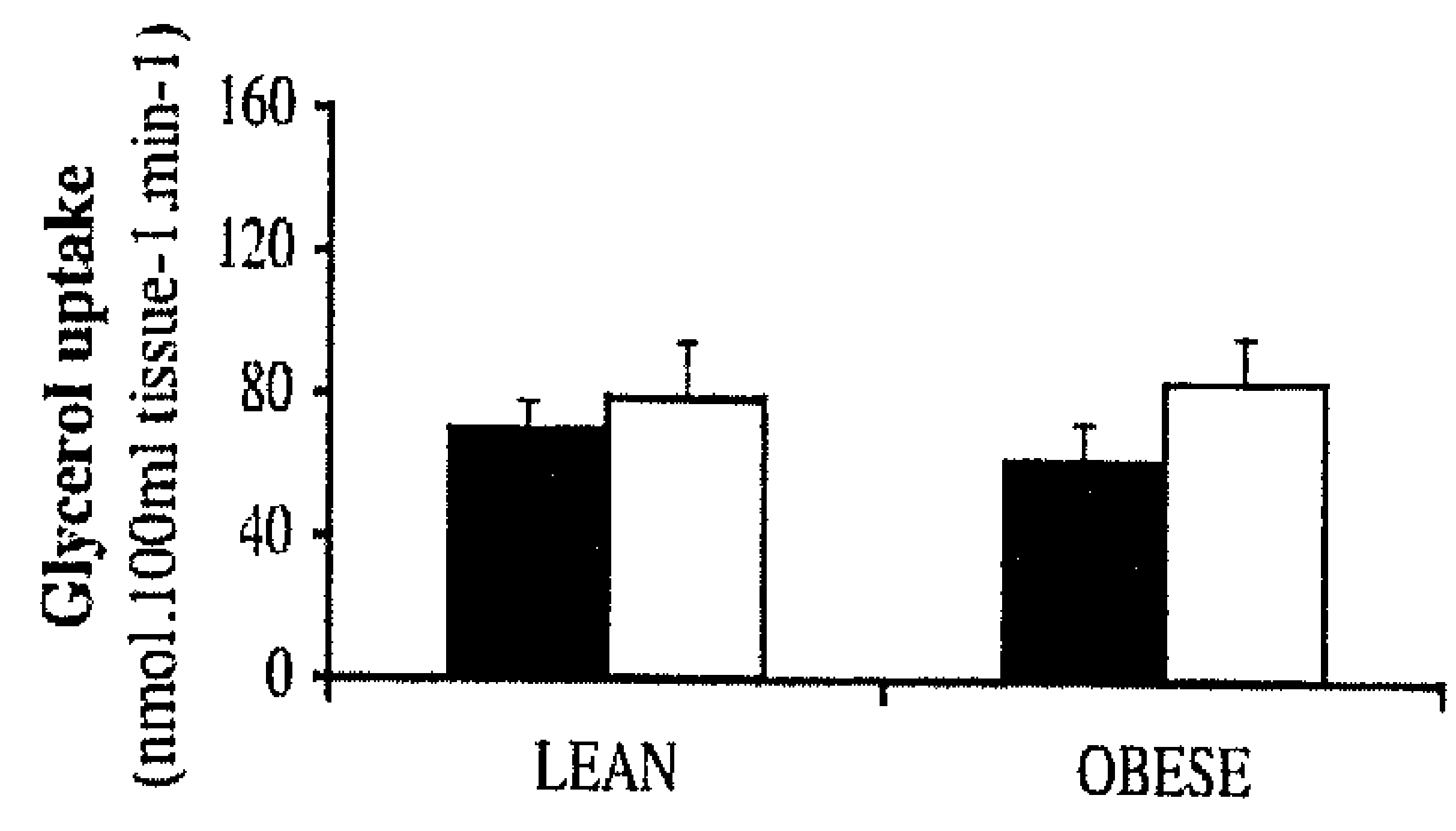

B

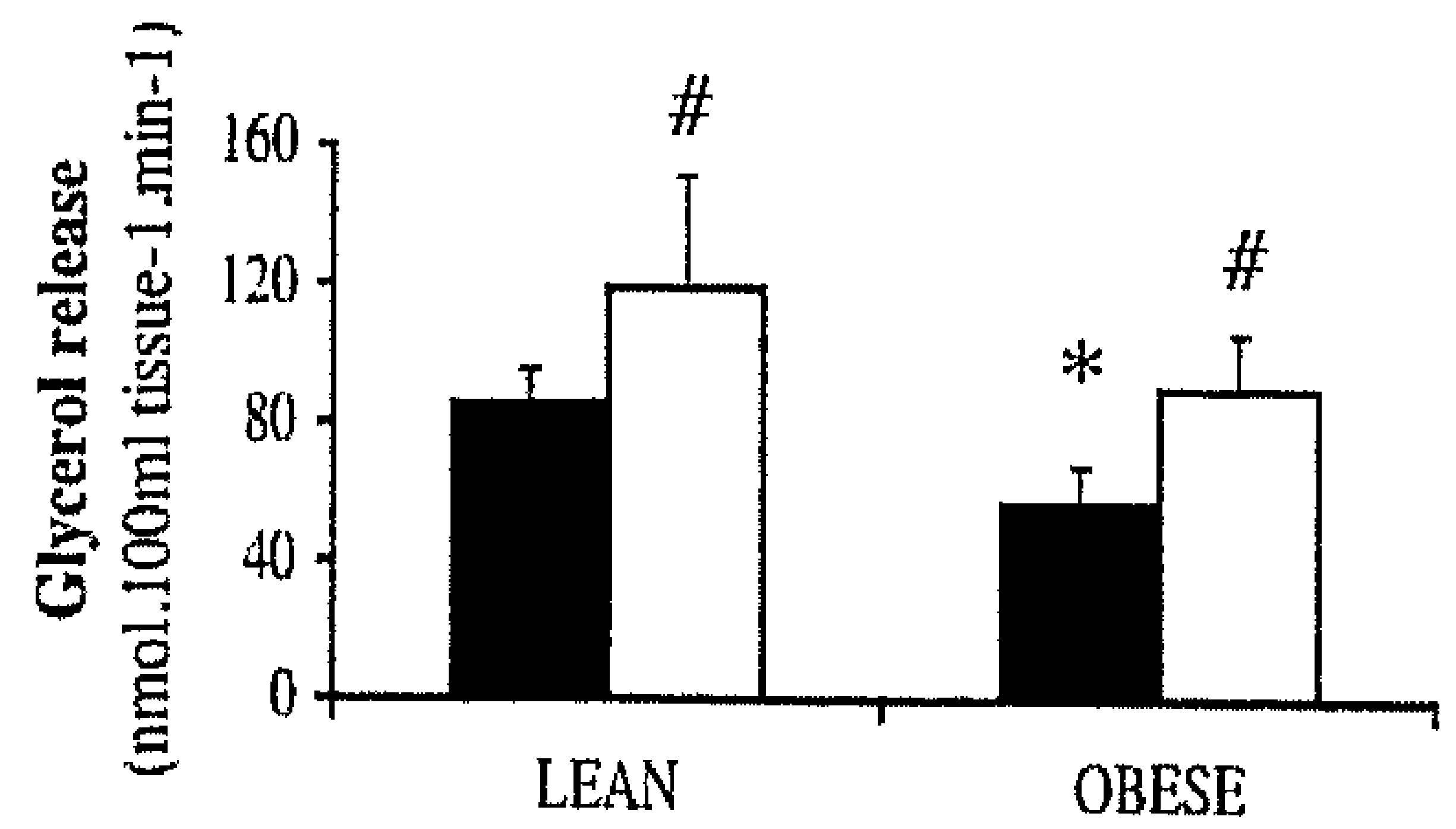

Figure 2. Total glycerol uptake (A) and release (B) across the forearm during baseline (black bars, and isoprenaline infusion (white bars, $\square$ ) in lean and obese subjects; $\left(^{*}\right) \mathrm{P}<0.05$ obese vs. lean; (\#) $\mathrm{P}<0.05$ ISO vs. baseline; Values are mean \pm SEM.

Total HSL protein expression and serine phosphorylation in the vastus lateralis muscle

Muscle HSL protein expression was significantly lower in obese compared with lean subjects $(\mathrm{P}<0.05)$ and did not change during beta-adrenergic stimulation (Figure $3 \mathrm{~A})$. Baseline HSL phosphorylation on $\operatorname{Ser}^{563}(\mathrm{P}<0.05), \operatorname{Ser}^{565}(\mathrm{P}<0.05)$ and $\operatorname{Ser}^{659}(\mathrm{P}=0.09)$ was reduced in obese compared with lean subjects (Figures 3B-D). No effect of beta-adrenergic stimulation was observed on HSL Ser ${ }^{563}$ or HSL Ser ${ }^{565}$ phosphorylation in both lean and obese subjects (Figures 3B and C). Obese subjects showed an increased HSL Ser ${ }^{659}$ phosphorylation $(\mathrm{P}<0.01$, Figure 3D), whilst in lean subjects HSL $\operatorname{Ser}^{659}$ phosphorylation was unchanged after ISO infusion.

\section{Methodological considerations}

We showed that glycerol TTR from arterialized and deep venous blood remained constant during the $6 \mathrm{~h}$ glycerol infusion under baseline and beta-adrenergic stimulation (Fig. 1). If the achievement of a steady-state would be a problem with short infusions then the discrepancy between expected and measured enrichments should decrease with time. Both during the $6 \mathrm{~h}$ pilot experiment as well as during the actual muscle lipolysis experiment ( $3 \mathrm{~h}$ infusion period) this was not the case, and for both conditions steady-state levels in labeled glycerol were achieved already after $1 \mathrm{~h}$. 


\section{[Chapter 5}

Thus, our data support the use of a relatively short infusion time ( $\geq 1 \mathrm{~h})$ to study glycerol metabolism.

A

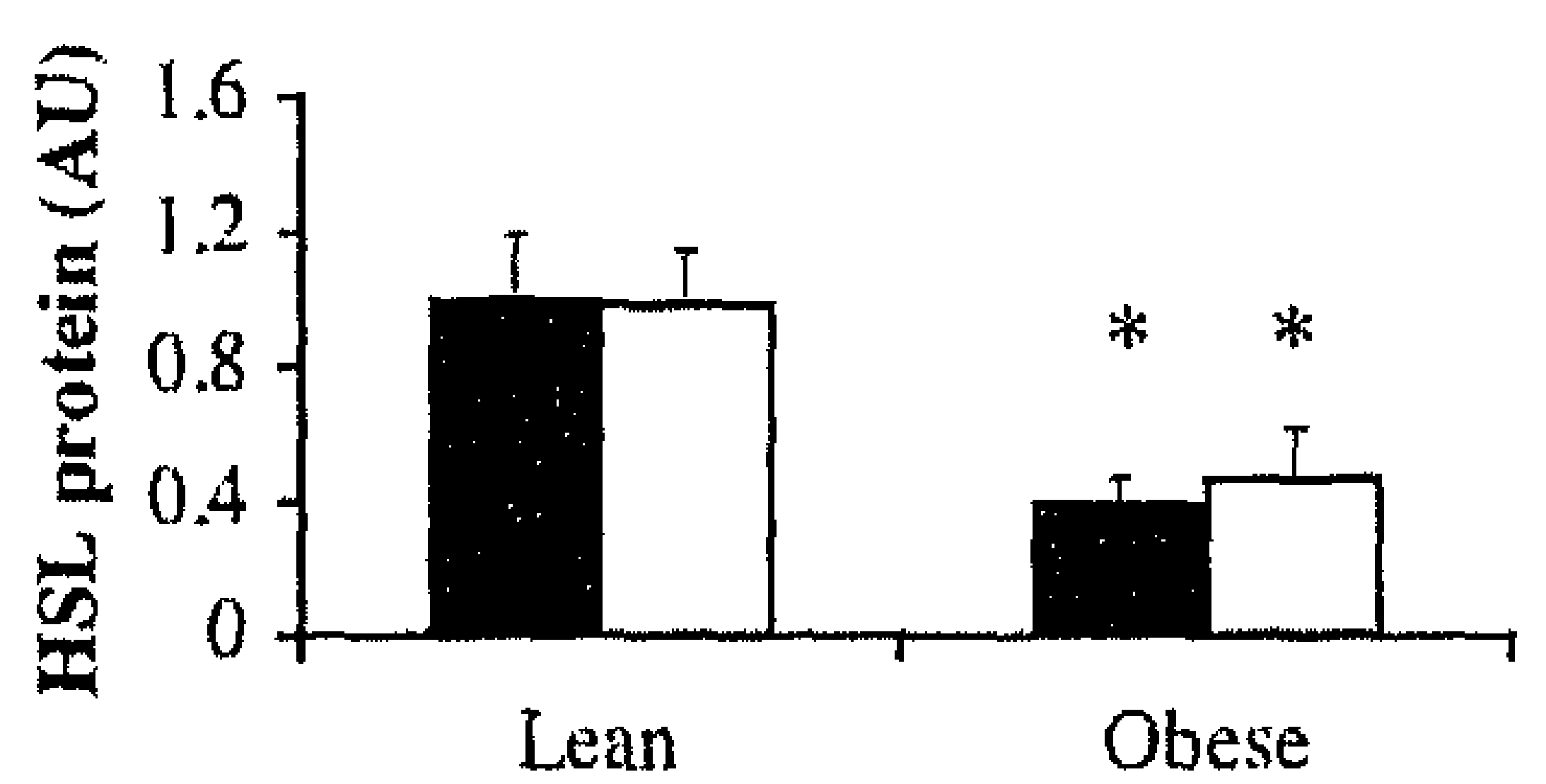

C

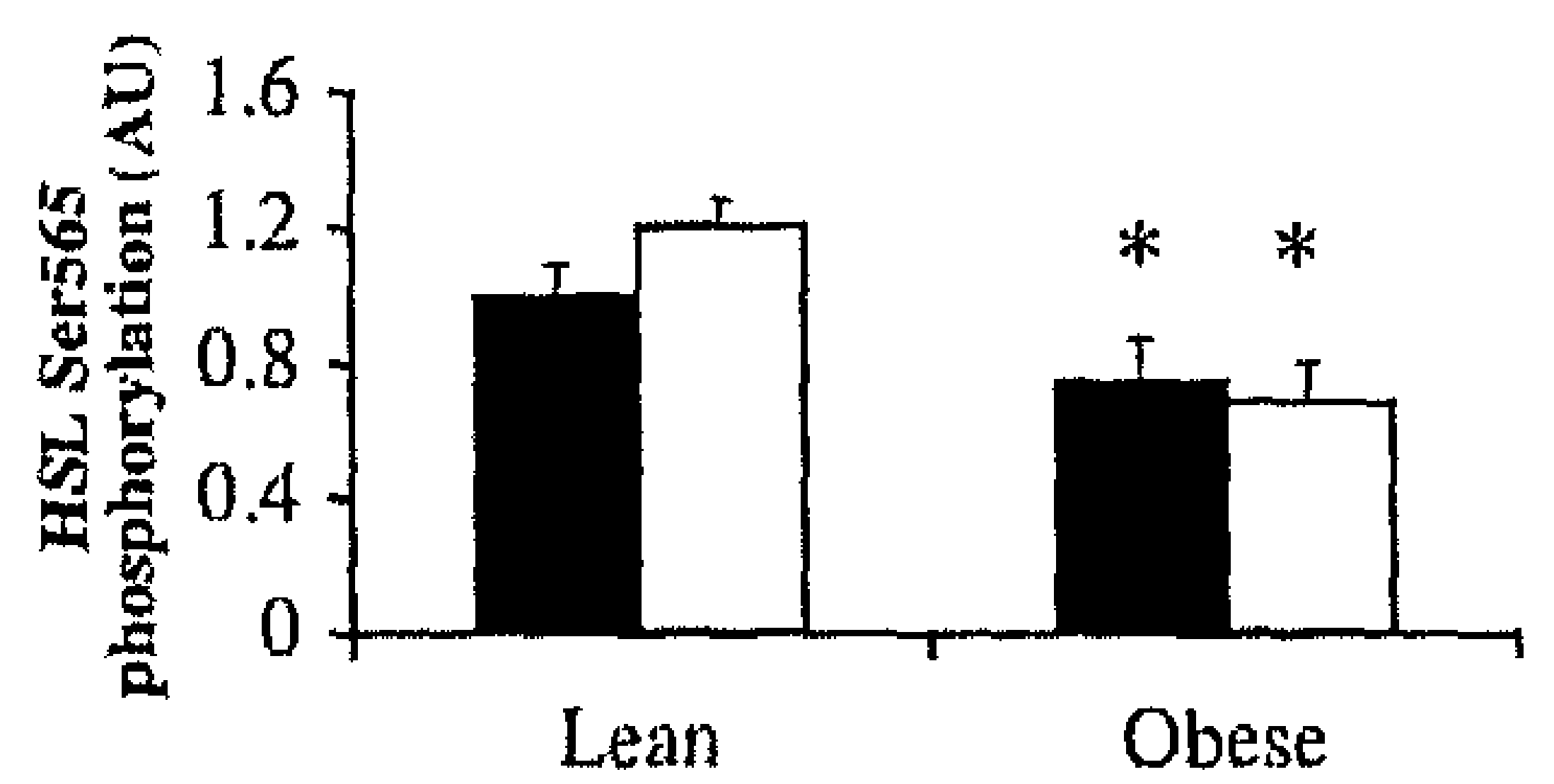

B

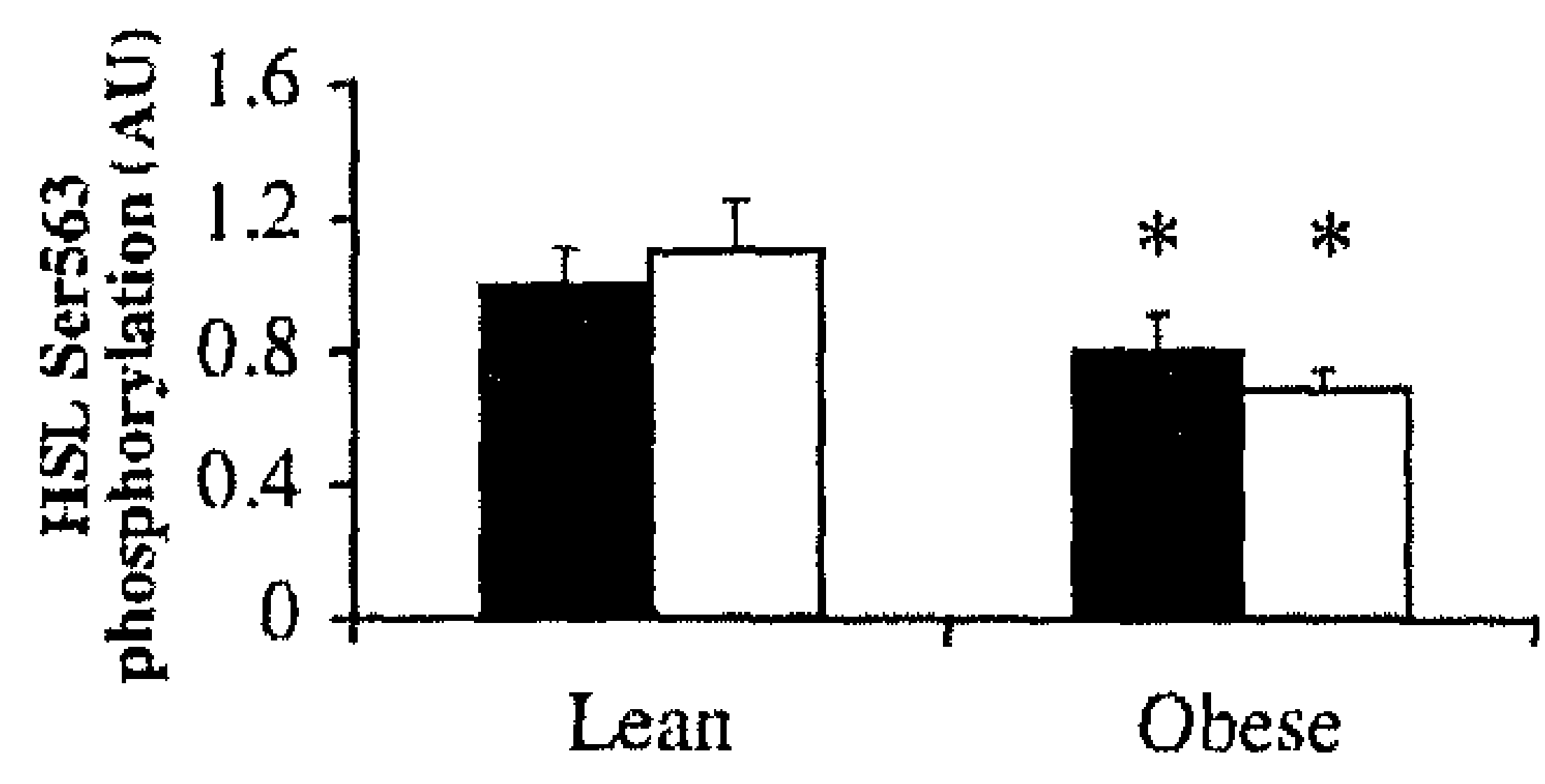

D

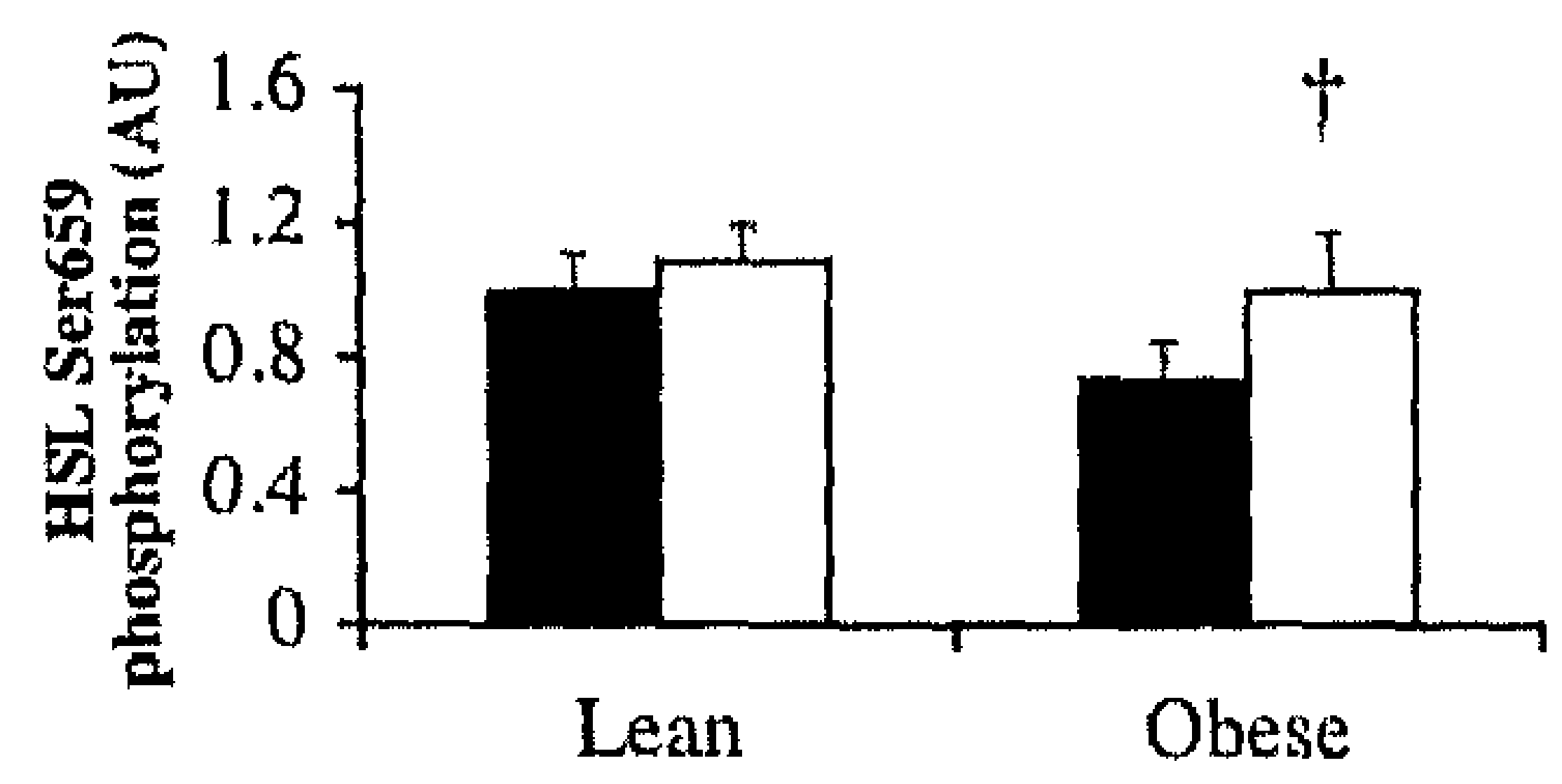

Figure 3. HSL protein expression (A) and $\operatorname{Ser}^{563}(\mathbf{B}), \operatorname{Ser}^{565}(\mathbf{C})$ and $\operatorname{Ser}^{659}(\mathbf{D})$ phosphorylation during baseline (black bars, $\mathbf{m}$ ) and isoprenaline infusion (white bars, $\square$ ) in lean and obese subjects. Data are expressed as arbitrary units $(\mathrm{AU}) ;\left({ }^{*}\right) \mathrm{P}<0.05$ obese vs. lean; ( $\dagger$ ) $\mathrm{P}<0.01$ obese vs. lean in change between baseline and ISO; Values are mean \pm SEM.

\section{Baseline muscle glycerol uptake}

The present observation of significant uptake of glycerol across the forearm (Fig. $2 \mathrm{~A}$ ) is in agreement with previous reports (11). The first indications for significant metabolism of glycerol in muscle came from Elia et al. (10) showing $50 \%$ loss of enriched glycerol across the forearm. More recently, studies confirmed the finding of significant uptake of glycerol by forearm muscle (9) and vastus lateralis muscle (36). The enzymatic machinery for utilization of glycerol seems to be present in skeletal muscle. Glycerol dehydrogenase, the enzyme that could initiate glycerol oxidation by skeletal muscle, has been demonstrated in humans (15), and oxidation of glycerol by skeletal muscle has been shown to occur in humans (15). Furthermore, glycerol kinase has been demonstrated in muscle of humans (27). Thus, glycerol taken up from the circulation might be oxidized or incorporated into IMTAG in humans as shown in rats (14). 
Skeletal muscle lipolysis]

\section{Baseline muscle lipolysis}

Our data show a blunted baseline total glycerol release per unit muscle mass in obese subjects (Fig. 2B). This blunted baseline lipolysis was accompanied by a lower total HSL protein expression in skeletal muscle of obese subjects (Fig. 3A). To our knowledge our data provide the first indication of a reduced muscle HSL protein expression in obese compared with lean subjects. It is well known that expression of HSL is markedly decreased in subcutaneous adipocytes and differentiated adipocytes from obese subjects, suggesting that at least in adipose tissue a decreased HSL expression is a primary defect in obesity $(22,23)$. However, we cannot exclude that the blunted muscle lipolysis in obese subjects was a secondary phenomenon caused by a higher degree of hyperinsulinemia. Still, it has been suggested that muscle lipolysis is primarily regulated by substrate supply and to a lesser degree is under hormonal control (39). This seems to be supported by studies showing no apparent suppression of in vivo skeletal muscle lipolysis by insulin (26, 30). Furthermore, our data suggest that phosphorylation of HSL on the PKA target sites $\mathrm{Ser}^{563}$ and $\mathrm{Ser}^{659}$, and on the AMPK target site $\mathrm{Ser}^{565}$ was lower in obese than in lean subjects. It should be recognized, however, that when corrected for total HSL protein. HSL Ser ${ }^{563}, \mathrm{Ser}^{565}$ and $\mathrm{Ser}^{659}$ phosphorylation was comparable between lean and obese subjects, suggesting that a similar percentage of HSL molecules were phosphorylated on these three serine sites in lean and obese subjects. Nevertheless, the reduced absolute number of HSL molecules phosphorylated on $\mathrm{Ser}^{659}$ may at least partly explain the blunted baseline lipolysis in obese compared to lean subjects. On the other hand, HSL Ser ${ }^{563}$ and $\mathrm{Ser}^{565}$ phosphorylation have been suggested not to be major regulators of HSL activity in human skeletal muscle $(31,32)$. Thus, the reduced phosphorylation of HSL on these two sites may not have been important in determining the blunted baseline lipolysis in obese subjects. It should be mentioned that also other lipases might contribute to the blunted baseline muscle lipolysis observed in obese subjects. Recently, a new lipase was identified that is primarily responsible for TAG hydrolysis during basal lipolysis, adipose triglyceride lipase (ATGL) $(21,40)$. More research is needed to elucidate the potential role of ATGL in skeletal muscle lipolysis.

\section{Baseline muscle fatty acid uptake}

In addition to the blunted baseline muscle lipolysis, there was a higher fatty acid uptake across the forearm of obese subjects as compared with lean subjects. Plasma fatty acids taken up by the forearm can be oxidized in the mitochondria or directed towards synthesis into IMTAG (33). Thus, the present data indicate that both an increased muscle fatty acid uptake as well as a reduced muscle lipolysis may contribute to the increased IMTAG storage in obese subjects.

\section{Muscle lipolysis during beta-adrenergic stimulation}

The present results showed a comparable forearm lipolytic response during systemic infusion of the non-selective beta-adrenergic agonist isoprenaline in lean and obese subjects. Previously, in situ microdialysis using a beta-2 agonist, salbutamol, showed a blunted lipolysis in the gastrocnemius muscle of obese insulin resistant 
[Chapter 5

subjects compared with lean subjects (5). Differences in systemic versus local infusion of beta-adrenergic agonists might partly explain this discrepancy. Secondly, in microdialysis studies, interstitial glycerol is used as a measure of lipolysis. As mentioned previously, glycerol is taken up by skeletal muscle, suggesting that interstitial glycerol may not reflect the overall rate of lipolysis, but may instead be the net result of TAG and glycerol metabolism in muscle thus reflecting net glycerol turnover (35). Finally, there may be marked heterogeneity in lipolysis between different muscle groups, possibly correlated to composition of fiber types (16). Accordingly, in rats it was shown that muscles with a majority of type 1 fibers had greater HSL activity compared with muscles with a majority of type 2 fiber (20). The higher content of type 1 fibers in the gastrocnemius muscle compared with forearm muscle may not only cause a generally higher lipolytic sensitivity to beta-adrenergic stimulation but may also influence the difference in beta-adrenergically stimulated lipolysis between lean and obese subjects.

It is known from studies with purified bovine adipocyte HSL (12) and in different cell lines transfected with wildtype and mutant forms of HSL (2) that betaadrenergic stimulation increases HSL activity through phosphorylation on several serine residues. In the present study HSL Ser ${ }^{699}$ phosphorylation significantly increased during beta-adrenergic stimulation in skeletal muscle of obese subjects, whilst no effect was seen in lean subjects. A previous study in men and women during exercise has shown that muscle $\mathrm{Ser}^{659}$ phosphorylation and muscle HSL activity show a very similar pattern with respect to exercise response and dependency on gender, indicating that $\mathrm{Ser}^{659}$ serves an important role in the regulation of HSL activity in human skeletal muscle (31), as has been demonstrated in adipocytes (2). It can be speculated that obese subjects increase HSL Ser ${ }^{659}$ phosphorylation during beta-adrenergic stimulation to deal with a reduced total HSL protein expression, increasing muscle HSL activity to a level comparable with lean subjects. In addition, HSL Ser ${ }^{660}$ appears to be a major PKA target site and HSL activity-controlling site (2), but in the present study, HSL Ser ${ }^{660}$ phosphorylation was not measured. Finally, phosphorylation of the PKA target site $\mathrm{Ser}^{563}$ on HSL did not increase significantly during beta-adrenergic stimulation. This is in accordance with previous studies, where HSL $\mathrm{Ser}^{53}$ phosphorylation was not increased during exercise despite an increase in circulating epinephrine $(31,32)$. Maybe HSL Ser ${ }^{53}$ is already maximally phosphorylated in the basal, resting state. Moreover, it has been argued that HSL Ser ${ }^{563}$ may not be an important regulator of HSL activity in human skeletal muscle (32).

\section{Muscle lactate release during beta-adrenergic stimulation}

Circulating lactate and glucose levels were unaffected by beta-adrenergic stimulation. No significant change in muscle glucose uptake was observed by betaadrenergic stimulation, despite a two to threefold increase in plasma insulin, as previously reported $(6,7,24)$. Nevertheless, net lactate release across the forearm increased during beta-adrenergic stimulation, and this increase was higher in obese compared with lean subjects, suggesting that the glycolytic flux was stimulated to a greater extent by isoprenaline in obese than in lean subjects. This seems in line with previous findings showing an increased lactate release during beta-adrenergic 
stimulation in obese subjects (6), persisting after weight reduction (7), indicating that this disturbance might be an early factor in the etiology of obesity.

In conclusion, the obese insulin resistant state is accompanied by a reduced muscle lipolysis during baseline fasting conditions, which was accompanied by a lower HSL protein expression and phosphorylation on the PKA target sites $\mathrm{Ser}^{563}$ and $\mathrm{Ser}^{659}$, and on the AMPK target site $\mathrm{Se}^{565}$. This impairment may be an important factor contributing to the increased lipid storage in skeletal muscle of obese insulin resistant subjects. Further studies are necessary to address in more detail whether these impairments are primary factors or adaptational responses to the obese insulin resistant state.

\section{Acknowledgments}

The authors greatly appreciate the technical support of Jos Stegen, Anneke van Hees and the willingness of the volunteers to participate in this study. This research was supported by a grant from The Netherlands Organization for Health Research and Development (NWO/ZonMw contract no. 015.01.095) to Prof. dr. EE. Blaak. Dr. C. Roepstorff and Prof. dr. B Kiens were supported by the Commission of the European Communities (contract no. LSHM-CT-2004-005272 EXGENESIS), the Copenhagen Muscle Research Centre and the Ministry of Food, Agriculture and Fisheries. We thank Prof. dr. D. Grahame Hardie, Division of Molecular Physiology, School of Life Sciences, University of Dundee, Dundee, Scotland, UK, for kindly providing the anti-phospho HSL Ser antibodies.

\section{References}

1. Abumrad NN, Rabin D, Diamond MP, and Lacy WW. Use of a heated superficial hand vein as an alternative site for the measurement of amino acid concentrations and for the study of glucose and alanine kinetics in man. Metabolism 30: 936-940, 1981.

2. Anthonsen MW, Ronnstrand L, Wernstedt C, Degerman E, and Holm C. Identification of novel phosphorylation sites in hormone-sensitive lipase that are phosphorylated in response to isoproterenol and govern activation properties in vitro. $J$ Biol Chem 273:215-221, 1998.

3. Blaak EE. Basic disturbances in skeletal muscle fatty acid metabolism in obesity and type 2 diabetes mellitus. Proc Nutr Soc 63: 323-330, 2004.

4. Blaak EE. Fatty acid metabolism in obesity and type 2 diabetes mellitus. Proc Nutr Soc 62: 753$760,2003$.

5. Blaak EE, Schiffelers SL, Saris WH, Mensink M, and Kooi ME. Impaired beta-adrenergically mediated lipolysis in skeletal muscle of obese subjects. Diabetologia, 2004.

6. Blaak EE, Van Baak MA, Kemerink GJ, Pakbiers MT, Heidendal GA, and Saris WH. Betaadrenergic stimulation of energy expenditure and forearm skeletal muscle metabolism in lean and obese men. Am J Physiol 267: E306-315, 1994.

7. Blaak EE, Van Baak MA, Kemerink GJ, Pakbiers MT, Heidendal GA, and Saris WH, betaAdrenergic stimulation of skeletal muscle metabolism in relation to weight reduction in obese men. Am J Physiol 267: E316-322, 1994. 


\section{[Chapter 5}

8. Blaak EE, Wagenmakers AJ, Glatz JF, Wolffenbuttel BH, Kemerink GJ, Langenberg CJ, Heidendal GA, and Saris WH. Plasma FFA utilization and fatty acid-binding protein content are diminished in type 2 diabetic muscle. Am J Physiol Endocrinol Metab 279: E146-154, 2000.

9. Coppack SW, Persson M, Judd RL, and Miles JM. Glycerol and nonesterified fatty acid metabolism in human muscle and adipose tissue in vivo. Am J Physial 276: E233-240, 1999.

10. Elia M, Khan $\mathrm{K}$, Calder $\mathrm{G}$, and Kurpad A. Glycerol exchange across the human forearm assessed by a combination of tracer and arteriovenous exchange techniques. Clin Sci (Lond) 84: 99-104, 1993.

11. Frayn KN, Coppack SW, and Humphreys SM. Glycerol and lactate uptake in human forearm. Metabolism 40: 1317-1319, 1991.

12. Garton AJ, Campbell DG, Carling D, Hardie DG, Colbran RJ, and Yeaman SJ. Phosphorylation of bovine hormone-sensitive lipase by the AMP-activated protein kinase. A possible antilipolytic mechanism. Eur J Biochem 179: 249-254, 1989.

13. Goossens GH, Blaak EE, Saris WH, and van Baak MA. Angiotensin II-induced effects on adipose and skeletal muscle tissue blood flow and lipolysis in normal-weight and obese subjects. $J$ Clin Endocrinol Metab 89: 2690-2696, 2004.

14. Guo Z and Jensen MD. Blood glycerol is an important precursor for intramuscular triacylglycerol synthesis. J Biol Chem 274: 23702-23706, 1999.

15. Hagenfeldt $\mathrm{L}$ and Wahren J. Human forearm muscle metabolism during exercise. II. Uptake, release and oxidation of individual FFA and glycerol. Scand J Clin Lab Invest 21:263-276, 1968.

16. Hagstrom-Toft E, Qvisth V, Nennesmo I, Ryden M, Bolinder H, Enoksson S, Bolinder J, and Arner P. Marked heterogeneity of human skeletal muscle lipolysis at rest. Diabetes 51: 3376-3383, 2002.

17. Kelley DE and Simoneau JA. Impaired free fatty acid utilization by skeletal muscle in non-insulindependent diabetes mellitus. J Clin Invest 94: 2349-2356, 1994.

18. Krssak M, Falk Petersen K, Dresner A, DiPietro L, Vogel SM, Rothman DL, Roden M, and Shulman GI. Intramyocellular lipid concentrations are correlated with insulin sensitivity in humans: a 1H NMR spectroscopy study. Diabetologia 42: 113-116, 1999.

19. Langfort J, Ploug T, Ihlemann J, Enevoldsen LH, Stallknecht B, Saldo M, Kjaer M, Holm C, and Galbo H. Hormone-sensitive lipase (HSL) expression and regulation in skeletal muscle. $A d v$ Exp Med Biol 441: 219-228, 1998.

20. Langfort J, Ploug T, Thlemann J, Saldo M, Holm C, and Galbo H. Expression of hormone-sensitive lipase and its regulation by adrenaline in skeletal muscle. Biochem J $340(\mathrm{Pt} 2): 459-465,1999$.

21. Langin D, Dicker A, Tavernier G, Hoffstedt J, Mairal A, Ryden M, Arner E, Sicard A, Jenkins CM, Viguerie N, van Harmelen V, Gross RW, Holm C, and Arner P. Adipocyte lipases and defect of lipolysis in human obesity. Diabetes 54:3190-3197, 2005.

22. Large V, Reynisdottir S, Langin D, Fredby K, Klannemark M, Holm C, and Arner P. Decreased expression and function of adipocyte hormone-sensitive lipase in subcutaneous fat cells of obese subjects. J Lipid Res 40: 2059-2066, 1999.

23. Lofgren P, Hoffstedt J, Ryden M, Thorne A, Holm C, Wahrenberg H, and Arner P. Major gender differences in the lipolytic capacity of abdominal subcutaneous fat cells in obesity observed before and after long-term weight reduction. J Clin Endocrinol Metab 87: 764-771, 2002.

24. Lundholm $\mathrm{L}$ and Svedmyr $\mathrm{N}$. Influence of adrenaline on blood flow and metabolism in the human forearm. Acta Physiol Scand 65: 344-351, 1965.

25. Matthews DR, Hosker JP, Rudenski AS, Naylor BA, Treacher DF, and Turner RC. Homeostasis model assessment: insulin resistance and beta-cell function from fasting plasma glucose and insulin concentrations in man. Diabetologia 28: 412-419, 1985.

26. Moberg E, Sjoberg S, Hagstrom-Toft E, and Bolinder J. No apparent suppression by insulin of in vivo skeletal muscle lipolysis in nonobese women. Am J Physiol Endocrinol Metab 283: E295301,2002 
27. Montell E, Lerin C, Newgard CB, and Gomez-Foix AM. Effects of modulation of glycerol kinase expression on lipid and carbohydrate metabolism in human muscle cells. $J$ Biol Chem 277: 26822686, 2002.

28. Perseghin G, Scifo P, De Cobelli F, Pagliato E, Battezzati A, Arcelloni C, Vanzulli A, Testolin G, Pozza G, Del Maschio A, and Luzi L. Intramyocellular triglyceride content is a determinant of in vivo insulin resistance in humans: a $1 \mathrm{H}-13 \mathrm{C}$ nuclear magnetic resonance spectroscopy assessment in offspring of type 2 diabetic parents. Diabetes 48: 1600-1606, 1999.

29. Petersen KF and Shulman GI. Etiology of insulin resistance. Am J Med 119: S10-16, 2006.

30. Qvisth V, Hagstrom-Toft E, Enoksson S, Sherwin RS, Sjoberg S, and Bolinder J. Combined hyperinsulinemia and hyperglycemia, but not hyperinsulinemia alone, suppress human skeletal muscle lipolytic activity in vivo. J Clin Endocrinol Metab 89: 4693-4700, 2004.

31. Roepstorff C, Donsmark M, Thiele M, Vistisen B, Stewart G, Vissing K, Schjerling P, Hardie DG, Galbo H, and Kiens B. Sex differences in hormone-sensitive lipase expression, activity, and phosphorylation in skeletal muscle at rest and during exercise. Am J Physiol Endocrinol Metab 291: E1106-1114, 2006.

32. Roepstorff C, Vistisen B, Donsmark M, Nielsen JN, Galbo H, Green KA, Hardie DG, Wojtaszewski JF, Richter EA, and Kiens B. Regulation of hormone-sensitive lipase activity and Ser563 and Scr565 phosphorylation in human skeletal muscle during exercise. J Physiol 560: 551$562,2004$.

33. Sacchetti M, Saltin B, Osada T, and van Hall G. Intramuscular fatty acid metabolism in contracting and non-contracting human skeletal muscle. $J$ Physiol 540: 387-395, 2002.

34. Sinha R, Dufour S, Petersen KF, LeBon V, Enoksson S, Ma YZ, Savoye M, Rothman DL, Shulman GI, and Caprio S. Assessment of skeletal muscle triglyceride content by (1)H nuclear magnetic resonance spectroscopy in lean and obese adolescents: relationships to insulin sensitivity, total body fat, and central adiposity. Diabetes 51: 1022-1027, 2002.

35. Sjostrand M, Gudbjornsdottir S, Holmang A, Strindberg L, Ekberg K, and Lonnroth P. Measurements of interstitial muscle glycerol in normal and insulin-resistant subjects. $J$ Clin Endocrinol Metab 87: 2206-2211, 2002.

36. van Hall G, Sacchetti M, Radegran G, and Saltin B. Human skeletal muscle fatty acid and glycerol metabolism during rest, exercise and recovery. J Physiol 543: 1047-1058, 2002.

37. Watt MJ, Holmes AG, Pinnamaneni SK, Garnham AP, Steinberg GR, Kemp BE, and Febbraio MA. Regulation of HSL serine phosphorylation in skeletal muscle and adipose tissue. $A m J$ Physiol Endocrinol Metab 290: E500-508, 2006.

38. Webb DJ. The pharmacology of human blood vessels in vivo. $J$ Vasc Res 32: 2-15, 1995.

39. Wicklmayr M, Dietze G, Rett K, and Mehnert H. Evidence for a substrate regulation of triglyceride lipolysis in human skeletal muscle. Horm Metab Res 17: 471-475, 1985.

40. Zimmermann R, Strauss JG, Haemmerle G, Schoiswohl G, Birner-Gruenberger R, Riederer M, Lass A, Neuberger G, Eisenhaber F, Hermetter A, and Zechner R. Fat mobilization in adipose tissue is promoted by adipose triglyceride lipase. Science 306: 1383-1386, 2004. 


\section{6}

\section{Adipose TriGlyceride Lipase (ATGL) expression in human skeletal muscle is type I (oxidative) fiber specific}

Jocken JWE ${ }^{1}$, Smit $E^{1}$, Goossens $\mathrm{GH}^{1}$, Essers $\mathrm{YPG}^{1}$, van Baak MA ${ }^{1}$, Mensink $\mathrm{M}^{1}$, Saris $\mathrm{WHM}^{1}$ and Blaak $\mathrm{EE}^{1}$

${ }^{\prime}$ Department of Human Biology, Nutrition and Toxicology Research Institute Maastricht (NUTRIM), Maastricht University, Maastricht, The Netherlands

FASEB Journal (IQ accepted-invited to submit) 
[Chapter 6

\begin{abstract}
Recent evidence indicates that increased fat storage in nonadipose tissues, such as skeletal muscle, plays an important role in the etiology of insulin resistance and type 2 diabetes mellitus. Recently the identification of a new lipase was reported: adipose triglyceride lipase (ATGL). ATGL deficient animals show significant fat accumulation in non-adipose tissues such as skeletal muscle. Here we demonstrate that ATGL protein is present in human skeletal muscle, and is exclusively expressed in type I (oxidative) muscle fibers, suggesting an important role for ATGL in intramuscular fat breakdown and storage.
\end{abstract}


ATGL in skeletal muscle]

\section{Introduction}

Recent evidence indicates that increased fat storage in non-adipose tissues (ectopic fat), such as skeletal muscle plays an important role in the etiology of insulin resistance and type 2 Diabetes mellitus (6). A disturbed fat breakdown (lipolysis) may be a factor contributing to an increased fat storage in the form of intramuscular triacylglycerols (IMTAG) and lipid intermediates (1). The enzymatic regulation of fat breakdown in muscle is incompletely understood, even in healthy volunteers. The general view is that fat stores can be mobilized by hormone-sensitive lipase (HSL), which is controlled by the action of catecholamines and muscle contraction. Recently the identification of a new lipase was reported that is primarily responsible for the hydrolysis of triacylglycerols: adipose triglyceride lipase (ATGL) (7). ATGL mRNA expression has been demonstrated in skeletal muscle of rodents (7). ATGL may play a pivotal role in skeletal muscle lipolysis and ectopic fat storage, since ATGL deficient animals show significant triacylglycerol accumulation in nonadipose tissues such as skeletal muscle (3). However, up to the present, ATGL protein expression in human skeletal muscle has not been shown. The aim of the present study was to investigate whether ATGL is expressed at the protein level in human skeletal muscle and whether this expression is muscle fiber type specific.

\section{Material \& Methods}

\section{Subjects}

Needle biopsies were taken under local anesthesia from the vastus lateralis muscle of 8 male subjects after an overnight fast [mean body mass index, BMI: $28.9 \pm 1.9$ $\mathrm{kg} / \mathrm{m}^{2}$ (range: $21.0-34.5 \mathrm{~kg} / \mathrm{m}^{2}$ ) and mean age: $50 \pm 3$ yr (range: $38-59 \mathrm{yr}$ )]. Muscle tissue was frozen immediately in isopentane and stored at $-80^{\circ} \mathrm{C}$ until further analysis. All subjects were asked to refrain from drinking alcohol and to perform no strenuous exercise for a period of 24h prior to the biopsy. The Medical Ethical Review Committee of Maastricht University approved the study protocol and the clinical investigations were performed according to the Declaration of Helsinki. All subjects gave their informed consent before participating in the study.

\section{Immunostaining and immunofluorescence protocol}

Transverse serial sections $(10 \mu \mathrm{m})$ were cut from each biopsy and each section was placed on a glass slide and air dried at room temperature. Skeletal muscle ATGL protein expression and fiber type were investigated by means of a combined immunostaining and immunofluorescence protocol. The sections were fixed using $0.3 \%$ $\mathrm{H}_{2} \mathrm{O}_{2}$ in methanol. After washing with phosphate buffered saline (PBS) the sections were incubated overnight with a polyclonal antibody raised against human ATGL (Cat. No. 10006409 , Cayman Chemical, Michigan, USA) in PBS at room temperature. Thereafter, slides were incubated with a secondary antibody (swine-antirabbit; biotin labeled, DAKO 0353). Subsequently, slides were washed with $0.05 \%$ Tween in PBS and incubated with the ABC peroxidase kit (Vectastain Elite PK610, 
[Chapter 6

Vector, Burlingame, California). The ATGL immunostaining was visualized with diaminobenzidine (DAB) solution (Fluka Chemie, GmbH, Buchs, Germany) diluted in $0.05 \mathrm{M}$ Tris, $\mathrm{pH} 7.6$ and $0.03 \% \mathrm{H}_{2} \mathrm{O}_{2}$. Coloring was followed by microscope and stopped with water. For determining muscle fiber type the same slides were shortly washed in PBS and then incubated with a monoclonal antibody raised against adult human slow myosin heavy chain and a monoclonal antibody reactive with adult human fast IIa myosin heavy chain (2). The antibodies were diluted in PBS and incubated at room temperature. The following secondary antibodies were used: goat anti-mouse IgM conjugated with Alexa Fluor 555 (red) (GAMIgMAlexa555) and goat anti-mouse IgG1 conjugated with Alexa Fluor 488 (green) (GAMIgGlAlexa488; Molecular Probes Europe, Leiden, The Netherlands), diluted in PBS and incubated at room temperature. Finally, nuclei were colored using Haematoxilin and slides were included in Mowiol. Sections were viewed and photographed using a Nikon Eclipse E800 microscope mounted with an Axiocam color CCD camera (Nikon, Melville, NY USA).
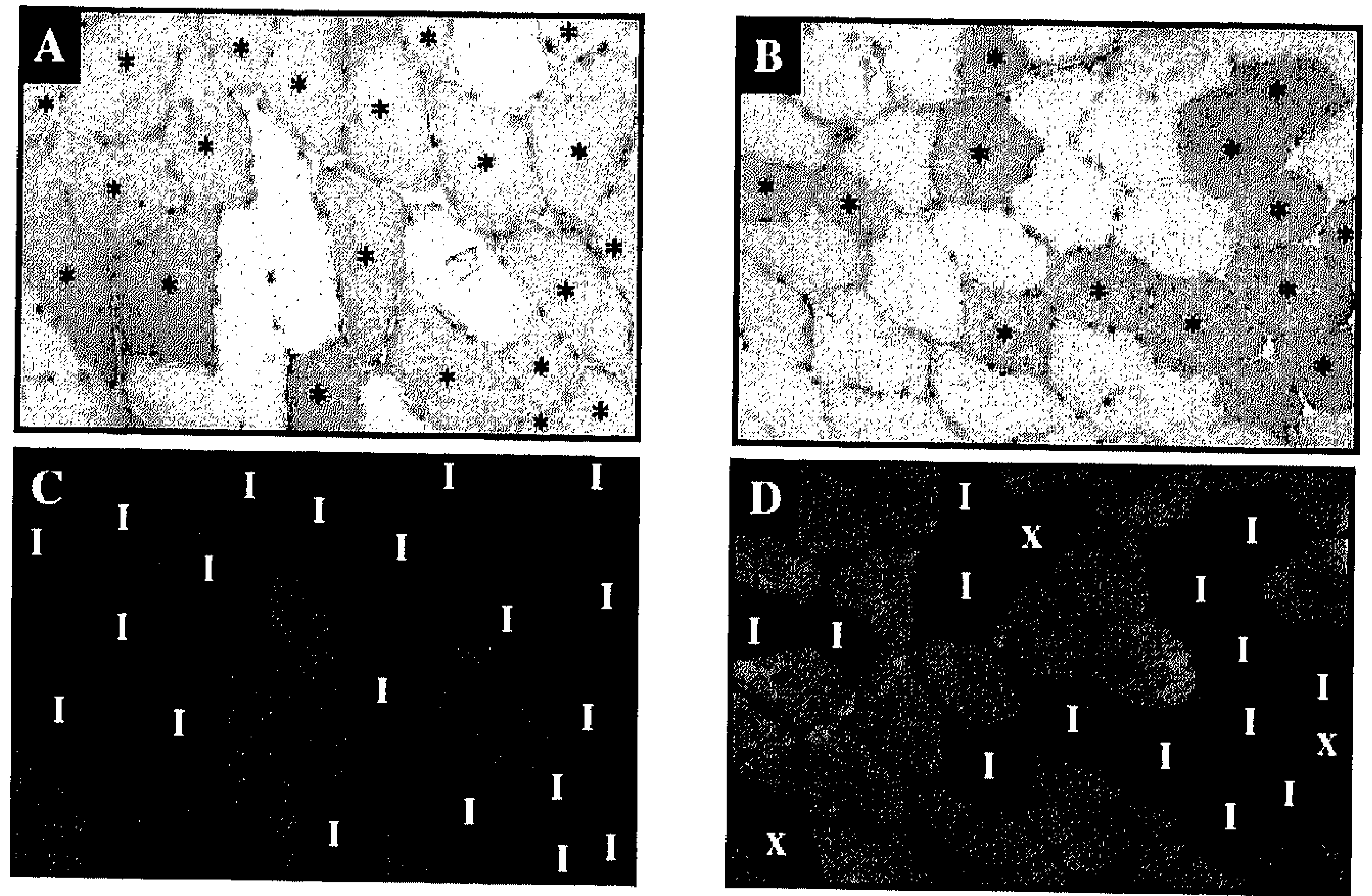

Figure 1. Immunohistochemical ATGL staining combined by immunofluorescent fiber typing in skeletal muscle of a lean (BMI: $21.0 \mathrm{~kg} / \mathrm{m}^{2}$, panel A and C) and an obese (BMI: $32.4 \mathrm{~kg} / \mathrm{m}^{2}$, panel B and D) subject. (A and B) Muscle fibers that contain ATGL stained brown using DAB (fibers positively stained for ATGL are indicated by *). (C and D) Dual-immunofluorescent staining of muscle fibers; type I muscle fibers stained red (indicated by I), type IIa muscle fibers stained green and type IIx muscle fibers were unstained (indicated by $\mathrm{X}$ ). Images are of the same area of the same section from the same lean (panel A and C) or obese (panel B and D) individual and demonstrate that ATGL is expressed exclusively in type I muscle fibers. 
ATCL in sketetal muscle]

\section{Results}

In Figure $1 \mathrm{~A}$ and $\mathrm{B}$ we demonstrate that AT(iI. protein is indeed expressed in human skeletal muscle of lean and obese subjects, respectively (visualized as hrown diaminohenzidin (I)AB / staining. This observation was representative for all lean (BMI $25 \mathrm{kgm}, \mathrm{n} 3$ ) and ohese (BMI $30 \mathrm{~kg} / \mathrm{m}, 5$ male subjects. Preincubation of the ATCiI. antibody with the ATCil peptide or incubation of the slides without ATGL antibody resulted in the complete disappearance of this staining, indicating that this staining is highly AT(iL specific. The dual-immunofluoresent staining of skeletal muscle fibers is shown in panels ( and D of Figure 1 for lean and ohese subjects, respectively. Type I fihers stained red and type lla fihers stained green: type IIx fibers were unstained. Images are of the same area of the same section from the same individual. Combining the four images we observed that ATGL is expressed exclusively in type I fibers, both in lean and obese subjects. All type I fihers stained positive for ATGil. None of the type II fibers showed a positive staining for
ATGL.

\section{Discussion}

It is known that type I (slow-twitch, oxidative) muscle fibers have an increased triacylglycerol content compared to type Ila and IIx (fast-twitch tibers) (5). The present finding of exclusive expression of ATGL in type I fibers, with high triacylglycerol content, may suggest an important role for ATGL in intramuscular triacylglycerol breakdown and storage in human subjects. It has been shown that HSL is also expressed in human skeletal muscle. Although HSL expression is not fiber type specific. higher levels are also found in type I fibers (4). Taken together, there is an urgent need to investigate the physiological role of ATGL in skeletal muscle lipolysis in healthy volunteers and under obese insulin resistant conditions. In addition, it should be examined whether a possible impairment can be reversed by interventions like weight loss or physical activity that improve insulin sensitivity.

In summary, the present data show for the first time that ATGL protein is present in human skeletal muscle, and is exclusively expressed in type I (oxidative) muscle
fibers.

\section{References}

1. Blaak EF, Schiffelers SI., Saris WH, Mensink M. and Kooi ME. Impaired beta-adrenergically mediated lipolysis in skeletal muscle of ohese subjects. Diahetologia 47: 1462-1468.2004.

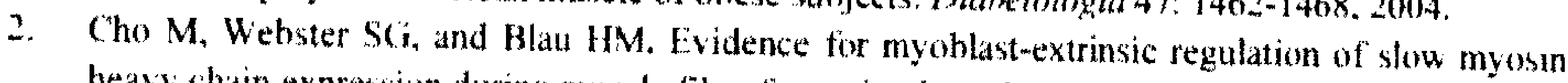
heavy chain expression during muscle fiber formation in embryonic development. $J$ (c)ll biol 121: $795-810,1943$.

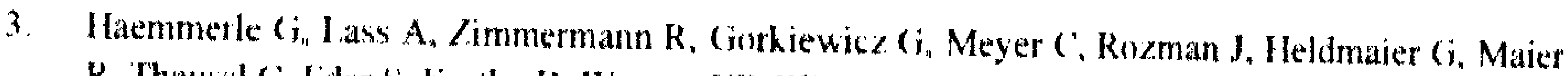

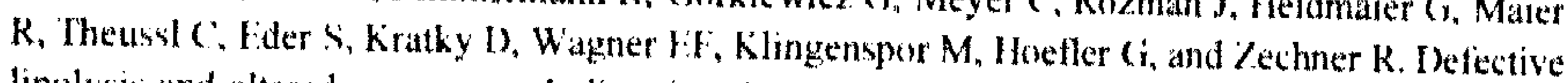
lipolysiv and altered energy metabolism in mice lacking adipose triglyceride lipase. Scienct 312 : $734.737,21106$. 


\section{[Chapter 6}

4. Langfort J, Ploug T, Thlemann J, Saldo M, Holm C, and Galbo H. Expression of hormone-sensitive lipase and its regulation by adrenaline in skeletal muscle. Biochem J 340 (Pt 2): 459-465, 1999.

5. Malenfant P, Joanisse DR, Theriault R, Goodpaster BH, Kelley DE, and Simoneau JA. Fat content in individual muscle fibers of lean and obese subjects. Int J Obes Relat Metab Disord 25: 1316$1321,2001$.

6. Petersen KF and Shulman GI. Etiology of insulin resistance. Am J Med 119: S10-16, 2006.

7. Zimmermann R, Strauss JG, Haemmerle G, Schoiswohl G, Birner-Gruenberger R, Riederer M, Lass A, Neuberger G, Eisenhaber F, Hermetter A, and Zechner R. Fat mobilization in adipose tissue is promoted by adipose triglyceride lipase. Science 306: 1383-1386, 2004. 


\section{7}

\section{Association of a beta-2 adrenoceptor (ADRB2) gene variant with a blunted in vivo lipolysis and fat oxidation}

Jocken $\mathbf{J W}^{1}$, Blaak $\mathrm{EE}^{1}$, Schiffelers $\mathrm{S}^{1}$, Arner $\mathrm{P}^{2}$, van Baak $\mathrm{MA}^{1}$ and Saris $\mathrm{WH}^{1}$.

\footnotetext{
'Department of Human Biology, Nutrition and Toxicology Research Institute Maastricht (NUTRIM), Maastricht University, Maastricht, The Netherlands

${ }^{2}$ Department of Medicine, Karolinska Institute, Huddinge University Hospital, Stockholm, Sweden
}

Int J Obes 2007;31(5):813-9 
[Chapter 7

\begin{abstract}
Background: Obesity is associated with a blunted betaadrenoceptor mediated lipolysis and fat oxidation. We investigated whether polymorphism in codons 16,27 and 164 of the $\beta 2$-adrenoceptor gene (ADRB2); and exon 10 of the $G$ protein $\beta 3$-subunit gene (GNB3), are associated with alterations in in vivo lipolysis and fat oxidation.
\end{abstract}

Methods: 65 male and 43 female overweight and obese subjects (BMI range: $26.1-48.4 \mathrm{~kg} / \mathrm{m}^{2}$ ) were included. Energy expenditure (EE), respiratory quotient (RQ), circulating free fatty acid (FFA) and glycerol levels were determined after stepwise infusion of increasing doses of the non-selective beta-agonist isoprenaline (ISO).

Results: In women the $\operatorname{Arg} 16$ allele of the $A D R B 2$ gene was associated with a blunted increase in circulating FFA, glycerol and a decreased fat oxidation during ISO stimulation. In men the Arg16 allele was significantly associated with a blunted increase in FFA but not in glycerol or fat oxidation.

Conclusions: These results suggest that genetic variation in the $A D R B 2$ gene is associated with disturbances in in vivo betaadrenoceptor mediated lipolysis and fat oxidation during betaadrenergic stimulation in overweight and obese subjects; these effects are influenced by gene-gender interactions. 
The ADRB2 gene in obesity]

\section{Introduction}

Obesity is characterized by increased circulating fatty acid (FFA) concentrations resulting from increased triacylglycerol (TAG) storage within adipose tissue. In vivo studies have shown that the development or maintenance of increased adipose tissue stores might be promoted by a blunted lipolytic response and fat oxidation after beta-adrenergic stimulation or exercise in obese or obese type 2 diabetic subjects $(4,6-8)$. This blunted beta-adrenoceptor mediated lipolysis and fat oxidation persisted after weight reduction, indicating this disturbance may be an early, even primary factor, in the development or maintenance of increased adipose stores (8). There are indications that the blunted beta-adrenergically mediated lipolysis in obesity may be related to an impaired function or a reduced number of adipocyte beta- 2 $\left(\beta_{2}\right)$ adrenoceptors $(31,34)$.

$\beta_{2}$-Adrenoceptors are stimulatory $\mathrm{G}$ protein-coupled $\left(\mathrm{G}_{\mathrm{s}}\right)$ receptors. The $\beta_{2^{-}}$ adrenoceptor (ADRB2) gene is encoded by an intronless gene on chromosome 5q31-q32 $(25,26)$. Several polymorphisms of the human ADRB2 gene have been described $(28,29)$. Among these, three common single nucleotide polymorphisms (SNPs) result in the substitution of an amino acid. One is located at codon 16 substituting arginine for glycine (Arg16Gly). The other one is located at codon 27 substituting glutamic acid for glutamine (Gln27Glu). Both variants are located in the extracellular amino-terminal region of the receptor and alter cellular trafficking and desensitization of the receptor (19). Previous studies have reported associations between codon 16 and 27 polymorphisms and obesity, insulin resistance and hypertension (12-22). Finally, the substitution of isoleucine for threonine at codon 164 (Thr164Ile), in the receptor transmembrane spanning domain, alters agonist binding and decreases coupling of the $\mathrm{G}_{\mathrm{s}}$ protein to the receptor $(17,18)$. There is evidence from in vitro studies that some of these receptor variants might be important for catecholamine-induced adipocyte lipolysis in humans $(23,27)$.

Furthermore, polymorphisms in $G$ proteins involved in catecholamine signaling may alter corresponding receptor and hormone function. Recently, a common polymorphism substituting a cytosine for a thymine at position 825 (C825T) in exon 10 of the G-Protein $\beta_{3}$-subunit (GNB3) gene (chromosome 12p13), coding an isoform of the $G$ protein $\beta$ subunit $\left(G \beta_{3}\right)$, has been identified (37). $G_{s}$ deficiency is also observed in obesity and the C825T polymorphism is associated with obesity and hypertension in both white and non-white populations $(2,11,14,21,22,30,35$, 36). In vitro studies indicated that the $825 \mathrm{~T}$ variant of $\mathrm{G} \beta_{3}$ in its homozygous form was associated with a decreased amount of $\mathrm{G} \beta_{3}$ in fat cells. Thereby inhibiting signaling through $\beta_{1^{-}}, \beta_{2^{-}}$, and $\alpha_{2}$-adrenoceptors, resulting in decreased catecholamine action and blunted lipolysis in isolated subcutaneous adipocytes of male and female obese subjects (32).

Thus, there are indications that polymorphisms in the ADRB2 gene and the GNB3 gene may be related to an impaired in vitro lipolytic response. So far, however, few in vivo lipolysis studies on these polymorphisms have been performed. For this reason the present study investigated the effect of genetic variation in the $A D R B 2$ gene and the GNB3 gene on in vivo lipolysis and fat oxidation in overweight and obese subjects. 
[Chapter 7

\section{Methods}

\section{Subjects}

The study group consisted of 108 overweight and obese (BMI range: $26.1-48.4$ $\mathrm{kg} / \mathrm{m}^{2}$ ) subjects $(43 \mathrm{~F} / 65 \mathrm{M})$. Twenty-four overweight subjects (BMI between 25 and $29.9 ; 11 \mathrm{~F} / 13 \mathrm{M})$ and eighty-four obese subjects $(\mathrm{BMI}>29.9 ; 32 \mathrm{~F} / 52 \mathrm{M})$ were included. The basic selection criteria were age $20-50 \mathrm{y}$ and $\mathrm{BMP}>25 \mathrm{~kg} / \mathrm{m}^{2}$. Exclusion criteria were: weight change $>3 \mathrm{~kg}$ within 3 months prior to the study start; drug treated hypertension, diabetes or hyperlipidemia; thyroid disease; surgically treated obesity; pregnancy, alcohol or drug abuse and participation in other simultaneous ongoing trials. All subjects were recruited by means of an advertisement in a local newspaper. All subjects were in good health as assessed by medical history and physical examination and were not taking any medication. A normal resting electrocardiogram $(E C G)$ and blood pressure were a prerequisite for participation. The study protocol was reviewed and approved by the Medical Ethical Review Committee of Maastricht University. The subjects were informed in detail about the investigation and their consent was obtained before participating in the study.

Table 1. Subject characteristics

\begin{tabular}{lccc}
\hline & Men $(\mathrm{n}=65)$ & Women $(\mathrm{n}=43)$ & P-value \\
\hline Age $(\mathrm{yr})$ & $43.3 \pm 1.0$ & $38.8 \pm 1.3$ & $*$ \\
BMI $\left(\mathrm{kg} / \mathrm{m}^{2}\right)$ & $32.5 \pm 0.5$ & $32.3 \pm 0.6$ & $\mathrm{NS}$ \\
$\%$ body fat & $31.7 \pm 0.7$ & $42.4 \pm 0.7$ & $* *$ \\
WHR & $1.04 \pm 0.01$ & $0.86 \pm 0.02$ & $* *$ \\
EE resting $(\mathrm{kJ} / \mathrm{min}) \#$ & $5.56 \pm 0.10$ & $5.72 \pm 0.13$ & $\mathrm{NS}$ \\
RQ resting & $0.81 \pm 0.01$ & $0.82 \pm 0.01$ & $\mathrm{NS}$ \\
Fasting FFA $(\mu \mathrm{mol} / \mathrm{L})$ & $477 \pm 27$ & $607 \pm 30$ & $* *$ \\
Fasting glycerol $(\mu \mathrm{mol} / \mathrm{L})$ & $73 \pm 3$ & $77 \pm 7$ & $\mathrm{NS}$ \\
\hline
\end{tabular}

All values are mean \pm SEM; BMI body mass index, WHR waist-to-hip ratio, $E E$ energy expenditure, $R Q$ respiratory quotient, FFA free fatty acids. \# $\mathrm{EE}$ adjusted for $\mathrm{FFM} .{ }^{*} \mathrm{P}=0.01,{ }^{* * \mathrm{P}}<0.001$ men $v$, women using Student's unpaired t-test.

\section{Antropometric Measurements}

Body weight was determined on an electronic scale, accurate to $0.1 \mathrm{~kg}$. Waist and hip circumference measurements to the nearest $1 \mathrm{~cm}$ were made with subjects standing upright. BMI was calculated as body weight in kilograms divided by squared height in meters. Body density was obtained by underwater weighing with residual pulmonary volume measurement by the helium dilution method (Volugraph 2000, Mijnhardt) and was converted to percent body fat using the equation of Siri (38). Fat mass (FM) and fat-free mass (FFM) were calculated from the percent body fat and body weight. 
The ADRB2 gene in obesity]

\section{Study Design}

The subjects arrived at the laboratory at $0800 \mathrm{~h}$ after an overnight fast (of at least $12 \mathrm{~h}$ ) by car or public transport. They were studied while resting supine on a comfortable bed in a room kept at $23-25^{\circ} \mathrm{C}$. At the beginning of the experiment a catheter was inserted into a forearm vein for blood sampling. A second catheter was inserted in the contralateral arm for infusion of the non-selective $\beta$-agonist isoprenaline (ISO). $30 \mathrm{~min}$ after insertion of the catheters, the measurement protocol started. Energy expenditure and substrate oxidation were measured during the entire period with an open circuit ventilated hood system. After 30 minutes blood was sampled for baseline measurements and genetic analysis. Following the $30 \mathrm{~min}$ baseline period, ISO infusion started at increasing concentrations of 6,12 and $24 \mathrm{ng}$. $\mathrm{kg} \mathrm{FFM}^{-}$ ${ }^{1} \cdot \mathrm{min}^{-1}$, each dose for 30 minutes. At the end of each infusion period venous blood samples were taken, centrifuged and stored at $-80^{\circ} \mathrm{C}$ until further analysis. During ISO infusion heart rate was kept under close observation by means of an ECG. When the heart rate increased by more than 30 beats $/ \mathrm{min}$ above baseline or in case of an irregular heart rhythm ISO infusion was stopped.

\section{Genetic Analysis}

Genomic DNA was extracted from peripheral blood leukocytes by digestion with protein $\mathrm{K}$ followed by phenol/chloroform extraction. Amplification of the relevant segments of the $A D R B 2$ and GNB3 genes was done by polymerase chain reaction as previously described $(27,32)$. The PCR products were digested at $37^{\circ} \mathrm{C}$ for $1 \mathrm{~h}$ using BsrDI, ItaI, MnlI or BseDI. The digested fragments were visualized using ethidium bromide staining and UV transmitted light. Finally, we evaluated the accuracy of the RFLP method by direct sequencing of random samples and got $100 \%$ agreement. In addition, two persons independently evaluated samples and identical results were obtained.

\section{Biochemical analysis}

Whole blood was collected in tubes containing EDTA and centrifuged for $10 \mathrm{~min}$ at $3000 \mathrm{rpm}\left(4^{\circ} \mathrm{C}\right)$ and the plasma removed for the enzymatic calorimetric quantitation of FFA (NEFA C kit, Wako, Neuss, Germany) and glycerol (Boehringer Mannheim, Germany) on a COBAS FARA centrifugal spectrometer (Roche Diagnostica). Standard samples with known concentrations were included in each run for quality control.

\section{Statistical analysis}

All statistical calculations were performed with SPSS for Macintosh (version 11.0; SPSS inc., Chicago, IL, USA). The initial statistical analysis, performed for the whole group $(\mathrm{n}=108)$, indicated a significant gender effect for the Arg 16 allele on lipolytic parameters (iAUC $\triangle \mathrm{FFA}: \mathrm{P}=0.01$, allel*gender interaction) and fat oxidation (iAUC $\triangle R Q$ : $P=0.042$ ). For this reason the presented analysis is stratified by gender. The effect of genotypes on lipolytic responses and fat oxidation was investigated using ANOVA (adjusted for age and BMI). Post-hoc testing was performed 


\section{[Chapter 7}

by student's unpaired t-test with Bonferroni correction. Linkage disequilibrium was estimated according to Devlin et al (13). Diplotype analyses were performed as described before $(15,16)$. The goodness of fit between observed and expected genotype frequency (Hardy-Weinberg Equilibrium, HWE) was statistically tested using the $\chi^{2}$-test (33). Allele and genotype frequency distributions for the whole group $(n=108)$ are presented in Table 2. Energy expenditure (EE) was adjusted for FFM by means of covariance analysis (ANCOVA). The ISO-induced effect on fat oxidation (RQ), thermogenesis (EE) and lipolysis (FFA, glycerol) were expressed as incremental area under the curve (iAUC) above baseline, calculated according to the trapezium rule. All data are represented as mean \pm standard error of the mean (SEM). $\mathrm{P}<0.05$ was considered as statistically significant.

\section{Power calculation}

A power analysis was performed to estimate the sample size required enabling the accurate and reliable statistical judgments for the 2-way parametric statistics. There are little or no published studies regarding the effect of $A D R B 2$ and GNB3 gene variants and whole body lipolysis and fat oxidation, although the results of in vitro studies in human adipocytes support a major effect. We therefore estimated our sample size using published data of the effect of beta-adrenergic stimulation on whole body lipolysis and fat oxidation $(7,9,24)$. Power calculation indicated that to detect a difference in circulating FFA of $100 \mu \mathrm{mol} / \mathrm{L}$ (with a SD of $50 \mu \mathrm{mol} / \mathrm{L}$ ) or circulating glycerol of $50 \mu \mathrm{mol} / \mathrm{L}$ (with a SD of $25 \mu \mathrm{mol} / \mathrm{L}$ ) and a power of 0.80 $(\alpha=0.05$ and $\beta=0.20$ ), the number of subjects in each group (2-tailed) should be 16 .

\section{Results}

As mentioned under statistical methods, initial analysis performed for the whole group $(n=108)$ indicated a significant gender effect for the Arg16 allele. For this reason the presented analysis is stratified by gender.

\section{Subjects}

Anthropometric and metabolic characteristics of the study subjects are shown in Table 1. Women had significantly higher percentage body fat, a lower waist-hip ratio and were significantly younger compared to male participants. Additionally, women had a significantly higher fasting FFA level. No significant differences were observed for BMI, resting EE (adjusted for FFM) and fasting glycerol levels between genders.

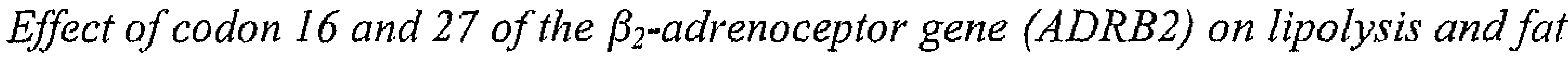
oxidation after beta-adrenergic stimulation.

Allele and genotype frequency distributions for the ADRB2 gene are shown in Table 2. For women ANOVA analysis indicated a significant genotype effect for codon 16 and a blunted increase in FFA $(\mathrm{P}=0.046$, see Figure 1), glycerol $(\mathrm{P}=0.037$, 
The ADRB2 gene in obesity]

see Figure 1) and fat oxidation ( $\mathrm{P}=0.042$, see Figure 2), even after correction for age and BMI. Post-hoc analysis indicated that in women the Arg16Gly genotype was significantly associated with a blunted increase in circulating FFA (iAUC $\triangle F F A$ after ISO: $379 \pm 35 v s .493 \pm 40 \mu \mathrm{mol} / \mathrm{L}, \mathrm{P}=0.041$, see Figure 1) and glycerol (iAUC $\Delta$ Glycerol after ISO: $86 \pm 11$ vs. $128 \pm 14 \mu \mathrm{mol} / \mathrm{L}, \mathrm{P}=0.026$, see Figure 1) during stimulation compared to female Gly16 homozygotes. In addition to a blunted lipolytic response, female Arg16 Gly heterozygotes showed a blunted increase in fat oxidation compared to Gly16 homozygotes (iAUC $\triangle R Q$ after ISO: $0.004 \pm 0.007 v s$. $-0.017 \pm 0.008, \mathrm{P}=0.043$, see Figure 2) and a comparable thermogenic response (iAUC $\triangle$ EE after ISO: $0.51 \pm 0.07$ vs. $0.70 \pm 0.09 \mathrm{~kJ} / \mathrm{min}, \mathrm{NS}$ ).

Table 2. Allele, genotype and diplotype frequency distributions of the ADRB2 gene and GNB3 gene polymorphisms

\begin{tabular}{lc}
\hline & $\mathrm{n}=108$ \\
\hline Allele frequency & 0.394 \\
Arg16 & 0.569 \\
Gln27 & 0.972 \\
Thr164 & 0.741 \\
C & \\
Genotype frequency & 0.371 \\
Gly16Gly (wt) & 0.472 \\
Arg16Gly & 0.157 \\
Arg16Arg & 0.352 \\
Gln27Gln (wt) & 0.435 \\
Gln27Glu & 0.213 \\
Glu27Glu & 0.944 \\
Thr164Thr (wt) & 0.056 \\
Thr164Ile & 0 \\
Ile164Ile & 0.537 \\
CC & 0.407 \\
CT & 0.055 \\
TT & \\
Diplotype frequency & 0.185 \\
Gly16Gly/Glu27Glu & 0.018 \\
Gly16Gly/Gln27Gln & 0.148 \\
Arg16Arg/Gln27Gln &
\end{tabular}

Alleles, genotypes and diplotypes are presented as decimals. All SNPs were in HWE; wt wild type, Arg arginine, Gly glycine, Gln glutamic acid, Glu glutamine, Thr threonine, Ile isoleucine.

Because lipolytic response and fat oxidation appeared to be reduced in both Arg16Gly and Arg16Arg carriers, Arg16 heterozygotes and homozygotes were combined into one group (Arg16Gly+Arg16Arg). Female Arg carriers (Arg16 Gly+Arg16Arg) appeared to have a blunted increase in circulating FFA $(382 \pm 31$ vs. $493 \pm 43 \mu \mathrm{mol} / \mathrm{L}, \mathrm{P}=0.042)$ and glycerol $(89 \pm 10$ vs. $129 \pm 18 \mu \mathrm{mol} / \mathrm{L}$, $\mathrm{P}=0.038)$ after beta-adrenergic stimulation compared to Gly16Gly homozygotes. This altered lipolytic response in female Arg carriers (Arg16Gly+Arg16Arg) was accompanied by a decreased fat oxidation after stimulation (iAUC $\triangle$ RQ after ISO 


\section{[Chapter 7}

$0.003 \pm 0.007$ vs. $-0.016 \pm 0.005, \mathrm{P}=0.024)$. No differences were found in ISOinduced thermogenesis (iAUC $\triangle \mathrm{EE}$ after ISO: $0.57 \pm 0.07$ vs. $0.70 \pm 0.09 \mathrm{~kJ} / \mathrm{min}$, $\mathrm{NS}$ ), body weight, BMI and other anthropometric variables. Data in male overweight subjects were less consistent: ANOVA analysis (adjusted for age and BMI) indicated only a significant genotype effect of codon 16 and a blunted increase in FFA $(\mathrm{P}=0.022$, see Figure 1). Post-hoc analysis revealed that male carriers of the Arg16Gly genotype had a significantly blunted increase in circulating FFA during beta-adrenergic stimulation compared to male Gly16 homozygotes, (266 \pm 30 vs. $401 \pm 34 \mu \mathrm{mol} / \mathrm{L}, \mathrm{P}=0.005$; see Figure 1). However, this blunted FFA response was not accompanied by a blunted increase in circulating glycerol (see Figure 1) nor a decreased fat oxidation (iAUC $\triangle R Q$, see Figure 2). Furthermore, taking Arg16 heterozygotes and homozygotes together into one group, male (Arg16Gly+Arg16Arg) showed a blunted increase in circulating FFA $(281 \pm 21$ vs. $406 \pm 41 \mu \mathrm{mol} / \mathrm{L}$, $P=0.004)$ compared to Gly16Gly carriers, whilst ISO-induced changes in glycerol, thermogenesis and RQ were comparable between groups. Again, no differences were found in body weight, BMI and other anthropometric variables.

For neither female nor male subjects associations were found between genetic variation in codon 27 and 164 of the $\beta_{2}$-adrenoceptor gene (ADRB2) and alterations in fat oxidation or lipolytic response during beta-adrenergic stimulation.

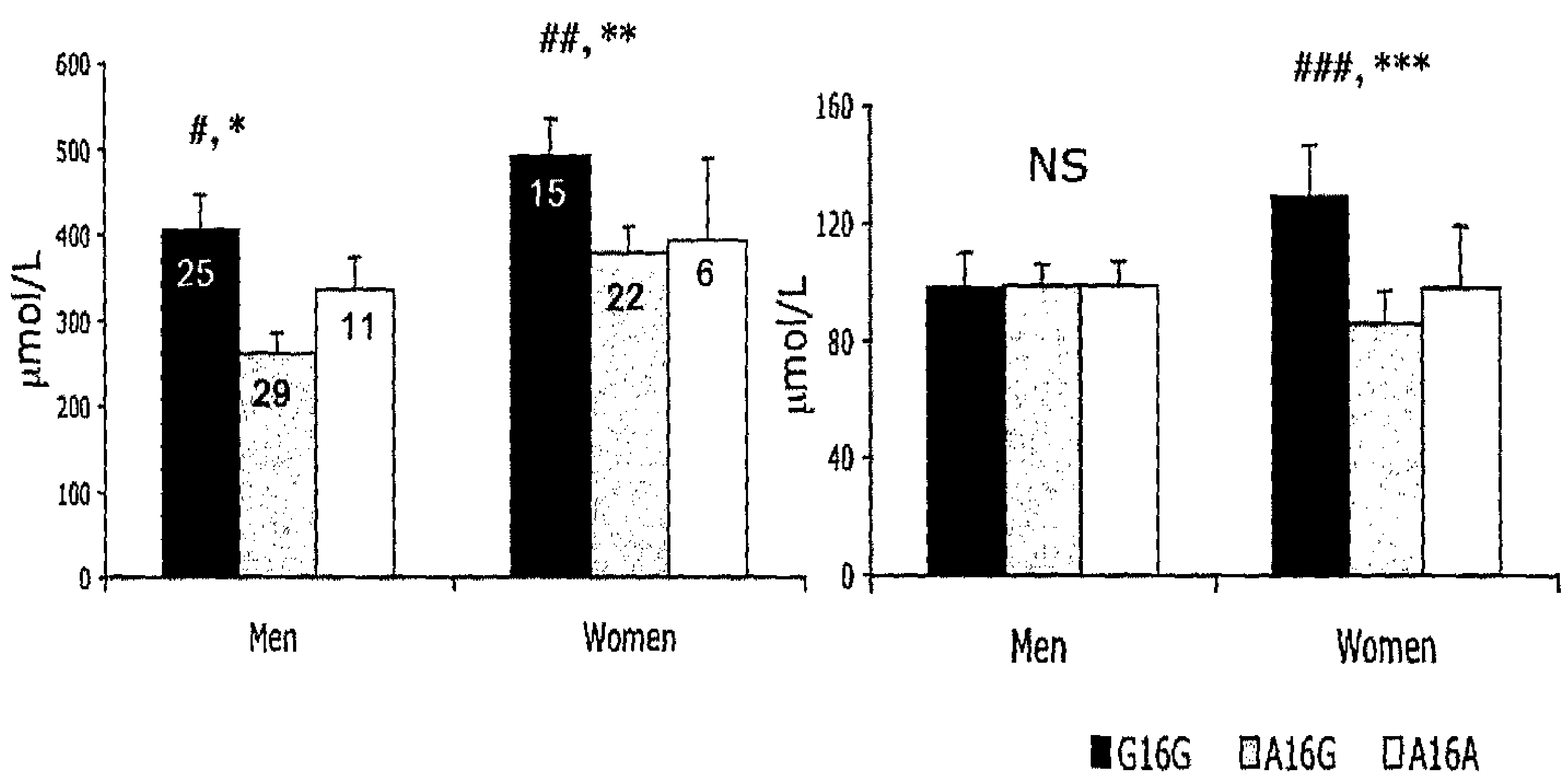

Figure 1. Lipolytic response for cadon 16 polymorphisms of the ADRB2 gene. All values are mean $\pm S E M$. Incremental area under the curve for circulating free fatty acid (left panel) or Glycerol concentration (right panel) during beta-adrenergic stimulation. G16G: Gly16Gly (black bar), A16G: Arg16Gly (grey bar), A16A: Arg16Arg (white bar). ANOVA (adjusted for age and BMI): " $\mathrm{P}=0.022$,

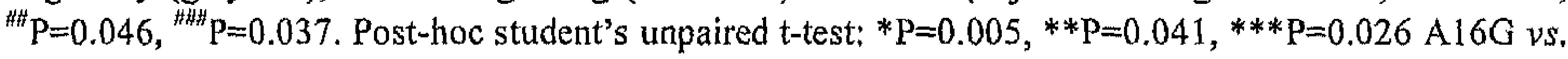
G16G. Number of subjects in each group are indicated in the bars. 
The ADRB2 gene in obesity]

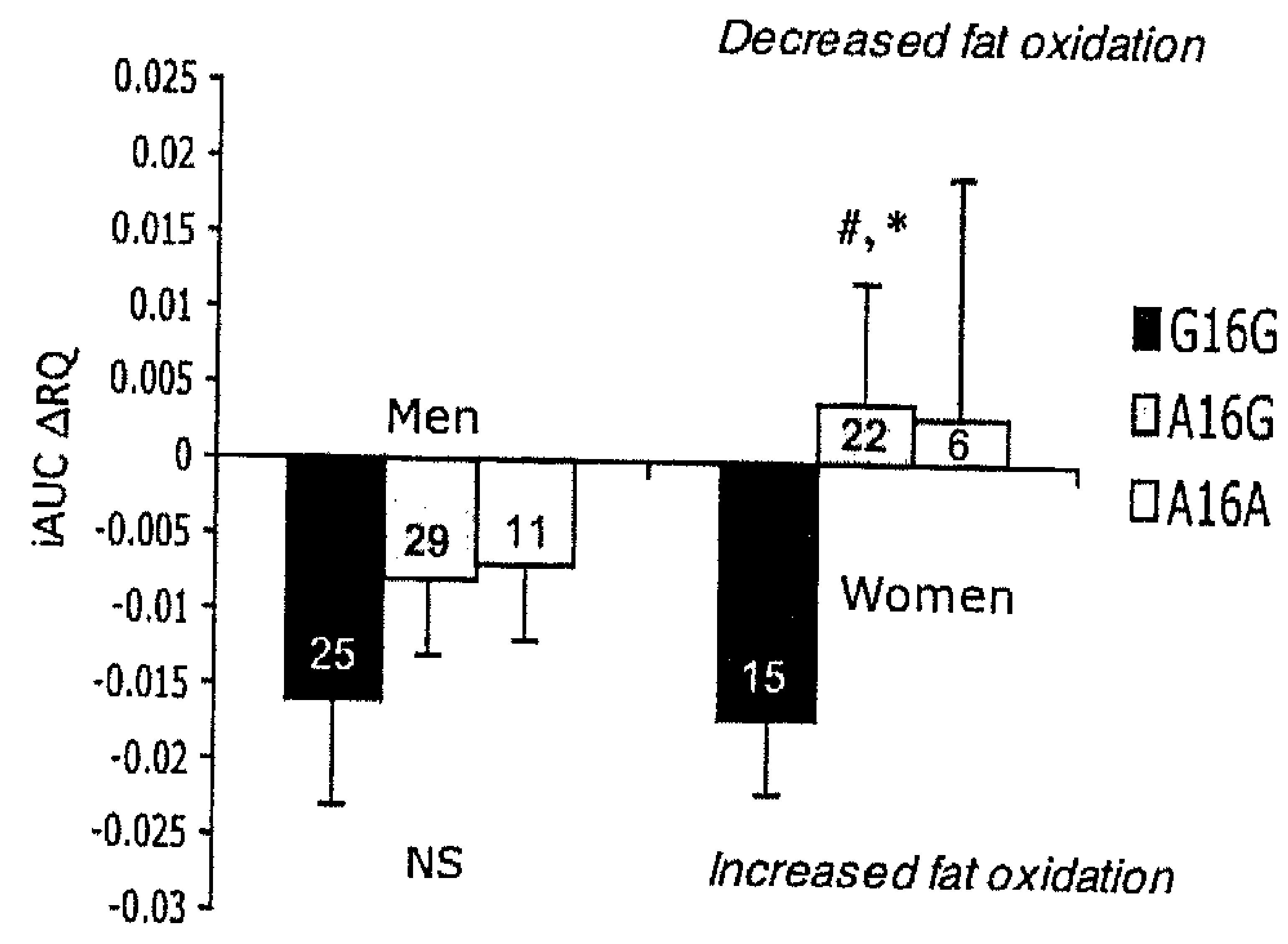

Figure 2. Fat oxidation for codon 16 polymorphisms of the ADRB2 gene. All values are means \pm SEM. iAUC $\triangle R Q$ : Incremental area under the curve for delta respiratory quotient (RQ) during beta-adrenergic stimulation. G16G: Gly 16Gly (black bar), A16G: Arg16Gly (grey bar), A16A: Arg16Arg (white bar). ANOVA (adjusted for age and BMI): ${ }^{~} \mathrm{P}=0.042$. Post-hoc student's unpaired t-test: ${ }^{*} \mathrm{P}=0.043 \mathrm{Gl} 6 \mathrm{G} v \mathrm{~s}$. A16G. Number of subjects in each group are indicated in the bars.

\section{Diplotype analysis}

Three homozygous and functional diplotypes were investigated in both male and female subjects: Gly16Gly/Glu27Glu, Arg16Arg/Gln27Gln and

Gly16Gly/Gln27Gln. The diplotype frequency distribution is depicted in Table 2. From the 55 men carrying the Gly 16 allele, 47 also carried the Glu 27 allele $\left(\chi^{2}=32.653, P<0.0001\right)$ indicating linkage disequilibrium $\left(\left|\mathrm{D}^{\prime}\right|=0.854, \mathrm{r}^{2}=0.494\right)$ (13). In $21.5 \% \quad(n=14)$ of the men and $14 \% \quad(n=6)$ of the women the Gly16Gly/Glu27Glu diplotype was apparent. This diplotype was not associated with a decreased lipolytic response (iAUC $\triangle F F A$ and iAUC $\triangle$ glycerol) or fat oxidation (iAUC $\triangle R Q$ ) in male or female subjects. Nevertheless, female carriers $(n=6)$ of the Gly16Gly/Glu27Glu diplotype had lower fasting FFA levels $(431 \pm 49 v$ s. $636 \pm 32 \mu \mathrm{mol} / \mathrm{L}, \mathrm{P}<0.05$ ) compared to female non-carriers $(\mathrm{n}=37)$. No differences were found in body weight, BMI and other anthropometric variables. The other two diplotypes (Arg16 Arg/Gln27Gln and Gly $16 \mathrm{Gly} / \mathrm{Gln} 27 \mathrm{Gln}$ ) were also not associated with an altered fat oxidation, thermogenic or lipolytic response in this population. Due to the relatively low sample size we were not able to identify beta-2 adrenoceptor haplotypes for both codons 16,27 and 164 with a frequency $>5 \%$. 


\section{[Chapter 7 \\ Effect of the C825T polymorphism in exon 10 of the G-protein beta-3 subunit (GNB3) gene on lipolysis and fat oxidation}

Allele and genotype frequency distributions for the GNB3 gene are shown in Table 2. Male TT carriers $(n=4)$ showed a tendency towards a blunted increase in circulating FFA (iAUC $\triangle$ FFA after ISO: $173 \pm 46 v s .435 \pm 32 \mu \mathrm{mol} / \mathrm{L}$ ) and glycerol (iAUC $\triangle$ Glycerol after ISO: $47 \pm 14$ vs. $107 \pm 8 \mu \mathrm{mol} / \mathrm{L}$ ) after beta-adrenergic stimulation compared to CT carriers $(n=29)$. Similar results were obtained for male CC carriers $(n=32)$. Unfortunately, the number of subjects in the TT group $(n=4)$ was too small to perform statistical analysis. In female overweight subjects no associations were found for the $\mathrm{C} 825 \mathrm{~T}$ polymorphism and an altered lipolytic response, thermogenesis or fat oxidation.

\section{Discussion}

To the best of our knowledge, this is the first study to investigate the association between genetic variability in the ADRB2 gene and GNB3 gene and in vivo lipolysis and fat oxidation in overweight and obese men and women.

The major findings of our study are: firstly, genetic variability in codon 16 of the $A D R B 2$ gene was associated with a blunted increase in circulating FFA and glycerol during beta-adrenergic stimulation with the non-selective beta-agonist isoprenaline (ISO) in female subjects. In male subjects codon 16 was associated with a blunted ISO-induced increase in FFA, whilst no difference in glycerol was apparent. In female subjects this blunted lipolytic response was also accompanied with a reduced fat oxidation. Finally, the TT genotype of the GNB3 gene was associated with a blunted increase in FFA and glycerol in male subjects. This blunted lipolytic response was not accompanied by a reduced fat oxidation.

Large et al. showed that the Arg16Gly genotype was associated with an in vitro five-fold increase in agonist sensitivity of the $\beta_{2}$-adrenoceptor in abdominal subcutaneous adipocytes of overweight female subjects, without any significant effect on glycerol release (27). In our study the Arg16 allele was associated with blunted ISO-induced responses in FFA, glycerol and fat oxidation (iAUC $\triangle R Q$ ) in women and a blunted increase in FFA in men. The reason for this apparent discrepancy with our findings may be related to differences in our in vivo versus the in vitro approach to study lipolysis. In the in vitro situation, in vivo factors like the neuroendocrine environment and local adipocyte blood flow are not taken into account. In addition, the majority of in vitro studies are performed on adipocytes derived from the subcutaneous region in both genders. It should be mentioned that there are major differences in catecholamine-induced lipolysis between depots (subcutaneous vs. visceral and gluteofemoral) and also gender differences in body fat distribution $(1,3,5)$. Our data indicate that variability in codon 16 of the $A D R B 2$ gene may contribute to a reduced in vivo beta-adrenoceptor mediated lipolysis and fat oxidation $(4,6-8)$, indicating that these blunted responses may be important primary factors in obesity.

Besides looking at individual codons, we also studied the effect of diplotypes. We choose to study two common ( $>10 \%$ in the population) and one less common 
The ADRB2 gene in obesity]

$(<5 \%$ ) homozygous combination (Gly16Gly/Glu27Glu, Arg16Arg/Gln27Gln and Gly16Gly/Gln27Gln) since they have been reported to have a significant effect on lipolysis (16). In addition, these SNPs belong to the same pathway and transfection experiments showed that they are functional (15). Finally, in our population, as has been reported before there is strong linkage disequilibrium between codon 16 and 27 (12). Nevertheless, no effect of diplotypes on lipolytic, thermogenic response or fat oxidation was found in our study. Only the Gly16Gly/Glu27Glu diplotype was associated with a lower fasting FFA concentration in female overweight subjects, which may possibly reflect a reduced rate of lipolysis in subcutaneous adipose tissue (20). Finally, literature suggests that the Thr164Ile $\beta_{2}$-adrenoceptor polymorphism is closely associated with Gly at position 16 and Gln at position $27(10,15)$. Nevertheless, due to the relatively low sample size we were not able to identify beta-2 adrenoceptor haplotypes for codons 16, 27 and 164 with a frequency $>5 \%$ (16).

The observed genotype frequency for the polymorphism in the GNB3 gene was similar to that previously reported in other Caucasian populations $(36,37)$. Rydén et al. showed that the $T$ variant of this polymorphism was associated with a blunted in vitro responsiveness for the non-selective beta-agonist isoprenaline in abdominal subcutaneous adipocytes of male and female overweight subjects (32). In contrast with Ryden et al. we found a tendency towards a reduced lipolysis in male overweight subjects. It should be mentioned that our sample has no adequate power to provide a conclusive result about a genotype effect for the C825T polymorphism in the GNB3 gene. Thus, further studies are necessary to confirm our in vivo findings in a larger population.

In summary, variation in codon 16 of the ADRB2 gene is associated with an impaired lipolytic response in male and female overweight and obese subjects and by a blunted fat oxidation in overweight and obese women. In conclusion, the present results suggest that genetic variability in the ADRB2 gene influences lipolysis regulation in vivo in overweight and obese subjects and that this is subject to genegender interactions. This indicates that genetic variability in the ADRB2 gene may be an important factor in the development or progression of obesity and obesityrelated disorders.

\section{Acknowledgements}

This study was supported by a research grant from The Netherlands Association for Scientific Research (NWO) to EE Blaak and Swedish Research Council to P Arner.

\section{Reference List}

1. Arner P. Catecholamine-induced lipolysis in obesity. Int J Obes Relat Metab Disord 23 Suppl 1: 10-13, 1999.

2. Benjafield AV, Jeyasingam CL, Nyholt DR, Griffiths LR, and Morris BJ. G-protein beta3 subunit gene (GNB3) variant in causation of essential hypertension. Hypertension 32: 1094-1097, 1998. 


\section{[Chapter 7}

3. Blaak E. Gender differences in fat metabolism. Curr Opin Clin Nutr Metab Care 4: 499-502, 2001.

4. Blaak EE, Saris WH, and Wolffenbuttel BH. Substrate utilization and thermogenic responses to beta-adrenergic stimulation in obese subjects with NIDDM. Int $J$ Obes Relat Metab Disord 23: 411-418, 1999.

5. Blaak EE, Schiffelers SL, Saris WH, Mensink $M$, and Kooi ME. Impaired beta-adrenergically mediated lipolysis in skeletal muscle of obese subjects. Diabetologia 47: 1462-1468, 2004.

6. Blaak EE, van Aggel-Leijssen DP, Wagenmakers AJ, Saris WH, and van Baak MA. Impaired oxidation of plasma-derived fatty acids in type 2 diabetic subjects during moderate-intensity exercise. Diabetes 49: 2102-2107, 2000.

7. Blaak EE, Van Baak MA, Kemerink GJ, Pakbiers MT, Heidendal GA, and Saris WH. Betaadrenergic stimulation of energy expenditure and forearm skeletal muscle metabolism in lean and obese men. Am J Physiol 267: E306-315, 1994.

8. Blaak EE, Van Baak MA, Kemerink GJ, Pakbiers MT, Heidendal GA, and Saris WH. betaAdrenergic stimulation of skeletal muscle metabolism in relation to weight reduction in obese men. Am J Physiol 267: E316-322, 1994.

9. Blaak EE, van Baak MA, and Saris WH. Beta-adrenergically stimulated fat oxidation is diminished in middle-aged compared to young subjects. J Clin Endocrinol Metab 84: 3764-3769, 1999.

10. Bruck H, Leineweber K, Buscher R, Ulrich A, Radke J, Insel PA, and Brodde OE. The Gln27Glu beta2-adrenoceptor polymorphism slows the onset of desensitization of cardiac functional responses in vivo. Pharmacogenetics 13: 59-66, 2003.

11. Carel JC, Le Stunff C, Condamine L, Mallet E, Chaussain JL, Adnot P, Garabedian M, and Bougneres P. Resistance to the lipolytic action of epinephrine: a new feature of protein Gs deficiency. J Clin Endocrinol Metab 84: 4127-4131, 1999.

12. Dallongeville J, Helbecque N, Cottel D, Amouyel P, and Meirhaeghe A. The Gly16-->Arg16 and Gln27--> Glu27 polymorphisms of beta2-adrenergic receptor are associated with metabolic syndrome in men. J Clin Endocrinol Metab 88: 4862-4866, 2003.

13. Devlin B and Risch N. A comparison of linkage disequilibrium measures for fine-scale mapping. Genomics 29: 311-322, 1995.

14. Dong Y, Zhu H, Wang X, Dalageorgou C, Carter N, Spector TD, and Snieder H. Obesity reveals an association between blood pressure and the G-protein beta3-subunit gene: a study of female dizygotic twins. Pharmacogenetics 14: 419-427, 2004.

15. Drysdale CM, McGraw DW, Stack CB, Stephens JC, Judson RS, Nandabalan K, Arnold K, Ruano $\mathrm{G}$, and Liggett SB. Complex promoter and coding region beta 2-adrenergic receptor haplotypes alter receptor expression and predict in vivo responsiveness. Proc Natl Acad Sci U S A 97: 10483$10488,2000$.

16. Eriksson P, Dahlman I, Ryden M, Hoffstedt J, and Arner P. Relationship between beta-2 adrenoceptor gene haplotypes and adipocyte lipolysis in women. Int J Obes Relat Metab Disord 28: 185$190,2004$.

17. Green SA, Cole G, Jacinto M, Innis M, and Liggett SB. A polymorphism of the human beta 2adrenergic receptor within the fourth transmembrane domain alters ligand binding and functional properties of the receptor. J Biol Chem 268: 23116-23121, 1993.

18. Green SA, Rathz DA, Schuster AJ, and Liggett SB. The Ile164 beta(2)-adrenoceptor polymorphism alters salmeterol exosite binding and conventional agonist coupling to G(s). Eur J Pharmacol 421: 141-147, 2001.

19. Green SA, Turki J, Innis M, and Liggett SB. Amino-terminal polymorphisms of the human beta 2adrenergic receptor impart distinct agonist-promoted regulatory properties. Biochemistry 33: 9414 $9419,1994$.

20. Hagstrom-Toft E, Bolinder J, Ungerstedt U, and Arner P. A circadian rhythm in lipid mobilization which is altered in IDDM. Diabetologia 40: 1070-1078, 1997. 
21. Hauner H, Meier M, Jockel KH, Frey UH, and Siffert W. Prediction of successful weight reduction under sibutramine therapy through genotyping of the G-protein beta3 subunit gene (GNB3) C825T polymorphism. Pharmacogenetics 13: 453-459, 2003.

22. Hegele RA, Anderson C, Young TK, and Connelly PW. G-protein beta3 subunit gene splice variant and body fat distribution in Nunavut Inuit. Genome Res 9: 972-977, 1999.

23. Hoffstedt J, Iliadou A, Pedersen NL, Schalling M, and Arner P. The effect of the beta(2) adrenoceptor gene Thr164lle polymorphism on human adipose tissue lipolytic function. Br J Pharmacol 133: 708-712, 2001 .

24. Kanaley JA, Cryer PE, and Jensen MD. Fatty acid kinetic responses to exercise. Effects of obesity, body fat distribution, and energy-restricted diet. J Clin Invest 92: 255-261, 1993.

25. Kobilka BK, Frielle T, Dohlman HG, Bolanowski MA, Dixon RA, Keller P, Caron MG, and Lefkowitz RJ. Delineation of the intronless nature of the genes for the human and hamster beta 2adrenergic receptor and their putative promoter regions. J Biol Chem 262: 7321-7327, 1987.

26. Kobilka BK, MacGregor C, Daniel K, Kobilka TS, Caron MG, and Lefkowitz RJ. Functional activity and regulation of human beta 2 -adrenergic receptors expressed in Xenopus oocytes. $J$ Biol Chem 262: 15796-15802, 1987.

27. Large V, Hellstrom L, Reynisdottir S, Lonnqvist F, Eriksson P, Lannfelt L, and Arner P. Human beta-2 adrenoceptor gene polymorphisms are highly frequent in obesity and associate with altered adipocyte beta-2 adrenoceptor function. J Clin Invest 100: 3005-3013, 1997.

28. Leineweber $\mathrm{K}$ and Brodde $\mathrm{OE}$. Beta2-adrenoceptor polymorphisms: relation between in vitro and in vivo phenotypes. Life Sci 74: 2803-2814, 2004.

29. Liggett SB. Pharmacogenetics of beta-1- and beta-2-adrenergic receptors. Pharmacology 61: 167 173, 2000.

30. Patten JL, Johns DR, Valle D, Eil C, Gruppuso PA, Steele G, Smallwood PM, and Levine MA. Mutation in the gene encoding the stimulatory $G$ protein of adenylate cyclase in Albright's hereditary osteodystrophy. N Engl J Med 322: 1412-1419, 1990.

31. Reynisdottir S, Wahrenberg H, Carlstrom K, Rossner S, and Arner P. Catecholamine resistance in fat cells of women with upper-body obesity due to decreased expression of beta 2-adrenoceptors. Diabetologia 37: 428-435, 1994.

32. Ryden M, Faulds G, Hoffstedt J, Wennlund A, and Arner P. Effect of the (C825T) Gbeta(3) polymorphism on adrenoceptor-mediated lipolysis in human fat cells. Diabetes 51: 1601-1608, 2002.

33. Schaid DJ and Jacobsen SJ. Biased tests of association: comparisons of allele frequencies when departing from Hardy-Weinberg proportions. Am J Epidemiol 149: 706-711, 1999.

34. Schiffelers SL, Blaak EE, Baarends EM, Van Baak MA, Saris WH, Wouters EF, and Schols AM. beta-Adrenoceptor-mediated thermogenesis and lipolysis in patients with chronic obstructive pulmonary disease. Am J Physiol Endocrinol Metab 280: E357-364, 2001.

35. Schunkert H, Hense HW, Doring A, Riegger GA, and Siffert W. Association between a polymorphism in the $G$ protein beta3 subunit gene and lower renin and elevated diastolic blood pressure levels. Hypertension 32: 510-513, 1998.

36. Siffert W, Forster P, Jockel KH, Mvere DA, Brinkmann B, Naber C, Crookes R, Du PHA, Epplen JT, Fridey J, Freedman BI, Muller N, Stolke D, Sharma AM, Al Moutaery K, Grosse-Wilde H, Buerbaum B, Ehrlich T, Ahmad HR, Horsthemke B, Du Toit ED, Tiilikainen A, Ge J, Wang Y, Rosskopf $\mathrm{D}$, and et al. Worldwide ethnic distribution of the $\mathrm{G}$ protein beta3 subunit 825T allele and its association with obesity in Caucasian, Chinese, and Black African individuals. $J$ Am Soc Nephrol 10: 1921-1930, 1999.

37. Siffert W, Rosskopf D, Siffert G, Busch S, Moritz A, Erbel R, Sharma AM, Ritz E, Wichmann HE, Jakobs KH, and Horsthemke B. Association of a human G-protein beta3 subunit variant with hypertension. Nat Genet 18: 45-48, 1998.

38. Siri WE. The gross composition of the body. Adv Biol Med Phys 4:239-280, 1956. 


\section{8}

\section{Blunted beta-adrenoceptor mediated fat oxidation in overweight subjects: a role for the hormone-sensitive lipase gene}

Jocken $\mathbf{J W E}^{1}$, Blaak $\mathrm{EE}^{1}$, van der Kallen $\mathrm{CJH}^{2}$, van Baak $\mathrm{MA}^{1}$ and Saris WHM ${ }^{1}$

\footnotetext{
${ }^{\prime}$ Department of Human Biology, Nutrition and Toxicology Research Institute Maastricht (NUTRIM), Maastricht University, Maastricht, The Netherlands

${ }^{2}$ Department of Internal Medicine, Laboratory of Molecular Metabolism and Endocrinology, Cardiovascular Research Institute Maastricht (CARIM), Maastricht University, Maastricht, The Netherlands
}

Metabolism (accepted-in press) 
[Chapter 8

\begin{abstract}
Background: Obesity is associated with a blunted betaadrenoceptor mediated lipolysis and fat oxidation, which persists after weight reduction. We investigated whether dinucleotide $(\mathrm{CA})_{\mathrm{n}}$ repeat polymorphisms in intron 6 (i6) or 7 (i7) and a $\mathrm{C}-60 \mathrm{G}$ promoter substitution of the hormone-sensitive lipase (HSL) gene are associated with a blunted in vivo beta ( $\beta$ )adrenoceptor mediated increase in circulating fatty acids, glycerol (estimation of lipolytic response) and fat oxidation in overweight-obese subjects.
\end{abstract}

Methods: A total of 103 overweight $\left(25 \leq \mathrm{BMI}<30 \mathrm{~kg} / \mathrm{m}^{2}\right)$ and obese $\left(B M I \geq 30 \mathrm{~kg} / \mathrm{m}^{2}\right)$ subjects ( $62 \mathrm{men}, 41$ women) were included. Energy expenditure (EE), respiratory quotient (RQ), circulating fatty acid and glycerol were determined after stepwise infusion of increasing doses of the non-selective $\beta$-agonist isoprenaline (ISO). The 16 , i7 (CA) $n$ repeat polymorphisms were determined by size resolved capillary electrophoresis and a C-60G promoter substitution was determined by restriction enzyme digestion assay.

Results: Female non-carriers of allele $184 \mathrm{i} 7(\mathrm{n}=18)$ and female carriers of allele 240 i6 $(n=12)$ showed an overall reduced fat oxidation (as indicated by changes in RQ) after $\beta$-adrenoceptor mediated stimulation, explaining respectively 6.9 and $20.8 \%$ of the variance in RQ. These effects were not seen in male subjects.

Conclusions: Our results suggest that variation in i7 and i6 of the HSL gene might be associated with a physiological effect on in vivo $\beta$-adrenoceptor mediated fat oxidation, at least in overweight-obese female subjects. 


\section{Introduction}

Obesity is characterized by excess fat accumulation, mainly in adipose tissue. Studies in our laboratory showed a blunted lipolytic response and blunted fat oxidation after beta ( $\beta$-adrenergic stimulation or exercise in obese and obese type 2 diabetic subjects $(3,5-7)$. This blunted $\beta$-adrenoceptor mediated lipolysis and fat oxidation persisted even after weight reduction, indicating that this disturbance may be a primary factor in the development or maintenance of increased adipose stores $(7,9)$. There are indications that the blunted $\beta$-adrenoceptor mediated lipolysis in adipose tissue may be related to a decreased function or number of $\beta_{2}$-adrenoceptors (23, $25)$. Additionally, in vitro studies in adipocytes from first degree relatives of obese subjects and adipocytes from elderly male subjects with several manifestations of the metabolic syndrome indicate also alterations at the level of the protein kinase A/hormone-sensitive lipase (HSL)-complex $(19,23)$. HSL catalyzes the hydrolysis of triacylglycerols and diacylglycerols. Recently, a new lipase (adipose triglyceride lipase, ATGL) was identified preferentially hydrolyzing triacylglycerols (30). Nevertheless, HSL seems to be the major lipase for catecholamine-stimulated lipolysis in humans (16). Although environmental factors contribute, it is obvious that genetic factors play an important role in the etiology of obesity (19). On basis of the findings described above, the hormone-sensitive lipase (HSL/LIPE) gene may be of particular interest.

The human gene encoding HSL is located on the long-arm of chromosome 19 $(\mathrm{q} 13.1 \rightarrow 13.2)(13,17)$. The exon-intron organization comprises nine main coding exons, spanning approximately $11 \mathrm{~kb}$. Furthermore, a C-60G substitution in the HSL gene promoter region is associated with a $40 \%$ reduced promoter activity (28), an increased insulin sensitivity in women and decreased level of plasma free fatty acids in men (11). Moreover, this polymorphism is protective against insulin resistance in healthy young male subjects $(27,28)$. In addition, a dinucleotide $(\mathrm{CA})_{n}$ repeat polymorphism located in intron 7 (i7) of the HSL gene has shown to be in linkage disequilibrium with a gene increasing susceptibility to abdominal obesity and thereby possibly to type 2 diabetes (15). Furthermore, a (CA) repeat polymorphism in intron 6 (i6) of the HSL gene is associated with a decreased in vitro lipolytic rate in abdominal subcutaneous fat cells, being more pronounced in men than in women (12). Moreover, the i6 polymorphism has shown to be a risk factor for body fat accumulation, in women (18). Magré et al. indicated an increased allelic frequency of this polymorphism in obese, impaired glucose tolerant or type 2 diabetics as compared to controls (20). So far, no data are available on the relationship between these polymorphic markers and in vivo lipolysis and fat oxidation in overweight and obese subjects.

The aim of this study was to determine if variation in dinucleotide $(\mathrm{CA})_{\mathrm{n}}$ repeats in i6 and i7, or a C-60G substitution in the promoter region of the HSL gene is associated with a blunted in vivo $\beta$-adrenoceptor mediated increase in circulating fatty acid and glycerol concentrations, and fat oxidation during stimulation with the nonselective $\beta$-agonist isoprenaline (ISO) in overweight and obese subjects. 
[Chapter 8

\section{Subjects and methods}

Subjects.

The study group consisted of 103 overweight-obese subjects, 62 men and 41 women. Overweight and obesity were defined according to the following criteria: 25 sbody mass index $(\mathrm{BMI})<30 \mathrm{~kg} / \mathrm{m}^{2}$ for overweight, and BMI $230 \mathrm{~kg} / \mathrm{m}^{2}$ for obese subjects. Clinical characteristics of the subjects are shown in Table 1 . All subjects were recruited by means of an advertisement in a local newspaper. All subjects were in good health as assessed by medical history and physical examination, and were not taking any medication. Women were premenopausal and some were taking oral anticonceptives. A normal resting electrocardiogram (ECG) and blood pressure were a prerequisite for participation. The study protocol was reviewed and approved by the Medical Ethical Review Committee of Maastricht University. The subjects were informed in detail about the investigation and their consent was obtained before participating in the study.

Table 1. Clinical characteristics of the subjects

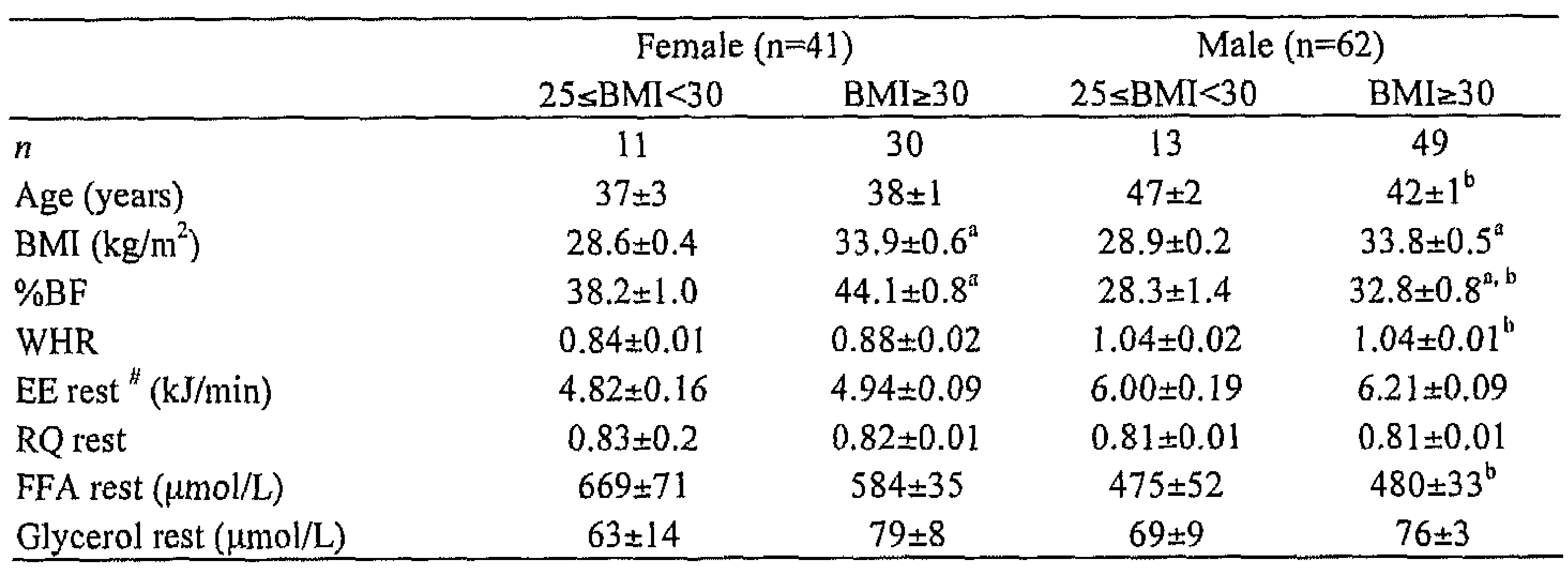

All values are mean $\pm \mathrm{SEM} ;{ }^{\#}$ adjusted mean for $\mathrm{FFM} ;{ }^{\mathrm{a}} \mathrm{P}<0.05$ overweight $v s$. obese; ${ }^{\mathrm{b}} \mathrm{P}<0.05$ male $v$. female (whole group); \%BF, Percentage Body Fat; WHR, Waist to hip ratio; EE, Energy Expenditure; RQ, Respiratory Quotient; FFA, Free Fatty Acids.

\section{Body composition}

Body weight was determined on an electronic scale, accurate to $0.1 \mathrm{~kg}$. Waist and hip circumference measurements to the nearest $1 \mathrm{~cm}$ were made with subjects standing upright. Waist to hip ratio (WHR) was calculated as waist divided by hip circumference. BMI was calculated as body weight in kilograms divided by squared height in meters. Body density obtained by underwater weighing with residual pulmonary volume measurement by the helium dilution method (Volugraph 2000, Mijnhardt) was converted to percent body fat (\%BF) using the equation of Siri (26). Fat mass (FM) and fat-free mass (FFM) were calculated from the percent body fat and body weight. 
The HSL gene in obesity]

\section{Experimental design}

Three days before participating in the study subjects were asked to maintain a standardized diet and physical activity level. At the day of the experiment, subjects arrived at the laboratory at $8 \mathrm{a} . \mathrm{m}$. after an overnight fast (of at least $12 \mathrm{~h}$ ) by car or public transport. Subjects were studied while resting supine on a comfortable bed in a room kept at $23-25^{\circ} \mathrm{C}$. At the beginning of the experiment a catheter was inserted into a forearm vein for blood sampling. A second catheter was inserted in the contralateral arm for infusion of the non-selective $\beta$-adrenergic agonist isoprenaline (ISO). After placement of the catheters, subjects were placed under an open-circuit ventilated hood system. Energy expenditure (EE) was calculated using the equation of Weir (29), and respiratory quotient (RQ) as $\mathrm{CO}_{2}$ production divided by $\mathrm{O}_{2}$ consumption. After a $30 \mathrm{~min}$ resting period blood was sampled for baseline measurements and genotyping. Following the $30 \mathrm{~min}$ baseline period isoprenaline infusion started at increasing concentrations 6,12 and $24 \mathrm{ng} \cdot \mathrm{kg} \mathrm{FFM}^{-1} \cdot \mathrm{min}^{-1}$, each dose for 30 minutes. At the end of each infusion period, blood samples were taken and immediately put into liquid nitrogen until further analysis. During isoprenaline infusion heart rate was kept under close observation by means of an ECG. ISO infusion was stopped for some subject, at different concentrations, based on an increase in heart rate by more than 30 beats/min or in case of an irregular ECG

\section{Genotyping}

Genomic DNA was extracted from peripheral blood leukocytes by digestion with protein $\mathrm{K}$ followed by purification with QIAamp DNA blood Mini Kit (Qiagen). Isolated DNA was examined for variable lengths of $(\mathrm{CA})_{\mathrm{n}}$ repeats in $\mathrm{i} 6$ and $\mathrm{i} 7$ of the HSL gene and a $\mathrm{C}-60 \mathrm{G}$ polymorphism in the promoter region was investigated.

PCR amplification of the DNA segment containing i6 or i7 of the HSL gene was carried out as described previously $(15,20)$. Briefly, the intron 6 fragment was amplified using the forward (sense) primer: 5'-CTCAGCAGGGAAACAGGACTG-3' and backward (antisense) primer: 5'-GTTTGAGCCACTGCACTCAGC-3'. The intron 7 fragment was amplified using the forward (sense) primer: 5'CAAAACTGCACCTAATCTTCCC-3' and reverse (antisense) primer: 5'GTAGGCTGTGTTTCCCCAGACT-3'. A negative control without DNA was performed every amplification run. Amplified products were size resolved by capillary electrophoresis on an ABI-310 PRISM genetic analyzer (Applied Biosystems) using performance-optimized polymer 4 (Applied Biosystems). Alleles were designated according to the size of the PCR product (Genescan analysis 2.0 ). The PCR amplification of the $\mathrm{C}-60 \mathrm{G}$ polymorphism of the HSL gene promoter was carried out as described previously (11). The forward (sense) primer was 5'GAGGGAGGAGGGGCTATGGGT-3' and the reverse (antisense) primer was 5'TCCCTGGGCTGGGACTACTGG-3'.

\section{Biochemical analysis}

Whole blood was collected in tubes containing EDTA and centrifuged for $10 \mathrm{~min}$ at $3000 \mathrm{rpm}\left(4^{\circ} \mathrm{C}\right)$. Plasma was removed for the enzymatic calorimetric quantization of free fatty acids (FFA) (WAKO chemicals GmbH, Nuess, Germany) and glycerol 
[Chapter 8

(Boehringer Mannheim) on a COBAS FARA centrifugal spectrometer (Roche Diagnostica).

\section{Statistical analysis}

All statistical calculations were performed with SPSS for Macintosh (version10.0; SPSS inc., Chicago, IL, USA). The distribution of each variable was tested using the one-sample Kolmogorov-Smirnov test. Due to the relative small sample size and high standard deviation (SD) of variables non-parametric statistics were used to analyze the data set. Gender differences in clinical parameters were tested by MannWhitney $U$ non-parametric statistics. A $\chi^{2}$-test was performed to test gender difference in allele frequency distribution after pooling frequencies $<5 \%$. The goodness of fit between observed and expected (under Hardy-Weinberg equilibrium) genotype frequency was statistical tested using the $\chi^{2}$-test (24). EE was adjusted for FFM using ANCOVA. The Kruskal-Wallis test, the non-parametric version of the two-way ANOVA was used to observe the overall trend in fat oxidation, circulating fatty acid and glycerol concentrations between allele carriers and non-carriers, during beta-adrenergic stimulation. A P-value $<0.05$ was considered statistical significant. All data are presented as mean \pm Standard Error of the Mean (SEM).

\section{Power calculation}

There are little or no published studies regarding the effect of the HSL gene and whole body lipolysis and fat oxidation, although the results of in vitro studies in human adipocytes support a major effect. We therefore estimated our sample size using published data of the effect of beta-adrenergic stimulation on whole body lipolysis and fat oxidation $(6,8,14)$. Power calculation indicated that to detect a difference in circulating fatty acids of $100 \mu \mathrm{mol} / \mathrm{L}$ (SD of $50 \mu \mathrm{mol} / \mathrm{L}$ ), circulating glycerol of $50 \mu \mathrm{mol} / \mathrm{L}$ (SD of $25 \mu \mathrm{mol} / \mathrm{L}$ ) or RQ of 0.01 (SD of 0.005 ) and a power of $0.80(\alpha=0.05$ and $\beta=0.20)$, the number of subjects in each group (2-tailed) should be 16 .

\section{Results}

Clinical characteristics of the subjects are shown in Table 1. BMI, fasting RQ and fasting glycerol were not significantly different between genders. Since regression analysis with gender as a covariate showed significant allele*gender interaction we stratified our sample by gender for subsequent analysis. Women $(n=41)$ had significantly higher percentage body fat (\%BF), fat mass (FM) and lower waist-to-hip ratio (WHR) compared to men $(n=62)$.

\section{Frequency distribution}

Frequency distributions, shown in Table 2, were comparable with other obese Caucasian populations $(11,15,20)$. We identified 12 alleles for the $(C A)_{n}$ repeat in i7 of the HSL gene, ranging in size from 166 to 190 base pairs (bp). Alleles 180, 182 and 184 were found to be the most common in both men and women. For both genders 
The HSL gene in obesity]

alleles with frequencies $>5 \%$ were further analyzed for differences in fatty acid and glycerol concentrations, and fat oxidation (allele 172, 180, 182, 184 and 186). Alleles with a frequency $<5 \%$ were pooled into one group for further statistical analysis.

Table 2. Allele frequency distribution of the different dinucleotide repeat polymorphisms in intron 7 or intron 6 of the $H S L$ gene and the genotype frequency distribution of the C-60G substitution in the HSL gene promoter region

\begin{tabular}{|c|c|c|}
\hline & Female & Male \\
\hline CA repeat intron 7 (bp) & $(n=40)$ & $(n=61)$ \\
\hline 166 & - & 1.6 \\
\hline 170 & 1.3 & 0.8 \\
\hline 172 & 7.5 & 8.2 \\
\hline 174 & 1.3 & 0.8 \\
\hline 176 & 1.3 & 1.6 \\
\hline 178 & 1.3 & 2.5 \\
\hline 180 & 8.8 & 18.9 \\
\hline 182 & 31.3 & 29.5 \\
\hline 184 & 35.0 & 30.3 \\
\hline 186 & 7.5 & 4.1 \\
\hline 188 & 3.8 & 1.6 \\
\hline 190 & 1.3 & - \\
\hline CA repeat intron $6(\mathrm{bp})$ & $(n=38)$ & $(n=55)$ \\
\hline 222 & 1.3 & 0.9 \\
\hline 230 & 1.3 & 4.5 \\
\hline 232 & - & 0.9 \\
\hline 234 & 6.6 & 11.8 \\
\hline 236 & 6.6 & 7.3 \\
\hline 238 & 52.6 & 50.9 \\
\hline 240 & 19.7 & 17.3 \\
\hline 242 & 10.5 & 3.6 \\
\hline 244 & 1.3 & 2.7 \\
\hline C-60G & $(n=40)$ & $(n=59)$ \\
\hline $\mathrm{CC}$ & 95.0 & 88.1 \\
\hline CG & 5.0 & 11.9 \\
\hline GG & 0.0 & 0.0 \\
\hline
\end{tabular}

All values are percentage (\%); Alleles with frequency $<5 \%$ were pooled for further statistical analysis. bp: base pair. 


\section{[Chapter 8}

For the $(\mathrm{CA})_{\mathrm{n}}$ repeat in $\mathrm{i} 6$ of the HSL gene we identified 9 alleles, ranging in size from 222 to 244 base pairs. Allele 232 was not observed in female subjects. Allele 238 was found to be the most common $(>50 \%)$ in both male and female subjects, 240 the second most common $(>16 \%)$. For both genders alleles with frequencies $>5 \%$ were further analyzed for differences in fatty acid and glycerol concentrations, and fat oxidation (allele $234,236,238,240,242$ ). Again, alleles with a frequency $<5 \%$ were pooled into one group for further statistical analysis. The allele frequency for the CA repeats in intron $6\left(\chi^{2}=6.123,5\right.$ d.f., $\left.P=0.294\right)$ and in intron $7\left(\chi^{2}=4.803\right.$, 5 d.f., $P=0.440$ ) were not significantly different in male $v$ s. female subjects. Genotype frequencies for the C-60G polymorphism are also shown in Table 2. The G$60 \mathrm{G}$ genotype was not observed in this population. The $\mathrm{C}-60 \mathrm{G}$ genotype frequency distribution was not significantly different for male $v s$. female subjects $\left(\chi^{2}=1.383,1\right.$ d.f, $\mathrm{P}=0.240$ ). Both male and female genotype and allele frequency distributions were in Hardy-Weinberg equilibrium.

\section{Dinucleotide $(C A)_{n}$ repeat polymorphisms in intron 7}

Female non-carriers of allele 184 i7 (clinical characteristics: Table 3) showed an overall blunted decrease in RQ after $\beta$-adrenergic stimulation (Kruskal-Wallis $\mathrm{P}=0.013$; Figure $1 \mathrm{C}$ ) and comparable thermogenic response. This indicates a diminished ability to stimulate fat oxidation in female non-carriers of allele $184 \mathrm{i} 7.6 .9 \%$ of the variability in delta RQ after $\beta$-adrenergic stimulation could be explained by allele 184 in female obese subjects. No associations were found in male noncarriers of allele 184. Furthermore, no associations were found for all other alleles in i7 of the HSL gene (i.e. allele $172,180,182,186$ ) with circulating fatty acid or glycerol concentrations, and fat oxidation after $\beta$-adrenergic stimulation.

Table 3. Clinical characteristics of allele 184 i7 carriers and non-carriers

\begin{tabular}{lcccc}
\hline & \multicolumn{2}{c}{ Female $(\mathrm{n}=40)$} & \multicolumn{2}{c}{ Male $(\mathrm{n}=61)$} \\
\hline$n$ & Carrier & Non-carrier & Carrier & Non-carrier \\
\hline Age $(\mathrm{yrs})$ & 22 & 18 & 33 & 28 \\
Weight $(\mathrm{kg})$ & $39 \pm 2$ & $37 \pm 2$ & $42 \pm 1$ & $44 \pm 2$ \\
BMI $\left(\mathrm{kg} / \mathrm{m}^{2}\right)$ & $89.5 \pm 2.2$ & $90.6 \pm 2.8$ & $104.4 \pm 2.9$ & $105.0 \pm 2.1$ \\
\%BF & $33 \pm 0.7$ & $33 \pm 1.0$ & $32.4 \pm 0.8$ & $33.4 \pm 0.6$ \\
FFM $(\mathrm{kg})$ & $42 \pm 1.2$ & $43 \pm 0.9$ & $31.1 \pm 1.1$ & $32.8 \pm 1.1$ \\
WHR & $51.7 \pm 1.0$ & $51.0 \pm 1.3$ & $71.2 \pm 1.4$ & $70.2 \pm 1.2$ \\
EE rest ${ }^{\#}(\mathrm{~kJ} / \mathrm{min})$ & $0.84 \pm 0.02$ & $0.89 \pm 0.03$ & $1.04 \pm 0.01$ & $1.04 \pm 0.01$ \\
RQ rest & $4.83 \pm 0.11$ & $5.04 \pm 012$ & $6.07 \pm 0.15$ & $6.49 \pm 0.15$ \\
FFA rest $(\mu \mathrm{mol} / \mathrm{L})$ & $0.83 \pm 0.01$ & $0.82 \pm 0.009$ & $0.81 \pm 0.008$ & $0.81 \pm 0.007$ \\
Glycerol rest $(\mu \mathrm{mol} / \mathrm{L})$ & $560 \pm 26$ & $670 \pm 60$ & $495 \pm 41$ & $461 \pm 39$ \\
\hline
\end{tabular}

All values are mean \pm SEM. "adjusted mean for FFM.

\section{Dinucleotide $(C A)_{n}$ repeat polymorphisms in intron 6}

Female carriers of allele $240 \mathrm{i} 6$ (clinical characteristics: Table 4) showed a significant increase in RQ (Kruskal-Wallis $\mathrm{P}<0.001$; Figure $2 \mathrm{C}$ ) and comparable ther- 
The HSL gene in obesity]

mogenic response after $\beta$-adrenergic stimulation, suggesting a diminished ability to stimulate fat oxidation in female carriers of allele 240 i6. Moreover, 20.8\% $(P=0.098)$ of the variability in delta RQ could be explained by allele 240 in female obese subjects. No associations were found in male carriers of allele 240. Furthermore, no associations were found for allele 234, 236, 238 and 242 in i6 of the HSL gene with circulating fatty acid or glycerol concentrations, and fat oxidation after $\beta$ adrenergic stimulation.

(A) Fatty Acid release $(\mu \mathrm{mol} / \mathrm{L})$

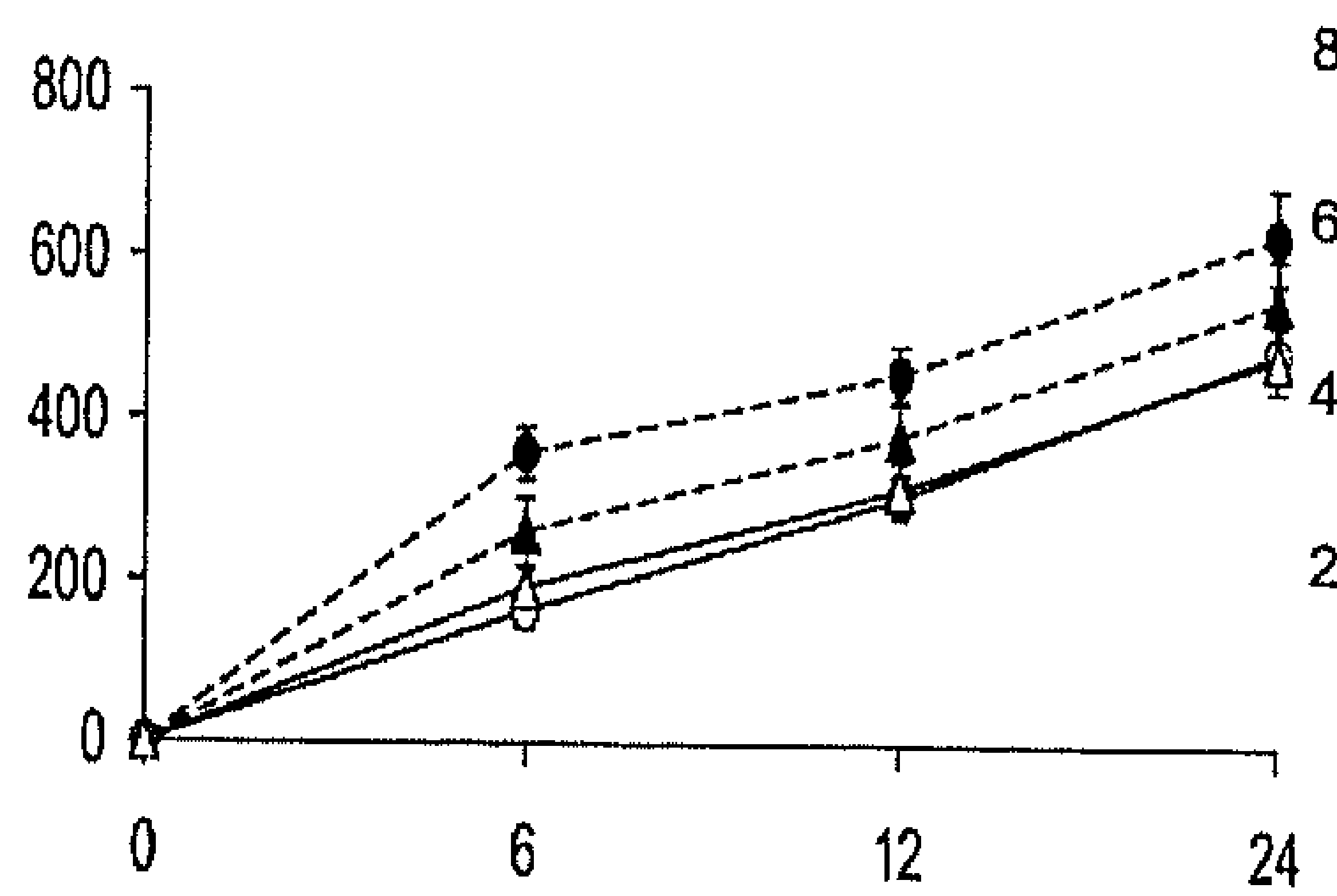

(B) Glycerol release $(\mu \mathrm{mol} / \mathrm{L})$

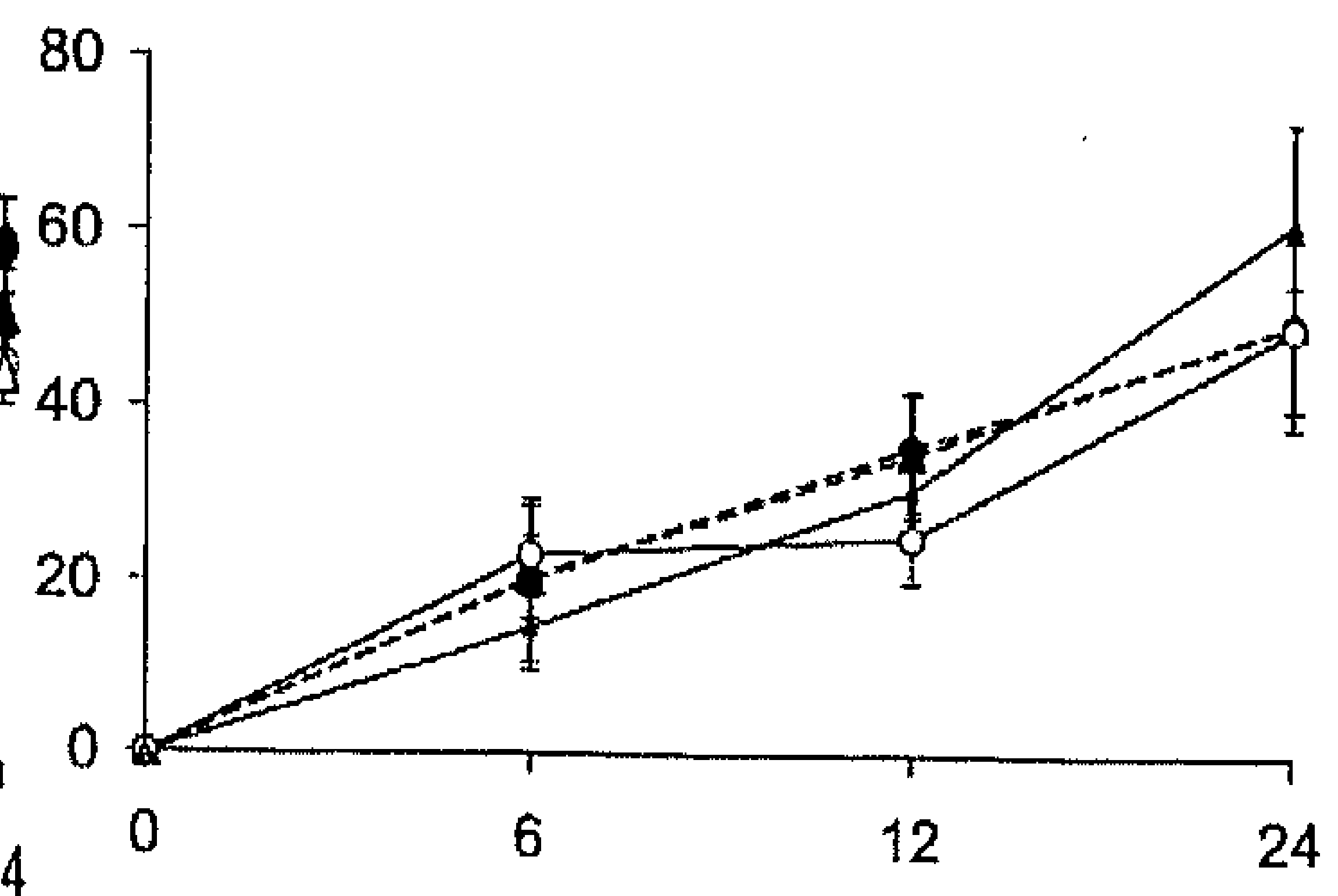

(C) $R Q$

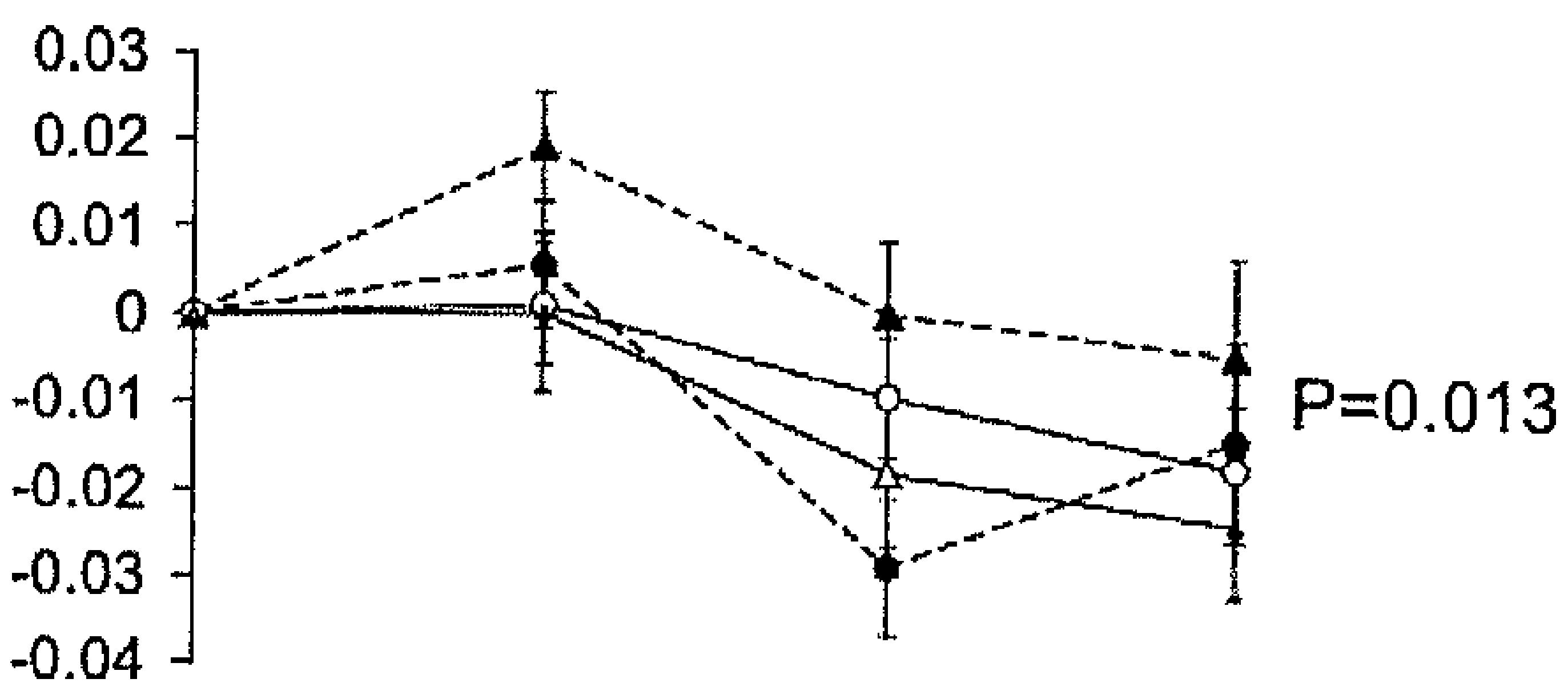

Figure 1. Change in circulating fatty acids (A), glycerol (B); and fat oxidation (RQ) (C) for male (solid lines) and female (dashed lines) carriers (circles) versus non-carriers (triangles) of allele 184 i7 of the HSL gene. Values are mean \pm SEM. $\mathrm{P}=0.013$ female carrier $v$ s. non-carrier using Kruskal-Wallis nonparametric statistics.

\section{C-60G substitution in the HSL promoter region}

In our population the $\mathrm{G}-60 \mathrm{G}$ genotype was not apparent. The C-60G genotype was apparent in 2 out of 40 female subjects. In male subjects the C-60G genotype was apparent in 7 out of 59 subjects. Within these small sized groups no significant associations were found between genotypes, circulating fatty acid or glycerol concentrations, and fat oxidation. 
[Chapter 8

Table 4. Clinical characteristics of allele 24016 carriers and non-carriers

\begin{tabular}{lcccc}
\hline & \multicolumn{2}{c}{ Female $(\mathrm{n}=38)$} & \multicolumn{2}{c}{ Male $(\mathrm{n}=55)$} \\
\cline { 2 - 5 }$n$ & Carrier & Non-carrier & Carrier & Non-carrier \\
\cline { 2 - 5 } Age $(\mathrm{yrs})$ & 12 & 26 & 19 & 36 \\
Weight $(\mathrm{kg})$ & $37 \pm 2$ & $38 \pm 1$ & $42 \pm 2$ & $44 \pm 1$ \\
BMI $\left(\mathrm{kg} / \mathrm{m}^{2}\right)$ & $86.4 \pm 3.4$ & $90.5 \pm 2.1$ & $107.6 \pm 2.1$ & $104.7 \pm 2.8$ \\
$\%$ BF & $32.8 \pm 1.1$ & $32.6 \pm 0.8$ & $33.6 \pm 0.8$ & $32.9 \pm 0.7$ \\
FFM $(\mathrm{kg})$ & $41.6 \pm 1.5$ & $42.7 \pm 0.9$ & $33.1 \pm 1.3$ & $31.9 \pm 1.0$ \\
WHR & $50.1 \pm 1.6$ & $51.5 \pm 0.9$ & $71.8 \pm 1.6$ & $70.6 \pm 1.3$ \\
EE rest ${ }^{*}(\mathrm{~kJ} / \mathrm{min})$ & $0.84 \pm 0.03$ & $0.88 \pm 0.02$ & $1.04 \pm 0.02$ & $1.04 \pm 0.01$ \\
RQ rest & $4.73 \pm 0.15$ & $4.99 \pm 0.10$ & $6.37 \pm 0.17$ & $6.21 \pm 0.13$ \\
FFA rest $(\mu \mathrm{mol} / \mathrm{L})$ & $0.83 \pm 0.01$ & $0.82 \pm 0.009$ & $0.81 \pm 0.009$ & $0.81 \pm 0.006$ \\
Glycerol rest $(\mu \mathrm{mol} / \mathrm{L})$ & $604 \pm 65$ & $618 \pm 39$ & $518 \pm 57$ & $472 \pm 34$ \\
\hline All & $73 \pm 15$ & $73 \pm 9$ & $78 \pm 7$ & $75 \pm 4$ \\
\hline
\end{tabular}

All values are mean \pm SEM. "adjusted mean for FFM

\section{Discussion}

In obese subjects it has been shown that $\beta$-adrenoceptor mediated lipolysis and fat oxidation are blunted $(5,6,8)$. This blunted lipolysis and fat oxidation persisted even after weight reduction, indicating that it may be an early, or even primary factor in the development of increased fat stores in obesity $(7,9)$. For this reason we investigated, for the first time, whether genetic variation in the hormone-sensitive lipase (HSL) gene is associated with a blunted in vivo $\beta$-adrenoceptor mediated increase in circulating fatty acid and glycerol concentration (as estimation of lipolysis), and fat oxidation in overweight and obese subjects. The major finding of the present study is that a blunted $\beta$-adrenoceptor mediated increase in fat oxidation might be associated with genetic variation in the HSL gene (allele 184 i7 and allele $240 \mathrm{i}$ ), at least in overweight-obese women.

\section{Limitations of the study}

The primary objective of this study was to investigate the effect of genetic variation in the HSL gene on beta-adrenoceptor mediated lipolysis and fat oxidation within a group of overweight-obese subjects. Due to the extensive phenotyping it was for practical reasons not possible to study a larger group. However, power analysis indicated that the number of subjects was adequate to detect differences in the primary outcomes of our study. An overall significant effect of allele 184 i7 and allele $240 \mathrm{i} 6$ on fat oxidation (indicated as RQ) was observed in our population. Moreover, both alleles explained respectively $6.9 \%$ and $20.8 \%$ of the variance in the change in RQ, indicating that these polymorphisms might have a physiological effect. Nevertheless, our results need to be confirmed in a larger population.

An in vitro experiment by Hoffstedt et al. showed that overweight male individuals with allele 238 (HSL i6 A5) had a 50\% lower lipolytic response in isolated abdominal subcutaneous adipocytes after stimulation with noradrenaline, isoprenaline, 
forskolin and dibutyryl cAMP (12). Our study found no associations between allele 238 and a blunted increase in circulating fatty acid or glycerol concentrations during isoprenaline stimulation. The reason for this discrepancy is not entirely clear, but may be related to the use of in vitro adipose tissue biopsies $v$ s. our in vivo approach. In vivo local lipolysis is influenced by the neuroendocrine environment and blood flow. The later determines the supply of different hormones (like insulin and catecholamines) that have an effect on local adipocyte lipolysis. In the in vitro situation these factors are not taken into account. In addition, the majority of in vitro studies are performed on adipocytes derived from the subcutaneous region in both genders. It should be mentioned that there are major differences in catecholamine-induced lipolysis between depots (subcutaneous vs. visceral) and body fat distribution between genders $(1,2,4)$.

\section{$\begin{array}{ll}\text { (A) Fatty Acid release }(\mu \mathrm{mol} / \mathrm{L}) & \text { (B) Glycerol release }(\mu \mathrm{mol} / \mathrm{L})\end{array}$}

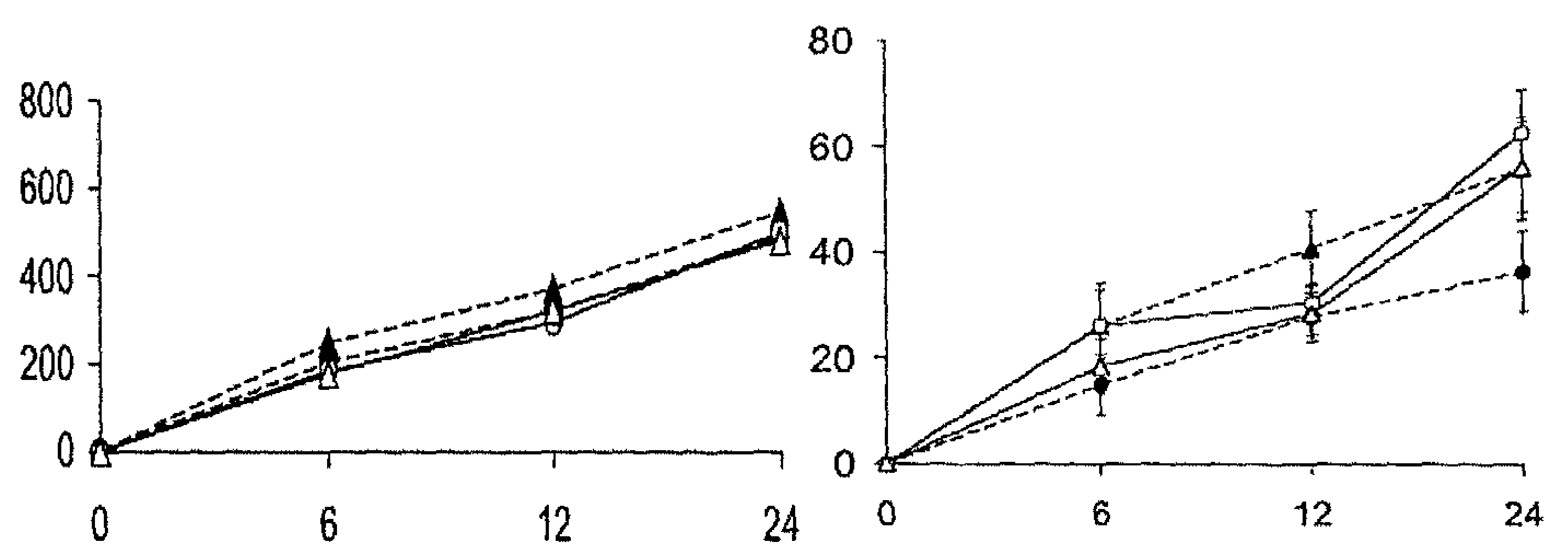

(C) RQ

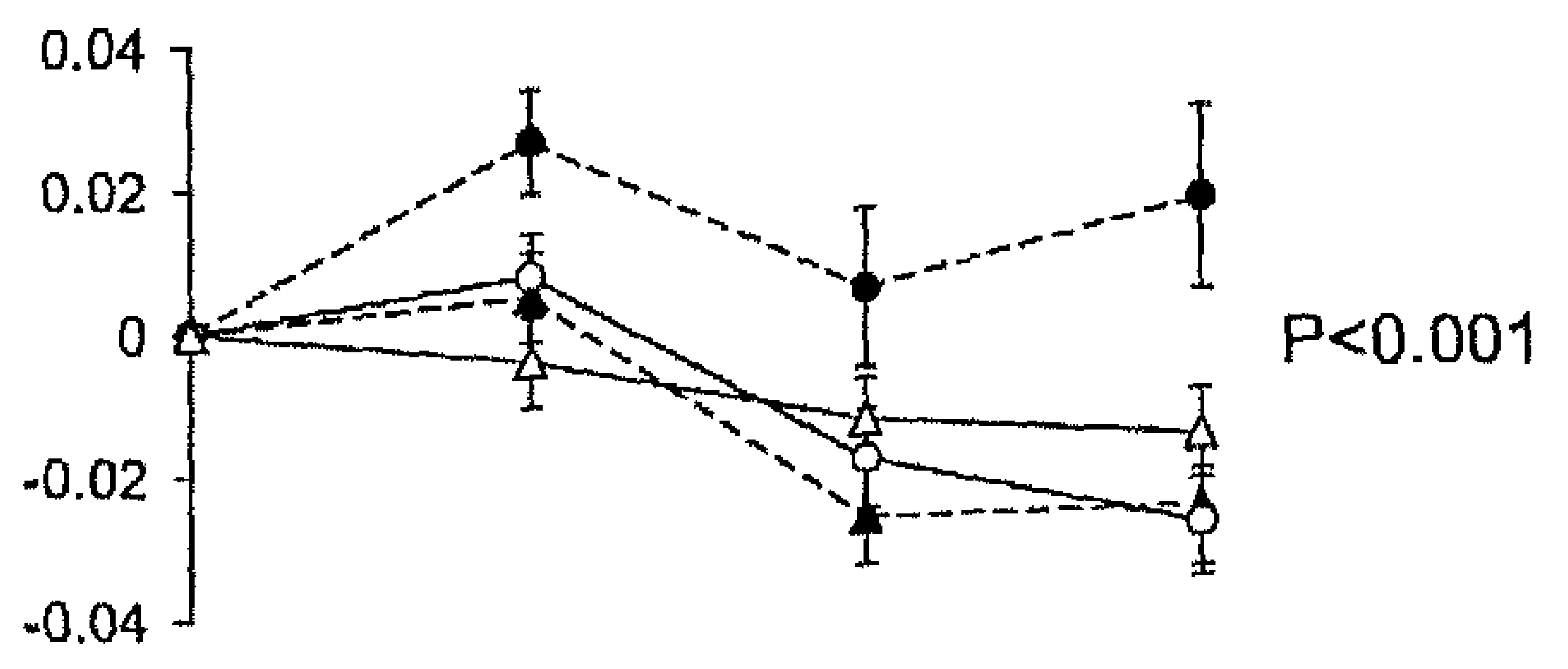

Figure 2. Change in circulating fatty acids (A), glycerol (B); and fat oxidation (RQ) (C) for male (solid lines) and female (dashed lines) carriers (circles) versus non-carriers (triangles) of allele 240 i6 of the HSL gene. Values are mean \pm SEM. $\mathrm{P}<0.001$ female carrier $v$ s. non-carrier using Kruskal-Wallis nonparametric statistics.

In contrast to men, an association with fat oxidation was observed in female noncarriers of allele 184 (i7) and female carriers of allele 240 (i6) (Figure 1C and 2C). Both alleles explained respectively $6.9 \%$ and $20.8 \%$ of the variance in the change in $R Q$, suggesting that genetic variability in the HSL gene might contribute to betaadrenoceptor mediated fatty acid handling in women. An in vivo study by Qi et al. 


\section{[Chapter 8}

found gender-specific associations between genetic variation in the HSL gene (promoter region and intron 2) and plasma lipid and glucose concentrations, being more pronounced in women (22). On this basis, it may be speculated that in women fatty acid handling during $\beta$-adrenergic stimulation is more influenced by genetic factors. In men gene-environmental interactions like eating habits, physical activity or metabolic factors might override genetic predisposition. As shown by Meirhaeghe et al. physical activity or other behavioural factors may counterbalance the effect of genetic predisposition to increase body weight, body fat and obesity in men (21). We only can hypothesize that in men behaviour might counterbalance genetic predisposition and further research is necessary to elucidate this interaction.

As already suggested by Klannemark et al. the polymorphic marker in i7 is in linkage disequilibrium (LD) with an allele and/or gene which increases susceptibility to abdominal obesity and thereby possibly to type 2 diabetes (15). The distance between i6 and i7 is only approximately $2800 \mathrm{bp}$. So, it is possible that there is linkage disequilibrium between allele 184 (i7) and allele 240 (i6). However, the frequency distribution of both alleles does not suggest a strong LD (e.g. for women $\mathrm{D}^{\prime}=0.22, \mathrm{r}^{2}=0.02$ ) in our population (10). It would be worthwhile to confirm these results in a larger population. Because of the fact that the investigated polymorphic markers are situated in non-coding intron structures of the HSL gene, it seems unlikely that these markers result in functional conformational changes of the HSL protein or act alone. However, it is unknown whether the polymorphic markers in i6 and i7 of the HSL gene are associated with e.g. cryptic splice junctions or alternative promoter creations, which could have major effects on function and expression of HSL or are in LD with another functional polymorphism in the HSL gene. Furthermore, we cannot exclude that a polymorphism in another gene, located nearby the HSL gene, is in LD with (240)i6 or (184)i7.

In conclusion, the present results suggest that variation in the polymorphic DNA marker i7 and i6 of the $H S L$ gene might be associated with a physiological effect on in vivo $\beta$-adrenoceptor mediated fat oxidation in overweight-obese female subjects. Further studies in larger populations are needed to confirm our results and to see whether another polymorphism in the HSL gene is in LD with $\mathrm{i} 6$ or i7 that might partly explain the current findings.

\section{Acknowledgements}

The authors greatly appreciated the willingness of the volunteers to participate in this study. This study was supported by a research grant of the Netherlands Association for Scientific Research (NWO 015.01.095) to Prof. dr. EE Blaak, department of Human Biology, University of Maastricht, Maastricht, The Netherlands.

\section{Reference list}

1. Arner P. Catecholamine-induced lipolysis in obesity. Int J Obes Relat Metab Disord 23 Suppl 1: 10-13, 1999. 
The HSL gene in obesity]

2. Blaak E. Gender differences in fat metabolism. Curr Opin Clin Nutr Metab Care 4: 499-502, 2001.

3. Blaak EE, Saris WH, and Wolffenbuttel BH. Substrate utilization and thermogenic responses to beta-adrenergic stimulation in obese subjects with NIDDM. Int $J$ Obes Relat Metab Disord 23: $411-418,1999$.

4. Blaak EE, Schiffelers SL, Saris WH, Mensink M, and Kooi ME. Impaired beta-adrenergically mediated lipolysis in skeletal muscle of obese subjects. Diabetologia 47: 1462-1468, 2004.

5. Blaak EE, van Aggel-Leijssen DP, Wagenmakers AJ, Saris WH, and van Baak MA. Impaired oxidation of plasma-derived fatty acids in type 2 diabetic subjects during moderate-intensity exercise. Diabetes 49: 2102-2107, 2000.

6. Blaak EE, Van Baak MA, Kemerink GJ, Pakbiers MT, Heidendal GA, and Saris WH. Betaadrenergic stimulation of energy expenditure and forearm skeletal muscle metabolism in lean and obese men. Am J Physiol 267: E306-315, 1994.

7. Blaak EE, Van Baak MA, Kemerink GJ, Pakbiers MT, Heidendal GA, and Saris WH. betaAdrenergic stimulation of skeletal muscle metabolism in relation to weight reduction in obese men. Am J Physiol 267: E3 16-322, 1994.

8. Blaak EE, van Baak MA, and Saris WH. Beta-adrenergically stimulated fat oxidation is diminished in middle-aged compared to young subjects. J Clin Endocrinol Metab 84: 3764-3769, 1999.

9. Blaak EE, Wolffenbuttel BH, Saris WH, Pelsers MM, and Wagenmakers AJ. Weight reduction and the impaired plasma-derived free fatty acid oxidation in type 2 diabetic subjects. $J$ Clin Endocrinol Metab 86: 1638-1644, 2001.

10. Devlin B and Risch N. A comparison of linkage disequilibrium measures for fine-scale mapping. Genomics 29:311-322, 1995.

11. Garenc C, Perusse L, Chagnon YC, Rankinen T, Gagnon J, Borecki IB, Leon AS, Skinner IS, Wilmore JH, Rao DC, and Bouchard C. The hormone-sensitive lipase gene and body composition: the HERITAGE Family Study. Int J Obes Relat Metab Disord 26: 220-227, 2002.

12. Hoffstedt J, Arner P, Schalling M, Pedersen NL, Sengul S, Ahlberg S, Iliadou A, and Lavebratt C. A common hormone-sensitive lipase i6 gene polymorphism is associated with decreased human adipocyte lipolytic function. Diabetes 50: 2410-2413, 2001.

13. Holm C, Kirchgessner TG, Svenson KL, Fredrikson G, Nilsson S, Miller CG, Shively JE, Heinzmann C, Sparkes RS, Mohandas T, and et al. Hormone-sensitive lipase: sequence, expression, and chromosomal localization to 19 cent-q13.3. Science 241: 1503-1506, 1988.

14. Kanaley JA, Cryer PE, and Jensen MD. Fatty acid kinetic responses to exercise. Effects of obesity, body fat distribution, and energy-restricted diet. J Clin Invest 92: 255-261, 1993.

15. Klannemark M, Orho M, Langin D, Laurell H, Holm C, Reynisdottir S, Arner P, and Groop L. The putative role of the hormone-sensitive lipase gene in the pathogenesis of Type II diabetes mellitus and abdominal obesity. Diabetologia 41: 1516-1522, 1998.

16. Langin D, Dicker A, Tavernier G, Hoffstedt J, Mairal A, Ryden M, Arner E, Sicard A, Jenkins CM, Viguerie N, van Harmelen V, Gross RW, Holm C, and Arner P. Adipocyte lipases and defect of lipolysis in human obesity. Diabetes 54: 3190-3197, 2005.

17. Laurell H, Grober J, Holst LS, Holm C, Mohrenweiser HW, and Langin D. The hormone-sensitive lipase (LIPE) gene located on chromosome 19q13.1-->13.2 is not duplicated on 19p13.3. Int $J$ Obes Relat Metab Disord 19: 590-592, 1995.

18. Lavebratt C, Ryden M, Schalling M, Sengul S, Ahlberg S, and Hoffstedt J. The hormone-sensitive lipase i6 gene polymorphism and body fat accumulation. Etur J Clin Invest 32; 938-942, 2002.

19. Loos RJ and Bouchard C. Obesity -is it a genetic disorder? J Intern Med 254: 401-425, 2003.

20. Magre J, Laurell H, Fizames C, Antoine PJ, Dib C, Vigouroux C, Bourut C, Capeau J, Weissenbach J, and Langin D. Human hormone-sensitive lipase: genetic mapping, identification of a new dinucleotide repeat, and association with obesity and NIDDM. Diabetes 47: 284-286, 1998.

21. Meirhaeghe A, Helbecque N, Cottel D, and Amouyel P. Beta2-adrenoceptor gene polymorphism, body weight, and physical activity. Lancet 353: 896, 1999. 


\section{[Chapter 8}

22. Qi L, Shen H, Larson I, Barnard JR, Schaefer EJ, and Ordovas JM. Genetic variation at the hormone sensitive lipase: gender-specific association with plasma lipid and glucose concentrations. Clin Genet 65: 93-100, 2004.

23. Reynisdottir S, Ellerfeldt $\mathrm{K}$, Wahrenberg $\mathrm{H}$, Lithell $\mathrm{H}$, and Arner $\mathrm{P}$. Multiple lipolysis defects in the insulin resistance (metabolic) syndrome. J Clin Invest 93: 2590-2599, 1994.

24. Schaid DJ and Jacobsen SJ. Biased tests of association: comparisons of allele frequencies when departing from Hardy-Weinberg proportions. Am J Epidemiol 149: 706-711, 1999.

25. Schiffelers SL, Blaak EE, Baarends EM, Van Baak MA, Saris WH, Wouters EF, and Schols AM. beta-Adrenoceptor-mediated thermogenesis and lipolysis in patients with chronic obstructive pulmonary disease. Am J Physiol Endocrinol Metab 280: E357-364, 2001

26. Siri WE. The gross composition of the body. Adv Biol Med Phys 4: 239-280, 1956.

27. Talmud PJ, Palmen J, Luan J, Flavell D, Byrne CD, Waterworth DM, and Wareham NJ. Variation in the promoter of the human hormone sensitive lipase gene shows gender specific effects on insulin and lipid levels: results from the Ely study. Biochim Biophys Acta 1537: 239-244, 2001.

28. Talmud PJ, Palmen J, and Walker M. Identification of genetic variation in the human hormonesensitive lipase gene and 5' sequences: homology of 5' sequences with mouse promoter and identification of potential regulatory elements. Biochem Biophys Res Commun 252: 661-668, 1998.

29. Weir JB. New methods for calculating metabolic rate with special reference to protein metabolism. J Physiol 109: 1-9, 1949.

30. Zimmermann R, Strauss JG, Haemmerle G, Schoiswohl G, Birner-Gruenberger R, Riederer M, Lass A, Neuberger G, Eisenhaber F, Hermetter A, and Zechner R. Fat mobilization in adipose tissue is promoted by adipose triglyceride lipase. Science 306: 1383-1386, 2004. 


\section{General Discussion}

Jocken JWE, Blaak EE. Adipose tissue and skeletal muscle lipolysis in obesity and insulin resistance: a critical review. Physiology \& Behavior (submitted) 
[Chapter 9

1. Methological considerations: use of $\left[{ }^{2} \mathbf{H}_{5}\right]$-glycerol as a tracer

2. Adipose tissue lipolysis in obesity and insulin resistance

2.1 fasting and beta-adrenergically mediated adipose tissue lipoly- 146 sis

2.2 The lipolytic picture revisited: a new lipase enters the picture

2.2.1 respective role of ATGL and HSL in human adipose tissue lipolysis

2.3 Possible mechanisms behind a blunted catecholamine-induced lipolysis in subcutaneous adipose tissue of obese subjects

2.4 Adipose tissue TAG extraction

3. Skeletal muscle lipolysis in obesity and insulin resistance

3.1 Skeletal muscle lipolysis after an overnight fast

3.2 Beta-adrenoceptor mediated skeletal muscle lipolysis

4. Physiological relevance of a blunted lipolysis in obesity: the chicken or the egg?

4.1 The case for prosecution: a blunted fasting and catecholamine-induced lipolysis as primary defect in obesity

4.2 The case for defence: a blunted lipolysis as consequence of the obese insulin resistant state

5. Main findings and conclusions of the thesis 
Obesity is characterized by increased fat storage in the form of triacylglycerol (TAG), mainly in adipose tissue. Disturbances in the regulation of adipose tissue lipolysis might contribute to the development and maintenance of increased adipose tissue stores and obesity. Excess fat accumulation in adipose tissue delivers more fatty acids (FA) to the circulation, i.e. resulting in lipid overflow. Lipid overflow may lead to increased storage of fat in skeletal muscle, which is a marker for the development of insulin resistance. Also intrinsic disturbances in skeletal muscle lipolysis could contribute to the accumulation of lipid and lipid intermediates in muscle of obese subjects. The studies described in this thesis focused on the physiological and molecular regulation of adipose tissue and skeletal muscle lipolysis in the obese insulin resistant state. We examined both local abdominal subcutaneous adipose tissue and skeletal muscle lipolysis in normal weight control subjects and obese subjects, combining state-of-the-art in vivo techniques and in vitro approaches. In this chapter, the results we have obtained will be discussed and put into a broader perspective and important issues for future research will be addressed. First, methodological considerations for the study of in vivo regulation of adipose tissue and skeletal muscle lipolysis in obesity, using $\left[{ }^{2} \mathrm{H}_{5}\right]$-glycerol tracer methodology, will be discussed.

\section{Methodological considerations: use of $\left.{ }^{2} \mathrm{H}_{5}\right]$-glycerol as a tracer}

Glycerol uptake using stable isotope tracers of glycerol by adipose tissue (47) and skeletal muscle $(17,18)$ has been reported in some studies but not in all $(17,43)$. In all these studies the infusion of glycerol tracer was relatively short (1-3h), opening the possibility that equilibration between labelled glycerol and the tissue glycerol pool might be incomplete. This may result in the disappearance of labelled glycerol into the tissue glycerol pool, wrongly interpreted as glycerol uptake. To investigate the time necessary to obtain a steady-state we investigated the isotopic glycerol enrichment of arterialized blood and blood draining the adipose tissue and the forearm vein during a three and six hour infusion period of labelled $\left[{ }^{2} \mathrm{H}_{5}\right]$-glycerol. In chapter 2 and 5 we demonstrated that in lean and obese subjects, a steady-state in enrichment from all sites was already observed after one hour $\left[{ }^{2} \mathrm{H}_{5}\right]$-glycerol infusion, which remained stable for the subsequent five hours. Furthermore, enrichments from all sites remained stable during fasting and beta-adrenergic stimulation in lean and obese subjects. These data support the use of a relative short infusion protocol to study glycerol exchange across adipose tissue and skeletal muscle. Moreover, the measured enrichment was consistently lower than the expected enrichment, implying uptake of glycerol by adipose tissue and forearm skeletal muscle. Uptake of glycerol means that the enzymatic machinery for utilization of glycerol must be present in both tissues. The enzyme glycerol kinase (GK) has been demonstrated in human adipose tissue (78), although concentrations are low, and human skeletal muscle (59). Beside re-esterification, glycerol can be oxidized in muscle. Likewise, glycerol dehydrogenase, the enzyme that initiates glycerol oxidation by skeletal muscle, has been demonstrated in human skeletal muscle (25). Glycerol uptake by subcutaneous adipose tissue (fractional extraction lean vs. obese: $16.6 \pm 4.5$ vs. $13.9 \pm 6.7 \%$ ) and forearm skeletal muscle (fractional extraction lean $v s$. obese: 


\section{[Chapter 9}

$40.2 \pm 3.4$ vs. $40.5 \pm 6.1 \%$ ) was not significantly different between groups, as shown in chapter 2 and 5. It remains to be determined whether glycerol taken up by adipose tissue and skeletal muscle is used in a higher extent for re-esterification and TAG synthesis in obese compared with lean subjects.

In this thesis $\left[{ }^{2} \mathrm{H}_{5}\right]$-glycerol tracer methodology was used to investigate in vivo regulation of adipose tissue and skeletal muscle lipolysis in obese compared with lean subjects. First, adipose tissue lipolysis in obesity will be discussed. Secondly, the respective role of different lipases in human adipose tissue lipolysis, and molecular disturbances in the lipolytic pathway in obesity will be highlighted. Finally, skeletal muscle lipolysis in obesity will be discussed.

\section{Adipose tissue lipolysis in obesity and insulin resistance}

Adipose tissue is the most important organ in the body for the storage and release of energy. There are indications from in vitro and in situ studies for a blunted catecholamine induced lipolysis in adipose tissue of obese subjects $(3,8,9,16,32,33,66$, 82). This catecholamine resistance of lipolysis can have profound effects on fat mass, body weight and the metabolic fate of FA. In vitro studies suggested that the site for this catecholamine resistance is abdominal subcutaneous adipose tissue (66). The study described in chapter 2 is the first to investigate in vivo abdominal subcutaneous adipose tissue lipolysis using a stable isotope $\left[{ }^{2} \mathrm{H}_{5}\right]$-glycerol tracer in combination with the arterio-venous balance technique. Lean and obese men were studied before and during beta-adrenergic stimulation with the non-selective betaagonist isoprenaline (chapter 2).

\section{I Fasting and beta-adrenergically mediated adipose tissue lipolysis}

In chapter 2 we demonstrated that in vivo, after an overnight fast, the lipolysis rate related to fat mass (as indicated by glycerol Ra per unit fat mass) is decreased in obesity. Additionally, fasting total glycerol and net FA release across abdominal subcutaneous adipose tissue tended to be lower in obese compared to lean subjects, although not statistically different between groups (chapter 2). Furthermore, we showed a blunted in vivo isoprenaline-induced increase in net FA and total glycerol release across abdominal subcutaneous adipose tissue of obese men, indicating a blunted lipolytic response per unit adipose tissue (chapter 2). This is consistent with in vitro and in situ studies that already suggested that the site of this catecholamine resistance in obesity is abdominal subcutaneous adipose tissue $(19,32)$. A down-regulation of lipolysis per unit fat mass might be attributed to hyperinsulinemia in obesity, since higher insulin concentrations were observed during fasting and beta-adrenergic stimulation in the obese (chapter 2). Alternatively, a blunted lipolysis per unit fat mass might be an early, even primary, factor in the development of increased adipose tissue stores and obesity, as will be discussed latter in this chapter. Next, the respective role of different lipases in fasting and catecholamine-induced lipolysis in human adipocytes will be discussed. 
General discussion]

\subsection{The lipolytic picture revisited: a new lipase enters the picture}

Recently, the lipolytic picture has been revisited by the identification of a new lipase: Adipose TriGlyceride Lipase (ATGL) (87). In contrast to Hormone-Sensitive Lipase (HSL), the regulation and physiologic relevance of ATGL in human lipolyis is less clear. Therefore, we aimed to investigate the physiological relevance of ATGL and HSL in human adipose tissue lipolysis during basal (non-hormonal) and catecholamine-stimulated conditions (chapter 3), as will be discussed next.

\subsubsection{Respective role of ATGL and HSL in human adipose tissue lipolysis}

In vitro state-of-the-art methodology was used to investigate the respective role of HSL and ATGL during basal and catecholamine-stimulated lipolysis in human adipocytes (chapter 3). First, we used the RNA interference (RNAi) technique to determine the effect of selective ATGL or HSL knock-down on basal and isoprenaline-stimulated lipolysis in differentiated human preadipocytes (chapter 3). RNAi mediated knock-down of HSL resulted in a decreased basal as well as isoprenalinestimulated glycerol release, whereas knock-down of ATGL only inhibited basal glycerol release (chapter 3). Furthermore, we observed a positive association between HSL protein expression and maximal in vitro lipolytic capacity in adipocytes from lean and obese subjects. This association was not found for ATGL protein expression. Taken together these data clearly indicate that in human adipose tissue HSL is of greater importance than ATGL in promoting catecholamine-stimulated lipolysis, at least when considering complete hydrolysis of TAG into glycerol and fatty acids. The strongest evidence for a superior role of HSL among lipases in regulating fat cell lipolysis was obtained from our studies in human mesenchymal stem cells (chapter 3 ). When these cells were subjected to complete HSL inhibition (using the selective inhibitor BAY) during proliferation, differentiation and lipolysis experiments, basal lipolysis was inhibited by $50 \%$ and stimulated lipolysis (using a range of different agonists) was almost completely blunted. The results presented in chapter 3 are conducted in human adipocytes and contrast the findings in murine adipocytes, since animal models suggested a contribution of ATGL to catecholamine-induced lipolysis $(24,60,61)$. As reviewed before (5), this is not the only regulatory aspect of lipolysis that is subject to major species differences, indicating caution is needed in interpreting data obtained from murine models and extrapolating them to the human level. However, we cannot preclude the possibility that ATGL may have roles in adipose tissue lipolysis, which are not revealed until more is known regarding the regulation of this lipase (e.g., phosphorylation, intracellular localization, and protein-protein interactions). In chapter 4, we showed that ATGL, HSL protein and mRNA expression (48) are highly correlated, indicating a tight co-regulation of transcriptional control. However, from the limited data available it appears that in comparison to HSL, ATGL is not a direct targe mediated phosphorylation and is localized on the lipid droplet in the bas mone-stimulated state of the cell (87). These observations suggest that Ai activated by phosphorylation and translocation to the lipid droplet as den for HSL. Instead, an activator protein regulates ATGL activity: CGI-58 , tive gene identification 58) $(50,72)$. Interestingly, in adipose tissue CGI-5 
[Chapter 9

the intracellular lipid droplet by interaction with perilipin A $(75,85)$. In response to PKA stimulation, perilipin is phosphorylated and CGI-58 is released from the lipid droplet, thereby becoming available for binding to ATGL resulting in an increased TAG hydrolysis (75). This reversible binding of CGI-58 to perilipin could potentially represent an indirect PKA-dependent mechanism controlling ATGL activity. Next, possible physiological and molecular disturbances in the lipolytic pathway in subcutaneous adipose tissue of obese subjects will be evaluated.

\subsection{Possible mechanisms behind a blunted catecholamine-induced lipolysis in sub- cutaneous adipose tissue of obese subjects}

Several physiological and molecular disturbances in the lipolytic pathway may underlie the catecholamine resistance of adipose tissue lipolysis observed in obesity. First, the magnitude of adipose tissue blood flow (ATBF) response may have contributed to the blunted isoprenealine-induced glycerol and FA release by abdominal subcutaneous adipose tissue of obese men $(36,70)$. Likewise, in chapter 2 we showed that the increase in ATBF during beta-adrenergic stimulation is less pronounced in obese than in lean subjects. This lowered ATBF response in obese subjects may have resulted in a diminished mobilization of stored fat by decreasing the delivery of isoprenaline to the tissue. In addition, a blunted ATBF response during fasting, postprandial and beta-adrenergic stimulated conditions might affect reesterification and whole-body lipid metabolism in obesity (21).

Furthermore, several receptor and post-receptor defects in the catecholamine signal transduction pathway are likely to be involved in the observed catecholamine resistance in subcutaneous adipose tissue of obese subjects. Accordingly, a decreased number and function of $\beta_{2}$-adrenoceptors have been observed in subcutaneous adipose tissue of obese subjects (66).

In chapter 3 we demonstrated that a decreased HSL protein expression is associated with a blunted in vitro catecholamine-induced lipolysis in adipocytes derived from obese women as compared with lean. This is in accordance with previous studies showing a decreased HSL expression in adipose tissue of obese subjects, and non-obese first-degree relatives of obese subjects $(29,49,51)$. These data suggest that a decreased HSL expression may be an early, even primary, defect contributing to the development of increased fat storage in adipose tissue and obesity, by reducing fat mobilisation. In contrast to HSL, we showed for the first time that adipose tissue ATGL protein expression is not reduced in abdominal subcutaneous adipocytes from obese as compared with lean women (chapter 3 ). In accordance, ATGL mRNA levels were unaffected by obesity in abdominal subcutaneous and visceral adipose tissue of both genders (53). At the present, however, it is not known whether ATGL activation (by e.g. CGI-58, phosphorylation and translocation) is impaired in adipose tissue of obese subjects. However, since HSL is of greater importance than ATGL in promoting catecholamine-induced lipolysis in human adipose tissue (chapter 3), it seems unlikely that an impaired ATGL expression or activity contributes to the catecholamine resistance observed in subcutaneous adipose tissue of obese subjects. Furthermore, a decreased access of lipases to the lipid substrate might result in a reduced TAG hydrolysis and favouring fat storage in distinct lipid droplets. In adipose tissue the lipid droplet associated protein 
perilipin A precludes the binding of HSL to the lipid droplet. Moreover, adipocytes derived from perilipin deficient mice show a blunted isoprenaline-induced lipolysis, due to a diminished HSL translocation towards the lipid droplet $(55,69,77,79)$. This indicates that perilipin is essential for HSL translocation and action during stimulated lipolysis. Data on perilipin A expression in human adipose tissue of lean and obese subjects are conflicting $(40,81)$. It is not known, however, whether Perilipin A and HSL phosphorylation, and subsequent translocation are impaired in adipose tissue of obese subjects.

Finally, the last step in the lipolytic pathway is the efflux of FA and glycerol into the circulation. Several FA transporters facilitate the transport of FA through the plasma membrane. On the other hand, aquaporin-7 (AQP7) appears to be one of the main channels for glycrol release from adipocytes $(22,52)$, and its expression seems to be regulated by catecholamines, at least in 3T3-L1 adipocytes (20). An impaired expression of these proteins might blunt FA and glycerol efflux from the adipocyte of obese subjects. This seems to be supported by the finding that AQP7 deficient mice show an impaired adrenaline-induced glycerol release from adipocytes and develops adult-onset obesity (30). Although data in human are scarce, a decreased AQP7 gene expression has been observed in subcutaneous adipose tissue of obese subjects $(14,54)$. Moreover, a defective glycerol exit results in intracellular glycerol accumulation, which induces the enzymatic activity of GK (86). The subsequent increase in glycerol-3-phosphate (G3P) promotes re-esterification and the synthesis of TAG, resulting in adipocyte hyperthrophy (27). In contrast to AQP7, the role of FA transporters for FA efflux from adipose tissue is poorly documented.

Beside a blunted regulation of intracellular lipolysis, increased uptake of circulating lipids by adipose tissue might contribute to the increased adipose tissue mass in obesity, as will be highlighted in the next section.

\subsection{Adipose tissue TAG extraction in obesity}

In chapter 2 we observed a tendency towards an increased positive net TAG flux across abdominal subcutaneous adipose tissue of obese subjects during betaadrenergic stimulation. Furthermore, increased circulating TAG concentrations during beta-adrenergic stimulation were observed in obese subjects (chapter 2). This may be explained by differences in TAG clearance and/or production. Net TAG flux across the muscle was not different in lean and obese subjects (chapter 5), suggesting comparable muscle TAG clearance. Alternatively, hepatic VLDL-TAG production may have been increased in the obese subjects $(12,28)$. Consequently, a greater VLDL-TAG delivery to adipose tissue and hence greater lipoprotein lipase (LPL) mediated hydrolysis, might possibly explain the observed net TAG flux across adipose tissue of obese subjects (chapter 2). In vivo LPL activity has been shown to increase during epinephrine infusion, at least in normal weight subjects (70). In agreement with our observation, an increased adipose tissue LPL activity has been shown in obesity $(23,56)$. Furthermore, leptin deificient obese mice (ob/ob) that lack LPL have a diminished fat mass (83). Beside the uptake of VLDLTAG and chylomicron derived FA, it has been shown recently that adipose tissue can also take up plasma FA directly from the circulation during fasting (73) and 
[Chapter 9

postprandial conditions $(6,17)$. At the present it is not known whether obese subjects have an impaired ability to take up FA directly from the circulation during beta-adrenergically stimulated conditions. Taken together, we concluded that beside a blunted catecholamine-mediated lipolysis, an increased TAG extraction might contribute to the development of an increased fat mass and obesity, by favouring fat storage in adipose tissue.

In addition to adipose tissue, we studied local skeletal muscle lipolysis in lean and obese subjects during fasting and beta-adrenergically stimulated conditions, as will be discussed next.

\section{Skeletal muscle lipolysis in obesity and insulin resistance}

In skeletal muscle lipids are stored in the form of intramuscular TAG (IMTAG), representing a potential large energy source. In both lean and obese subjects IMTAG content seems to be inversely related to insulin sensitivity $(46,62)$. Recent studies, however, have indicated that the accumulation of lipid intermediates (DAG and ceramides), rather then IMTAG per se, may be the direct link with skeletal muscle insulin resistance, through interference with insulin signalling (63).

Lipid overflow in obesity, due to the increased fat mass, results in an increased FA supply to skeletal muscle and liver. Using the forearm balance model, we observed an increased net uptake of FA across the forearm of obese subjects after an overnight fast (chapter 5). Likewise, in obese and type 2 diabetic men and women, the amount of sarcolemmal FA binding protein CD36 (facilitating FA uptake), measured in giant vesicles prepared from the rectus abdominalis muscle, is higher compared with lean controls (10). Whether this relates to an increased FA uptake into the muscle in vivo will also be dependent on the concentration gradient over the muscle membrane, which is determined by the plasma FA concentration and the intracellular FA concentration (i.e. rate of cellular metabolism). FA taken up by skeletal muscle can be used for re-esterification and TAG synthesis, or can be oxidized. In chapter 5 we observed that forearm lactate release increased during betaadrenergic stimulation, and was higher in the obese. This suggests a tendency towards a higher glycolytic flux in obese compared with lean men, as shown previously $(8,38,39)$.

Beside an impaired FA handling, a blunted lipolyisis might play an important role in the increased skeletal muscle lipid storage in obese insulin resistant subjects, by decreasing TAG hydrolysis during high energy demands like fasting and exercise. Therefore, we used $\left.{ }^{2} \mathrm{H}_{5}\right]$-glycerol tracer methodology in combination with the forearm balance model to study local skeletal muscle lipolysis after an overnight fast and during beta-adrenergic stimulation in lean and obese men.

\subsection{Skeletal muscle lipolysis after an overnight fast}

Using three hour $\left[{ }^{2} \mathrm{H}_{5}\right]$-glycerol tracer infusion in combination with the measurement of arterio-venous concentration differences across the forearm we demonstrated significantly lower glycerol release across the forearm of obese compared 
with lean men after an overnight fast (chapter 5 ). This suggests a blunted forearm skeletal muscle lipolysis in obese subjects.

To obtain more information on the underlying mechanism at the molecular level, we measured skeletal muscle HSL protein expression and HSL serine phorphorylation in vastus lateralis muscle biopsies of these subject. We observed that a blunted fasting glycerol release was accompanied by a reduced total HSL protein expression and a reduced HSL serine phosphorylation (i.e. $\mathrm{Ser}^{563}, \mathrm{Ser}^{565}$ and $\mathrm{Ser}^{659}$ ). These data suggest that the lower fasting lipolysis is partly due to a reduced HSL activity in skeletal muscle of obese subjects (chapter 5). However, this needs to be confirmed in future research.

It is currently unknown whether ATGL protein expression and activity is impaired in skeletal muscle of obese and lean subjects. We demonstrated that ATGL protein is expressed in human skeletal muscle of lean and obese subjects, being exclusively expressed in type 1 fibers (chapter 6). These type 1 fibers are the preferential fiber for FA oxidation, suggesting an important role for ATGL in muscle FA handling. Moreover, ATGL deficient mice are obese and show an increased TAG accumulation in skeletal muscle, suggesting that ATGL might play an important role in skeletal muscle lipolysis (24). ATGL deficient mice that have increased TAG accumulation in skeletal muscle show improved insulin sensitivity (24). In contrast, HSL deficient mice show an increased DAG storage and signs of impaired insulin sensitivity in skeletal muscle (chapter 1) $(60,61)$. So, it is tempting to speculate that a dysbalance between ATGL and HSL might increase the storage of lipid intermediates in muscle of obese insulin resistant subjects. Further studies are needed to see whether ATGL expression and activity is impaired in skeletal muscle of obese subjects.

Since our obese subjects were hyperinsulinemic, we cannot exclude that the blunted glycerol release is due to a stronger inhibition of lipolysis by insulin in muscle of obese subjects. However this seems unlikely, since it has been suggested that muscle lipolysis is primarily regulated by substrate supply and to a lesser degree under hormonal control (84). This seems to be further supported by studies showing no apparent suppression of in vivo skeletal muscle lipolysis by insulin $(58,65)$.

\subsection{Beta-adrenoceptor mediated skeletal muscle lipolysis}

Forearm lipolysis was also studied during systemic infusion of the non-selective beta-agonist isoprenaline. In chapter $\mathbf{5}$, we observed no difference in 'in vivo' isoprenaline-induced increase in glycerol release across the forearm muscle of lean as compared with obese men. However, in situ microdialysis data from our group has shown a blunted increase in interstitial glycerol concentration during local $\beta_{2}$ adrenergic stimulation with salbutamol in gastrocnemius muscle of obese subjects (7), suggesting that a blunted catecholamine-induced lipolyis might contribute to the increased fat storage in skeletal muscle of obese subjects. The reason for this apparent discrepancy may be related to the use of in situ microdialysis versus the in vivo arterio-venous balance technique in combination with a $\left[{ }^{2} \mathrm{H}_{5}\right]$-glycerol tracer. In the in situ microdialysis study the $\beta_{2}$-agonist was administered locally without producing generalized effects, which might have affected the results. Secondly, 
[Chapter 9

since others and we demonstrated that muscle takes up glycerol (chapter 5) $(17,18$, 80), interstitial glycerol may not reflect the overall rate of lipolysis, but may instead be the net result of TAG and glycerol metabolism and thus reflecting net glycerol turnover (74). Finally, the results were obtained in different muscle groups. Differences in fiber type composition between muscle groups might partly explain the observed difference (26). The highest lipolytic activity is found in muscles with a high portion of slow-twitch oxidative type 1 fibers (e.g. gastrocnemius), these muscles may need an endogenous source of fatty acids to a greater extent (e.g. endurance performance) than do muscles having a relative high content of fast-twitch, glycolytic type 2 fibers (26).

Beta-adrenergic stimulation increases PKA activity, which subsequently results in an increased HSL phosphorylation, translocation and activity. To elucidate which of the PKA phosphorylation sites on HSL are important in mediating the effect of catecholamines on in vivo muscle HSL activity, HSL phosphorylation on several serine phosporylation sites was investigated in vastus lateralis muscle biopsies from lean and obese men (chapter 5). Interestingly, HSL Ser ${ }^{659}$ phosphorylation, one of the major PKA target sites, significantly increased during beta-adrenergic stimulation in skeletal muscle of obese subjects, whilst no effect was seen in lean subjects (chapter 5) $(2,67)$. Therefore, we speculated that obese subjects increase HSL phosphorylation during beta-adrenergic stimulation to deal with a reduced total HSL protein expression, possibly increasing muscle HSL activity to a level comparable with lean subjects. This might partly explain why no difference in the isoprenaline-mediated increase in total glycerol release was observed across the forearm muscle of lean compared with obese men. However, care has to be taken in combining these data since muscle biopsies and glycerol release were measured in different muscle groups (vastus lateralis vs. forearm). Furthermore, other serine residues might be important in mediating the effect of catecholamines on in vivo lipolysis (e.g. HSL Ser ${ }^{660}$ ) (2). Mutational exclusion of $\mathrm{Ser}^{659}$ and $\mathrm{Ser}^{660}$ completely abolished in vitro activation and translocation of HSL, suggesting Ser ${ }^{659}$ and $\mathrm{Ser}^{660}$ to be the major PKA phosphorylation sites, at least in adipocytes (2). Beside HSL, ATGL might contribute to human skeletal muscle lipolysis (chapter 6). However, at the present it is not known whether and how catecholamines and obesity affect muscle ATGL activity.

\section{Physiological relevance of a blunted lipolysis in obesity: the chicken or the egg?}

Which came first, the chicken or the egg? Since the chicken emerges from an egg, and a chicken lays the egg, it is ambiguous which originally gave rise to the other. Likewise, a blunted fasting and catecholamine-induced lipolysis may be a primary causative factor in the development of increased fat stores in obesity or more a secondary consequence, a protective compensatory mechanism for the obese insulin resistant state by preventing excessive lipid overflow in the circulation. 
General discussion]

4.1 The case for the prosecution: a blunted fasting and catecholamine-induced lipolysis as primary defect in obesity

An impaired lipolytic function has been demonstrated in adipocytes derived from first-degree relatives of obese subjects, suggesting that primary adipocyte lipolytic defects are present in obesity (29). Moreover, catecholamine resistance of lipolysis did not improve after weight reduction (9) and is a feature of childhood onset obesity $(11,19)$, suggesting that an impaired lipolysis is an early, even primary, defect in obesity $(29,49,51)$. For this reason, we investigated whether genetic variability in the catecholamine signal transduction pathway is associated with a blunted in vivo lipolytic response and fat oxidation during beta-adrenergic stimulation. Therefore, two genetic association studies were performed in which a large group $(n=103$ and $n=108$ ) of overweight-obese men and women participated. These subjects were extensively phenotyped and genotyped for beta-adrenoceptor (chapter 7) and postreceptor (e.g. HSL; chapter 8) genetic variability. First, in chapter 7 we demonstrated that genetic variability in codon 16 of the $\beta_{2}$-adrenoceptor (ADRB2) gene is associated with a blunted in vivo increase in circulating FA and glycerol, and a reduced fat oxidation during beta-adrenergic stimulation in overweight-obese women. Consistent with this, in vitro data showed that genetic variability in the ADRB2 gene is associated with a decreased lipolytic sensitivity in adipocytes of obese subjects (4). For the C825T polymorphism in the G-protein $\beta 3$-subunit (GNB3) gene the effect on a blunted increase in circulating FA and glycerol was more pronounced in male overweight-obese subjects. In vitro data have shown that this polymorphism is associated with a blunted signalling through beta-adrenoceptors, resulting in a reduced catecholamine action in subcutaneous adipocytes of male and female obese subjects (68). Finally, in chapter 8 we showed that overweight-obese female non-carriers of allele 184 (intron 7) and female carriers of allele 240 (intron 6) of the HSL gene have a blunted in vivo $\beta$-adrenoceptor mediated fat oxidation. Because of the fact that this investigated polymorphic marker is situated in a noncoding intron structure of the HSL gene, it seems unlikely that it results in functional conformational changes of the HSL protein or acts alone. However, it is unknown whether the polymorphic markers in $\mathrm{i} 6$ and $\mathrm{i} 7$ of the HSL gene are associated with e.g. cryptic splice junctions or alternative promoter creations, which could have major effects on function and expression of HSL, or are in linkage disequilibrium (LD) with another functional polymorphism in the HSL gene or another gene. In contrast to in vitro findings (31), in chapter 8 no effect of the polymorphic markers in the HSL gene was observed on in vivo FA and glycerol concentrations. Taken together, on the basis of the research presented in chapter 7 and 8 of this thesis, we concluded that genetic variation in the catecholamine receptor signaling pathway is an early event involved in the blunted catecholamine-induced lipolytic response and the development of increased fat storage in obesity. However, it looks like genes load the gun but gene-gender and gene-environment factors pull the trigger. Gender differences in susceptibility to complex diseases such as obesity might be mediated by sex hormone induced gene-specific epigenetic modification of DNA (35). Finally, environmental factors, such as physical activity and high dietary fat intake, may counterbalance the effect of genetic predisposition to increase body weight, body fat, and obesity (57). 
[Chapter 9

4.2 The case for defense: a blunted lipolysis as consequence of the obese insulin resistant state

Alternatively, a blunted lipolysis during fasting and catecholamine stimulation can be more a consequence of hyperinsulinemia in obesity, decreasing FA outflow from adipose tissue and protecting against worsening of the insulin resistant state. An increased adipose tissue mass in obesity delivers more FA into the circulation, resulting in an increased FA concentration when compared with lean subjects. However, this is not found in all studies and observed circulating FA levels are lower than expected if all excess fat would have been liberating FA $(44,64)$ (chapter 2). One possible conclusion is that the rate of FA release per unit adipose tissue mass is down-regulated, due to fasting hyperinsulinemia in obesity (13). Likewise, fasting insulin concentrations are inversely related to FA output from adipose tissue (37). This view of a blunted lipolysis as consequence of hyperinsulinemia seems to be further supported by the finding of a negative relationship between insulin and lipase expression $(41,42,45,76)$. However, insulin resistance of adipose tissue lipolyis to the anti-lipolytic effect of insulin has been shown $(1,13,34)$, and a blunted in situ lipolytic response in abdominal subcutaneous adipose tissue of obese women is still observed when the confounding influence of hyperinsulinemia is excluded using a pancreatic hormonal clamp (32).

To further elucidate the effect of hyperinsulinemia and obesity per se on lipase expression, we investigated ATGL and HSL protein and mRNA expression in adipose tissue biopsies of overweight-obese subjects with a broad range in fat mass and degree of insulin sensitivity. In chapter 4 we demonstrated that hyperinsulinemia and the degree of insulin resistance were negatively correlated with ATGL and HSL protein expression, independent of fat mass. These data indicate that when the obese state has already developed, insulin resistance and hyperinsulinemia seem to be the major determinants for lipase expression, suggesting that a reduced expression of ATGL and HSL may be an adaptation to the insulin resistance state. Alternatively, a reduced lipase expression might be an important early factor in the development of increased adipose tissue stores under insulin resistant conditions. Significant weight reduction decreased, rather than increased ATGL and HSL mRNA and protein expression (chapter 4). However, our weight loss intervention had no significant effect on insulin sensitivity. Thus, to fully elucidate the effect of insulin resistance on ATGL and HSL expression an intervention should be performed which significantly improves insulin sensitivity (e.g. exercise training or treatment with a PPAR- $\gamma$ agonist).

\section{Main findings and conclusions of the thesis}

The series of studies described in this thesis provide better insight in the regulation of abdominal subcutaneous adipose tissue and skeletal muscle lipolysis of obese insulin resistant subjects. Based on the results we clearly demonstrated that:

1. in vivo (chapter 2) and in vitro (chapter 3) catecholamine-induced lipolysis is blunted in abdominal subcutaneous adipose tissue of obese subjects. This 
catecholamine resistance might be an important factor contributing to the development or maintenance of increased adipose tissue fat stores and obesity (chapter 2).

2. a reduced HSL expression in abdominal subcutaneous adipocytes is one of the best characterized defects that is associated with this blunted lipolytic response in obese subjects (chapter 3 ). In contrast to HSL, we showed for the first time that adipose tissue ATGL protein expression is not altered by obesity per se (chapter 3). Given that both ATGL and HSL are responsible for at least $95 \%$ of the degradation of stored TAG (72), this might have important implications for the pathogenesis of obesity and type 2 diabetes, and render ATGL and HSL as potential drug targets. This then leaves the question whether we have to stimulate or inhibit lipases as potential treatment of obese insulin resistant conditions. As the lipolytic process critically affects the concentration of circulating FA, inhibiting lipases to decrease FA release is considered a potential target for the treatment of insulin resistance in type 2 diabetes (15). Alternatively, lipase activators may have potential benefits for the treatment of obesity, by reducing fat mass. Thereby, FA oxidation should be increased to clear the released FA from the circulation (71).

3. HSL and not ATGL is the predominant lipase for stimulated lipolysis in human adipose tissue, suggesting that ATGL might not play an important role in the catecholamine resistance of lipolysis observed in abdominal subcutaneous adipose tissue of obese subjects (chapter 3). However, this does not exclude the possibility that ATGL may play an important role in human adipose tissue lipolysis, which is not revealed until more is known regarding the regulation of this lipase.

4. when the obese state has already developed, adipose tissue ATGL and HSL mRNA and protein expression is decreased as a consequense of hyperinsulinemia and the insulin resistant state (chapter 4). Alternatively, there is strong evidence that a reduced lipase expression and the resultant blunted lipolytic response is an early defect in obesity. We showed that genetic variability in different steps of the lipolytic pathway, like the $\beta_{2}$-adrenoceptor, G-protein, and HSL contribute to the blunted in vivo catecholamine-induced lipolysis and fat oxidation in obesity, suggesting that early genetic defects in the lipolytic pathway are indeed present in obesity (chapter 7 and 8 ). It should be mentioned, however, that both primary disturbances and secondary adaptational responses might coexist in obesity.

5. obese subjects have a blunted fasting forearm muscle lipolysis, which is accompanied by a lower total HSL protein expression and HSL serine phosphorylation, most probably reducing HSL activity (chapter $\mathbf{5}$ ). These data highlight that beside an impaired FA handling also intrinsic disturbances in muscle lipolysis may contribute to the increased lipid and lipid intermediate storage in skeletal muscle of obese subjects.

6. ATGL protein is expressed in a fiber type specific way in human skeletal muscle (chapter 6). This indicates that beside HSL also ATGL might play an important role in skeletal muscle lipolysis and FA handling, and thereby could have contributed to the blunted fasting skeletal muscle lipolysis in obesity. 


\section{[Chapter 9}

In conclusion, the above findings indicate that a reduced fat mobilisation plays and important role in the development and maintenance of increased fat storage in abdominal subcutaneous adipose tissue and skeletal muscle of obese subjects. Primary disturbances in the lipolytic pathway as well as secondary adaptational responses might contribute to this reduced fat mobilisation and coexist in obesity.

\subsection{A lot done, a lot to do: suggestions for future research}

Although this thesis has contributed significantly in elucidating the physiological and molecular regulation of human lipolysis in adipose tissue and skeletal muscle of obese subjects, some important issues are still unanswered. Some important questions that need to be addressed in future research include the following:

- How is ATGL activated in adipose tissue and skeletal muscle? Is this activation impaired in the obese state? From the limited data available, ATGL activity seems to be regulated by an activator protein (i.e. CGI-58) that interacts with the lipid droplet associated protein perilipin $\mathrm{A}$ and $\underline{A}$ dipose Differentiation $\underline{\mathrm{R}} \mathrm{e}-$ lated Protein (ADRP/adipophilin/ADPH) $(75,85$ ). It might be hypothesised that defects in the interaction between CGI-58 and Perilipin A or ADRP result in an impaired ATGL activity in adipose tissue or skeletal muscle of obese subjects.

- Does genetic variability in the ATGL (PNPLA2), CGI-58 (ABHD5) or perilipin (PLIN) gene contributes to a blunted in vivo lipolysis and fat oxidation in obese subjects?

- Is expression of the lipid droplet associated proteins perilipin A and ADRP (i.e. adipophilin/ADPH) impaired in respectively adipose tissue and skeletal muscle of obese subjects? Are these lipid droplet associated proteins involved in the regulation of fasting (basal, non-hormonal) and/or catecholamine-induced lipolysis in human obesity?

- Does an imbalance between ATGL and HSL expression, or incomplete reesterification of FA and glycerol contributes to the increased storage of lipid intermediates in skeletal muscle of obese insulin resistant subjects? Is there potential for lifestyle changes (i.e. diet and exercise) to improve this impairment?

- Is adipose tissue and skeletal muscle lipolysis differentially regulated by insulin during fasting and beta-adrenergic stimulated conditions? Does exercise or treatment with insulin sensitizing agents improve insulin sensitivity of lipolysis in both tissues of obese insulin resistant subjects?

\section{References}

1. Abbasi $\mathrm{F}$, McLaughlin $\mathrm{T}$, Lamendola $\mathrm{C}$, and Reaven $\mathrm{GM}$. Insulin regulation of plasma free fatty acid concentrations is abnormal in healthy subjects with muscle insulin resistance. Metabolism 49: 151-154, 2000.

2. Anthonsen MW, Ronnstrand L, Wernstedt C, Degerman E, and Holm C. Identification of novel phosphorylation sites in hormone-sensitive lipase that are phosphorylated in response to isoproterenol and govern activation properties in vitro. $J$ Biol Chem 273:215-221, 1998.

3. Arner P. Catecholamine-induced lipolysis in obesity. Int J Obes Relat Metab Disord 23 Suppl 1: 10-13, 1999. 
General discussion]

4. Arner P. Genetic variance and lipolysis regulation: implications for obesity. Ann Med 33: 542-546, 2001.

5. Arner P. Human fat cell lipolysis: biochemistry, regulation and clinical role. Best Pract Res Clin Endocrinol Metab 19: 471-482, 2005.

6. Bickerton AS, Roberts R, Fielding BA, Hodson L, Blaak EE, Wagenmakers AJ, Gilbert M, Karpe F, and Frayn KN. Preferential uptake of dietary Fatty acids in adipose tissue and muscle in the postprandial period. Diabetes 56: 168-176, 2007.

7. Blaak EE, Schiffelers SL, Saris WH, Mensink M, and Kooi ME. Impaired beta-adrenergically mediated lipolysis in skeletal muscle of obese subjects. Diabetologia 47: 1462-1468, 2004.

8. Blaak EE, Van Baak MA, Kemerink GJ, Pakbiers MT, Heidendal GA, and Saris WH. Betaadrenergic stimulation of energy expenditure and forearm skeletal muscle metabolism in lean and obese men. Am J Physiol 267: E306-315, 1994.

9. Blaak EE, Van Baak MA, Kemerink GJ, Pakbiers MT, Heidendal GA, and Saris WH. betaAdrenergic stimulation of skeletal muscle metabolism in relation to weight reduction in obese men. Am J Physiol 267: E316-322, 1994.

10. Bonen A, Parolin ML, Steinberg GR, Calles-Escandon J, Tandon NN, Glatz JF, Luiken JJ, Heigenhauser GJ, and Dyck DJ. Triacylglycerol accumulation in human obesity and type 2 diabetes is associated with increased rates of skeletal muscle fatty acid transport and increased sarcolemmal FAT/CD36. Faseb J 18: 1144-1 146, 2004.

11. Bougneres $P$, Stunff CL, Pecqueur C, Pinglier E, Adnot P, and Ricquier D. In vivo resistance of lipolysis to epinephrine. A new feature of childhood onset obesity. $J$ Clin Invest 99: 2568-2573, 1997.

12. Bulow J, Simonsen L, Wiggins D, Humphreys SM, Frayn KN, Powell D, and Gibbons GF. Coordination of hepatic and adipose tissue lipid metabolism after oral glucose. $J$ Lipid Res 40: 20342043, 1999.

13. Campbell PJ, Carlson MG, and Nurjhan N. Fat metabolism in human obesity, Am J Physiol 266: E600-605, 1994.

14. Ceperuelo-Mallafre V, Miranda M, Chacon MR, Vilarrasa N, Megia A, Gutierrez C, FernandezReal JM, Gomez JM, Caubet E, Frubbeck G, and Vendrell J. Adipose Tissue Expression of the Glycerol Channel Aquaporin-7 Gene Is Altered in Severe Obesity But Not in Type 2 Diabetes. $J$ Clin Endocrinol Metab 92: 3640-3645, 2007.

15. Claus TH, Lowe DB, Liang Y, Salhanick AI, Lubeski CK, Yang L, Lemoine L, Zhu J, and Clairmont KB. Specific inhibition of hormone-sensitive lipase improves lipid profile while reducing plasma glucose. J Pharmacol Exp Ther 315: 1396-1402, 2005

16. Connacher AA, Bennet WM, Jung RT, Bier DM, Smith CC, Scrimgeour CM, and Rennie MJ. Effect of adrenaline infusion on fatty acid and glucose turnover in lean and obese human subjects in the post-absorptive and fed states. Clin Sci (Lond) 81: 635-644, 1991.

17. Coppack SW, Persson M, Judd RL, and Miles JM. Glycerol and nonesterified fatty acid metabolism in human muscle and adipose tissue in vivo. Am J Physiol 276: E233-240, 1999.

18. Elia M, Khan K, Calder G, and Kurpad A. Glycerol exchange across the human forearm assessed by a combination of tracer and arteriovenous exchange techniques. Clin Sci (Lond) 84: 99-104, 1993.

19. Enoksson S, Talbot M, Rife F, Tamborlane WV, Sherwin RS, and Caprio S. Impaired in vivo stimulation of lipolysis in adipose tissue by selective beta2-adrenergic agonist in obese adolescent girls. Diabetes 49: 2149-2153, 2000.

20. Fasshauer M, Klein J, Lossner U, Klier M, Kralisch S, and Paschke R. Suppression of aquaporin adipose gene expression by isoproterenol, TNFalpha, and dexamethasone. Horm Metab Res 35: 222,-227, 2003

21. Frayn KN, Karpe F, Fielding BA, Macdonald IA, and Coppack SW. Integrative physiology of human adipose tissue. Int J Obes Relat Metab Disord 27: 875-888, 2003.

22. Frubbeck G. Obesity: aquaporin enters the picture. Nature 438: 436-437, 2005. 


\section{[Chapter 9}

23. Goldberg IJ and Merkel M. Lipoprotein lipase: physiology, biochemistry, and molecular biology. Front Biosci 6: D388-405, 2001.

24. Haemmerle G, Lass A, Zimmermann R, Gorkiewicz G, Meyer C, Rozman J, Heldmaier G, Maier R, Theuss I C, Eder S, Kratky D, Wagner EF, Klingenspor M, Hoefler G, and Zechner R. Defective lipolysis and altered energy metabolism in mice lacking adipose triglyceride lipase. Science 312: 734-737, 2006.

25. Hagenfeldt $\mathrm{L}$ and Wahren J. Human forearm muscle metabolism during exercise. II. Uptake, release and oxidation of individual FFA and glycerol. Scand J Clin Lab Invest 21:263-276, 1968.

26. Hagstrom-Toft E, Qvisth V, Nennesmo I, Ryden M, Bolinder H, Enoksson S, Bolinder J, and Arner P. Marked heterogeneity of human skeletal muscle lipolysis at rest. Diabetes 51: 3376-3383, 2002.

27. Hara-Chikuma $M$, Sohara E, Rai T, Ikawa M, Okabe M, Sasaki S, Uchida S, and Verkman AS. Progressive adipocyte hypertrophy in aquaporin-7-deficient mice: adipocyle glycerol permeability as a novel regulator of fat accumulation. J Biol Chem 280: 15493-15496, 2005.

28. Havel RJ, Kane JP, Balasse EO, Segel N, and Basso LV. Splanchnic metabolism of free fatty acids and production of triglycerides of very low density lipoproteins in normotriglyceridemic and hy. pertriglyceridemic humans. $J$ Clin Invest 49: 2017-2035, 1970.

29. Hellstrom L, Langin D, Reynisdottir S, Dauzats $M$, and Arner P. Adipocyte lipolysis in normal weight subjects with obesity among first-degree relatives. Diabetologia 39: 921-928, 1996.

30. Hibuse T, Maeda N, Funahashi T, Yamamoto K, Nagasawa A, Mizunoya W, Kishida K, Inoue K, Kuriyama H, Nakamura T, Fushiki T, Kihara S, and Shimomura I. Aquaporin 7 deficiency is associated with development of obesity through activation of adipose glycerol kinase. Proc Natl Acad Sci US A 102: 10993-10998, 2005.

31. Hoffstedt J, Arner P, Schalling M, Pedersen NL, Sengul S, Ahlberg S, Iliadou A, and Lavebratt C. A common hormone-sensitive lipase 16 gene polymorphism is associated with decreased human adipocyte lipolytic function. Diabetes 50: 2410-2413, 2001.

32. Horowitz JF and Klein S. Whole body and abdominal lipolytic sensitivity to epinephrine is suppressed in upper body obese women. Am J Physiol Endocrinol Metab 278: E1144-1152, 2000.

33. Jensen MD. Lipolysis: contribution from regional fat. Annu Rev Nutr 17: 127-139, 1997.

34. Jensen MD, Haymond MW, Rizza RA, Cryer PE, and Miles JM. Influence of body fat distribution on free fatty acid metabolism in obesity. $J$ Clin Invest 83: 1168-1173, 1989.

35. Kaminsky Z, Wang SC, and Petronis A. Complex disease, gender and epigenetics. Ann Med 38: 530-544, 2006.

36. Karpe F, Fielding BA, Ilic V, Macdonald IA, Summers LK, and Frayn KN. Impaired postprandial adipose tissue blood flow response is related to aspects of insulin sensitivity. Diabetes 51:2467$2473,2002$.

37. Karpe $\mathrm{F}$ and Tan GD. Adipose tissue function in the insulin-resistance syndrome. Biochem Soc Trans 33: 1045-1048, 2005.

38. Kelley DE, Goodpaster B, Wing RR, and Simoneau JA. Skeletal muscle fatty acid metabolism in association with insulin resistance, obesity, and weight loss. Am J Physiol 277: E1 130-1141, 1999.

39. Kelley DE and Simoneau JA. Impaired free fatty acid utilization by skeletal muscle in non-insulindependent diabetes mellitus. $J$ Clin Invest 94: 2349-2356, 1994.

40. Kern PA, Di Gregorio G, Lu T, Rassouli N, and Ranganathan G. Perilipin expression in human adipose tissue is elevated with obesity. J Clin Endocrinol Metab 89: 1352-1358, 2004.

41. Kershaw EE, Hamm JK, Verhagen LA, Peroni O, Katic M, and Flier JS. Adipose triglyceride lipase: function, regulation by insulin, and comparison with adiponutrin. Diabetes 55: 148-157, 2006.

42. Kim JY, Tillison $\mathrm{K}$, Lee $\mathrm{JH}$, Rearick DA, and Smas CM. The adipose tissue triglyceride lipase ATGL/PNPLA2 is downregulated by insulin and TNF- $\{$ alpha $\}$ in 3T3-L1 adipocytes and is a target for transactivation by PPAR \{gamma\}. Am J Physiol Endocrinol Metab 291: E1 15-127, 2006. 
43. Klein S, Coppack S, Chinkes D, and Villanueva-Meyer J. Regional transendothelial glycerol kinetics in humans. FASEB journal 10: A520, 1996.

44. Koutsari $\mathrm{C}$ and Jensen MD. Thematic review series: patient-oriented research. Free fatty acid metabolism in human obesity. J Lipid Res 47: 1643-1650, 2006.

45. Kralisch S, Klein J, Lossner U, Bluher M, Paschke R, Stumvoll M, and Fasshauer M. Isoproterenol, TNFalpha, and insulin downregulate adipose triglyceride lipase in 3T3-L1 adipocytes. Mol Cell Endocrinol 240: 43-49, 2005.

46. Krssak M, Falk Petersen K, Dresner A, DiPietro L, Vogel SM, Rothman DL, Roden M, and Shulman GI. Intramyocellular lipid concentrations are correlated with insulin sensitivity in humans: a 1H NMR spectroscopy study. Diabetologia 42: 113-1 16, 1999.

47. Kurpad A, Khan K, Calder AG, Coppack S, Frayn K, Macdonald 1, and Elia M. Effect of noradrenaline on glycerol turnover and lipolysis in the whole body and subcutaneous adipose tissue in humans in vivo. Clin Sci (Lond) 86: 177-184, 1994.

48. Langin D, Dicker A, Tavernier G, Hoffstedt J, Mairal A, Ryden M, Arner E, Sicard A, Jenkins CM, Viguerie N, van Harmelen V, Gross RW, Holm C, and Arner P. Adipocyte lipases and defect of lipolysis in human obesity. Diabetes 54: 3190-3197, 2005.

49. Large V, Reynisdottir S, Langin D, Fredby K, Klannemark M, Holm C, and Arner P. Decreased expression and function of adipocyte hormone-sensitive lipase in subcutaneous fat cells of obese subjects. J Lipid Res 40: 2059-2066, 1999.

50. Lass A, Zimmermann R, Haemmerle G, Riederer M, Schoiswohl G, Schweiger M, Kienesberger $P$, Strauss JG, Gorkiewicz G, and Zechner R. Adipose triglyceride lipase-mediated lipolysis of cellular fat stores is activated by CGI-58 and defective in Chanarin-Dorfman Syndrome. Cell Metab 3: 309-319, 2006.

51. Lofgren P, Hoffstedt J, Ryden M, Thorne A, Holm C, Wahrenberg H, and Arner P. Major gender differences in the lipolytic capacity of abdominal subcutaneous fat cells in obesity observed before and after long-term weight reduction. J Clin Endocrinol Metab 87: 764-771, 2002.

52. MacDougald $\mathrm{OA}$ and Burant CF. Obesity and metabolic perturbations after loss of aquaporin 7 , the adipose glycerol transporter. Proc Natl Acad Sci US A 102: 10759-10760, 2005.

53. Mairal A, Langin D, Arner P, and Hoffstedt J. Human adipose triglyceride lipase (PNPLA2) is not regulated by obesity and exhibits low in vitro triglyceride hydrolase activity. Diabetologia 49: 1629-1636, 2006.

54. Marrades MP, Milagro FI, Martinez JA, and Moreno-Aliaga MJ. Differential expression of aquaporin 7 in adipose tissue of lean and obese high fat consumers. Biochem Biophys Res Commun 339: 785-789, 2006.

55. Martinez-Botas J, Anderson JB, Tessier D, Lapillonne A, Chang BH, Quast MJ, Gorenstein D, Chen $\mathrm{KH}$, and Chan $\mathrm{L}$. Absence of perilipin results in leanness and reverses obesity in Lepr $(\mathrm{db} / \mathrm{db})$ mice. Nat Genet 26: 474-479, 2000.

56. Mead JR, Irvine SA, and Ramji DP. Lipoprotein lipase: structure, function, regulation, and role in disease. J Mol Med 80: 753-769, 2002.

57. Meirhaeghe A, Helbecque N, Cottel D, and Amouyel P. Beta2-adrenoceptor gene polymorphism, body weight, and physical activity. Lancet 353: 896, 1999.

58. Moberg E, Sjoberg S, Hagstrom-Toft E, and Bolinder J. No apparent suppression by insulin of in vivo skeletal muscle lipolysis in nonobese women. Am J Physiol Endocrinol Metab 283: E295301, 2002.

59. Montell E, Lerin C, Newgard CB, and Gomez-Foix AM. Effects of modulation of glycerol kinase expression on lipid and carbohydrate metabolism in human muscle cells. J Biol Chem 277: 26822686, 2002.

60. Mulder H, Sorhede-Winzell M, Contreras JA, Fex M, Strom K, Ploug T, Galbo H, Arner P, Lundberg C, Sundler F, Ahren B, and Holm C. Hormone-sensitive lipase null mice exhibit signs of impaired insulin sensitivity whereas insulin secretion is intact. $J$ Biol Chem 278: 36380-36388, 2003. 


\section{[Chapter 9}

61. Osuga J, Ishibashi S, Oka T, Yagyu H, Tozawa R, Fujimoto A, Shionoiri F, Yahagi N, Kraemer FB, Tsutsumi $O$, and Yamada N. Targeted disruption of hormone-sensitive lipase results in male sterility and adipocyte hypertrophy, but not in obesity. Proc Natl Acad Sci U S A 97: 787-792, 2000.

62. Perseghin G, Scifo P, De Cobelli F, Pagliato E, Battezzati A, Arcelloni C, Vanzulli A, Testolin G, Pozza G, Del Maschio A, and Luzi L. Intramyocellular triglyceride content is a determinant of in vivo insulin resistance in humans: a $1 \mathrm{H}-13 \mathrm{C}$ nuclear magnetic resonance spectroscopy assessment in offspring of type 2 diabetic parents. Diabetes 48: 1600-1606, 1999.

63. Petersen KF and Shulman Gl. Etiology of insulin resistance. Am J Med 119: S10-16, 2006.

64. Prentice AM, Black AE, Coward WA, Davies HL, Goldberg GR, Murgatroyd PR, Ashford J, Sawyer M, and Whitehead RG. High levels of energy expenditure in obese women. $\mathrm{Br}$ Med $J$ (Clin Res Ed) 292: 983-987, 1986.

65. Qvisth V, Hagstrom-Toft E, Enoksson S, Sherwin RS, Sjoberg S, and Bolinder J. Combined hyperinsulinemia and hyperglycemia, but not hyperinsulinemia alone, suppress human skeletal muscle lipolytic activity in vivo. J Clin Endocrinol Metab 89: 4693-4700, 2004.

66. Reynisdottir S, Wahrenberg H, Carlstrom K, Rossner S, and Arner P. Catecholamine resistance in fat cells of women with upper-body obesity due to decreased expression of beta 2-adrenoceptors. Diabetologia 37: 428-435, 1994.

67. Roepstorff C, Donsmark M, Thiele M, Vistisen B, Stewart G, Vissing K, Schjerling P, Hardie DG, Galbo $\mathrm{H}$, and Kiens B. Sex differences in hormone-sensitive lipase expression, activity, and phosphorylation in skeletal muscle at rest and during exercise. Am J Physiol Endocrinol Metab 291: E1106-1114, 2006.

68. Ryden M, Faulds G, Hoffstedt J, Wennlund A, and Arner P. Effect of the (C825T) Gbeta(3) polymorphism on adrenoceptor-mediated lipolysis in human fat cells. Diabetes 51: 1601-1608, 2002.

69. Saha PK, Kojima H, Martinez-Botas J, Sunehag AL, and Chan L. Metabolic adaptations in the absence of perilipin: increased beta-oxidation and decreased hepatic glucose production associated with peripheral insulin resistance but normal glucose tolerance in perilipin-null mice. $J$ Biol Chem 279: 35150-35158, 2004.

70. Samra JS, Simpson EJ, Clark ML, Forster CD, Humphreys SM, Macdonald IA, and Frayn KN. Effects of epinephrine infusion on adipose tissue: interactions between blood flow and lipid metabolism. An J Physiol 271: E834-839, 1996.

71. Schiffelers SL, Saris WH, and van Baak MA. The effect of an increased free fatty acid concentration on thermogenesis and substrate oxidation in obese and lean men. Int J Obes Relat Metab Disord 25:33-38, 2001.

72. Schweiger $M$, Schreiber R, Haemmerle G, Lass A, Fledelius C, Jacobsen P, Tornqvist $H$, Zechner $R$, and Zimmermann $R$. Adipose triglyceride lipase and hormone-sensitive lipase are the major enzymes in adipose tissue triacylglycerol catabolism. J Biol Chem 281: 40236-41, 2006.

73. Shadid $S$, Koutsari $C$, and Jensen MD. Direct free fatty acid uptake into human adipocytes in vivo: relation to body fat distribution. Diabetes 56: 1369-1375, 2007.

74. Sjostrand M, Gudbjornsdottir S, Holmang A, Strindberg L, Ekberg K, and Lonnroth P. Measurements of interstitial muscle glycerol in normal and insulin-resistant subjects. $J$ Clin Endocrinol Metab 87: 2206-2211, 2002.

75. Subramanian V, Rothenberg A, Gomez C, Cohen AW, Garcia A, Bhattacharyya S, Shapiro L, Dolios G, Wang R, Lisanti MP, and Brasaemle DL. Perilipin A mediates the reversible binding of CGI-58 to lipid droplets in 3T3-L,1 adipocytes. J Biol Chem 279: 42062-42071, 2004.

76. Sztalryd $\mathrm{C}$ and Kraemer FB. Regulation of hormone-sensitive lipase in streptozotocin-induced diabetic rats. Metabolism 44: 1391-1396, 1995.

77. Sztalryd C, Xu G, Dorward H, Tansey JT, Contreras JA, Kimmel AR, and Londos C. Perilipin A is essential for the translocation of hormone-sensitive lipase during lipolytic activation. $J$ Cell Biol 161: 1093-1103, 2003. 


\section{General discussion]}

78. Tan GD, Debard C, Tiraby C, Humphreys SM, Frayn KN, Langin D, Vidal H, and Karpe F. A "futile cycle" induced by thiazolidinediones in human adipose tissue? Nat Med 9: 811-812; author reply 812, 2003.

79. Tansey JT, Sztalryd C, Gruia-Gray J, Roush DL, Zee JV, Gavrilova O, Reitman ML, Deng CX, Li C, Kimmel AR, and Londos C. Perilipin ablation results in a lean mouse with aberrant adipocyte lipolysis, enhanced leptin production, and resistance to diet-induced obesity. Proc Natl Acad Sci U SA 98: 6494-6499, 2001.

80. van Hall G, Sacchetti M, Radegran G, and Saltin B. Human skeletal muscle fatty acid and glycerol metabolism during rest, exercise and recovery. $J$ Physiol 543: 1047-1058, 2002.

81. Wang Y, Sullivan S, Trujillo M, Lee MJ, Schneider SH, Brolin RE, Kang YH, Werber Y, Greenberg AS, and Fried SK. Perilipin expression in human adipose tissues: effects of severe obesity, gender, and depot. Obes Res 11: 930-936, 2003.

82. Webber J, Taylor J, Greathead H, Dawson J, Buttery PJ, and Macdonald IA. A comparison of the thermogenic, metabolic and haemodynamic responses to infused adrenaline in lean and obese subjects. Int J Obes Relat Metab Disord 18: 717-724, 1994.

83. Weinstock PH, Levak-Frank S, Hudgins LC, Radner H, Friedman JM, Zechner R, and Breslow JL. Lipoprotein lipase controls fatty acid entry into adipose tissue, but fat mass is preserved by endogenous synthesis in mice deficient in adipose tissue lipoprotein lipase. Proc Natl Acad Sci US A 94: 10261-10266, 1997.

84. Wicklmayr M, Dietze G, Rett K, and Mehnert H. Evidence for a substrate regulation of triglyceride lipolysis in human skeletal muscle. Horm Metab Res 17: 471-475, 1985.

85. Yamaguchi T, Omatsu N, Matsushita S, and Osumi T. CGl-58 interacts with perilipin and is localized to lipid droplets. Possible involvement of CGI-58 mislocalization in Chanarin-Dorfman syndrome. J Biol Chem 279: 30490-30497, 2004.

86. Yeh JI, Charrier V, Paulo J, Hou L, Darbon E, Claiborne A, Hol WG, and Deutscher J. Structures of enterococcal glycerol kinase in the absence and presence of glycerol: correlation of conformation to substrate binding and a mechanism of activation by phosphorylation. Biochemistry 43: 362 373, 2004.

87. Zimmermann R, Strauss JG, Haemmerle G, Schoiswohl G, Birner-Gruenberger R, Riederer M, Lass A, Neuberger G, Eisenhaber F, Hermetter A, and Zechner R. Fat mobilization in adipose tissue is promoted by adipose triglyceride lipase. Science 306: 1383-1386, 2004. 
Summary - Samenvatting 


\section{Summary}

Obesity is characterized by increased fat storage, as triacylglycerol (TAG), mainly in adipose tissue. This increased adipose tissue mass results in lipid overflow into the circulation. Inappropriately elevated fatty acid (FA) levels have many adverse metabolic effects and are associated with an increased risk for the development of insulin resistance, type 2 diabetes and cardiovascular diseases. Furthermore, lipid overflow may lead to an increased storage of fat in non-adipose tissues (e.g. skeletal muscle), which is associated with insulin resistance. An impaired lipolysis in adipose tissue and skeletal muscle might contribute to the development or maintenance of increased fat stores and obesity. Unraveling the underlying mechanism of a blunted lipolysis might increase pharmacological and lifestyle strategies to prevent or treat obesity, type 2 diabetes and cardiovascular diseases.

This thesis is focused on the molecular and physiological regulation of human adipose tissue and skeletal muscle lipolysis in obesity. Therefore, this thesis describes a variety of human in vitro and in vivo studies specially designed to investigate lipolytic regulation in both tissues, comparing obese and lean subjects

In human adipose tissue and skeletal muscle the regulation of lipolysis depends on the balance between lipolytic and anti-lipolytic hormones, as extensively reviewed in chapter 1. Catecholamines are the major lipolytic hormones that regulate lipolysis through beta-adrenoceptors. There are indications, from in vitro and in situ microdialysis studies, for the existence of a blunted catecholamine-induced lipolysis in obesity. However, real in vivo evidence is scarce. Therefore, in chapter 2 abdominal subcutaneous adipose tissue lipolysis was examined in vivo using $\left[{ }^{2} \mathrm{H}_{5}\right]$-glycerol tracer methodology in combination with the measurement of arterio-venous concentration differences. We demonstrated that in vivo, after an overnight fast, the lipolytic rate related to fat mass is decreased in obesity. Furthermore, we showed a blunted isoprenaline-induced (non-selective beta-agonist) increase in net FA and glycerol release across abdominal subcutaneous adipose tissue of obese men. This suggests a down-regulation of lipolysis per unit adipose tissue in the obese, which might be attributed to the hyperinsulinemia in obesity. Alternatively, a blunted lipolysis per unit fat mass might be an early even primary factor in the development of increased adipose tissue stores and obesity.

Post-receptor signaling and activation of lipases (e.g. hormone-sensitive lipase; HSL) and lipid droplet associated proteins (e.g. perilipin) results in increased TAG hydrolysis, releasing glycerol and FA in the circulation. Recently the lipolytic pathway has been revisited by the identification of a new lipase: 'adipose triglyceride lipase' (ATGL). In chapter 3 we used RNA interference (RNAi) to unravel the physiological relevance of ATGL and HSL for human adipose tissue lipolysis. A superior role of HSL in promoting catecholamine-induced lipolysis was clearly observed in human adipocytes, contrasting previous findings in murine adipocytes. However, we cannot preclude the possibility that ATGL may have roles in adipose tissue lipolysis, beside promoting basal lipolytic rate, which are not revealed until more in known regarding its regulation. 


\section{[Summary}

Several molecular receptor and post-receptor defects in the lipolytic pathway might contribute to the observed catecholamine resistance in obesity and provide new therapeutic targets. In chapter 3 we demonstrated that a decreased HSL expression is associated with a blunted in vitro catecholamine-induced lipolysis in human adipocytes. In contrast, we showed for the first time that adipose tissue ATGL expression is not reduced in abdominal subcutaneous adipocytes derived from obese subjects. Given that HSL is of greater importance than ATGL in promoting catecholamine-induced lipolysis, (chapter 3) it seems unlikely that that ATGL contributes to the catecholamine resistance observed in adipose tissue of obese subjects. However, in chapter 4 we showed that when the obese state has already developed, adipose tissue ATGL and HSL mRNA and protein expression is decreased as a consequence of hyperinsulinemia and the insulin resistant state. This decreased lipase expression might reduce fatty acid outflow from the adipose tissue and consequently protect against worsening of the insulin resistant state. Alternatively, there is substantial evidence that a reduced lipase expression is and early defect in obesity. Indeed, we showed that genetic variability in different steps of the lipolytic patway, like the beta-2 adrenoceptor (chapter 7) and HSL (chapter 8) contribute to a blunted in vivo catecholamine induced lipolysis and fat oxidation in obesity. It should be metioned, however, that both primary disturbances and secondary adaptational responses might coexist in obesity. This then leaves the question whether we have to stimulate or inhibit lipases as potential treatment of obese insulin resistant conditions. As the lipolytic process critically affects the concentration of circulating FA, inhibiting lipases to decrease FA release is considered a potential target for the treatment of insulin resistance in type 2 diabetes. Alternatively, lipase activators may have potential benefits for the treatment of obesity by reducing fat mass. Thereby, FA oxidation should be increased to clear the released FA from the circulation.

Finally, lipid overflow in obesity may lead to an increased storage of fat in skeletal muscle, which is associated with insulin resistance. Besides an impaired FA handling, intrinsic disturbances in skeletal muscle lipolysis might contribute to this increased fat storage. We therefore examined skeletal muscle lipolysis in vivo using $\left[{ }^{2} \mathrm{H}_{5}\right]$-glycerol tracer methodology in combination with the forearm balance model. In chapter 5, we demonstrated significantly lower glycerol release across the forearm of obese compared with lean subjects after an overnight fast. Interestingly, this was accompanied by a reduced total HSL expression and HSL serine phosphorylation, suggesting a blunted fasting muscle lipolysis. Furthermore, we were the first to demonstrate ATGL protein expression in human skeletal muscle, being exclusively expressed in type 1 oxidative fibers (chapter 6). This suggests an important role for ATGL in human muscle FA handling and lipolyis. Since in particular lipid metabolites (e.g. diacylglycerol (DAG), and ceramides) interfere with insulin signaling, it is tempting to speculate that a dysbalance between ATGL and HSL might increase the storage of these lipid metabolites in muscle of obese insulin resistant subjects. Future research is necessary to examine whether ATGL expression and activity is impaired in skeletal muscle of obese subjects. 
In summary, from the series of studies described in this thesis the main conclusions are that:

1. in vivo and in vitro catecholamine-induced lipolysis is blunted in abdominal subcutaneous adipose tissue of obese subjects. This catecholamine resistance might be an important factor contributing to the development or maintenance of increased adipose tissue fat stores and obesity.

2. a reduced HSL expression in abdominal subcutaneous adipocytes is one of the best characterized defects that is associated with this blunted lipolytic response in obese subjects. In contrast to HSL, adipose tissue ATGL protein expression is not altered by obesity per se.

3. HSL and not ATGL is the predominant lipase for stimulated lipolysis in human adipose tissue, suggesting ATGL might not play an important role in the catecholamine resistance of lipolysis observed in abdominal subcutaneous adipose tissue of obese subjects. However, this does not exclude the possibility that ATGL may play an important role in human adipose tissue lipolysis, which is not revealed until more is known regarding the regulation of this lipase.

4. when the obese state has already developed, adipose tissue ATGL, HSL mRNA and protein expression is decreased as a consequense of hyperinsulinemia and the insulin resistant state. Alternatively, genetic variability in different steps of the lipolytic pathway (e.g. beta-2 adrenoceptor, and HSL) contributes to the blunted in vivo catecholamine-induced lipolysis and fat oxidation in obesity. This suggests that early genetic defects in the lipolytic pathway are present in obesity. It should be mentioned, however, that both primary disturbances and secondary adaptational responses might coexist in obesity.

5. obese subjects have a blunted fasting forearm muscle lipolysis, which is accompanied by a lower total HSL protein expression and HSL serine phosphorylation, most probably reducing HSL activity. These data highlight that beside an impaired FA handling also intrinsic disturbances in muscle lipolysis may contribute to the increased lipid and lipid metabolites storage in skeletal muscle of obese subjects.

6. ATGL protein is expressed in a fiber type specific way in human skeletal muscle. This indicates that in addition to HSL also ATGL might play an important role in skeletal muscle lipolysis, FA handling, and thereby could have contributed to the blunted fasting skeletal muscle lipolysis in obesity. 


\section{Samenvatting}

Obesitas (zwaarlijvigheid) wordt gekenmerkt door een verhoogde opslag van vetten in de vorm van triacylglycerol (TAG) in het vetweefsel. Een vergrote vetmassa resulteert in een verhoogde vrijzetting van lipiden in de circulatie. Deze stijging in circulerende lipiden heeft een aantal ongunstige metabole effecten en is geassocieerd met een verhoogd risico op de ontwikkeling van insuline resistentie, type 2 diabetes en cardiovasculaire aandoeningen. Verder resulteert een stijging in circulerende lipiden in een verhoogde toevoer en opslag van vetten in andere perifere weefsels zoals de skeletspier. Een verstoorde afbraak van opgeslagen vetten (intracellulaire lipolyse) in vetweefsel en de skeletspier kan bijdragen aan de ontwikkeling en het behoud van een vergrote vetopslag en obesitas. Het ontrafelen van de onderliggende mechanismen van een verstoorde lipolyse kan leiden tot de ontwikkeling van nieuwe farmacologische en leefstijl interventies voor het voorkomen of de behandeling van obesitas, type 2 diabetes en cardiovasculaire aandoeningen.

De focus van dit proefschrift ligt op de moleculaire en fysiologische regulatie van vetweefsel en skeletspier lipolyse bij mensen met obesitas. Daarom worden in dit proefschrift een aantal humane in vitro en in vivo studies besproken die speciaal ontworpen zijn om de regulatie van lipolyse in deze weefsel te bestuderen in slanke normaal gewichtige en obese proefpersonen.

De regulatie van het lipolytische proces in humaan vetweefsel en de skeletspier is afhankelijk van de balans tussen lipolytische (bv. catecholaminen) en antilipolytische hormonen (bv. insuline), zoals uitgebreid besproken in hoofdstuk 1. Catecholaminen zijn de voornaamste lipolytisch hormonen die het lipolytisch proces reguleren via beta-adrenoceptoren. Er zijn aanwijzingen vanuit in vitro en in situ microdialyse onderzoek voor een verminderde lipolytsiche response van catecholaminen in obesitas. In vivo bewijs is echter zeldzaam. Daarom bestudeerden we in hoofdstuk 2 in vivo abdominaal subcutaan vetweefsel lipolyse door gebruik te maken van $\left[{ }^{2} \mathrm{H}_{5}\right]$-glycerol tracer methodologie in combinatie met het meten van arterioveneuze concentratie verschillen. Zo toonden we aan, dat na een nacht vasten, lipolyse per eenheid vetweefsel verlaagd is bij obesen. Verder zagen we een verminderde netto vrijzetting van vetzuren en glycerol vanuit het abdominale subcutane vetweefsel van obese proefpersonen tijdens stimulatie met de niet-selectieve beta-agonist isoprenaline. Deze resultaten veronderstellen een down-regulatie van lipolyse per eenheid vetweefsel in obesitas. Deze down-regulatie kan mogelijkerwijs veroorzaakt worden door de hyperinsulinemie die vaak aanwezig is bij obesitas. Het kan echter ook een vroege primaire factor zijn bij het ontstaan van een vergrote vetmassa en obesitas.

Post-receptor signalering en activatie van lipasen (bv. hormoon-gevoelig lipase; HSL) en eiwitten geassocieerd met de vetdruppel (bv. perilipin) resulteert in een verhoogde afbraak van opgeslagen TAG en het vrijzetten van glycerol en vetzuren in de circulatie. Recent is de lipolytsche pathway herzien door de ontdekking van 
[Samenvatting

een nieuw lipase: 'adipose triglyceride lipase' (ATGL). In hoofdstuk 3 hebben we de fysiologische relevantie van ATGL en HSL voor lipolyse in humaan vetweefsel trachten te ontsluieren. Zo blijkt HSL een superieure rol te spelen tijdens catecholamine geïnduceerde lipolyse in humane vetcellen, hetgeen in tegenspraak is met bevindingen in adipocyten afkomstig van knaagdieren. Naast een bijdrage aan basale (niet gestimuleerde) lipolyse kunnen we echter niet uitsluiten dat ATGL een belangrijke rol speelt in humane vetweefsel lipolyse tot er meer bekend is over de regulatie van dit lipase.

Tal van moleculaire receptor en post-receptor defecten in de lipolytische pathway kunnen bijdragen aan de catecholamine resistentie in vetweefsel, en gebruikt worden als therapeutisch target bij obesitas. In hoofdstuk 3 toonden we aan dat in humane adipocyten een verminderde HSL expressie geassocieerd was met een verminderde lipolytische response op catecholaminen. In tegenstelling tot HSL, toonden we voor het eerst aan dat ATGL protein expressie niet verlaagd is in abdominale subcutane vetcellen van obese in vergelijking met slanke, normaal gewichtige proefpersonen. Vermits HSL belangrijker is dan ATGL voor catecholamine geïnduceerde lipolyse (hoofdstuk 3) lijkt het onwaarschijnlijk dat ATGL in belangrijke maten bijdraagt aan de catecholamine resistentie in vetweefsel van mensen met obesitas. Alhoewel, in hoofdstuk 4 toonden we aan dat ATGL, HSL mRNA en eiwit expressie in vetweefsel verlaagd is als gevolg van hyperinsulinemie en insuline resistentie bij mensen met obesitas. Deze down-regulatie van lipasen kan resulteren in een verminderde vrijzetting van vetzuren vanuit het vetweefsel in de circulatie, hetgeen mogelijkerwijs een verslechtering van de insuline resistentie voorkomt. Er is echter ook bewijs dat een verminderde expressie van lipasen een vroeg en zelfs primair defect is bij het ontstaan van obesitas. Zo toonden we in hoofdstuk 7 en 8 aan dat genetische variabiliteit in het beta-2 adrenoceptor en HSL gen bijdraagt aan de verminderde in vivo lipolytische respons op catecholaminen en vetoxidatie bij mensen met obesitas. Des al niettemin kunnen zowel primaire als secundaire verstoringen samen voorkomen bij mensen met obesitas. Blijft echter de vraag of we lipasen moeten activeren of inhiberen als mogelijke behandeling voor obesitas en andere insuline resistente aandoeningen. Het inhiberen van de activiteit van lipasen kan gezien worden als een potentiële behandeling van insuline resistentie en type 2 diabetes. Het resulteert namelijk in een verminderde vrijzetting van vetzuren en heeft zo een kritisch effect op circulerende vetzuur concentraties. Een alternatief zijn activatoren van lipasen die de vetmassa kunnen reduceren als behandeling voor overgewicht en obesitas. Er dient dan echter rekening gehouden te worden dat gelijktijdig de oxidatie van vetten verhoogd wordt opdat de vrijgekomen vetzuren uit de circulatie verwijderd kunnen worden.

Tot slot kan een toename in de concentratie van circulerende lipiden leiden tot een verhoogde aanvoer en opslag van vetten in de skeletspier, hetgeen geassocieerd is met insuline resistentie. Naast een verstoorde verwerking (opname en oxidatie) van vetten kunnen ook intrinsieke verstoringen in skeletspier lipolyse bijdragen aan deze verhoogde vetopslag. Daarom onderzochten we in vivo skeletspier lipolyse met behulp van $\left[{ }^{2} \mathrm{H}_{5}\right]$-glycerol tracer methodologie in combinatie met het onderarm model. In hoofdstuk 5 toonden we aan dat de vrijzetting van glycerol vanuit de onderarm verlaagd is bij obese proefpersonen na een nacht vasten. Bovendien bleek dit 
gepaard te gaan met een verminderde HSL expressie en fosforylatie op belangrijke serine residuen, hetgeen wijst op een verminderde lipolyse in de skeletspier van obesen. Naast HSL toonden we als eersten aan dat bij de mens ATGL eiwit exclusief in type 1 (oxidatieve) spiervezels tot expressie komt (hoofdstuk 6). Deze observatie veronderstelt een belangrijke rol voor ATGL in vetzuur verwerking en lipolyse in humane spier. Sinds voomamelijk lipide metabolieten (diacylglycerol (DAG) en ceramiden) interfereren met de insuline signalering, is het verleidelijk om te postuleren dat een onevenwicht tussen ATGL en HSL expressie de opslag van deze metabolieten kan verhogen in de skeletspier van obese insuline resistente personen. Verder onderzoek is echter nodig om te kijken of expressie en activiteit van ATGL verstoord is in de skeletspier van mensen met obesitas.

Samengevat, de belangrijkste conclusies die getrokken kunnen worden uit de studies die beschreven staan in dit proefschrift zijn dat:

1. de in vivo en in vitro catecholamine geïnduceerde lipolytische respons verminderd is in abdominaal subcutaan vetweefsel van mensen met obesitas. Deze catecholamine resistentie zou een belangrijke factor kunnen zijn die bijdraagt aan de ontwikkeling of het behoud van een vergrote vetopslag en obesitas.

2. een verminderde HSL expressie in abdominaal subcutaan vetweefsel is een van de best gekarakteriseerde defecten die geassocieerd zijn met een verminderde lipolytische respons bij mensen met obesitas. In tegenstelling tot HSL wordt ATGL expressie niet aangetast door obesitas per se.

3. HSL en niet ATGL is het voornaamste lipase voor catecholamine gestimuleerde lipolyse bij de mens. Dit verondersteld dat ATGL geen belangrijke rol speelt bij de catecholamine resistentie in abdominaal subcutaan vetweefsel van mensen met obesitas. Het sluit echter niet uit dat ATGL een belangrijke rol speelt in humane vetweefsel lipolyse die niet ontdekt is tot er meer bekend is over de regulatie van dit lipase.

4. bij mensen met obesitas wordt ATGL, HSL mRNA en eiwit expressie in vetweefsel verlaagd als gevolg van hyperinsulinemie en insuline resistentie. Ook genetische variabiliteit in verschillende stappen van de lipolytische pathway zoals de beta- 2 adrenoceptor en HSL draagt bij aan een verminderde in vivo catecholamine geïnduceerde lipolyse en vetoxidatie bij mensen met obesitas. Dit geeft aan dat ook vroege genetische defecten in de lipolytische pathway aanwezig zijn bij mensen met obesitas. Des al niettemin kunnen primaire verstoringen en secundaire adaptaties samen voorkomen in obesitas.

5. een verminderde vrijzetting van glycerol vanuit de skeletspieren is geassocieerd met een verminderde expressie en serine phosphorylatie van HSL, hetgeen wijst op een verminderde skeletspier lipolyse bij mensen met obesitas. Deze data geven ook aan dat naast een verstoorde verwerking (opname en oxidatie) van vetzuren ook een verstoorde lipolyse kan bijdragen aan de verhoogde opslag van vetten en lipide metabolieten in de skeletspier van mensen met obesitas.

6. in humane skeletspier komt ATGL eiwit exclusief tot expressie in type 1 (oxidatieve) spiervezels. Dit geeft aan dat naast HSL ook ATGL een belangrijke rol zou kunnen spelen in skeletspier lipolyse en de verwerking van vetzuren en dat 


\section{[Samenvatting}

ATGL mogelijkerwijs bijdraagt aan de verminderde gevaste lipolyse in de skeletspier van obese proefpersonen. 
Acknowledgements - dankwoord 
Acknowledgements - Dankwoord]

\section{Acknowledgements - dankwoord}

Dit proefschrift is het resultaat van 4 heel bijzondere jaren, waarin vele bergen zijn beklommen maar ook diepe dalen moesten worden overwonnen. Een reis waarin ik mezelf vaak tegen kwam en die me heeft gevormd tot wie ik nu ben. Deze reis was echter niet mogelijk zonder de hulp van verschillende mensen die ik bij deze allemaal ontzettend wil bedanken.

Beste Ellen, van co-promotor naar promotor en van Dr. naar Prof. het zijn 'maar' titels maar je weet er een bijzonder geslaagde invulling aan te geven. "Ziet er goed uit, maar heb nog enkele 'kleine' opmerkingen. Zenuwachtig voor je presentatie? Nee, nog niet. Komt vast wel. Is normaal hoor." Het zijn maar enkele van je kritische opmerkingen die me bijgebleven zijn. Ze hebben me doen inzien dat je een berg enkel hebt beklommen als je de top hebt bereikt. Dank om altijd in me te blijven geloven, me de vrijheid te geven om een meer moleculaire invulling te geven aan het onderzoek beschreven in dit proefschrift en me de liefde voor de wetenschap bij te brengen. Naast je professionaliteit heb ik ook je menselijkheid enorm gewaardeerd als ik weer eens afgewezen werd door een reviewer. Hoop nog vele bergen samen te mogen beklimmen.

Beste Wim, van de UM naar DSM maar als promotor hield je van op afstand de voortgang altijd kritisch in het oog. "Mooi verhaal. Kijk nog eens even naar...; Prima. Erg lange zinnen." Deze korte en krachtige opmerkingen in potlood gaven me vaak de extra motivatie die ik nodig had om mijn beklimming voort te zetten.

I would like to acknowledge my gratitude to Jan Glatz, Edwin Mariman, Hanno Pijl, Hans Romijn, Coen Stehouwer and Rudolf Zechner for critical evaluation of this thesis and/or being part of the corona during the public defense of my thesis.

Peter Arner, Keith Frayn, Gijs Goossens, Cecilia Holm, Carla van der Kallen, Bente Kiens, Dominique Langin, Carsten Roepstorff, Mikael Rydén, Egbert Smit and Jos Stegen, thank you for your collaboration and contribution to the different chapters, giving this thesis an international character.

Cheryl, vriendin en paranimf, ik zal onze eerste kennismaking niet snel vergeten. Aan de start van je promotietraject zei je: "vanaf nu ga ik het eens wat rustiger aandoen!" Wel als er iemand is die het zeker niet rustiger aan heeft gedaan de afgelopen 4 jaar dan ben jij het wel. Ik heb enorme bewondering voor wie je bent, waar je voor staat, voor de Cheryl als moeder van een geweldige dochter (Eowyn) en vrouw van Ed. Ik heb onze gezamelijke congresbezoeken en etentjes enorm gewaardeerd. Je was en bent er steeds om me uit het dal te halen, maar ook om samen op de top te genieten van het mooie uitzicht. Dankzij jou heb ik de afgelopen 4 jaar als een heel aangename tijd ervaren waar ik met veel plezier aan terugdenk.

Leden van het beruchte AV-team (Gijs, Marleen, Ellen, Paula en Anneke v H) samen hebben we ochtenden lang naar dunne en dikke buiken liggen staren opzoek naar die ene 'tummy vein'. Het was prettig met jullie te mogen samenwerken en van jullie te leren. Luc, Marco en Wim dank voor het nemen van de vele spiebiop- 


\section{[Acknowledgements - Dankwoord}

ten op de meest onmogelijke tijdstippen. Ook dank aan de proefpersonen voor het deelnemen aan de verschillende invasieve onderzoeken. Zonder jullie inzet was de wetenschap nergens en had ik dit proefschrift nooit kunnen schrijven. Anneke v Hees en Paula van der Baan, bedankt voor jullie inzet als stagiares bij de vaak lange testdagen en het analyseren van de vele samples. Veel succes met jullie promotietrajecten bij Humane Biologie en Interne Geneeskunde.

Leden van het vetstofoverleg (Anneke v H, Anneke J, Chantalle M, Cheryl, Eefje, Ellen, Gijs, Hanneke, Judith, Nicole J, Marleen, Yvonne) ik heb ontzettend genoten van de vaak luidruchtige maar leerzame bijeenkomsten.

Tanja en Marja, dank voor de leuke gesprekken als ik weer eens snoepjes uit de pot kwam halen. Veel succes me de kids en de nieuwe baan! Eef, Sjonnie komt de snoeppot snel eens bijvullen met lekkers uit Zweden!

Ik heb heel wat kamergenoten versleten in 4 jaar tijd. Een Belg is dan ook niet de makkelijkste in de omgang! Ik maakte mijn start op verdieping 2 met Gijs, Cyriel en later Anneke v H. Dank voor de samenwerking en de vele discussies over de verschillen tussen Belgen en Nederlanders. Wij hebben beiden verschillende eet- en drinkgewoonten, geven 1 of meerdere koekjes bij de koffie, gaan lekker op hotel of met de sleurhut (caravan), spreken zacht of oorverdovend luid. Maar verschillen moeten er zijn, zeker tussen buurlanden. Met zo een 'enorme' cultuurkloof was het bijna onvernijdelijk om te worden 'verbannen' naar de kamer der terminale patiënten wiens laatste dagen en uren als AIO waren geslagen. Daar op verdieping 1 trof ik Mandy, Julian en Stefan (de middenlob is top!), Chantal D, Lydia (tot snel in Zweden), Myriam (Veel succes bij of was het nu op Mars) en Rachel. Bedankt voor het aanhoren van mijn klaagzang tijdens het afronden van dit proefschrift. Veel succes met jullie promotie en jullie carrière in de wetenschap of elders. Verder wil ik Mandy en Niels B bedanken voor de leuke tijd in Athene. Heel veel succes met jullie nieuwe baan als post-doc in Ierland (Mandy) en als onderzoeker bij Unilever (Niels).

Loek en Paul bedankt voor alle hulp als ik weer eens in gevecht was met mijn computer. Once you go Mac you never go back!

Beste Jos enorm bedankt voor het analyseren van de honderden stabiele isotopen samples in Birmingham en je technische ondersteuning bij het analyseren van de vele plasma monsters. Jij bent de echte 'vader, père, vater, padre, pater, pitar' van $\mathrm{HB}$. Je tracht je kroost bij elkaar te brengen/ houden met het organiseren van tal van activiteiten waarbij het bier rijkelijk mag vloeien en de geur van frietvet je al van ver tegemoet komt. Waarvoor enorme bewondering!

Antoine, Egbert, Freek en Yvonne dank voor alle hulp tijdens het gieten van gelen en het maken van de vele blots. Dankzij jullie expertise heb ik mijn proefschrift een moleculair karakter kunnen meegeven. Yvonne, hoop dat we in de toekomst even succesvol mogen samenwerken. 
Claudia, Larisa, Ilona, Kerstin en Desiree jullie staan/stonden altijd voor me klaar als ik weer eens in gevecht ben met het faxtoestel (na 4 jaar weet ik nog steeds niet hoe dat ding werkt) of als de handtekening van Wim 'nagemaakt' moest worden. Niets is jullie teveel, waarvoor dank!

Dank aan alle overige collega's van humane biologie die ik nog niet genoemd heb (het zijn er dan ook zo enorm veel) voor de prettige werksfeer. Twee bijzondere (ex)-collega's die ik toch graag zou willen vernoemen zijn Gabby en Petra. Zonder jullie was ik 4 jaar geleden nooit aan deze baan gekomen, mijn oprechte dank hiervoor. Het ijsje laat al vier jaar op zich wachten dus het word eens tijd om mijn schuld af te betalen!

Dear Peter Arner and Mikael Ryden I am very honoured you welcomed me to work in your superb lab at the Karolinska Institutet in Stockholm, Sweden. I have great respect for your high-quality research and hope to learn a lot from your expertise and make our collaboration successful. Lena Lindberg thanks for helping me to find a place to stay in Stockholm.

$\mathrm{Mu}$, Little Sister and paranimf, as an MD and $\mathrm{PhD}$ at Munich University, Germany and researcher at Diamed-Eurogen, Belgium you are my example of a real scientist: helping those who are suffering and not thinking about impact factor, position and making career. My heartfelt thanks for your support and helping me to become myself.

Nathalie en Maarten ook al zien we elkaar niet zo vaak ik geniet enorm van jullie korte bezoekjes. Bedankt dat jullie er altijd voor me zijn. Veel succes met het huisje, tuintje, boompje en hopelijk snel het kindje!

Carl, Mark en Huubke dank voor de leuke uitjes en de vele tassen koffie. Ik zal niet snel onze carnaval als de Ali's en Frans in Maastricht vergeten!

Lieve Charles ruim een jaar geleden leerden we elkaar kennen. Het klikte vanaf dag 1 en we vormen sindsdien een onafscheidelijk duo. Dank voor je liefde, begrip en de vrijheid die je me geeft om mijn 'dromen' waar te maken. Samen in ons huisje is het mooiste wat me ooit is overkomen. Een echte thuis!

Jacques, Gonnie, Simon, Carlijn, Jean, Manon, Pie, Giel en oma Truus dank om me vanaf dag 1 op te nemen in jullie warme familie. Jean enorm bedankt voor je enthousiasme bij het ontwerpen van de omslag van dit boekje. Alleen had ik dit nooit voor elkaar gekregen!

Papa en mama, jullie hebben de afgelopen vier jaar heel wat met me moeten meemaken maar toch staan jullie altijd voor me klaar. Dankzij jullie sta ik hier vandaag. Daarom draag ik dit proefschrift speciaal aan jullie op. Jullie hebben me de vrijheid en de mogelijkheden gegeven om te doen wat ik wilde doen en te zijn wie ik ben. Ik ben enorm blij met jullie als ouders. Bedankt voor alles! 
Curriculum vitae 


\section{Curriculum Vitae}

Johan W.E. Jocken was born on June $1^{\text {ste }} 1981$ in Hasselt, Belgium. In 1999 he completed secondary school at the Sint Jozelfs College in Hasselt, Belgium. In the same year he started his master in medical sciences with specialization molecular biology at the Medical Faculty of the Limburgs Universitair Centrum (LUC), Diepenbeek, Belgium, were he graduated with distinction (cum laude) in 2003. In July of the same year, he started his PhD at the Department of Human Biology, Maastricht University, under supervision of Prof. dr. E.E. Blaak and Prof. dr. W.H.M. Saris, funded by a NWO-ZonMW grant (015.01.095). In June 2005 he was nominated for the Young Investigators United award at the European Congress on Obesity (ECO) in Athens, Greece. In April 2006 he was awarded a travel grant to give the President's poster lecture for most outstanding research at the International Congress on Obesity (ICO), Sydney, Australia. In October 2006 he was nominated for the Foppe Ten Hoor young investigators award from The Netherlands Association for Scientific Research (NWO). In June 2007 the Faculty of Health, Medicine and Life Sciences from the University of Maastricht, Maastricht, The Netherlands awarded his work by the Kootstra-Talent fellowship to continue his research. Johan Jocken is currently working as a post-doctoral researcher at the Department of Medicine, of the Karolinska Institute in Stockholm, Sweden and funded by a prestigious NWO-Rubicon grant (820.07.025). 
List of publications 
List of publications]

\section{List of publications}

Full papers

Adam TC, Jocken J, Westerterp-Plantenga MS. Decreased glucagon-like peptide 1 release after weight loss in overweight/obese subjects. Obesity Research $2005 ; 13(4): 710-6$.

Jocken JW, Blaak EE, Schiffelers S, Arner P, van Baak MA, Saris WH. Association of a beta-2 adrenoceptor (ADRB2) gene variant with a blunted in vivo lipolysis and fat oxidation. International Journal of Obesity 2007;31(5):813-9.

Goossens GH, Jocken JW, Blaak EE, Schiffers PM, Saris WH, van Baak MA. Endocrine role of the rennin-angiotensin system in human adipose tissue and muscle: effect of beta-adrenergic stimulation. Hypertension 2007;49(3):542-7.

Rydén $M$, Jocken J, Dicker A, Hoffstedt J, Wirén $M$, Blomqvist $M$, Mairal A, Langin D, Blaak E, Arner P. Comparative studies of the role of hormone-sensitive lipase and adipose triglyceride lipase in human fat cell lipolysis. American Journal of Physiology-Endocrinology and Metabolism 2007;292(6):E1874-55.

Jocken JW, Langin D, Smit E, Saris W, Valle C, Hul GB, Holm C, Arner P, Blaak E. Adipose triglyceride lipase (ATGL) and hormone-sensitive lipase (HSL) protein expression is decreased in the obese insulin-resistant state. Journal of Clinical Endocrinology and Metabolism 2007;92(6):2292-9.

Jocken JWE, Goossens GH, van Hees A, Frayn KN, Schiffelers S, van Baak MA, Stegen J, Pakbiers MTW, Saris WHM, Blaak EE. Effect of beta-adrenergic stimulation on whole-body and abdominal subcutaneous adipose tissue lipolysis in lean and obese men. Diabetologia (accepted-in press)

Jocken JWE, Blaak EE, van der Kallen CJH, van Baak MA, Saris WHM. Blunted beta-adrenoceptor mediated fat oxidation in overweight subjects: a role for the hormone-sensitive lipase gene. Metabolism (accepted-in press)

Goossens GH, Jocken JWE, van Baak MA, Jansen EHJM, Saris WHM, Blaak EE. Short-term $\beta$-Adrenergic regulation of leptin, adiponectin and IL-6 secretion in vivo in lean and obese subjects. Diabetes Obesity and Metabolism (accepted-in press)

Jocken JWE, Roepstorff C, van der Baan P, Goossens GH, van Baak MA, Saris WHM, Kiens B, Blaak EE. HSL serine phosphorylation and glycerol exchange across skeletal muscle before and during beta-adrenergic stimulation in lean and obese subjects. Diabetes (revised)

Jocken JWE, Smit E, Goossens GH, Essers YPG, van Baak MA, Mensink M, Saris WHM, Blaak EE. Adipose TriGlyceride Lipase (ATGL) expression in human 
[List of publications

skeletal muscle is type I (oxidative) fiber specific. FASEB Journal (IQ acceptedinvited to submit)

Jocken JWE, Blaak EE. Adipose tissue and skeletal muscle lipolysis in obesity and insulin resistance: a critical review. Physiology \& Behavior (submitted) 
List of publications]

Abstracts

Jocken JWE, Blaak EE, vd Kallen CJH, v Baak MA, Saris WHM, de Bruin TWA. Blunted beta-adrenoceptor mediated lipolysis and fat oxidation in overweight subjects: a role for the HSL gene? International Journal of Obesity 2004;28(1):S108.

JWE Jocken, EE Blaak, P Arner, MA van Baak, WHM Saris. Association between genetic variation in the beta-2 adrenoceptor (ADRB2) gene and the G-protein beta3 (GNB3) gene with a blunted in vivo lipolysis and fat oxidation in overweight subjects. Obesity Reviews 2005;6(1):38.

JWE Jocken, GH Goossens, MA van Baak, WHM Saris, EE Blaak. The effect of beta-adrenergic stimulation on abdominal subcutaneous adipose tissue substrate fluxes in lean and obese men. Obesity Reviews 2005;6(1):74.

GH Goossens, JW Jocken, EE Blaak, WHM Saris, PM Schiffers, MA van Baak. Angiotensin II release from adipose tissue and the forearm in lean and obese men: effect of beta-adrenergic stimulation. Obesity Reviews 2005;6(1):75.

Jocken JWE, Smit E, Saris WHM, Hul GB, Holm C, Blaak E. Adipose triglyceride lipase (ATGL) and hormone-sensitive lipase (HSL) protein expression are decreased in obese insulin resistant subjects. Obesity Reviews 2006;7(2):103.

Jocken Johan WE, Roepstorff Carsten, Goossens Gijs H, van Baak Marleen, Saris Wim HM, Kiens Bente, Blaak Ellen. HSL serine phosphorylation and glycerol exchange across skeletal muscle before and during beta-adrenergic stimulation in lean and obese subjects. International Journal of Obesity 2007;31(1):S23.

Goossens Gijs H, Jocken Johan WE, Blaak Ellen E, Schiffers Paul M, Saris Wim $H M$, van Baak Marleen A. Endocrine role of the rennin-angiotensin system in adipose tissue and skeletal muscle in vivo in human: effect of beta-adrenergic stimulation. International Journal of Obesity 2007;31(1):S91.

Goossens Gijs H, Jocken Johan WE, van Baak Marleen A, Jansen Eugene HJM, Saris wim HM, Blaak Ellen E. Beta-adrenergic regulation of leptin, adiponectin and interleukin-6 secretion in vivo in lean and obese subjects. International Journal of Obesity 2007;31(1):S32.

JWE Jocken, GH Goossens, A van Hees, KN Frayn, M van Baak, M Pakbiers, WHM Saris, EE Blaak. Effect of beta-adrenergic stimulation on whole-body and regional abdominal subcutaneous adipose tissue lipolysis in lean and obese men. Diabetologia 2007; 50(1): S86. 
Abbreviations]

\section{Abbreviations}

\begin{tabular}{|c|c|}
\hline$\% \mathrm{BF}$ & Percentage Body Fat \\
\hline$\% \mathrm{HbO}_{2}$ & Percentage oxyhemoglobin \\
\hline$\left[{ }^{2} \mathrm{H}_{5}\right]$-glycerol & Stabile isotope tracer $[1,1,2,3,3-2 \mathrm{H} 5]$ glycerol \\
\hline$\left|D^{\prime}\right|$ & Linkage disequilibrium measure \\
\hline${ }^{133} \mathrm{Xe}$ & Radioactive Xenon \\
\hline 3T3-L1 & Mouse embryonic fibroblast - adipose like cell line \\
\hline A & Adenine \\
\hline a.m. & ante meridiem (before noon) \\
\hline ABHD5 & Abhydrolase domain containing 5 (CGI-58) \\
\hline $\mathrm{AC}$ & Adenylate Cyclase \\
\hline ADPH & Adipophilin (human ADRP orthologue) \\
\hline $\mathrm{ADR}$ & Adrenoceptor \\
\hline ADRB2 & beta- 2 adrenoceptor gene \\
\hline ADRP & Adipose Differentiation-Related Protein \\
\hline AFABP & Adipocyte Fatty Acid Binding Potein \\
\hline AMP & Adenosine MonoPhosphate \\
\hline AMPK & AMP-activated protein kinase \\
\hline ANCOVA & Analysis of covariance \\
\hline ANOVA & Analysis of variance \\
\hline ANP & Atrial Natriuretic Peptide \\
\hline AQP7 & Aquaporin 7 \\
\hline Arg & Arginine \\
\hline $\mathrm{AT}$ & Adipose Tissue \\
\hline ATBF & Adipose Tissue Blood Flow \\
\hline ATGL & Adipose TriGlyceride Lipase \\
\hline$B$ & Unstandardized beta-coefficient \\
\hline $\mathrm{BAT}$ & Brown Adipose Tissue \\
\hline BAY & $\begin{array}{l}\text { 4-isopropyl-3-methyl-2-[1-(3-(S)-methyl-piperidin-1-yl)-methanoyl]-2H- } \\
\text { isoxazol-5-1 (selective HSL inhibitor) }\end{array}$ \\
\hline $\mathrm{BCA}$ & Bicinchoninic acid \\
\hline BMI & Body Mass Index \\
\hline bp & base pair \\
\hline $\mathrm{BSA}$ & Bovine Serum Albumin \\
\hline $\mathrm{C}$ & Cytosine \\
\hline $\mathrm{CaCl}_{2}$ & Calcium chloride \\
\hline CaMKII & Calcium/calmoduline-dependent Kinase II \\
\hline cAMP & cyclic Adenosine MonoPhosphate \\
\hline CD36/FAT & Fatty acid transporter (Fatty Acid Translocase) \\
\hline cDNA & DeoxyriboNucleic acid (DNA) copy \\
\hline CGI-58 & Comparative Gene Identification 58 \\
\hline cGMP & cyclic GMP \\
\hline CHAPS & 3-[(3-cholamidopropyl) dimethylammonio]-1-propane sulfonate \\
\hline $\mathrm{CHCl}_{3}$ & Chloroform \\
\hline $\mathrm{CHO}$ & Chinese Hamster Ovary cell line \\
\hline $\mathrm{CI}$ & Confidence Inteval \\
\hline $\mathrm{CO}_{2}$ & Carbon dioxide \\
\hline $\cos$ & African green monkey (cercopithecus aethiops) kidney cell line \\
\hline d.f. & degrees of freedom \\
\hline $\mathrm{DAB}$ & Diaminobenzidine \\
\hline $\mathrm{DAG}$ & Diacylglycerol \\
\hline
\end{tabular}




\section{[Abbreviations}

\begin{tabular}{|c|c|}
\hline $\begin{array}{l}\text { DBP } \\
\text { dcAMP }\end{array}$ & $\begin{array}{l}\text { Diastolic Blood Pressure } \\
\text { dibutyryl cAMP }\end{array}$ \\
\hline DMEM & Dulbecco's Modified Eagle's Medium \\
\hline DNA & Deoxyribonucleic acid \\
\hline e.g. & [exempli gratia], for instance \\
\hline ECG & ElectroCardioGram \\
\hline ECL & Enhanced ChemiLuminescence \\
\hline $\mathrm{ECO}$ & European Congress on Obesity \\
\hline EDTA & EthyleneDiamineTetraAcetic acid \\
\hline $\mathrm{EE}$ & Energy Expenditure \\
\hline ERK & Extracellular signal Regulated Kinase \\
\hline et al. & $\begin{array}{l}\text { 'et alii' (masculine plural) or 'et aliae' (feminine plural) or 'et alia' (neutral } \\
\text { plural) when referring to a number of people }\end{array}$ \\
\hline $\mathrm{F}$ & Isotope infusion rate \\
\hline FABP4/aP2 & Fatty Acid Binding Protein (AFABP) \\
\hline FBF & Forearm Blood Flow \\
\hline FCV & Fat Cell Volume \\
\hline FCW & Fat Cell Weight \\
\hline FFA (FA/NEFA) & (plasma) Free Fatty Acid (Non-Esterified Fatty Acid) \\
\hline FFM & Fat-Free Mass \\
\hline FM & Fat Mass \\
\hline fract & fractional extraction \\
\hline G & Guanine \\
\hline G3P & Glycerol-3-Phosphate \\
\hline GC-MS & Gas Chromatography-Mass Spectrometry \\
\hline $\mathrm{Gi}$ & Inhibitory G-protein \\
\hline Gk & Glycerol Kinase \\
\hline Gln & Glutamic acid \\
\hline Glu & Glutamine \\
\hline Gly & Glycine \\
\hline GMP & Guanosine MonoPhosphate \\
\hline GNB3 & G-protein beta-3 $\left(\mathrm{G} \beta_{3}\right)$ subunit gene \\
\hline GPDH & Glycerol-3-phosphate dehydrogenase \\
\hline Gs & Stimulatory G-protein \\
\hline h & hour \\
\hline $\mathrm{H}_{2} \mathrm{O}_{2}$ & Hydrogen Peroxide \\
\hline HEPADIP & HEPatic and ADIPose tissue and functions in the metabolic syndrome \\
\hline HEPES & 4-(2-hydroxyethyl)-1-piperazineethanesulfonic acid \\
\hline HFAA & Heptafluorobutyric acid anhydride \\
\hline hMSC & Human Mesenchymal Stem Cells \\
\hline $\mathrm{HOMA}_{\mathrm{IR}}$ & Homeostasis Model Assessment for Insulin Resistance \\
\hline HSL & Hormone-Sensitive Lipase \\
\hline HWE & Hardy-Weinberg Equilibrium \\
\hline$i$ & intron (i6 and i7) \\
\hline i.e. & [id est], that is \\
\hline iAUC & incremental Area Under the Curve \\
\hline ICO & International Congress on Obesity \\
\hline $\operatorname{Ig}$ & Immunoglobulin \\
\hline Ile & Isoleucine \\
\hline IMTAG & IntraMuscular TriAcylGlycerol \\
\hline $\mathrm{IPLA}_{2} \zeta$ & Calcium-independent phospholipase $A_{2}$ [zeta] (ATGL) \\
\hline IR & Insulin Receptor or Insulin Resistant (ir) \\
\hline IRS & Insulin-like Receptor Substrate \\
\hline
\end{tabular}

190] 
Abbreviations]

IS

ISBN

ISO

$\mathrm{kb}$

$\mathrm{kDa}$

$\mathrm{kg}$

1

LD

LIPE

$\ln$

LPL

LUC

$\mathrm{m}$

M

$\mathrm{m} / \mathrm{z}$

$\mathrm{MAG}$

$\mathrm{MgCl}_{2}$

MGL

min

$\mathrm{mmHg}$

mRNA

MW

$n$

NA

$\mathrm{NaCl}$

$\mathrm{NADH}$

$\mathrm{NaF}$

NASO

NO

NP

NUGENOB

NUTRIM

NWO

$\mathrm{O}_{2}$

OD

$P$

PBS

PCOS

PCR

PDE3B

$\mathrm{pH}$

PI3K

PKA

PKB

PKC

PLIN

PMSF

PNPLA2

PPAR

PVDF

$\mathrm{r}$

$\mathrm{Ra}$

RFLP

Insulin Sensitive

International Standard Book Number

Isoprenaline (non-selective beta-agonist)

kilobase (Unit of length for DNA fragments equal to 1000 nucleotides)

kiloDalton $(\mathrm{kD})$ (unit of molecular mass equal to 1000 daltons)

kilogram

liter

Linkage Disequilibrium

Hormone sensitive lipase gene

[logaritmus naturalis]

LipoProtein Lipase

Limburgs Universitair Centrum

meter

Molar concentration

mass-to-charge ratio

Monoacylglycerol

Magnesium chloride

MonoacylGlycerol Lipase

minute

Millimeter of mercury

messenger RiboNucleic Acid

Molecular Weight

number

Noradrenaline

Natrium (sodium) chloride

Nicotinamide adenine dinucleotide (oxidized form)

Natrium (sodium) fluoride

Netherlands Association for the Study of Obesity

Nitric Oxide

Natriuretic Peptide

Nutrient-GENe interactions in human OBesity

Nutrition and Toxicology Research Institute Maastricht

Netherlands Organization for Scientific Research

Oxygen

Optical Density

Probability value

Phosphate Buffered Saline

Polycystic Ovarian Syndrome

Polymerase Chain Reaction

Phosphodiesterase 3B

Hydrogen potential (measure of the acidity or alkalinity of a solution)

Phosphatidyl Inositol 3 Kinase

Protein Kinase A

Protein Kinase B

Protein Kinase C

Human homologue of perilipin (gene)

PhenylMethylSulfonyl Fluoride

Patatin-like phospholipase domain containing 2 (ATGL)

Peroxisome Proliferator Activator Receptor

PolyVinyliDine Fluoride

correlation coefficient

Rate of appearance

Restriction Fragment Length Polymorphism 


\section{[Abbreviations}

\begin{tabular}{ll} 
RIA & RadioImmunoAssay \\
RNA & RiboNucleic Acid \\
RNAi & RNA interference \\
rpm & rotation per minute \\
RQ & Respiratory Quotient \\
rRNA & ribosomal RNA \\
RT-qPCR & Real-Time quantitative Polymerase Chain Reaction \\
RU & Relative Units \\
SAT & Subcutaneous Adipose Tissue \\
SBP & Systolic Blood Pressure \\
SD & Standard Deviation \\
SDS-PAGE & Sodium Dodecyl Sulphate-PolyAcrylamide Gel Electrophoresis \\
SEM & Standard Error (SE) of the Mean \\
Ser & Serine \\
SGBG & Sex Hormone Binding Globuline \\
siRNA & short interfering RNA \\
SM & Skeletal Muscle \\
T & Thymine \\
TAG & Triacylglycerol \\
Thr & Threonine \\
TNF- $\alpha$ & Tumor Necrosis Factor alpha \\
Tris-HCl & 2-Amino-2-(hydroxymethyl)-1,3-propanediol, hydrochloride \\
TTR & Tracer/Tracee Ratio \\
U & Unit or Uridine (nucleoside) \\
VLAG & Voeding, Levensmiddelentechnologie, Agrobiotechnologie en Gezondheid \\
VLDL & Very Low Density Lipoprotein (VLDL-TAG) \\
WAT & White Adipose Tissue \\
WHO & World Health Organisation \\
WHR & Waist-to-Hip Ratio \\
Yoh & Yohimbine (alpha-2 receptor antagonist) \\
yr & year \\
\hline
\end{tabular}

